\title{
Clinical dilemmas in sentinel node biopsy for breast cancer
}

Citation for published version (APA):

Maaskant, A. J. G. (2014). Clinical dilemmas in sentinel node biopsy for breast cancer. [Doctoral Thesis, Maastricht University]. Maastricht University. https://doi.org/10.26481/dis.20140117am

Document status and date:

Published: 01/01/2014

DOI:

10.26481/dis.20140117am

Document Version:

Publisher's PDF, also known as Version of record

\section{Please check the document version of this publication:}

- A submitted manuscript is the version of the article upon submission and before peer-review. There can be important differences between the submitted version and the official published version of record.

People interested in the research are advised to contact the author for the final version of the publication, or visit the DOI to the publisher's website.

- The final author version and the galley proof are versions of the publication after peer review.

- The final published version features the final layout of the paper including the volume, issue and page numbers.

Link to publication

\footnotetext{
General rights rights.

- You may freely distribute the URL identifying the publication in the public portal. please follow below link for the End User Agreement:

www.umlib.nl/taverne-license

Take down policy

If you believe that this document breaches copyright please contact us at:

repository@maastrichtuniversity.nl

providing details and we will investigate your claim.
}

Copyright and moral rights for the publications made accessible in the public portal are retained by the authors and/or other copyright owners and it is a condition of accessing publications that users recognise and abide by the legal requirements associated with these

- Users may download and print one copy of any publication from the public portal for the purpose of private study or research.

- You may not further distribute the material or use it for any profit-making activity or commercial gain

If the publication is distributed under the terms of Article $25 \mathrm{fa}$ of the Dutch Copyright Act, indicated by the "Taverne" license above, 


\section{Clinical dilemmas in sentinel node biopsy}

\section{for breast cancer}

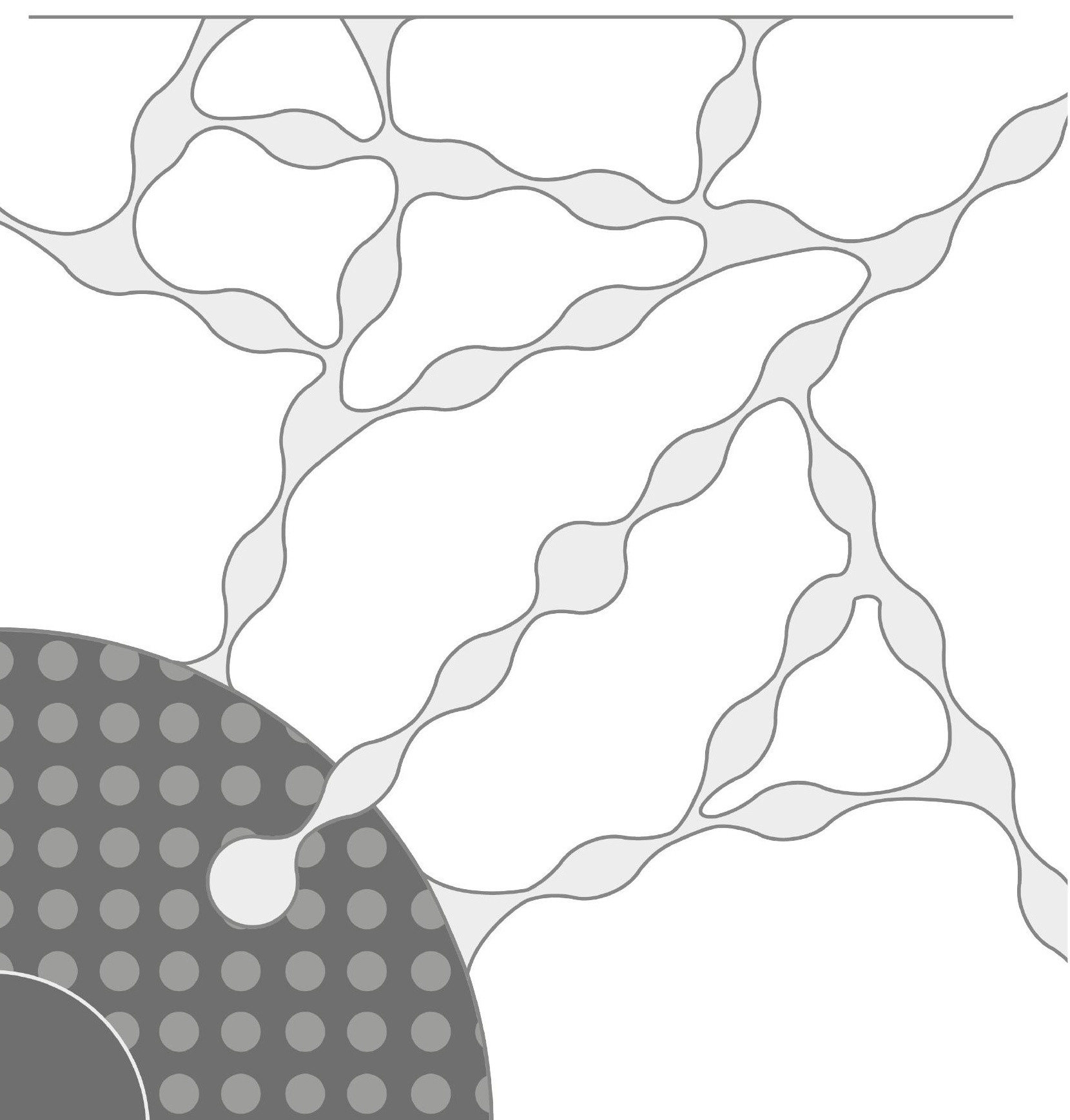


Printing of this thesis was financially supported by:

- Agendia

- Amgen

- Catharina Ziekenhuis, Eindhoven

- $\quad$ Comprehensive Cancer Center South (Integraal Kankercentrum Zuid, IKZ)

- Covidien

- $\quad$ Dutch Cancer Society-KWF

- $\quad$ LifeCell

- Quest Innovations

- Welmed

Part of the research described in this thesis was supported by a grant from the Dutch Cancer Society-KWF (Grant number: 2009-4466).

Copyright (C) Sabrina Maaskant 2014

Cover Design: Marjolein Pijnappels, Studio Lakmoes

Layout: Yvonne Leenders

Printed by: GVO drukkers \& vormgevers B.V.|Ponsen \& Looijen

ISBN: $978-90-6464-737-6$

All rights reserved. No part of this thesis may be reproduced or transmitted in any form or by any means, electronic or mechanical, including photocopying, recording or any information storage or retrieval system, without permission in writing from the author, or, when appropriate, from the publishers of the publications. 


\title{
Clinical dilemmas in sentinel node biopsy for breast cancer
}

\author{
PROEFSCHRIFT \\ ter verkrijging van de graad van doctor aan de Universiteit Maastricht, \\ op gezag van de Rector Magnificus, prof. dr. L.L.G. Soete, \\ volgens het besluit van het College van Decanen, \\ in het openbaar te verdedigen \\ op vrijdag 17 januari 2014 om 14.00 uur \\ door
}

Adriana Jacoba Gerdina Maaskant 


\section{Promotor}

Prof. dr. H.J.T. Rutten

\section{Copromotores}

Dr. G.A.P. Nieuwenhuijzen (Catharina Ziekenhuis, Eindhoven)

Dr. R.M.H. Roumen (Máxima Medisch Centrum, Veldhoven)

Dr. A.C. Voogd

\section{Beoordelingscommissie}

Prof. dr. V.C.G. Tjan-Heijnen (voorzitter)

Prof. dr. R. van Hillegersberg (Universitair Medisch Centrum Utrecht)

Dr. M.L. Smidt 
Your time is limited, so don't waste it living someone else's life. Don't be trapped by dogma - which is living with the results of other people's thinking. Don't let the noise of others' opinions drown out your own inner voice. And most important, have the courage to follow your heart and intuition. They somehow already know what you truly want to become. Everything else is secondary.

Steve Jobs 



\section{Contents}

1 General introduction

History of breast cancer surgery

Axillary staging in breast cancer

Outline of the thesis

Prognostic impact of minimal nodal disease and the role of axillary lymph node dissection after introduction of the sentinel node procedure

2 Stage migration due to introduction of the sentinel node

procedure: A population-based study

3 Axillary and systemic treatment of patients with breast cancer and

micrometastatic disease or isolated tumour cells in the sentinel lymph node

4 Sentinel node micrometastases in breast cancer do not affect prognosis:

A population-based study

5 Axillary radiotherapy as a treatment modality for sentinel node-positive breast cancer patients

Repeat sentinel node biopsy for locally recurrent breast cancer

6 Staging and management of axillary lymph nodes in patients with

local recurrence in the breast or chest wall after a previous negative sentinel node procedure

7 Repeat sentinel node biopsy in patients with locally recurrent breast cancer: A systematic review and meta-analysis of the literature

$8 \quad$ Lymphatic mapping after previous breast surgery

9 Sentinel Node And Recurrent Breast cancer (SNARB): Results of a

nationwide registration study

10 Summary, discussion and recommendations

Samenvatting, discussie en aanbevelingen 

Chapter 1

General introduction<smiles>C1CC2CCC(C1)CCC1CCCCC1CC2</smiles> 
Chapter 1 


\section{General introduction}

Over 13000 women are diagnosed with invasive breast cancer each year in The Netherlands and the lifetime risk of being diagnosed with breast cancer is $12-13 \% \%^{1}$. It is the most common type of cancer among the Dutch population ${ }^{1}$.

The incidence of breast cancer in the Netherlands has increased markedly over the last 30 years ${ }^{2}$. This increase can be partly ascribed to adverse changes in risk factors, in particular lower parity and shorter or no lactation, hormonal intake, nutrition, obesity and increased alcohol consumption ${ }^{3 / 4}$. Increasing awareness and introduction of mass screening have contributed to an increased breast cancer incidence as well ${ }^{2}$. On the other hand, mortality has declined as a result of the introduction of more effective treatment strategies and population mammography screening ${ }^{5,6}$. The combination of an increased breast cancer incidence and improved survival rates implies that the number of prevalent breast cancer cases will continue to rise along with a subsequent burden on health care.

This chapter consists of an overview of the history of breast cancer surgery and the introduction and validation of sentinel node biopsy (SNB) as an axillary staging procedure. Special attention will be given to pathological work-up of sentinel nodes and detection of minimal nodal involvement as well as the role of axillary lymph node dissection in the era of sentinel node biopsy. Finally, possible contraindications for SNB and the use of SNB in case of recurrent breast cancer will be discussed. From this overview several clinical dilemmas concerning sentinel node biopsy for breast cancer were identified and addressed in this thesis.

\section{History of breast cancer surgery}

Surgery, derived from the Greek word cheir (hand) and ergon (to work) and the Latin word chirurgia, is defined as "the treatment of disease, injury or deformity by manual or instrumental operations, as the removal of diseased parts of tissue by cutting ${ }^{\prime \prime \prime}$. Surgery was probably born in prehistoric times as a result of the need to protect health and life against accidents and attacks from enemies as well as to overcome the unknown evil of demoniac disease ${ }^{8}$.

Since ancient times, breasts have been considered a symbol of femininity, fertility and beauty. As a result, most women hesitated to undergo breast amputation, which was considered a punishment or a mutilation, and women's modesty regarding exposure and examination of their breasts has hindered early diagnosis and timely treatment of breast cancer from the dawn of humanity until today ${ }^{9}$. 


\section{Ancient times and Middle Ages}

Breast cancer has been known as a disease since prehistoric times and breast cancer cases have been recorded in medical writings for more than 5000 years. Management of breast cancer evolved slowly through the centuries from antiquity up to the Renaissance, but absence of scientifically verifiable knowledge of the true nature and natural history of the disease resulted in a lack of effective treatment ${ }^{10}$.

Hippocrates of Cos (460-377 BC), regarded as the "father of medicine", described the "carcinoma appartus", which was a malignant ulcer, and the "carcinoma occusus", which was a non-ulcerated deep-seated tumour. He set forth the humoral concept of cancer growth, cancer being due to an excess of black bile. He also believed that cancer was a systemic disease and that surgery may have harmful systemic repercussions ${ }^{8}$. These theories were further supported by Galen (AD 121-203) ${ }^{10,11}$, who invented the term "crab" to describe cancer: "we have often seen in the breast a tumour exactly resembling the animal called the $\mathrm{crab}^{\prime{ }^{12}}$. Although he directed therapy at getting rid of excess black bile by diets, purgation, venesection and leaching, he also advocated excision of readily removable breast tumours "in a circle in the region where it borders on the healthy tissue" and was probably responsible for the first surgical treatment of breast cancer ${ }^{12}$. Galen's opinions dominated medicine for over 1000 years. From the fall of the Roman Empire to the Renaissance (about AC 500-1400), medical progress remained stagnant as Christianity and Islam prohibited anatomical dissection and put a ban on the barbarous practice of surgery for breast cancer. It was believed that diseases were a punishment from God and only faith could cure. Typical of these times was the statement that Apollo discovered medicine, Asclepius extended the knowledge of medicine and Hippocrates perfected $i^{8}{ }^{8}$. Despite edicts to restrict the performance of surgery, eminent surgeons, such as Henri de Mondeville (1260-1320) and Guy de Chauliac (1300-1368) in his text Chirurgia Magna, advocated limited surgery for breast cancers that could be completely excised, while William of Salicet (1210-1277) and Lanfranc of Milan (1250-1315) advocated complete removal of the breast ${ }^{8}$.

\section{Renaissance}

The Renaissance (roughly from the $14^{\text {th }}$ to the $17^{\text {th }}$ century) stimulated medical practice and physicians and scholars began to scientifically study and teach medicine. Men, such as the anatomist Andreas Vesalius (1514-1564), began to interpret true human anatomy and the publication of his De Humani Corporis Fabrica in 1543 marks the beginning of modern anatomy. Vesalius was one of the first to oppose Galen's doctrines and to discard the old anatomy ${ }^{10,12}$. He applied his knowledge to practical surgery and advised wide surgical excision for breast tumours and using ligatures to ligate blood vessels rather than attempting to control bleeding by cauterization ${ }^{13}$. Ambroise Paré (1510-1590), surgeon to four kings of France and the most famous surgeon of the $16^{\text {th }}$ century, was the first to 
describe the spread of cancer to regional sites as he described the swelling of the axillary lymph nodes: "When cancer possesses the breast, it often causes inflammation of the armholes and sends the swelling even to the glandules thereof ${ }^{\prime 14}$. In 1590, his pupil, Bartholeny Gabrol, who had noted that tumours often infiltrated into the muscle, advocated radical mastectomy with removal of the pectoralis muscle as the correct treatment for breast cancer ${ }^{14}$. Several great surgeons of that time contributed to the advancement of surgery. Marcus Aurelius Severinus (1580-1656) was one of the first surgeons to remove enlarged axillary nodes at the time of radical excision of breast cancer $^{15}$ and Joyannes Scultetus (1595-1645) described in his Armamentarium Chirurgicum in detail his procedure used for removal of the breast ${ }^{16}$. Nicolas Tulp (1628-1653), a professor of Surgery in Amsterdam, believed that breast cancer was contagious ${ }^{12}$ and Wilhelm Fabry von Hilden (1560-1624) devised an instrument to perform mastectomies with great speed and thereby reducing the pain. During these times surgical excision was primitive and brutal due to lack of anaesthesia and aseptic techniques causing wound infections and therapeutic nihilism was still the prevailing attitude towards breast cancer $^{9}$. Despite these remarkable contributions exorcism was still widely used, for example by William Clowes (1516-1584), physician to Queen Elizabeth, who used the simple ritual of lying on the royal hands.

\section{$18^{\text {th }}$ and $19^{\text {th }}$ century}

In the $18^{\text {th }}$ century the practice of surgery was transformed by taking into account scientific data of that time. Henri Francois Le Dran (1685-1773) reasoned that because axillary nodal involvement in a patient with breast cancer was indicative of a worse prognosis, the disease must spread through the lymphatics and then into the general circulation $^{17}$. He favoured the idea that cancer, at its earliest phase of development, is a local disease, which could be effectively treated by surgery. He dissected out routinely enlarged axillary nodes in breast cancer and recognized the need for early operation ${ }^{10,12}$. Jean-Louis Petit (1674-1750) was a strong advocate of Le Dran's concepts and he proposed a form of ablative surgery that required excising the breast (not the skin or nipple, unless it was involved), palpable axillary lymph nodes and the underlying pectoral fascia or even the pectoralis major muscle itself en bloc, which could be considered the first radical mastectomy ${ }^{18}$. During the first decades of the $19{ }^{\text {th }}$ century no clear advances were noted and many eminent surgeons, including James Syme, Sir James Paget and Robert Liston, were pessimistic about finding a cure for breast cancer through surgery. James Syme (1799-1870) stated that palliative procedures (such as purging, bleeding and applications of ointments) should be condemned and agreed that the glands should be removed, but he felt that the results were almost uniformly unsatisfactory and that it could not prevent the patient's relapse ${ }^{19}$. During the second half of the $19^{\text {th }}$ century, the introduction of microscopic examination revealed the cellular origin of cancer and the 
local pattern of its progression. This better understanding of tumour biology provided a rational framework on which to structure surgical treatment. Also, the development of anaesthesia and antisepsis facilitated further refinement of surgical treatment of breast cancer $^{20}$. For example, in 1867, Charles Moore (1821-1879) emphasized the importance of not exposing the tumour during operation to prevent local recurrence and he proposed that recurrences were determined by centrifugal dispersion from the primary growth and not by an independent organic origin ${ }^{21}$. Samuel W. Gross (1838-1889) and Richard von Volkmann (1830-1889) advocated removal of all breast tissue and the pectoral fascia, in conjunction with a complete axillary dissection for diseased lymph nodes ${ }^{22,23}$. Ernst Kuster (1838-1922) proposed, in addition, that a complete axillary dissection should be performed in all patients, regardless of whether the lymph nodes were clinically positive $^{24}$.

Rudolf Virchow (1821-1902) studied the morbid anatomy of breast cancer and his meticulous dissections radically influenced the management of patients with breast cancer. He argued that the breast tumour arises from epithelial cells and spreads along fascial planes and lymphatic channels. Thus, he considered breast cancer a local disease evolving from normal cells, which could be cured with local therapy. He also postulated that regional lymph node metastases represent a temporary barrier to distant dissemination $^{25}$. William Halsted (1852-1923), a surgeon at the Johns Hopkins Hospital, USA, at the end of the $19^{\text {th }}$ century, was greatly influenced by Virchow's theories and was in agreement with the London surgeon William Sampson Handley (1872-1962), who emphasized that cancers arise in one focus and spread in all directions centrifugally, along the lymphatic pathways without overlooking the spread by direct infiltration ${ }^{26,27}$. Although none of this was new, its publication made a great impact on the surgical management of breast cancer throughout the world. Halsted extended the operation by Von Volkmann with resection of the entire pectoralis major muscle, because the "Volkmann operation" was in his opinion incomplete as it failed to encompass fully the surrounding structures. He first published the description of his surgical technique in 1891 and the en bloc removal of the entire breast and pectoralis major muscle with wide resection of the skin and axillary nodes became known as the Halsted mastectomy, later known as the radical mastectomy ${ }^{28}$. Halsted compared the local recurrence rates in his patients with the results achieved by surgeons in Europe who were performing the Von Volkmann mastectomy. Their local recurrence rates ranged from 50-80\%, while Halsted was able to report a remarkably low recurrence rate of only $6 \%{ }^{26}$. Ultimately, Halsted synthesized the best points of the techniques that had been suggested by the most advanced surgeons of the period and placed radical mastectomy on a scientific and logical basis. It was in the completeness of his method and his meticulous operative technique that he achieved a success that set a new standard in the development of breast surgery ${ }^{20}$. 


\section{$20^{\text {th }}$ century}

For most of the twentieth century, breast cancer was treated by the Halsted radical mastectomy. Surgeons often disagreed, however, about how extensive that operation should $b^{29}$. Some believed that the radical mastectomy was insufficient given the assumption that breast cancer was a local disease that spread throughout the body by contiguous expansion. The extended or super-radical mastectomy was introduced in 1951 by Jerome Urban and included en bloc resection of the chest wall and internal mammary nodes and at a later stage also supraclavicular and mediastinal nodes ${ }^{30,31}$. The introduction and increasing awareness of the value of testing hypotheses by laboratory experiments and within randomized clinical trials in the second half of the twentieth century led Bernard Fisher of the National Surgical Adjuvant Breast and Bowel Project (NSABP) to formulate his alternative systemic hypothesis for breast cancer. He stated that breast cancer is a systemic disease at the time of diagnosis, involving a complex spectrum of host-tumour inter-relations, and that the ultimate outcome of the patient would unlikely be influenced solely by locoregional treatment ${ }^{32}$. This systemic hypothesis, together with progressive improvement in radiotherapy techniques and its use in prevention of regional breast cancer recurrences, led to the progressive search for an operation less radical than the Halsted mastectomy. This search had already started in the 1930's when D.H. Patey of the Middlesex Hospital in London spared the pectoralis major muscle and introduced the "modified radical mastectomy"33. The concept of breast cancer being a systemic disease already at the time of diagnosis was supported by the results of randomized controlled trials that found no difference in overall survival between the radical mastectomy and extended or super-radical mastectomy at long-term follow-up ${ }^{34,35}$. In 1971, George Crile Jr. was an early proponent of breast conservation. He reported on 57 patients treated with local excision of the tumour, in most instances without axillary dissection or postoperative irradiation. Their 5 -year survival rate was almost identical to that of patients treated by simple or modified radical mastectomy ${ }^{36}$. He recommended a randomized study and in 1981 the first results comparing radical mastectomy with quadrantectomy, axillary dissection and radiotherapy became available and showed no differences in disease-free or overall survival ${ }^{37}$. These early results were confirmed by other trials ${ }^{38,39}$. Concomitantly, increased patient awareness and education as well as advances in mammography, stereotactic biopsy and fine-needle aspiration resulted in earlier diagnosis of breast cancer. The size of the primary lesion and the extent of axillary nodal metastases diminished and breast conservation became a reasonable alternative to mastectomy. Long-term results of the aforementioned trials confirm the early findings $\mathrm{s}^{40,41}$ and the need to administer adjuvant radiotherapy as part of breastconserving treatment $(B C T)$ was well established in a large meta-analysis ${ }^{42}$. Altogether, nowadays BCT is considered to be the standard of care for stage I and II breast cancer. 


\section{Axillary staging in breast cancer}

As mentioned before, ever since the $18^{\text {th }}$ century axillary nodal involvement in breast cancer has been recognized as indicative for a worse prognosis and from that moment on surgery of the axillary nodal basin has been a routine component of breast cancer surgery. The French anatomist Marie Philibert Constant Sappey (1810-1896) first visualized the lymphatic drainage of the breast by injecting mercury into the dermis of cadavers. In his book "Anatomie, Physiology, Pathologie des vaisseaux lymphatiques", published in 1874, he described lymphatic drainage of the breast occurring in a centripetal direction towards the areola where pooling occurs before the lymph passes by specific channels to the axillary lymphatics ${ }^{43}$. Although there is still some controversy on the role of this subareolar plexus, it is generally believed to be a critical region in which the parenchymal lymph, the cutaneous lymphatics and the fascial plexus communicate with each other ${ }^{44,45}$. However, some lymph vessels do not follow this pattern and pass over or through the breast parenchyma to the contralateral axilla or course beside the branches of the internal mammary vessels ${ }^{46}$.

Even in the era of gene-expression profiling (i.e. micro-array), axillary nodal status remains an important independent prognostic factor of disease behaviour and ultimate outcome $^{47}$ and development of effective adjuvant systemic therapies has made recognition of axillary metastases critical for patient management. Axillary lymph node dissection (ALND) has long been the standard of care for adequate axillary staging.

\section{Introduction and validation of the sentinel node procedure}

In analogy with the trend to use a more conservative approach with regard to surgery of the breast over the last decades, the search for a less invasive alternative to ALND led to the introduction of the sentinel node procedure in the early 1990's. According to the sentinel node hypothesis the sentinel node is the first (axillary) lymph node draining the tumour and it is thus most likely to contain breast cancer metastases. The sentinel node concept was introduced by Gould et al. in 1959, who presented their experience with an anatomically localized "sentinel node" in patients with parotid cancer ${ }^{48}$. In 1977, Cabañas, an urologist from Paraguay, described visualization of lymphatic channels by lymphangiography and sentinel node biopsy based on anatomical localization in patients with penile carcinoma ${ }^{49}$. He noted that the same lymph node was visualized in each patient, which was essentially the sentinel node. Morton et al., who used blue dye to visualize the sentinel node in patients with melanoma, confirmed and revitalised this concept ${ }^{50}$. A big advantage compared to the technique from Cabañas was that the sentinel node was now visible during surgery. Also, an intracutaneous injection of the dye could be used instead of an injection directly into the lymphatic vessels, which made the procedure easier to execute. Krag et al. published a technique of gamma probe 
localization of radiolabelled lymph nodes to identify the sentinel node and they concluded that its use was technically feasible in the majority of breast cancer patients ${ }^{51}$. Subsequently, Giuliano et al. reported on lymphatic mapping in breast cancer patients using a vital blue dye and they concluded that this technique could accurately identify the sentinel node $\mathrm{s}^{5}$. The technique of sentinel node biopsy for breast cancer rapidly evolved ${ }^{53-}$ ${ }^{56}$ and ultimately an identification rate of $96 \%$ was described using the combined techniques of lymphoscintigraphy, gamma probe localization and blue dye ${ }^{57}$. Identification and evaluation of the sentinel node(s) has been shown to accurately predict axillary nodal status ${ }^{58,59}$ with significantly lower morbidity than ALND ${ }^{60,61}$. Furthermore, the risk of axillary recurrence after negative SNB is very low ${ }^{62}$ and a randomised trial showed the 8-year survival to be equal in the SNB-group and the ALND-group ${ }^{63}$. These findings supported the validity and safety of SNB as a staging procedure and thus the removal of clinically negative axillary lymph nodes by ALND was no longer justifiable.

\section{Pathologic work-up and detection of minimal nodal involvement}

The introduction of the SNB allowed the application of more extensive time-consuming and costly pathologic examination techniques such as serial sectioning, immunohistochemistry (IHC) and reverse-transferase polymerase chain reaction (RT-PCR). Conventional lymph node examination is based on a Hematoxylin \& Eosin (H\&E) staining of one or two sections through the largest diameter of the lymph node. In The Netherlands the pathology protocol advocated by the EORTC Breast Cancer Group has been adopted by the pathologists and is included in the Dutch evidence-based guideline for the treatment of breast cancer ${ }^{64}$. According to this guideline, sentinel nodes should be investigated at three levels at $0.25 \mathrm{~mm}$ intervals and from each section at least two slides should be made: one for $\mathrm{H} \& \mathrm{E}$ staining and one for IHC.

The use of serial sections and IHC was advocated in the case of an H\&E negative sentinel node in order to detect smaller metastases. Indeed, its potential to trace micrometastases and isolated tumour cells is reflected by the detection of minimal nodal involvement in $9-23 \%$ of originally Hematoxylin \& Eosin negative cases $^{65}$ and by the significant increase in the incidence of patients with micrometastases, following the introduction of the $\mathrm{SNB}^{66,67}$. In a prospective study comparing the risk of axillary nodal metastases in SNB versus ALND specimens, Giuliano et al. found a $13 \%$ higher risk in the group who underwent SNB with multiple sectioning and IHC staining of sentinel nodes ${ }^{68}$. This excess risk could be explained almost completely by the detection of micrometastases and it was argued that the accuracy of staging might have improved by the identification of this minimal nodal involvement.

A lively debate followed on the prognostic significance of these micrometastases and the possible subsequent need for additional systemic and regional treatment. Some studies on the prognostic significance of micrometastases in ALND before introduction of the 
sentinel node biopsy showed that patients with axillary micrometastases had higher recurrence rates and lower overall survival ${ }^{69-72}$, others however demonstrated no such difference ${ }^{73,74}$. Although most studies with larger sample sizes and longer follow-up tend to show a negative effect of micrometastatic disease on overall and disease free survival ${ }^{75,76}$, comparison between these retrospective studies and extrapolation to patients with SNB is hampered by different inclusion criteria and large technical variances in the assessment of micrometastases. Studies conducted in the era after introduction of the SNB still could not make it possible to draw definitive conclusions regarding this dilemma, with several studies showing conflicting results ${ }^{77-80}$.

\section{Role of axillary lymph node dissection in the era of SNB}

As discussed earlier, ALND as a staging method in clinically node-negative patients has largely been replaced by the less invasive technique of SNB, allowing completion ALND to be performed selectively in patients with sentinel node metastases. ALND plays a role in locoregional disease control ${ }^{38}$, which in turn may contribute to the reduction of breast cancer mortality ${ }^{42,81,82}$. For that reason, treatment of the axilla is indicated in case of node-positivity, according to national breast cancer treatment guidelines in The Netherlands ${ }^{83}$. This advice includes the presence of micrometastastic disease and is based on the observation in the literature that patients with sentinel node metastases have an approximately $20-50 \%$ chance of having additional non-sentinel node involvement, depending on the extent of tumour involvement in the sentinel node and the number of positive sentinel nodes found ${ }^{67,84,85}$. On the other hand, despite of the fact that the proportion of patients who underwent SNB alone for small volume sentinel node metastases increased from 24.7 to $45.3 \%$ in a population-based study, axillary recurrence and survival were not significantly decreased compared to patients that underwent completion ALND ${ }^{86}$. In order to predict which patients are at greater risk of having nonsentinel node metastases and might benefit from a completion ALND, several nomograms were developed based on which the risk of node-positivity in the completion ALND could be predicted ${ }^{87}$. Unfortunately, validation studies showed that the performance of these nomograms was insufficient to make it a useful tool for individual decision-making in other than the original patient populations ${ }^{88,89}$.

ALND has well-documented, considerable side effects, such as lymphedema, shoulder pain, paraesthesia and impaired range of motion of the shoulder, which have a negative impact on physical complaints and psychosocial problems of women who underwent ALND for breast cancer ${ }^{\circ}$. In the search for alternative methods for axillary treatment in breast cancer patients the use of axillary radiotherapy (AxRT) was investigated. Radiation therapy has been used for many years instead of or in addition to axillary dissection and its success in controlling microscopic disease in lymph nodes has extensively been described in patients with clinically negative axillary lymph nodes. Low axillary recurrence 
rates were consistently reported with no significant differences in survival and a more favourable complication rate ${ }^{91-95}$. Regarding the use of AxRT as a treatment modality for sentinel node-positive breast cancer patients unfortunately no prospective data are yet available and we are awaiting the results of the EORTC 10981-22023 AMAROS trial (After Mapping of the Axilla: Radiotherapy or Surgery?).

Publication of the results of the ACOSOG Zooo11 trial, in which SNB positive patients were randomized between ALND and observation, further nurtured the discussion on management of SNB positive patients ${ }^{96-97}$. Despite of the fact that an estimated $27 \%$ of the patients had additional metastases in the undissected axillary nodes, regional recurrence rates were less than $1 \%$ in the SNB alone group. Furthermore, in these cases with restricted tumour involvement of the sentinel node, ALND did not result in improved survival or a better local axillary control compared to SNB alone. Apparently, not all nonsentinel node metastases develop into clinically detectable disease. It is important to realize, however, that in the ACOSOG Zoo11 trial $97 \%$ of the patients received adjuvant systemic therapy and $89 \%$ of the patients received whole-breast irradiation with the use of tangential fields. Adjuvant systemic therapy is known for its potential to diminish locoregional recurrence in breast cancer patients ${ }^{98}$ and approximately $25 \%$ of patients with positive lymph nodes who are treated with chemotherapy have complete eradication of nodal disease ${ }^{99}$. Furthermore, whole-breast irradiation with tangential fields includes the majority of level I and II axillary lymph nodes. It is estimated that more than $50 \%$ of level I and $20-30 \%$ of level II nodes receive $95 \%$ of the prescribed radiation dose, depending on patient anatomy and the upper tangential field border ${ }^{100,101}$. Therefore, It is very well possible that the radiation treatment of the breast also delivered radiation to the axilla and eradicated potentially present disease.

In conclusion, recognition of the complexity of tumour biology has changed cancer treatment over the last decades and breast cancer patients undergoing breast-conserving therapy are nowadays largely treated with whole-breast radiation therapy with tangential fields and adjuvant systemic treatment. The question has risen if these patients still benefit from a therapeutic ALND or if the multidisciplinary approach of systemic treatment and radiotherapy (whether this is whole-breast radiation therapy with tangential fields or regional nodal irradiation) is sufficient in reducing the risk of locoregional breast cancer recurrences.

\section{Indications and contraindications for sentinel node biopsy}

On introduction of the sentinel node procedure for breast cancer it was indicated for patients with cytological/histologically proven breast cancer without clinically positive axillary lymph nodes. Initially, important contraindications for performing this procedure were clinical or radiological tumour diameter $\geq 2 \mathrm{~cm}$, multifocal and/or multicentric breast cancer and prior surgery or radiotherapy of breast and/or axilla ${ }^{102}$. Indications for SNB in 
relation to tumour diameter have been extended to include patients with $T_{1}$ and $T_{2}$ tumours, since several trials have shown its safety in these larger tumours ${ }^{62,103,104}$. With regard to multifocality and/or multicentricity still some controversy exists on the validity of the SNB due to uncertainty about the true lymphdrainage pathways ${ }^{105}$ and a possible higher risk of false-negative results ${ }^{106,107}$. For these reasons, next to the fact that nodepositivity rates are relatively high, multicentricity comprising an area larger than $5 \mathrm{~cm}$ is still regarded a relative contraindication for performing $\mathrm{SNB}^{108}$. Prior surgery and radiotherapy as contraindications for performing SNB have become a topic of increasing interest. It has been established that prior surgical biopsy does not affect detection rate of SNB, although it has a slightly higher false-negative rate ${ }^{109,110}$. This could be due to a change in lymph drainage pattern following excision biopsy of the breast ${ }^{111}$. Nevertheless, the advantages of the SNB are thought to outweigh this small increase of false-negativity and surgical excision biopsy is not regarded an absolute contraindication for SNB anymore.

Approximately 5 to $10 \%$ of breast cancer patients develop a local recurrence in the breast or chest wall ${ }^{40,112}$. In accordance with primary breast cancer, axillary staging in case of locally recurrent breast cancer could be of benefit to improve locoregional control and may play a role in making recommendations for adjuvant systemic treatment ${ }^{81,82}$. For these reasons it seems sensible to perform axillary staging in case of locally recurrent breast cancer, despite the absence of guidelines on this topic. Until recently, this meant that patients with locally recurrent breast cancer and a previous negative sentinel node biopsy most probably would receive an ALND and that patients with a previous ALND would receive no additional axillary staging. In analogy to surgical excision biopsy, one might ask if a so-called repeat SNB would be a regional staging option for these patients as well. Not only could patients with a tumour-negative repeat SNB be spared additional morbidity from an ALND, but staging could also be improved by identifying aberrant drainage pathways emerged due to prior surgery and/or radiotherapy leading to a possible alteration of adjuvant treatment strategies. Furthermore, residual disease in the ipsilateral axilla after a previous ALND could be detected with repeat SNB. Although several mainly small, retrospective and heterogeneous studies have shown that a repeat SNB seems technically feasible and can provide useful information ${ }^{113-115}$, it remains questionable whether it is a safe alternative to ALND in locally recurrent breast cancer.

\section{Outline of the thesis}

This thesis on clinical dilemmas in sentinel node biopsy for breast cancer consists of two main parts. The first part, covering chapters 2, 3, 4 and 5, concerns the increased identification of minimal nodal disease due to enhanced pathologic work-up of the 
sentinel node and its impact on breast cancer treatment and prognosis as well as the role of axillary lymph node dissection after introduction of the sentinel node procedure. Chapter 2 deals with the question whether or not introduction of the SNB in Southeast region of The Netherlands has changed the incidence of axillary nodal micrometastases and induced a stage migration on a population-based level. In chapter 3 the impact of presence of micrometastatic disease and isolated tumour cells on the use of adjuvant systemic treatment and completion ALND in the Southeast Netherlands is described and chapter $\mathbf{4}$ describes the prognostic impact of minimal nodal disease in breast cancer on overall survival, corrected for the possible influence of age, $\mathrm{pT}$, grade and adjuvant systemic treatment. Ultimately, in chapter $\mathbf{5}$, the use of axillary radiotherapy instead of ALND as a treatment modality for sentinel node-positive breast cancer is evaluated with respect to axillary recurrence and morbidity.

The second part of this thesis, consisting of chapters 6, 7, 8 and 9, deals with the use of the so-called repeat SNB as an axillary staging method in locally recurrent breast cancer. In chapter 6 staging and management of axillary lymph nodes in patients with locally recurrent breast cancer is described. A systematic review and meta-analysis of the literature was conducted to evaluate the available knowledge on the topic of repeat SNB in locally recurrent breast cancer (chapter 7). The prospective trial that is described in chapter 8 researches the feasibility and aberrant drainage rates of lymphatic mapping after previous breast surgery and in chapter 9 the results of the Dutch national "Sentinel Node And Recurrent Breast cancer" (SNARB) registration study are described.

For the studies described in chapter 2, 3, 4 and 6, data of the Eindhoven Cancer Registry (ECR) of the Comprehensive Cancer Centre South were used. The region covered by the ECR comprises 2.3 million inhabitants and 10 general hospitals at 16 locations and is served by 6 regional pathology laboratories and two large radiotherapy institutes. The region is characterised by good access to medical care without financial obstacles. The distance to a hospital has always been less than 20 kilometres. 


\section{References}

1. Dutch Cancer Registry, Comprehensive Cancer Centre the Netherlands (CCCNL). Available from URL: http://cijfersoverkanker.nl [accessed 2 march, 2012]

2. Louwman WJ, Voogd AC, Van Dijck JAAM, et. al. On the rising trends of incidence and prognosis for breast cancer patients diagnosed 1975-2004: a long-term population-based study in southeastern Netherlands. Cancer Causes Control 2008;19:97-106

3. Macmahon B. Epidemiology and the causes of breast cancer. Int J Cancer 2006;118:2373-2378

4. Signaleringscommissie Kanker. De rol van voeding bij het ontstaan van kanker. KWF Kankerbestrijding 2004

5. Vervoort MM, Draisma G, Fracheboud J, van de Poll-Franse LV, de Koning HJ. Trends in the usage of adjuvant systemic therapy for breast cancer in the Netherlands and its effect on mortality. Br J Cancer 2004;91:242-247

6. Otto SJ, Fracheboud J, Looman CW, Broeders MJ, Boer R, Hendriks JH, Verbeek AL, de Koning $\mathrm{HJ}$. Initiation of population-based mammography screening in Dutch municipalities and effect on breast-cancer mortality: a systematic review. Lancet 2003;361:1411-1417

7. Rutkow IM. Prescientific and primitive surgery. In: Surgery: An illustrative history 1993:1-3. Mosby Ed, St Louis, IL, USA

8. Sakorafas GH, Safioleas M. Breast cancer surgery: an historical narrative. Part I. From prehistoric times to Renaissance. Eur J Cancer Care 2009;18:530-544

9. Ariel IM. The diagnosis and treatment of breast cancer: a historic review. In: Breast Cancer: Controversies in Management 1994:5-23. Futura Publishing Company, Inc., New York, USA

10. Roses DF. Development of modern breast cancer treatment. In: Breast Cancer 1999:289-308. Churchill Livingstone, New York, USA

11. Ariel IM. Breast cancer, a historic review: is the past prologue? In: Breast cancer diagnosis and treatment 1987:3-26. McGraw-Hill, New York, USA

12. Lewinson EF. The surgical treatment of breast cancer; an historical and collective review. Surgery 1953:34:904-953

13. Wagner FB. History of breast diseases and its treatment. In: The Breast 1991;1-9. WB Saunders, Philadelphia, PA, USA

14. Wolff J. Die Lehre Von Der Krebskrankheit, vol I. 1907. G Fischer, Jena, Germany

15. Meade RH. An Introduction to the History of General Surgery, Chapter 13. 1968. WB Saunders, Philadelphia, PA, USA

16. Scultetus J. Armamentarium Chirurgicum. In: Cheiroplotheke 1653;50-51. B. Kuhnen B, Ulm, Germany

17. Le Dran HF. Memoires avec un précis de plusieurs observations sur le cancer. Memoires de I'Academie Royale de Chirurgie 1757;3:1-54

18. Petit JL. Oeuvres completes, Section VI. 1837. R. Chapuoulard, Limoges, France

19. Syme J. Principles of Surgery. 1842. H. Bailliere, London, UK

20. Sakorafas GH, Safioleas M. Breast cancer surgery: an historical narrative. Part II. 18th and 19th centuries. Eur J Cancer Care 2010;19:6-29

21. Moore $\mathrm{CH}$. On the influence of inadequate operations on the theory of cancer. Royal Medical Chirurgical Society of London 1867;1:244-280

22. Gross SW. A Practical Treatise on Tumors of the Mammary Gland; Embracing Their Histology, Pathology, Diagnosis and Treatment. 1880. Appleton and Co, New York, USA

23. Volkmann R. Beitrage zur Chirurgie. 1875. Breitkops \& Hartel, Leipzig, Germany

24. Kuster E. Zur behandlung des brustkrebses. Archiv fur Klinische Chirurgie 1883;29:723-735

25. Virchow R. Cellular Pathology. 1863. JB Lippincott, Philadelphia, PA, USA 
26. Halsted WS. The results of operations for cure of cancer of the breasts performed at the Johns Hopkins Hospital from June 1889 to January 1894. Johns Hopkins Hospital Reports 18941895;4:297-350

27. Halsted WS. The results of radical operations for the cure of cancer of the breast. Annals of Surgery 1907;46:1-19

28. Halsted WS. Operations for carcinoma of the breast. Johns Hopkins Hospital Reports 18901891a;2:277-280

29. Fisher B. The surgical dilemma in the primary therapy of invasive breast cancer: a critical appraisal. Curr Probl Surg 1970;3-53

30. Urban JA. Radical excision of chest wall in mammary cancer. Cancer 1951;4: 1263-1265

31. Wangensteen $\mathrm{OH}$, Lewis FJ, Arhelger SW. The extended or super-radical mastectomy for carcinoma of the breast. Surg Clin North Am 1956;1051-1063

32. Fisher B. From Halsted to prevention and beyond: Advances in the management of breast cancer during the twentieth century. Eur J Cancer 1999;35:1963-1973

33. Patey $\mathrm{DH}$, Dyson WH. The prognosis of carcinoma of the breast in relation to the type of operation performed. Br J Cancer 1948;2:7-13

34. Lacour J, Le M, Caceres E, Koszarowski T, Veronesi U, Hill C. Radical mastectomy versus radical mastectomy plus internal mammary node dissection. Ten-year results of an international cooperative trial in breast cancer. Cancer 1983;51:1941-1943

35. Veronesi $U$, Valagussa P. Inefficacy of internal mammary nodes dissection in breast cancer surgery. Cancer 1981;47:170-175

36. Crile G Jr., Hoerr SO. Results of treatment of carcinoma of the breast by local excision. Surg Gynec Obstet 1971;132:780-782

37. Veronesi $U$, Saccozzi $R$, Del vecchio $M$, et al. Comparing radical mastectomy with quadratectomy, axillary dissection and radiotherapy in patients with small cancers of the breast. N Engl J Med 1981;305: 6-11

38. Fisher $B$, Baver $M$, Margolese $R$, et al. Five-year results of a randomized clinical trial comparing total mastectomy and segmental mastectomy with of without radiation in the treatment of breast cancer. N Engl J Med 1985;312: 665-673

39. Sarrazin $\mathrm{D}$, Le MG, Fontaine MF, Arriagada R. Conservative treatment versus mastectomy in $\mathrm{T}_{1}$ or small $T_{2}$ breast cancer - a randomized trial. In: Harris JR, Hellman S, Silen W, eds. Conservative treatment of breast cancer: new surgical and radiotherapeutic techniques. Philadelphia: J.B. Lippincott, 1983:101-111

40. Veronesi U, Cascinelli N, Mariani L, et al. Twenty-year follow-up of a randomized study comparing breast-conserving surgery with radical mastectomy for early breast cancer. $\mathrm{N}$ Engl J Med 2002;347:1227-1232

41. Fisher B, Anderson S, Bryant J, et al. Twenty-year follow-up of a randomized trial comparing total mastectomy, lumpectomy, and lumpectomy plus irradiation for the treatment of invasive breast cancer. N Engl J Med 2002;347:1233-1241

42. Early Breast Cancer Trialists' Collaborative Group (EBCTCG). Effect of radiotherapy after breast-conserving surgery on 10-year recurrence and 15-year breast cancer death: metaanalysis of individual patient data for 10801 women in 17 randomised trials. Lancet 2011;378:1707-1716

43. Sappey MP. Anatomie, Physiologie, Pathologie des vaisseaux Lymphatiques consideres chez L'homme at les Vertebres. Paris: A. Delahaye and E. Lecrosnier; 1874

44. Grant RN, Tabah EJ, Adair FE. The surgical significance of the subareolar lymph plexus in cancer of the breast. Surgery 1953;33:71-78 
45. Suami H, Pan W, Taylor Gl. Historical review of breast lymphatic studies. Clinical Anatomy 2009;22:531-536

46. Suami H, Pan W, Mann GB, Taylor GI. The lymphatic anatomy of the breast and its implications for sentinel lymph node biopsy. Ann Surg Oncol 2007;15:863-871

47. van de Vijver MJ, He YD, van 't Veer LJ, et al. A gene-expression signature as a predictor of survival in breast cancer. N Engl J Med 2002;347:1999-2009

48. Gould EA, Winship T, Philbin PH, et al. Observations on a "sentinel node" in cancer of the parotid. Cancer 1960;13:77-78

49. Cabañas RM. An approach for the treatment of penile carcinoma. Cancer 1977;39:456-466

50. Morton $\mathrm{DL}$, Wen $\mathrm{DR}$, Wong JH, et al. Technical details of intraoperative lymphatic mapping for early stage melanoma. Arch Surg 1992;127:392-399

51. Krag DN, Weaver DL, Alex JC, et al. Surgical resection and radiolocalization of the sentinel lymph node in breast cancer using a gamma probe. Surg Oncol 1993;2:335-340

52. Giuliano AE, Kirgan DM, Guenther JM, Morton DL. Lymphatic mapping and sentinel lymphadenectomy for breast cancer. Ann Surg 1994;220:391-398

53. Veronesi U, Paganelli G, Galimberti V, et al. Sentinel-node biopsy to avoid axillary dissection in breast cancer with clinically negative lymphnodes. Lancet 1997;349:1864-1867

54. Pijpers R, Meijer S, Hoekstra OS, et al. Impact of lymphoscintipraphy on sentinel node identification with technetium-99m-colloidal albumin in breast cancer. J Nucl Med 1997;38:366-368

55. Roumen RM, Valkenburg JG, Geuskens LM. Lymphoscintigraphy and feasibility of sentinel node biopsy in 83 patients with primary breast cancer. Eur J Surg Oncol 1997;23:495-502

56. Cox CE, Pendas S, Cox JM, et al. Guidelines for sentinel node biopsy and lymphatic mapping of patients with breast cancer. Ann Surg 1998;227:645-653

57. Kim T, Giuliano AE, Lyman GH. Lymphatic mapping and sentinel lymph node biopsy in earlystaged breast carcinoma, a metaanalysis. Cancer 2006;106:4-16

58. Krag $D$, Weaver $D$, Ashikaga $T$, et al. The sentinel node in breast cancer - a multicenter validation study. N Engl J Med 1998;339:941-946

59. Cox CE, Bass SS, McCann CR, et al. Lymphatic mapping and sentinel lymph node biopsy in patients with breast cancer. Annu Rev Med 2000;51:525-542

6o. Schijven MP, Vingerhoets AJ, Rutten $\mathrm{HJ}$, et al. Comparison of morbidity between axillary lymph node dissection and sentinel node biopsy. Eur J Surg Oncol 2003;29:341-350

61. Purushotham AD, Upponi $S$, Klevesath $M B$, et al. Morbidity after sentinel lymph node biopsy in primary breast cancer: results from a randomized controlled trial. J Clin Oncol 2005;23:43124321

62. Naik AM, Fey J, Gemignani $M$, et al. The risk of axillary relapse after sentinel lymph node biopsy for breast cancer is comparable with that of axillary lymph node dissection, a follow-up study of 4008 procedures. Ann Surg 2004;240: 462-471

63. Veronesi U, Paganelli G, Viale G, Luini A, et al. Sentinel-lymph-node biopsy as a staging procedure in breast cancer: update of a randomised controlled study. Lancet Oncol 2006;7:983990

64. Roumen RMH, Pijpers HJ, Thunissen FBJM, et al. Samenvatting van de richtlijn "Schildwachtklierbiopsie bij mammacarcinoom". Ned Tijdschr Geneeskd 2000;144:1864-1867

65. Tjan-Heijnen VC, Bult $P$, de Widt-Levert LM, et al. Micro-metastases in axillary lymph nodes: an increasing classification and treatment dilemma in breast cancer due to the introduction of the sentinel lymph node procedure. Breast Cancer Res Treat 2001;70:81-88 
66. van der Heiden-van der Loo M, Bezemer PD, Hennipman A, et al. Introduction of sentinel node biopsy and stage migration of breast cancer. Eur J Surg Oncol 2006;32:710-714

67. Van Rijk MC, Peterse JL, Nieweg OE, et al. Additional axillary metastases and stage migration in breast cancer patients with micrometastases or submicrometastases in sentinel lymph nodes. Cancer 2006;107:467-471

68. Giuliano A, Dale PS, Turner RR, Morton DL, Evans SW, Krasne DL. Improved axillary staging of breast cancer with sentinel lymphadenectomy. Ann Surg 1995;222:394-399

69. de Mascarel I, Bonichon G, Coindre J, et al. Prognostic significance of breast cancer axillary lymph node metastases assessed by two special techniques: reevaluation with longer followup. Br J Cancer 1992;66:523-527

70. Hainsworth $\mathrm{P}, \mathrm{Tjandra} J$, Stillwell $\mathrm{R}$, et al. Detection and significance of occult metastases in node-negative breast cancer. Br J Surg 1993;80:459-463

71. Ludwig Breast Cancer Study Group. Prognostic importance of occult axillary lymph node micrometastases from breast cancers. Lancet 1990;335:1565-1568

72. Kuijt GP, Voogd AC, van de Poll-Franse LV, et al. The prognostic significance of axillary lymphnode micrometastases in breast cancer patients. Eur J Surg Oncol 2005;31:500-505

73. Nasser I, Lee A, Bosari S, et al. Occult axillary lymph node metastases in node-negative breast carcinoma. Hum Pathol 1993;24:950-957

74. Fitzgibbons $P$, Page $D$, Weaver $D$, et al. Prognostic factors in breast cancer: College of American Pathologists Consensus statement 1999. Arch Pathol Lab Med 2000;124:966-978

75. Grabau D. Breast cancer patients with micrometastases only: Is a basis provided for tailored treatment? Surg Oncol 2008;17:211-217

76. Tan LK, Giri D, Hummer AJ et al. Occult axillary node metastases in breast cancer are prognostically significant: Results in 368 node-negative patients with 20-year follow-up. J Clin Oncol 2008;26:1803-1809

77. Chen SL, Hoehne FM, Guiliano AE. The prognostic significance of micrometastases in breast cancer: A SEER population-based analysis. Ann Surg Oncol 2007;14:3378-3384

78. de Boer M, van Deurzen CHM, van Dijck JAAM, et al. Micrometastases or isolated tumor cells and the outcome of breast cancer. N Engl J Med 2009;361:653-663

79. Gobardhan PD, Elias SG, Madsen EVE, et al. Prognostic value of micrometastases in sentinel lymph nodes of patients with breast carcinoma: a cohort study. Ann Oncol 2009;20:41-48

8o. Hansen NM, Grube B, Ye X, et al. Impact of micrometastases in the sentinel node of patients with invasive breast cancer. J Clin Oncol 2009;27:4679-4684

81. Overgaard M, Hansen PS, Overgaard J, et al. Postoperative radiotherapy in high-risk premenopausal women with breast cancer who receive adjuvant chemotherapy. $\mathrm{N}$ Engl J Med 1997;337:949-955

82. Orr RK. The impact of prophylactic axillary node dissection on breast cancer survival - a Bayesian meta-analysis. Ann Surg Oncol 1999;6:109-116

83. Nationaal Borstkanker Overleg Nederland (NABON). Richtlijn behandeling van het mammacarcinoom. 2008; Available: www.oncoline.nl

84. Cserni G, Gregori D, Merletti F, et al. Meta-analysis of non-sentinel node metastases associated with micrometastatic sentinel nodes in breast cancer. Br J Surg 2004;91:1245-1252

85. Fan $Y, T a n Y, W u C$, et al. The effect of sentinel node tumor burden on non-sentinel node status and recurrence rates in breast cancer. Ann Surg Oncol 2005;12:705-711

86. Bilimoria KY, Bentrem DJ, Hansen NM, et al. Comparison of sentinel lymph node biopsy alone and completion axillary lymph node dissection for node-positive breast cancer. J Clin Oncol 2009;27:2946-2953 
87. van Zee KJ, Manasseh DM, Bevilacqua JL, et al. A nomogram for predicting the likelihood of additional nodal metastases in breast cancer patients with a positive sentinel node biopsy. Ann Surg Oncol 2003;10:1140-1151

88. van den Hoven I, Kuijt GP, Voogd AC, et al. Value of Memorial Sloan-Kettering Cancer Center nomogram in clinical decision making for sentinel lymph node-positive breast cancer. Br J Surg 2010;97:1653-1658

89. Fougo JL, Senra FS, Araújo C, et al. Validating the MSKCC nomogram and a clinical decision rule in the prediction of non-sentinel node metastases in a Portuguese population of breast cancer patients. Breast 2011;20:134-140

90. Voogd AC, Ververs JM, Vingerhoets AJ, Roumen RM, Coebergh JW, Crommelin MA. Lymphoedema and reduced shoulder function as indicators of quality of life after axillary lymph node dissection for invasive breast cancer. $\mathrm{Br} J$ Surg 2003;90:76-81

91. Hoebers FJ, Borger JH, Hart AA, Peterse JL, Rutgers EJ, Lebesque JV. Primary axillary radiotherapy as axillary treatment in breast-conserving therapy for patients with breast carcinoma and clinically negative axillary lymph nodes. Cancer 2000;88:1633-1642

92. Fisher $B$, Baver $M$, Margolese $R$, et al. Five-year results of a randomized clinical trial comparing total mastectomy and segmental mastectomy with of without radiation in the treatment of breast cancer. N Engl J Med 1985;312:665-673

93. Louis-Sylvestre $C$, Clough $K$, Asselain B, et al. Axillary treatment in conservative management of operable breast cancer: dissection or radiotherapy? Results of a randomized study with 15 years of follow-up. J Clin Oncol 2004;22:97-101

94. Veronesi U, Orecchia R, Zurrida $S$, et al. Avoiding axillary dissection in breast cancer surgery: a randomized trial to assess the role of axillary radiotherapy. Ann Oncol 2005;16:383-388

95. Martelli G, Boracchi P, De Palo $M$, et al. A randomized trial comparing axillary dissection to no axillary dissection in older patients with $\mathrm{T}_{1}$ No breast cancer: results after 5 years of follow-up. Ann Surg 2005;242:1-9

96. Giuliano AE, McCall L, Beitsch $P$, Whitworth PW, Blumencranz $P$, Leitch $A M$, et al. Locoregional recurrence after sentinel lymph node dissection with or without axillary dissection in patients with sentinel lymph node metastases. Ann Surg 2010;252:426-433

97. Giuliano $A E$, Hunt $K K$, Ballman $K V$, et al. Axillary dissection vs no axillary dissection in women with invasive breast cancer and sentinel node metastasis: a randomized clinical trial. JAMA 2011;305:569-575

98. Buchholz TA, Tucker SL, Erwin J, et al. Impact of systemic treatment on local control for patients with lymph node-negative breast cancer treated with breast-conservation therapy. J Clin Oncol 2001;19:2240-2246

99. Gralow JR, Burstein HJ, Wood W, et al. Preoperative therapy in invasive breast cancer: Pathologic assessment and systemic therapy issues in operable disease. J Clin Oncol 2008;26:814-819

100. Schlembach PJ, Buchholz TA, Ross MI, et al. Relationship of sentinel and axillary level I-II lymph nodes to tangential fields used in breast irradiation. Int J Radiat Oncol Biol Phys 2001;51:671678

101. Reznik J, Cicchetti MG, Degaspe $B$, et al. Analysis of axillary coverage during tangential radiation therapy to the breast. Int J Radiat Oncol Biol Phys 2005;61:163-168

102. Roumen RM, Pijpers HJ, Thunnissen FB, Ruers TJ. Summary of the guideline "Sentinel node biopsy in breast cancer". Dutch Work Group "Sentinel node biopsy for breast cancer". Ned Tijdschr Geneesk 2000;144:1864-1867 
103. Olson Jr JA, Fey J, Winawer J, et. al. Sentinel lymphadenectomy accurately predicts nodal status in T2 breast cancer. J Am Coll Surg 2000;191:593-599

104. Kuijt GP, van de Poll-Franse LV, Voogd AC, Nieuwenhuijzen GAP, Roumen RMH. Survival after negative sentinel lymph node biopsy in breast cancer at least equivalent to after negative extensive axillary dissection. Eur J Surg Oncol 2007;33:832-837

105. Estourgie SH, Nieweg OE, Valdes Olmos RA, Rutgers EJT, Kroon BBR. Lymphatic drainage patterns from the breast. Ann Surg 2004;239:232-237

106. Ozmen V, Muslumanoglu M, Cabiolglu N, et. al. Increased false negative rates in sentinel lymph node biopsies in patients with multifocal breast cancer. Breast Cancer Res Treat 2002;76:237-244

107. Leidenius MHK, Krogerus LA, Toivonen TS, von Smitten KAJ. Sentinel node biopsy is not sensible in breast cancer patients with large primary tumours. Eur J Surg Oncol 2005;31:364368

108. Spillane AJ, Brennan ME. Accuracy of sentinel lymph node biopsy in large and multifocal/multicentric breast carcinoma - A systematic review. Eur J Surg Oncol 2011;37:371385

109. Javan H, Gholami H, Assadi M, Fani Pakdel A, Sadeghi R, Keshtgar M. The accuracy of sentinel node biopsy in breast cancer patients with the history of previous surgical biopsy of the primary lesion: Systematic review and meta-analysis of the literature. Eur J Surg Oncol 2012;38:95-109

110. Heuts EM, van der Ent FWC, Kengen RAM, van der Pol HAG, Hulsewé KWE, Hoofwijk AGM. Results of sentinel node biopsy not affected by previous excisional biopsy. Eur J Surg Oncol 2006;32:278-281

111. Estourgie SH, Valdes Olmos RA, Nieweg OE, et al. Excision biopsy of breast lesions changes the pattern of lymphatic drainage. BJS 2007;94:1088-1091

112. Voogd AC, Nielsen $M$, Peterse JL, et. al. Differences in risk factors for local and distant recurrence after breast-conserving therapy or mastectomy for stage I and II breast cancer: pooled results of two large European randomized trials. J Clin Oncol 2001;15:1688-1697

113. Roumen RMH, Kuijt GP, Liem IH. Lymphatic mapping and sentinel node harvesting in patients with recurrent breast cancer. Eur J Surg Oncol 2006;32:1076-81

114. Port ER, Garcia-Etienne CA, Park J, Fey J, Borgen PI, Cody HS 3rd. Reoperative sentinel lymph node biopsy: a new frontier in the management of ipsilateral breast tumor recurrence. Ann Surg Oncol 2007;14:2209-2214

115. Intra M, Trifirò G, Galimberti V, Gentilini O, Rotmensz N, Veronesi P. Second axillary sentinel node biopsy for ipsilateral breast tumour recurrence. Br J Surg 2007;94:1216-1219 
Chapter 1 


\section{Chapter 2}

\section{Stage migration due to introduction of the sentinel node procedure: A population- based study}

A.J.G. Maaskant

L.V. van de Poll-Franse

A.C. Voogd

J.W.W. Coebergh

M.C.B.J.E. Tutein Nolthenius-Puylaert G.A.P. Nieuwenhuijzen

Breast Cancer Res Treat 2009;113:173-179 


\begin{abstract}
Background Introduction of sentinel node biopsy (SNB) as an axillary staging procedure in breast cancer patients could have led to upstaging as well as downstaging of their disease. Intensified pathological processing could have led to upstaging due to presence of micrometastases, whereas the described false negative rate of $5 \%$ could be a cause of downstaging. We investigated whether or not the introduction of the sentinel node procedure has changed the incidence of axillary nodal micrometastases and induced stage migration on a population-based level.
\end{abstract}

Methods Data from the population based Eindhoven Cancer Registry were used on all $(n=17100)$ women diagnosed with invasive breast cancer in the Southeast region of The Netherlands in the period 1994-2005.

Results The percentage of patients staged with SNB increased from o\% in 1994 to $62 \%$ in 2005. The percentage of patients with micrometastases increased from $1.0 \%$ in 1994 to $4.3 \%$ in 2005 ( $P<0.0001)$, whereas no significant increase was observed of the proportion of patients with positive axillary lymph nodes. After adjustment for tumour size, age at diagnosis and histology the probability of having a positive axillary lymph node status was 10\% higher in period 2003-2005, as compared to period 1994-1996. Furthermore, women diagnosed in the period 2003-2005 had a 3.5 times higher risk of having micrometastases compared to women diagnosed in the period 1994-1996 (i.e., before the introduction of SNB).

Conclusion The introduction of SNB in the Southeast region of The Netherlands has led to stage migration, as is reflected by the small but significant increase of the proportion of patients with positive axillary lymph nodes after adjustment for tumour size and age. 


\section{Introduction}

Determining axillary lymph node status is of critical importance in staging patients with early breast cancer. Even in the era of gene-expression profiling (i.e., micro-array), it remains an important independent prognostic marker of disease behaviour and ultimate outcome $^{1,2}$. Furthermore, it plays a role in regional tumour control ${ }^{3}$, which in turn has been shown to contribute to the reduction of breast cancer mortality ${ }^{4-6}$. Axillary lymph node dissection (ALND) has long been the standard of care for adequate axillary staging. Long-term complications of this treatment, however, are relatively common and include lymphedema, seroma formation, shoulder dysfunction, pain and numbness ${ }^{7,8}$. As an alternative for ALND sentinel node biopsy (SNB) was introduced some ten years ago with similar staging capacities ${ }^{9,10}$ but with markedly lower morbidity ${ }^{11}$. According to the sentinel lymph node hypotheses, tumour cells migrating from a primary tumour colonize one or a few lymph nodes before involving others. Injection with blue dye and/or radiolabelled colloid around the area of the tumour permits identification of a sentinel node and its status accurately predicts the status of the remaining regional lymphnodes ${ }^{12}$. Theoretically, the increasing use of SNB as an axillary staging procedure could have led to downstaging as well as upstaging of disease. Due to reported false negative rates of SNB averaging 5 percent $^{12}$, downstaging might have occurred and ALND and adjuvant systemic treatment might have been omitted unjustly. On the other hand, the elaborate pathologic examination of the sentinel node and the use of more sensitive techniques, such as serial sectioning and immunohistochemistry, have resulted in an easier identification of malignant cells. As a consequence, occult or micrometastases are being detected in 9-23 percent of originally Hematoxylin\&Eosin node-negative $\operatorname{cases}^{13}$. These patients will be upstaged to the group of node-positive patients. Despite these uncertainties, most treatment guidelines have endorsed SNB as an alternative to ALND in clinically node-negative patients ${ }^{14}$ and most surgeons have adopted the technique as the standard procedure for axillary staging ${ }^{15}$.

The purpose of our study was to investigate whether or not the gradual introduction of the SNB in the Southeast region of The Netherlands has changed the incidence of axillary nodal micrometastases and induced a stage migration on a population based level.

\section{Patients and methods}

Patient data were retrieved from the population based Eindhoven Cancer Registry, which records data on all patients newly diagnosed with cancer in the Southeast region of the Netherlands, an area with approximately 2.4 million inhabitants. Collected data were derived from 10 hospitals, consisting of large non-university teaching hospitals and community hospitals, and two radiotherapy departments. Data on patient- and tumour 
characteristics and treatment were collected by the Cancer Registry based on the pathology reports and medical records. The patients were staged according to the Tumour-Node-Metastasis (TNM) system of the International Union Against Cancer $(\mathrm{UICC})^{16}$. Data were continually revised to assure completeness and accuracy ${ }^{17}$.

For this study specifically, data on axillary staging procedure, disease stage and presence of micrometastases were categorized according to year and period of diagnosis, as this shows the increasing implementation of the SNB technique in the area. Sentinel node biopsy followed by axillary lymph node dissection was introduced in the Southeast Netherlands in 1995. In 1997, surgeons started performing SNB procedures as a routine staging procedure and since the year 2000 indications for SNB are being described in national guidelines ${ }^{18}$.

In order to be able to perform a true population-based analysis we included all women diagnosed with primary invasive breast cancer in the period 1994-2005 ( $n=17100)$ and we used characteristics and data of the entire group in the analyses.

Statistical analyses were carried out using SAS (version 9.1 for Windows, SAS institute Inc., Cary, NC). We performed trend analyses for incidence of SNB (with or without concurrent ALND), $\mathrm{T}$ - and N-stages. Furthermore we performed logistic regression analyses with both axillary lymph node status (negative vs. positive, including macroand/or micrometastases) and presence of micrometastases (yes vs. no) as outcome parameters. Three periods were defined to study the trends. Period 1 represents the years 1994-1996 (before introduction of the SNB), period 2 the years 1997-2002 (during implementation of the SNB) and period 3 the years 2003-2005 (after implementation of the SNB). In these models we adjusted for the possible confounding influences of tumour size (defined as T-stage), age at diagnosis and histology. Because of the large fraction of unknown tumour grades in the early years, we left the association between grade and axillary lymph node status out of the analysis. P-values $<0.05$ were considered statistically significant.

\section{Results}

Between 1994 and 2005 a total of 17100 patients were treated for primary invasive breast cancer in the Southeast region of The Netherlands. Their characteristics are shown in Table 1 , stratified according to the three pre-defined periods of diagnosis. Agedistribution did not significantly differ in these three periods, but $\mathrm{T}$-stage, $\mathrm{N}$-stage, grade, histology, type of definitive surgery and type of axillary surgery did change significantly. In the years $2003-200553 \%$ of patients had a $\mathrm{T}_{1}$ tumour compared to $49 \%$ in the years 1994-1996. From 2003-2005, after implementation of the SNB, 60\% of patients underwent SNB with or without ALND compared to $0 \%$ from $1994-1996$ and $31 \%$ from 
1997-2002. In 42\% of patients who underwent SNB from 2003-2005 the SNB was not followed by an ALND. The percentage of patients that had an ALND that was not preceded by a SNB decreased from $87 \%$ in the period $1994-1996$ to $55 \%$ in the period 1997-2002 and $29 \%$ in the period 2003-2005.

Table 1 Patient characteristics by period of diagnosis of 17100 patients treated for primary breast cancer in the Southeast Netherlands from 1994-2005.

\begin{tabular}{|c|c|c|c|c|}
\hline $\begin{array}{l}\text { Period of diagnosis } \\
\text { Number of patients (\%) }\end{array}$ & $\begin{array}{r}1994-1996 \\
3637(21.3) \\
\end{array}$ & $\begin{array}{l}1997-2002 \\
8603(50.3) \\
\end{array}$ & $\begin{array}{r}2003-2005 \\
4860(28.4) \\
\end{array}$ & P-value \\
\hline $\begin{array}{l}\text { Age at diagnosis } \\
\leq 35 \\
36-49 \\
50-69 \\
\geq 70\end{array}$ & $\begin{array}{r}120(3.3) \\
821(22.6) \\
1755(48.3) \\
941(25.9)\end{array}$ & $\begin{array}{r}257(3.0) \\
1956(22.7) \\
3946(45.9) \\
2444(28.4)\end{array}$ & $\begin{array}{r}143(2.9) \\
1080(22.2) \\
2326(47.9) \\
1311(27.0)\end{array}$ & 0.06 \\
\hline $\begin{array}{l}\text { pT-Stage } \\
1 \\
2 \\
3 \\
4 \\
\text { Unknown } \\
\end{array}$ & $\begin{array}{r}1779(48.9) \\
1173(32.3) \\
105(2.9) \\
221(6.1) \\
359(9.9) \\
\end{array}$ & $\begin{array}{r}4433(51.5) \\
2604(30.3) \\
219(2.6) \\
399(4.6) \\
948(11.0) \\
\end{array}$ & $\begin{array}{r}2596(53.4) \\
1511(31.1) \\
134(2.8) \\
83(1.7) \\
536(11.0) \\
\end{array}$ & $<0.0001$ \\
\hline $\begin{array}{l}\text { pN-Stage } \\
\mathrm{N}+^{*} \\
\mathrm{~N}- \\
\text { Unknown }\end{array}$ & $\begin{array}{r}1309(36.0) \\
1962(54.0) \\
366(10.0)\end{array}$ & $\begin{array}{r}3230(37.6) \\
4492(52.2) \\
881(10.2)\end{array}$ & $\begin{array}{r}1802(37.1) \\
2695(55.5) \\
363(7.5)\end{array}$ & $<0.0001$ \\
\hline $\begin{array}{l}\text { Grade } \\
\text { I } \\
\text { II } \\
\text { III } \\
\text { Unknown }\end{array}$ & $\begin{array}{r}106(2.9) \\
363(10.0) \\
552(15.2) \\
2612(71.9)\end{array}$ & $\begin{array}{r}659(7.7) \\
1751(20.4) \\
1900(22.1) \\
4293(49.9)\end{array}$ & $\begin{array}{r}1047(21.5) \\
1673(34.4) \\
1226(25.2) \\
914(18.8)\end{array}$ & $<0.0001$ \\
\hline $\begin{array}{l}\text { Histology } \\
\text { Ductal } \\
\text { Lobular/mixed } \\
\text { Mucinous/tubular/medullary } \\
\text { Other }\end{array}$ & $\begin{array}{r}2757(75.8) \\
595(16.4) \\
205(5.6) \\
80(2.2)\end{array}$ & $\begin{array}{r}6631(77.1) \\
1370(15.9) \\
397(4.6) \\
205(2.4)\end{array}$ & $\begin{array}{r}3932(80.9) \\
672(13.8) \\
168(3.5) \\
88(1.8)\end{array}$ & $<0.0001$ \\
\hline $\begin{array}{l}\text { Type of definitive surgery } \\
\text { Breast-conserving surgery } \\
\text { Mastectomy } \\
\text { None/unknown }\end{array}$ & $\begin{array}{r}1637(45.0) \\
1663(45.7) \\
337(9.3) \\
\end{array}$ & $\begin{array}{r}3966(46.1) \\
3818(44.8) \\
819(9.5) \\
\end{array}$ & $\begin{array}{r}2553(52.5) \\
1901(39.1) \\
406(8.4) \\
\end{array}$ & $<0.0001$ \\
\hline $\begin{array}{l}\text { Type of axillary surgery } \\
\text { SNB alone } \\
\text { SNB+ALND } \\
\text { ALND alone } \\
\text { None }\end{array}$ & $\begin{array}{r}0(0.0) \\
1(0.0) \\
3154(86.7) \\
482(13.3)\end{array}$ & $\begin{array}{l}1564(18.2) \\
1088(12.7) \\
4742(55.1) \\
1209(14.1)\end{array}$ & $\begin{array}{r}2029(41.8) \\
884(18.2) \\
1415(29.1) \\
532(11.0)\end{array}$ & $<0.0001$ \\
\hline
\end{tabular}

SNB: Sentinel Node Biopsy; ALND: Axillary Lymph Node Dissection

* By macro- and/or micrometastatic disease 
The percentage of patients staged with SNB (with of without following ALND) gradually and significantly increased from $0 \%$ in 1994 to $62 \%$ in 2005 (Figure 1). The percentage of patients with micrometastases increased significantly after introduction of the SNB from $1.0 \%$ in 1994 to $4.3 \%$ in 2005 ( $\mathrm{P}<0.0001)$, whereas the proportion of patients with positive axillary lymph nodes showed no significant change (Figure 2 ).

Figure 1 Incidence of SNB (with or without following ALND) for 17100 patients treated for primary invasive breast cancer in the Southeast Netherlands from 1994-2005.

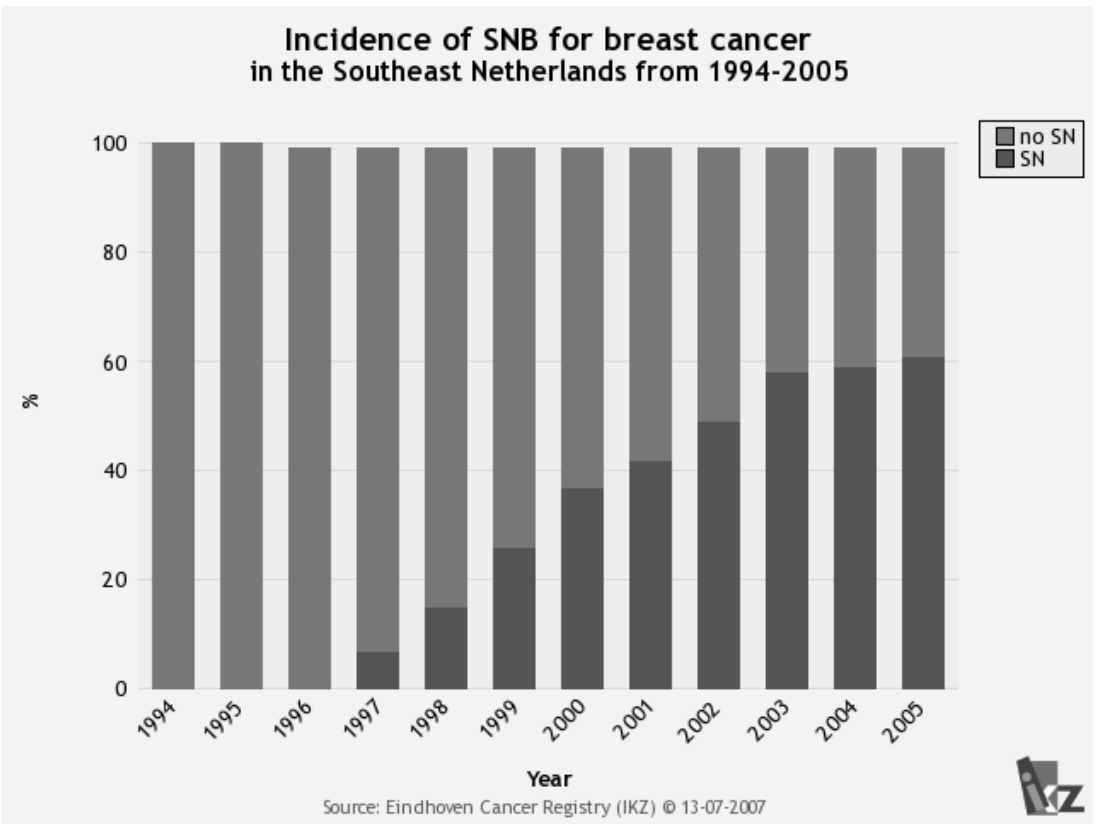


Figure 2 Trend in pN distribution for 17100 patients treated for primary invasive breast cancer in the Southeast Netherlands from 1994-2005.

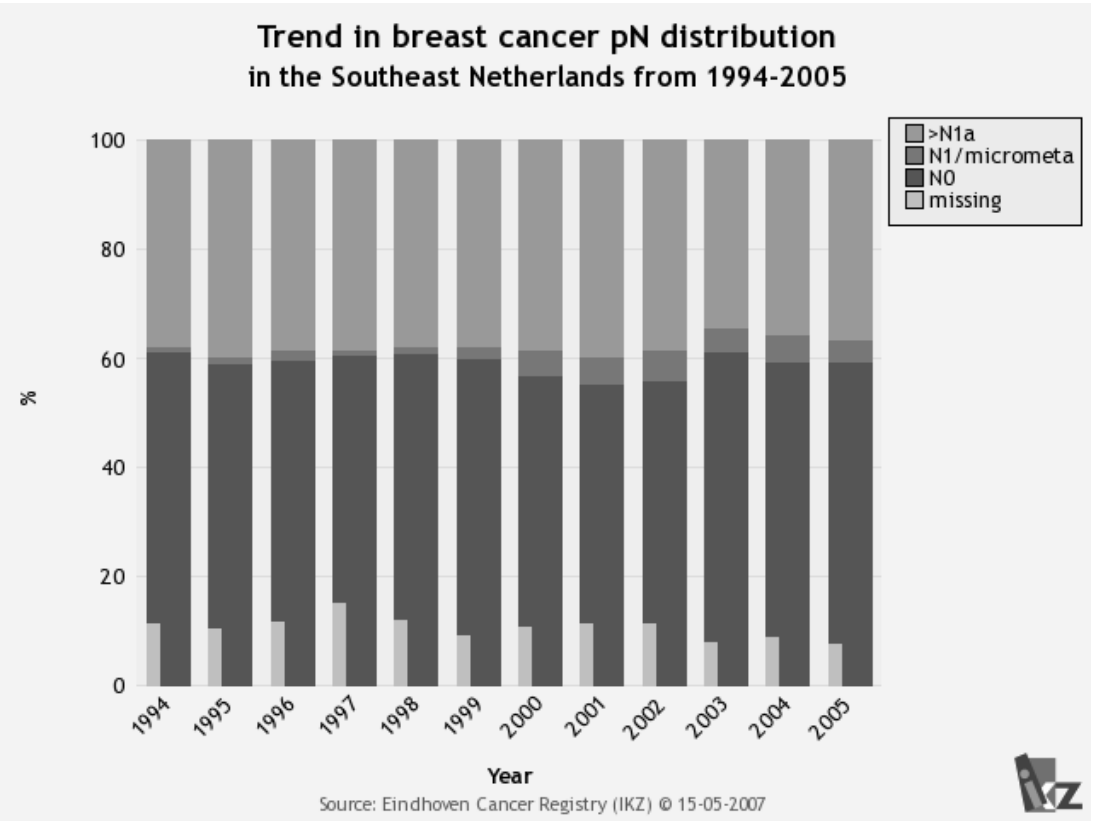

To determine the probability of having a positive axillary lymph node status (i.e., microand/or macrometastatic disease) in each period, a multivariate logistic regression analysis was performed, adjusting for covariates postoperative tumour size (pT), age at diagnosis and histology (Table 2 ). The risk of having a positive axillary lymph node status was $14 \%$ (95\% Cl, 1.0-1.3) higher in period 1997-2002 and $10 \%(95 \% \mathrm{Cl}, 1.0-1.2)$ higher in period 2003-2005, as compared to period 1994-1996. 
Table 2 Logistic regression analysis: Probability of having a positive axillary nodal status (i.e., macro- and/or micrometastatic disease) by period of diagnosis of 17100 patients treated for primary breast cancer in the Southeast Netherlands from 1994-2005.

\begin{tabular}{|c|c|c|c|c|}
\hline & \multicolumn{2}{|c|}{ Univariate } & \multicolumn{2}{|c|}{ Multivariate } \\
\hline & Crude OR & $95 \% \mathrm{Cl}$ & OR & $95 \% \mathrm{Cl}$ \\
\hline Period of diagnosis & & & & \\
\hline $1994-1996$ & 1 & & 1 & \\
\hline $1997-2002$ & 1.08 & $1.00-1.17$ & 1.14 & $1.04-1.25$ \\
\hline $2003-2005$ & 1.00 & $0.91-1.01$ & 1.10 & $1.00-1.22$ \\
\hline pT-Stage & & & & \\
\hline 1 & 1 & & 1 & \\
\hline 2 & 3.04 & $2.82-3.27$ & 3.03 & $2.81-3.26$ \\
\hline 3 & 7.81 & $6.28-9.72$ & 7.68 & $6.15-9.58$ \\
\hline 4 & 8.17 & $6.77-9.86$ & 9.00 & $7.42-10.91$ \\
\hline Age at diagnosis & & & & \\
\hline$<36$ & 1 & & 1 & \\
\hline $36-49$ & 0.96 & $0.80-1.16$ & 0.98 & $0.80-1.20$ \\
\hline $50-69$ & 0.66 & $0.55-0.79$ & 0.73 & $0.60-0.88$ \\
\hline$\geq 70$ & 0.74 & $0.62-0.90$ & 0.63 & $0.52-0.77$ \\
\hline Histology & & & & \\
\hline Ductal & 1 & & 1 & \\
\hline Lobular/mixed & 1.16 & $1.06-1.27$ & 1.00 & $0.91-1.10$ \\
\hline Mucinous/tub/med & 0.37 & $0.30-0.44$ & 0.40 & $0.33-0.49$ \\
\hline Other & 0.50 & $0.35-0.70$ & 0.41 & $0.28-0.59$ \\
\hline
\end{tabular}

OR: Odds Ratio; 95\% Cl: 95\% Confidence Interval

Multivariate logistic regression analyses showed that women diagnosed in the period 2003-2005 had a 3.5 (95\% Cl, 2.5-4.9) times higher risk of having micrometastases compared to women diagnosed in period 1994-1996, adjusted for the effect of covariates pT, age and histology (Table 3). In the second model, adjusted for $\mathrm{pT}$, age and histology and also taking into account the method of staging (SNB with or without subsequent ALND vs. ALND), women undergoing SNB were found to have a 4.1 (95\% Cl, 3.3-5.2) times higher risk of having micrometastases in period 2003-2005 compared to period 1994-1996. Because of the strong association between period and method of staging, the effect of period disappeared when both variables were included in one model simultaneously. This implicates that the increased possibility of having axillary nodal micrometastases is almost entirely due to introduction of the SNB. 
Table 3 Logistic regression analysis: Probability of being diagnosed with micrometastases by period of diagnosis (model I) and by method of staging (model II) of 17100 patients treated for primary breast cancer in the Southeast Netherlands from 1994-2005.

\begin{tabular}{|c|c|c|c|c|c|c|}
\hline & \multicolumn{2}{|c|}{ Univariate } & \multicolumn{2}{|c|}{ Multivariate model I } & \multicolumn{2}{|c|}{ Multivariate model II } \\
\hline & Crude OR & $95 \% \mathrm{Cl}$ & OR & $95 \% \mathrm{Cl}$ & OR & $95 \% \mathrm{Cl}$ \\
\hline $\begin{array}{l}\text { Method of staging } \\
\text { ALND alone } \\
\text { SNB* }\end{array}$ & $\begin{array}{c}1 \\
4.30 \\
\end{array}$ & $3.53-5.23$ & & & $\begin{array}{c}1 \\
4.10 \\
\end{array}$ & $3.25-5.18$ \\
\hline $\begin{array}{l}\text { Period of diagnosis } \\
\begin{array}{c}1994-1996 \\
1997-2002 \\
2003-2005\end{array}\end{array}$ & $\begin{array}{c}1 \\
2.58 \\
3.58 \\
\end{array}$ & $\begin{array}{l}1.87-3.55 \\
2.58-4.97\end{array}$ & $\begin{array}{c}1 \\
2.57 \\
3.52 \\
\end{array}$ & $\begin{array}{l}1.87-3.55 \\
2.53-4.90 \\
\end{array}$ & $\begin{array}{c}1 \\
1.30 \\
1.20 \\
\end{array}$ & $\begin{array}{l}0.91-1.85 \\
0.82-1.76\end{array}$ \\
\hline $\begin{array}{c}\text { pT-Stage } \\
1 \\
2 \\
3 \\
4\end{array}$ & $\begin{array}{c}1 \\
0.88 \\
1 \\
0.44\end{array}$ & $\begin{array}{l}0.72-1.06 \\
0.60-1.66 \\
0.24-0.80\end{array}$ & $\begin{array}{c}1 \\
0.87 \\
0.95 \\
0.49\end{array}$ & $\begin{array}{l}0.72-1.06 \\
0.57-1.59 \\
0.26-0.89\end{array}$ & $\begin{array}{c}1 \\
1.05 \\
1.68 \\
0.81\end{array}$ & $\begin{array}{l}0.87-1.28 \\
0.99-2.84 \\
0.44-1.51\end{array}$ \\
\hline $\begin{array}{l}\text { Age at diagnosis } \\
<36 \\
\begin{array}{l}36-49 \\
50-69 \\
>70\end{array}\end{array}$ & $\begin{array}{c}1 \\
1.43 \\
1.21 \\
0.71\end{array}$ & $\begin{array}{l}0.82-2.50 \\
0.70-2.08 \\
0.40-1.26\end{array}$ & & & & \\
\hline $\begin{array}{l}\text { Histology } \\
\text { Ductal } \\
\text { Lobular/mixed } \\
\text { Mucinous/tub/med } \\
\text { Other }\end{array}$ & $\begin{array}{c}1 \\
1.18 \\
0.56 \\
0.53\end{array}$ & $\begin{array}{l}0.94-1.49 \\
0.32-0.97 \\
0.24-1.19\end{array}$ & $\begin{array}{c}1 \\
1.24 \\
0.56 \\
0.88\end{array}$ & $\begin{array}{l}0.99-1.57 \\
0.32-0.99 \\
0.39-2.01\end{array}$ & $\begin{array}{c}1 \\
1.18 \\
0.57 \\
0.85\end{array}$ & $\begin{array}{l}0.93-1.49 \\
0.32-1.00 \\
0.37-1.93\end{array}$ \\
\hline
\end{tabular}

OR: Odds Ratio; 95\% Cl: 95\% Confidence Interval; ALND: Axillary Lymph Node Dissection; SNB: Sentinel Node Biopsy

* SNB with or without following ALND

\section{Discussion}

After its introduction in the Southeast region of The Netherlands in 1997, the use of SNB as an axillary staging method increased to $62 \%$ of the breast cancer patients in 2005 . Although the percentage of patients with micrometastases increased significantly from $1.0 \%$ in 1994 to $4.3 \%$ in 2005 , no significant change was observed of the percentage of patients with positive axillary lymph nodes during this period. However, after adjustment for tumour size and age at diagnosis a small but significant increase in the risk of reporting a positive axillary lymph node status could be demonstrated.

By using data of the Eindhoven Cancer Registry, we were able to present results based on a large, population-based and unselected patient population. The patients were treated in both teaching and community hospitals and data thus reflect usual care in The Netherlands. By covering the period $1994-2005$, we were able to make a true comparison 
in time between a period before and after implementation of the sentinel node technique.

The introduction of the SNB allowed the application of more time-consuming and costly pathologic examination techniques of serial sectioning, immunohistochemistry and reverse-transferase polymerase chain reaction. Conventional lymph node examination is based on an H\&E staining of one or two sections through the largest diameter of the lymph node. The use of serial sections and immunohistochemistry (IHC) has been increasingly advocated in the case of an H\&E negative $\mathrm{SN}$ in order to detect smaller metastases. Furthermore, molecular methods using reverse transcriptase polymerase chain reaction (RT-PCR) have been used to identify RNA from occult malignant cells in axillary lymphnodes ${ }^{18}$. In The Netherlands the pathology protocol advocated by the EORTC Breast Cancer Group has been adopted by the pathologists and included in the Dutch evidence-based guideline for the treatment of breast cancer. According to this guideline, sentinel nodes should be sliced in at least three sections at $0.25 \mathrm{~mm}$ intervals and from each section at least two slides should be made: one for H\&E staining and one for $\mathrm{IHC}^{19}$. In a prospective study, comparing the risk of axillary node metastases in SNB versus ALND specimens, Giuliano et al. found a $13 \%$ higher risk in the group who underwent SNB with multiple sectioning and immunohistochemical staining of sentinel nodes $^{20}$. This excess risk could be explained almost completely by the detection of micrometastases.

A recent study from the Comprehensive Cancer Centre Middle Netherlands showed that the percentage of patients diagnosed with positive lymph nodes increased from $30 \%$ in 1997 to $40 \%$ in $2002^{21}$. This increase could be entirely explained by the increasing proportion of patients with micrometastatic disease, which rose from $1 \%$ to $10 \%$. Although the authors concluded that the introduction of SNB led to significant upstaging of breast cancer patients, they only included patients with tumours of $5 \mathrm{~cm}$ and smaller and patients diagnosed during the introduction of SNB. In order to determine whether a true stage migration on a population based level occurred, we expanded inclusion criteria to the entire population of breast cancer patients instead of only those with $T_{1}$ and $T_{2}$ tumours. Furthermore, we included patients diagnosed over a longer period of time and compared two periods before and after introduction of the SNB. Remarkably, despite the availability of a national guideline regarding SNB, our study showed a smaller increase in number of micrometastases than the report from the central part of The Netherlands ${ }^{21}$. The most likely explanation for this discrepancy is a difference in the thoroughness of the examination of the $\mathrm{SN}$ between pathology laboratories, with a varying number of sections and cutting intervals. However, the potential under diagnosis of micrometastatic disease in our region did not result in a survival difference between node-negative breast cancer patients after a SNB without completion ALND or after an ALND ${ }^{22}$. In another recent study a non-significant increase was observed in the proportion of patients with 
lymph node involvement ( $32 \%$ vs. $27 \% ; P=.16$ ) after SNB implementation, as compared to the period before the implementation ${ }^{23}$. However, in this study, no attempt was made to adjust for changes in tumour size during the study period.

In our study, the increased detection of micrometastases was not accompanied by an increase in the proportion of patients with positive axillary lymph nodes. This could be explained by the effects of the introduction of the breast cancer surveillance program in the same period. This breast cancer screening program promotes bi-annual screening of women for breast cancer with mammography and was first introduced in The Netherlands in 1988 for women between the ages of 50-69 and in 1998 the criteria were expanded to include women between the ages 50-75. Screening is more likely to detect slower growing tumours, which could lead to a more favourable stage and grade distribution. After correction for this effect indeed a small but significant stage migration was visible on a population based level.

In conclusion, the introduction of SNB in the Southeast region of The Netherlands has resulted in stage migration, as is reflected by the fourfold increase of the proportion of patients with micrometastases and the small but significant increase of the proportion of patients with positive lymph nodes, after adjustment for the favourable trend in tumour size. The impact on consideration for adjuvant therapy and implications of micrometastatic disease on survival remain uncertain. 


\section{References}

1. van de Vijver MJ, He YD, van 't Veer LJ, et al. A gene-expression signature as a predictor of survival in breast cancer. N Engl J Med 2002;347:1999-2009

2. Glodhirsch A, Glick JH, Gelber RD, Senn HJ. Meeting highlights: international consensus panel on the treatment of primary breast cancer. J Natl Cancer Instit 1998;90:1601-1608

3. Fisher B, Redmond C, Fisher ER, et al. Ten-year results of a randomized clinical trial comparing radical mastectomy and total mastectomy with or without radiation. $\mathrm{N}$ Eng J Med 1985;312:674-681

4. Orr RK. The impact of prophylactic axillary node dissection on breast cancer survival - a Bayesian meta-analysis. Ann Surg Oncol 1999;6:109-116

5. Overgaard $M$, Jensen $M B$, Overgaard J, et al. Postoperative radiotherapy in high-risk postmenopausal breast-cancer patients given adjuvant tamoxifen: Danish Breast Cancer Cooperative Group DBCG 82C randomized trial. Lancet 1999;353:1641-1648

6. Clarke M, Collins R, Darby $S$, et al. Effects of radiotherapy and of differences in the extent of surgery for early breast cancer on local recurrence and 15 -year survival: an overview of the randomized trials. Lancet 2005;366:2087-2106

7. Voogd AC, Ververs JM, Vingerhoets AJ, Roumen RM, Coebergh JW, Crommelin MA. Lymphoedema and reduced shoulder function as indicators of quality of life after axillary lymph node dissection for invasive breast cancer. Br J Surg 2003; 90:76-81

8. Ververs JM, Roumen RM, Vingerhoets AJ, et al. Risk, severity and predictors of physical and psychological morbidity after axillary lymph node dissection for breast cancer. Eur J Cancer 2001;37:991-999

9. Cox CE, Bass SS, McCann CR, et al. Lymphatic mapping and sentinel lymph node biopsy in patients with breast cancer. Annu Rev Med 2000;51:525-542

10. Veronesi U, Paganelli G, Galimberti V, et al. Sentinel-node biopsy to avoid axillary dissection in breast cancer with clinically negative lymphnodes. Lancet 1997;349:1864-1867

11. Schijven MP, Vingerhoets AJ, Rutten HJ, et al. Comparison of morbidity between axillary lymph node dissection and sentinel node biopsy. Eur J Surg Oncol 2003;29:341-350

12. Krag $D$, Weaver $D$, Ashikaga $T$, et al. The sentinel node in breast cancer-a multicenter validation study. N Engl J Med 1998;339:941-946

13. Tjan-Heijnen VC, Bult P, de Widt-Levert LM, Ruers TJ, Beex LV. Micro-metastases in axillary lymph nodes: an increasing classification and treatment dilemma in breast cancer due to the introduction of the sentinel lymph node procedure. Breast Cancer Res Treat 2001;70:81-88

14. Lyman GH, Giuliani AE, Somerfiedl MR, et al. American Society of Clinical Oncology Guideline Recommendations for sentinel lymph node biopsy in early-stage breast cancer. J Clin Oncol 2005;23:7703-7720

15. Edge SB, Niland JC, Bookman MA, et al. Emergence of sentinel node biopsy in breast cancer as standard-of-care in academic comprehensive cancer centers. J Natl Cancer Inst 2003;95:14151521

16. Hermanek P, Sobin LH, editors. UICC TNM classification of malignant tumors. Berlin: SpringerVerlag 1987;94-99

17. Eindhoven Cancer Registry, Comprehensive Cancer Centre South. Available from URL: http://www.ikcnet.nl/ikz

18. Bostick PJ, Huynh KT, Sarantou T, et al. Detection of metastases in sentinel lymph nodes of breast cancer patients by multiple-marker RT-PCR. Int J Cancer 1998;79:645-651

19. Roumen RMH, Pijpers HJ, Thunnisen FBJM, Ruers TJM. Samenvatting van de richtlijn "Schildwachtklierbiopsie bij mammacarcinoom". Ned Tijdschr Geneeskd 2000;144:1864-1867 
20. Giuliano A, Dale PS, Turner RR, Morton DL, Evans SW, Krasne DL. Improved axillary staging of breast cancer with sentinel lymphadenectomy. Ann Surg 1995;222:394-399

21. van der Heiden-van der Loo M, Bezemer PD, Hennipman A, et al. Introduction of sentinel node biopsy and stage migration of breast cancer. Eur J Surg Oncol 2006;32:710-714

22. Kuijt GP, van de Poll-Franse LV, Voogd AC, Nieuwenhuijzen GAP, Roumen RMH. Survival after negative sentinel lymph node biopsy in breast cancer at least equivalent to after negative extensive axillary dissection. Eur J Surg Oncol 2007;33:832-837

23. Vanderveen KA, Schneider PD, Khatri VP, Goodnight JE, Bold RJ. Upstaging and improved survival of early breast cancer patients after implementation of sentinel node biopsy for axillary staging. Ann Surg Oncol 2006;13:1450-1456 
Chapter 2 


\title{
Chapter 3
}

\author{
Axillary and systemic treatment of \\ patients with breast cancer and \\ micrometastatic disease or isolated \\ tumour cells in the sentinel lymph node
}

A.J.G. Maaskant-Braat

A.C. Voogd

L.V. van de Poll-Franse

J.W.W. Coebergh

G.A.P. Nieuwenhuijzen

Breast 2012;21:524-528

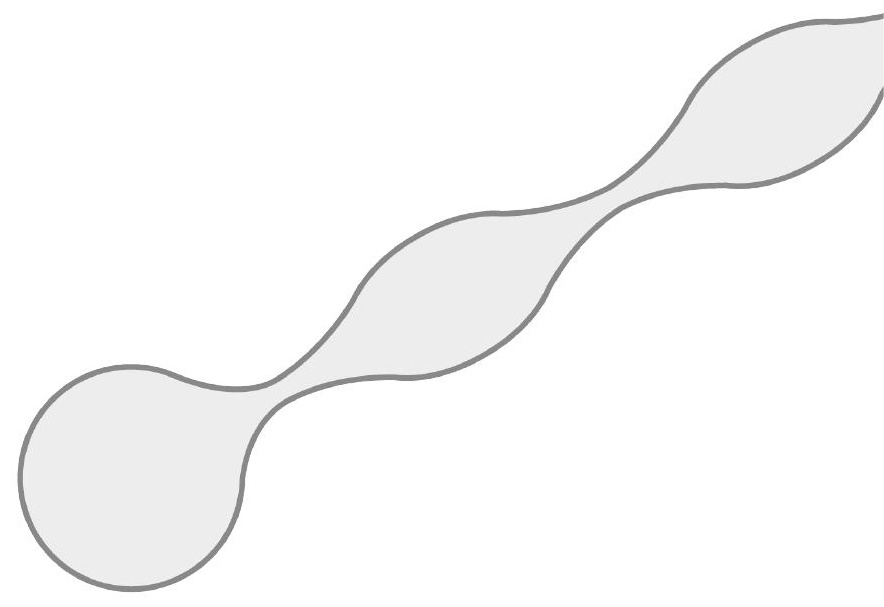




\begin{abstract}
Background After introduction of sentinel node biopsy (SNB) in patients with breast cancer a higher proportion of micrometastases and isolated tumour cells are being detected. Prognostic impact and clinical relevance of this minimal nodal involvement is under debate and substantial variation in the use of axillary surgery and/or systemic adjuvant treatment could be expected.
\end{abstract}

Methods Data from the population based Eindhoven Cancer Registry were used on all $(n=9038)$ women who underwent SNB for invasive breast cancer from 1996-2008 and medical files were studied to determine the role of minimal nodal involvement in the decision to use adjuvant systemic treatment.

Results Forty-five percent of 172 patients with isolated tumour cells and $76 \%$ of 605 patients with micrometastases received adjuvant systemic treatment. Thirty-five of 59 patients with isolated tumour cells and 153 of 193 patients with micrometastases received systemic therapy based on primary tumour characteristics. The remainder probably received adjuvant therapy based on presence of minimal nodal involvement. Thirty-seven percent of the patients with isolated tumour cells underwent an axillary lymph node dissection compared to $75 \%$ when micrometastases were present. Multivariate analyses showed a significantly higher chance of receiving systemic treatment when isolated tumour cells (OR $1.5\left(95 \% \mathrm{Cl}_{1} \mathbf{1 . 0 5 - 2 . 1 5}\right)$ ) or micrometastases (OR 10.7 (95\% Cl, 8.5613.27)) were present, compared to a negative lymph node status.

Conclusion The debate on necessity of performing completion ALND and administration of systemic therapy in patients with minimal nodal involvement is reflected by the treatment patterns observed in our population-based study. 


\section{Introduction}

Axillary lymph node dissection (ALND) has traditionally been a routine component of the management of early breast cancer. It has proven its value for disease control, tumour staging and decision-making regarding the use of adjuvant systemic treatment ${ }^{1-3}$. However, the substantial morbidity associated with ALND and the decreasing incidence of nodal involvement over time have prompted the technical development and introduction of the sentinel node biopsy (SNB). Identification and evaluation of the sentinel node(s) has been shown to accurately predict axillary nodal status ${ }^{4,5}$ with significantly lower morbidity compared to the ALND ${ }^{6,7}$.

The accuracy of staging might have improved by the identification of micrometastatic disease $^{8}$. Indeed, in 9-23\% of originally Hematoxylin \& Eosin negative cases micrometastases or isolated tumour cells can be detected with the combined use of serial sectioning (SS) and immunohistochemistry $(\mathrm{IHC})^{9}$. A study, in which 368 initially ALND node-negative patients were re-examined, showed that $23 \%$ of patients were re-classified as node-positive, because of the finding of isolated tumour cells $(73 \%)$, micrometastases $(20 \%)$ or lymph node macrometastases $(6 \%)^{10}$. The potential of serial sectioning and IHC to detect micrometastases is also reflected by the significant increase in the incidence of patients with micrometastases, following the introduction of the SNB as reported in several studies ${ }^{11-13}$. In these studies the proportion of patients with micrometastases ranged between 4 and $10 \%$.

The prognostic impact of isolated tumour cells and micrometastases remains unclear, with several studies showing conflicting results ${ }^{14-18}$. As a consequence, the 2008 Dutch treatment guidelines contain no specific recommendations regarding the administration of adjuvant systemic therapy, based solely on presence of micrometastases ${ }^{19}$.

Another important question that has risen is whether or not the presence of micrometastases in the sentinel node warrants a completion axillary lymph node dissection. The chance of having non-sentinel node involvement when micrometastases are present in the sentinel node is approximately $20-35^{20,21}$. Based on this finding, routine completion ALND for micrometastases is recommended in Dutch guidelines, even though $65-80 \%$ of these patients are known to receive an unnecessary treatment.

Knowing the uncertainties regarding the prognostic and clinical relevance of micrometastases and isolated tumour cells in sentinel nodes, substantial variation in the use of axillary surgery and/or systemic adjuvant treatment could be expected. The aim of this study was therefore to describe the patterns of care regarding the use of ALND as well as adjuvant systemic treatment in breast cancer patients with sentinel node micrometastases and isolated tumour cells in the Southeast part of The Netherlands. 


\section{Patients and methods}

All patients with primary invasive breast cancer in the Southeast part of The Netherlands that underwent SNB between 1996 and 2008 were enrolled in this study. Patient data were retrieved from the population based Eindhoven Cancer Registry, which records data on all patients newly diagnosed with cancer in this region, an area with approximately 2.4 million inhabitants. Collected data were derived from 10 hospitals, consisting of large non-university teaching hospitals and community hospitals, and two radiotherapy departments. Data on patient- and tumour characteristics and treatment were collected by the Cancer Registry based on the pathology reports and medical records. Furthermore, after obtaining written approval for access to the medical files from the treating physicians, we studied the medical files of 416 out of 605 patients with sentinel node micrometastases and 115 out of 172 patients with isolated tumour cells, most of whom were diagnosed in the period 1996-2006. We verified the axillary staging procedure and the use of adjuvant systemic treatment and we determined whether or not the presence of micrometastases or isolated tumour cells might have played a role in the decision to administer adjuvant systemic treatment. This was done by determining which patients should not have received adjuvant systemic therapy according to the Dutch guidelines, based on age and tumour characteristics, such as tumour size and histological grade or mitotic activity index. After initially evaluating the period 1996-2006, we extended the period to include the data from 2007 and 2008. Data on administration of adjuvant systemic treatment to patients with isolated tumour cells and micrometastases, however, were not updated due to the fact that this would be very time intensive and would not change our conclusions.

SNB initially followed by a confirming ALND was introduced in the Southeast Netherlands in 1995. In 1997, surgeons started performing SNB procedures as a routine staging procedure and since the year 2000 indications for SNB and recommended pathology protocol are being described in national guidelines ${ }^{19}$. The pathology protocol advocated by the EORTC Breast Cancer Group has been adopted by the pathologists since 2000 and is included in the Dutch evidence-based guidelines for the treatment of breast cancer. According to these guidelines, sentinel nodes should be investigated at three levels at $0.25 \mathrm{~mm}$ intervals and from each section at least two slides should be made: one for H\&E staining and one for IHC. The patients were staged according to the Tumour-Node-Metastasis (TNM) system of the International Union Against Cancer (UICC) version $6^{22}$.

Data were categorized according to axillary lymph node status. Node-negative patients were categorized as pNo. Patients with metastases smaller than $0.2 \mathrm{~mm}$ were categorized as $\mathrm{pNo}(\mathrm{i}+$ ) (isolated tumour cells) and patients with metastases between 0.2 $\mathrm{mm}$ and $2.0 \mathrm{~mm}$ as $\mathrm{pN} 1 \mathrm{mi}$ (micrometastases). Node-positive patients were categorized 
as $\mathrm{pN} 1 \mathrm{a}$ if 1 to 3 axillary lymph nodes were positive and $>\mathrm{pN} 1 \mathrm{a}$ if more than 3 axillary lymph nodes were positive or if metastases were present in supraclavicular or internal mammary lymph nodes. The discrimination between micrometastases and isolated tumour cells in the Cancer registration data has only been made since 2003, after introduction of the revised TNM system in 2002.

Statistical analyses were carried out using SAS (version 9.1 for Windows, SAS institute Inc., Cary, NC). The patient subgroups, as defined by axillary nodal status, were compared with respect to age and tumour characteristics by using Chi-square tests. Multivariate logistic regression analyses were performed to determine the independent prognostic effect of axillary lymph node status on the use of adjuvant systemic treatment and completion ALND. In these analyses we adjusted for the possible confounding influences of period of diagnosis, age at diagnosis, tumour size (defined as pT-stage) and grade. In the multivariate analysis of completion ALND the patients treated before 2001 and those with a negative axillary nodal status were excluded, as only very few patients with negative lymph nodes underwent 'confirmatory' completion ALND, mostly before 2001 as part of the learning curve of SNB. P-values <0.05 were considered statistically significant.

\section{Results}

Between 1996 and 2008 a total of 9038 patients underwent SNB for primary invasive breast cancer in the Southeast region of The Netherlands. Their characteristics, stratified according to axillary lymph node status, are demonstrated in Table 1. Micrometastatic lymph node involvement was observed in 605 patients (6.7\%). Isolated tumour cells were detected in 172 patients (1.9\%). Age at diagnosis, pT-stage, grade and histology all differed significantly according to nodal status $(P<0.0001)$. With increasing age the proportion of patients diagnosed with a positive nodal status decreased. Also, distribution of age, tumour size and grade of patients with minimal nodal involvement lie between those of patients with node-negative and patients with node-positive disease.

\section{Adjuvant systemic treatment}

Forty-five percent of the patients with isolated tumour cells and $76 \%$ of those with micrometastases received adjuvant systemic treatment. No clear trends in the use of adjuvant systemic treatment could be observed in these two groups in the period 19962008 (Figure 1). However, in patients with a negative lymph node status the use of adjuvant systemic treatment increased from $25 \%$ from $1996-2000$ to $38 \%$ in the period 2007-2008. 
Table 1 Patient characteristics by lymph node status of 9038 patients who underwent SNB for primary invasive breast cancer in the Southeast Netherlands, 1996-2008.

\begin{tabular}{|c|c|c|c|c|c|c|}
\hline \multirow[t]{2}{*}{ Characteristic } & \multicolumn{6}{|c|}{ Lymph node status } \\
\hline & $\begin{array}{r}\text { pNo } \\
(\mathrm{N}=6101) \\
\end{array}$ & $\begin{array}{l}\text { pNo(i+) } \\
(\mathrm{N}=172)\end{array}$ & $\begin{array}{r}\text { pNımi } \\
(\mathrm{N}=605)\end{array}$ & $\begin{array}{r}\text { pN1a } \\
(\mathrm{N}=1749)\end{array}$ & $\begin{array}{r}>p N 1 a \\
(N=411)\end{array}$ & P-value \\
\hline $\begin{array}{l}\text { Period of diagnosis } \\
\begin{array}{l}1994-2000 \\
2001-2003 \\
2004-2006 \\
2007-2008 \\
\end{array} \\
\end{array}$ & $\begin{array}{r}705(12) \\
1606(26) \\
2134(35) \\
1656(27) \\
\end{array}$ & $\begin{array}{r}0(0) \\
24(14) \\
75(44) \\
73(42) \\
\end{array}$ & $\begin{array}{r}64(11) \\
183(30) \\
216(36) \\
142(23) \\
\end{array}$ & $\begin{array}{l}304(17) \\
483(28) \\
551(32) \\
411(24) \\
\end{array}$ & $\begin{array}{r}54(13) \\
116(28) \\
143(35) \\
98(24) \\
\end{array}$ & $<0.0001$ \\
\hline $\begin{array}{l}\text { Age at diagnosis } \\
\quad \leq 35 \\
36-49 \\
50-69 \\
\geq 70\end{array}$ & $\begin{array}{r}128(2) \\
1292(21) \\
3347(55) \\
1334(22) \\
\end{array}$ & $\begin{array}{r}2(1) \\
48(28) \\
89(52) \\
33(19) \\
\end{array}$ & $\begin{array}{r}17(3) \\
147(24) \\
328(54) \\
113(19) \\
\end{array}$ & $\begin{array}{r}58(3) \\
519(30) \\
869(50) \\
303(17) \\
\end{array}$ & $\begin{array}{r}19(5) \\
128(31) \\
201(49) \\
63(15) \\
\end{array}$ & $<0.0001$ \\
\hline $\begin{array}{l}\text { pT-stage } \\
1 \\
2 \\
3 \\
4 \\
\text { Unknown }\end{array}$ & $\begin{array}{r}1568(26) \\
3011(50) \\
1360(23) \\
47(1) \\
115(2) \\
\end{array}$ & $\begin{array}{r}34(20) \\
76(44) \\
57(33) \\
3(2) \\
2(1) \\
\end{array}$ & $\begin{array}{r}102(17) \\
300(50) \\
181(30) \\
10(2) \\
12(2) \\
\end{array}$ & $\begin{array}{r}149(9) \\
766(44) \\
57(33) \\
3(2) \\
2(1) \\
\end{array}$ & $\begin{array}{r}17(4) \\
129(31) \\
221(54) \\
25(6) \\
19(5) \\
\end{array}$ & $<0.0001$ \\
\hline $\begin{array}{l}\text { Histological type } \\
\text { Ductal } \\
\text { Lobular or Lobular-mixed } \\
\text { Other or unknown }\end{array}$ & $\begin{array}{r}4840(79) \\
842(14) \\
419(7) \\
\end{array}$ & $\begin{array}{r}127(74) \\
35(21) \\
10(6) \\
\end{array}$ & $\begin{array}{r}482(80) \\
99(16) \\
24(4) \\
\end{array}$ & $\begin{array}{r}1400(80) \\
308(18) \\
41(2) \\
\end{array}$ & $\begin{array}{r}312(76) \\
90(22) \\
9(2) \\
\end{array}$ & $<0.0001$ \\
\hline $\begin{array}{l}\text { Grade } \\
\text { I } \\
\text { II } \\
\text { III } \\
\text { Unknown }\end{array}$ & $\begin{array}{l}1598(26) \\
2189(36) \\
1282(21) \\
1032(17)\end{array}$ & $\begin{array}{l}47(27) \\
69(40) \\
38(22) \\
18(10)\end{array}$ & $\begin{array}{r}135(22) \\
247(41) \\
125(21) \\
98(16) \\
\end{array}$ & $\begin{array}{l}361(21) \\
652(37) \\
420(24) \\
316(18) \\
\end{array}$ & $\begin{array}{r}58(14) \\
151(37) \\
126(31) \\
76(18) \\
\end{array}$ & $<0.0001$ \\
\hline $\begin{array}{l}\text { Adjuvant systemic therapy } \\
\text { Chemotherapy } \\
\text { Hormonal therapy } \\
\text { Chemo- and hormonal } \\
\text { therapy } \\
\text { None }\end{array}$ & $\begin{array}{r}578(9) \\
77(13) \\
528(9) \\
4216(69)\end{array}$ & $\begin{array}{l}21(12) \\
38(22) \\
19(11) \\
97(55)^{\prime}\end{array}$ & $\begin{array}{r}73(12) \\
232(38) \\
152(25) \\
148(24)\end{array}$ & $\begin{array}{l}310(18) \\
683(39) \\
648(37) \\
106(6)\end{array}$ & $\begin{array}{r}88(22) \\
98(24) \\
190(47) \\
32(8)\end{array}$ & $<0.0001$ \\
\hline $\begin{array}{l}\text { Type of axillary surgery } \\
\text { SNB alone } \\
\text { SNB+ALND }\end{array}$ & $\begin{array}{r}5619(92) \\
482(8)\end{array}$ & $\begin{array}{r}108(63) \\
64(37)\end{array}$ & $\begin{array}{l}150(25) \\
455(75)\end{array}$ & $\begin{array}{r}166(9) \\
1583(91) \\
\end{array}$ & $\begin{array}{r}11(3) \\
400(97)\end{array}$ & $<0.0001$ \\
\hline
\end{tabular}

SNB: Sentinel Node Biopsy; ALND: Axillary Lymph Node Dissection

Review of charts of 115 patients with isolated tumour cells revealed that 35 of 59 patients who had received adjuvant systemic treatment had an indication for this treatment, based on the characteristics of the primary tumour. Hence, in the remaining 24 patients (21\%) the decision to administer adjuvant systemic treatment was probably based on the presence of the isolated tumour cells. Review of the charts of 416 patients with micrometastases showed that 153 of 319 patients who received adjuvant systemic 
treatment fulfilled the criteria for its use as defined in the national guidelines, based on the characteristics of the primary tumour. The remaining 166 patients (40\%) did not meet these criteria and the use of adjuvant systemic treatment seems to have been prompted by the presence of micrometastatic disease.

Figure 1 Trend in the use of adjuvant systemic treatment among patients who underwent SNB for primary invasive breast cancer in the Southeast Netherlands, 1996-2008, according to axillary lymph node status.

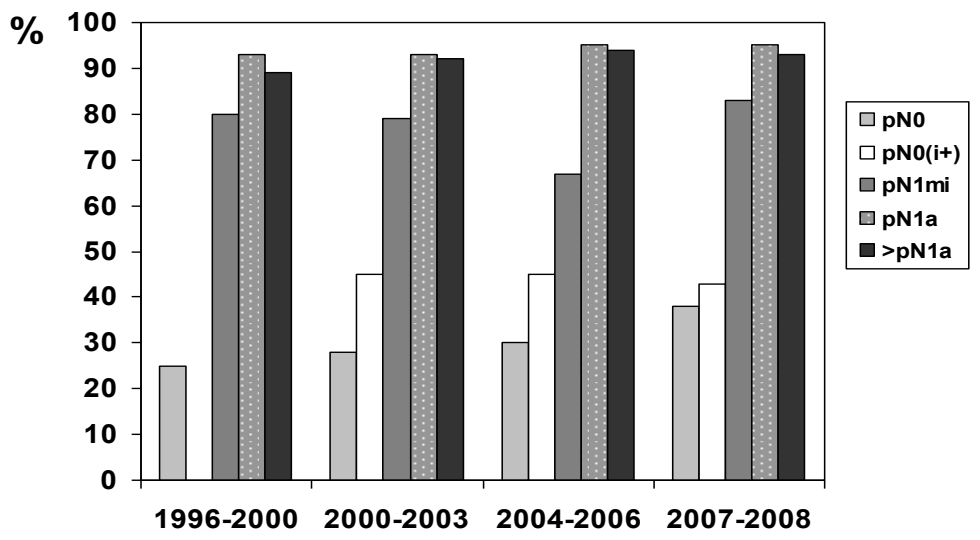

In multivariate analysis adjusted for period of diagnosis, age, PT and grade, the probability of receiving adjuvant systemic treatment was significantly higher for patients with isolated tumour cells (OR $1.5(95 \% \mathrm{Cl}, 1.05-2.15)$ ) or micrometastases (OR 10.7 (95\% $\mathrm{Cl}$, 8.56-13.27)), as compared to patients with negative lymph nodes (Table 2). Patients with isolated tumour cells also had a higher probability of receiving hormonal treatment (OR 1.48 (95\% Cl, 1.06-2.08)), but not of receiving adjuvant chemotherapy (OR 1.03 (95\% $\mathrm{Cl}, 0.66-1.60)$ ). Patients with sentinel node micrometastases showed a higher probability of receiving both hormonal- and chemotherapy ((OR 6.66 (95\% Cl, 5.54-8.00) and (OR $3.89(95 \% \mathrm{Cl}$, 3.09-4.90)). 
Table 2 Multivariate analysis of the likelihood of receiving adjuvant systemic treatment in patients who underwent SNB for primary invasive breast cancer in the Southeast Netherlands, 1996-2008 $(\mathrm{N}=9038)$.

\begin{tabular}{|c|c|c|c|}
\hline Characteristic & Systemic treatment & Chemotherapy & Hormonal treatment \\
\hline & OR $(95 \% \mathrm{Cl})$ & OR $(95 \% \mathrm{Cl})$ & OR $(95 \% \mathrm{Cl})$ \\
\hline $\mathrm{pNo}$ & 1.00 (Ref) & 1.00 (Ref) & 1.00 (Ref) \\
\hline $\mathrm{pNo}(\mathrm{i}+)$ & $1.50(1.05-2.15)$ & $1.03(0.66-1.60)$ & $1.48(1.06-2.08)$ \\
\hline $\mathrm{pN} 1 \mathrm{mi}$ & $10.7(8.56-13.27)$ & $3.89(3.09-4.90)$ & $6.66(5.54-8.00)$ \\
\hline $\mathrm{pN} 1 \mathrm{a}$ & $53.7(42.97-67.02)$ & $9.52(8.09-11.19)$ & $11.50(10.07-13.13)$ \\
\hline$>\mathrm{pN} 1 \mathrm{a}$ & $26.7(18.03-39.57)$ & $16.97(12.43-23.16)$ & $6.71(5.33-8.44)$ \\
\hline \multicolumn{4}{|l|}{ Period of diagnosis } \\
\hline $1994-2000$ & 1.00 (Ref) & 1.00 (Ref) & 1.00 (Ref) \\
\hline $2001-2003$ & $1.03(0.84-1.27)$ & $1.44(1.14-1.82)$ & $1.12(0.93-1.34)$ \\
\hline $2004-2006$ & $1.12(0.91-1.38)$ & $2.04\left(1.62-2.5^{8}\right)$ & $1.34(1.12-1.61)$ \\
\hline $2007-2008$ & $2.11(1.70-2.61)$ & $3.57(2.80-4.55)$ & $2.02(1.67-2.44)$ \\
\hline \multicolumn{4}{|l|}{ Age at diagnosis } \\
\hline$<50$ & 1.00 (Ref) & 1.00 (Ref) & 1.00 (Ref) \\
\hline $50-69$ & $0.54(0.47-0.62)$ & $0.16(0.14-0.19)$ & $1.05(0.93-1.19)$ \\
\hline$>70$ & $0.31(0.26-0.37)$ & $0.002(0.001-003)$ & $1.22(1.05-1.42)$ \\
\hline \multicolumn{4}{|l|}{ pT-Stage } \\
\hline $\mathrm{pT} 1$ & 1.00 (Ref) & 1.00 (Ref) & 1.00 (Ref) \\
\hline $\mathrm{pT} 2$ & $4.68(4.09-5.35)$ & $2.91(2.54-3.34)$ & $2.47(2.21-2.76)$ \\
\hline $\mathrm{pT}_{3}-4$ & $5.03(2.94-8.60)$ & $1.78(1.08-2.98)$ & $2.81(1.88-4.19)$ \\
\hline \multicolumn{4}{|l|}{ Grade } \\
\hline 1 & 1.00 (Ref) & 1.00 (Ref) & 1.00 (Ref) \\
\hline II & $2.88(2.46-3.39)$ & $2.23(1.85-2.67)$ & $1.98(1.72-2.27)$ \\
\hline III & $16.95(14.05-20.45)$ & $14.38(11.74-17.60)$ & $2.37(2.03-2.77)$ \\
\hline Unknown & $2.58(2.10-3.17)$ & $2.24(1.78-2.83)$ & $1.48(1.24-1.77)$ \\
\hline
\end{tabular}

OR: Odds Ratio; 95\% Cl: 95\% Confidence Interval

\section{Completion Axillary Lymph Node Dissection}

Of the patients with isolated tumour cells $37 \%$ underwent a subsequent ALND, as compared to $75 \%$ of the patients with micrometastases (Table 1 ). The proportion of patients with isolated tumour cells undergoing completion ALND decreased from $50 \%$ $(12 / 24)$ in the period 2001-2003 to $25 \%(19 / 76)$ in the period 2007-2008. In contrast, the proportion of patients with micrometastases undergoing completion ALND increased from $50 \%(32 / 64)$ in the period $1996-2000$ to $83 \%$ (179/216) in the period 2004-2006, while no further increase was observed after 2006 (Figure 2). 
Figure 2 Trend in the use of completion ALND among patients who underwent SNB for primary invasive breast cancer in the Southeast Netherlands, 1996-2008, according to axillary lymph node status.

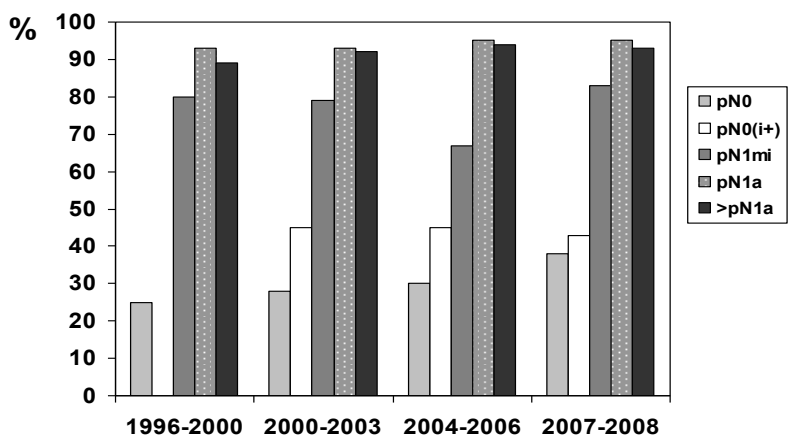

In the multivariate analysis the probability of undergoing completion ALND was significantly larger for patients with micrometastases, as compared to those with isolated tumour cells (OR $4.79(95 \% \mathrm{Cl}, 2.95-7.79)$ ) (Table 3). Also patients with a T2 tumour had a higher probability of undergoing completion ALND, as compared to those with a $\mathrm{T}_{1}$ tumour (OR 1.46 (95\% Cl, 1.05-2.05)). Patients aged 70 years or older had a lower risk of undergoing completion ALND, as compared to those younger than 50 years (OR 0.34 $(95 \% \mathrm{Cl}, 0.22-0.52)$ ).

\section{Discussion}

Our study shows that $37 \%$ of the patients with isolated tumour cells in their sentinel nodes underwent a subsequent ALND and in $20.9 \%$ of the patients adjuvant systemic therapy was administered probably based solely on the presence of isolated tumour cells. Seventy-five percent of patients with micrometastatic disease underwent ALND and $39.9 \%$ of them received adjuvant systemic therapy based on presence of these sentinel node micrometastases.

According to national breast cancer treatment guidelines in The Netherlands ${ }^{19}$, treatment of the axilla is indicated in any case of node-positivity, including micrometastases. Patients with isolated tumour cells are regarded as being node-negative. This advice is based on the observation in the literature that patients with micrometastatic SNB disease have an approximately $20 \%$ chance of having additional non-sentinel node involvement $^{21,23}$. 
Table 3 Multivariate analysis of the likelihood of receiving completion axillary lymph node dissection in patients who underwent SNB for primary invasive breast cancer in the Southeast Netherlands, 2001-2008 ( $N=2515)$. Patients with a negative axillary lymph node status ( $\mathrm{pNo}$ ) have been excluded.

\begin{tabular}{|l|l|l|}
\hline & OR & $(95 \% \mathrm{Cl})$ \\
\hline Axillary nodal status & & \\
pNo(i+) & 1.00 (Ref) & $(2.95-7.79)$ \\
pN1mi & 4.79 & $(10.1-26.9)$ \\
pN1a & 16.5 & $(22.7-163.0)$ \\
>pN1a & 60.9 & \\
\hline Period of diagnosis & & \\
2001-2003 & 1.00 (Ref) & $(1.04-2.34)$ \\
$2004-2006$ & 1.56 & $(0.92-2.09)$ \\
2007-2008 & 1.39 & \\
\hline Age at diagnosis & & \\
$<50$ & 1.00 (Ref) & $(0.67-1.41)$ \\
$50-69$ & 0.97 & $(0.22-0.52)$ \\
\hline$>70$ & 0.34 & \\
\hline pT-Stage & & \\
pT1 & $($ Ref) & $(1.05-2.05)$ \\
pT2 & 1.47 & $(0.47-3.57)$ \\
pT3-4 & 1.30 & \\
\hline Grade & & $(0.89-2.00)$ \\
I & 1.00 (Ref) & $(0.85-2.16)$ \\
II & 1.33 & $(0.70-1.93)$ \\
III & 1.36 & \\
Unknown & 1.16 & \\
\hline
\end{tabular}

OR: Odds Ratio; 95\% Cl: 95\% Confidence Interval

Van Rijk et al. showed that $19 \%$ of patients with micrometastases in the sentinel node had additional metastases in the completion ALND ${ }^{12}$. In 16 patients (15\%) a macrometastasis was discovered with a sequential upstaging. Seven of these patients were offered additional systemic treatment that would not have been provided if information from the ALND had not been available. On the other hand, a recent population-based study showed that the proportion of patients who underwent SNB alone (without a subsequent completion ALND) for micrometastases increased from 24.7 to $45.3 \%$ in recent years ${ }^{24}$. Axillary recurrence and survival, however, were not significantly decreased compared to patients that underwent completion ALND. Furthermore, the recent American College of Surgeons Oncology Group Zoo11 trial by Guiliano et al. in which SNB positive patients were randomized between observation and ALND showed that in cases with restricted tumour involvement of the sentinel node, ALND did not result in a increased survival or better local axillary control ${ }^{25}$. It is important to realize that both locoregional irradiation, in which part of the axilla is often captured in the irradiation field, and systemic treatment reduce the incidence of locoregional 
recurrence ${ }^{26,27}$. In the ACOSOG Zoo11 trial, $97 \%$ of the patients received adjuvant systemic therapy and $89 \%$ of the patients received irradiation of the breast.

In order to predict which patients are at greater risk of having non-sentinel node metastases and might benefit from a completion ALND, a nomogram was developed based on which the risk of node-positivity in the completion ALND could be predicted ${ }^{28}$. Unfortunately, several validation studies showed that the performance of these nomograms were insufficient to make it a useful tool for individual decision making in other than the original patient populations ${ }^{29,30}$. These nomograms were originally developed to identify those patients in whom an ALND could be omitted. With the results of the ACOSOG Zoo11 trial in mind, future nomograms should be developed which identify those patients that could benefit from an ALND.

As stated before, clinical relevance and prognostic implication of micrometastases remain unclear. While several retrospective studies show that patients with micrometastases and isolated tumour cells in their sentinel node had a significantly worse disease-free and overall survival compared to node-negative patients ${ }^{14,15}$, other studies could not confirm this observation ${ }^{16-18}$. Hence, it is still unclear whether or not the presence of micrometastases is an independent prognostic factor on which adjuvant systemic therapy should be proposed.

Despite of on-going discussions, current Dutch guidelines for treatment of breast cancer still advocate performing a completion ALND in patients with sentinel node micrometastases and no advice is given on the topic of administration of adjuvant systemic therapy based solely on the presence of micrometastases. This debate for many years is reflected in the variation in axillary and systemic treatment proposed to the breast cancer patients with sentinel node micrometastases or isolated tumour cells in our population based study in the Southeast Netherlands from 1996-2008. 


\section{References}

1. Glodhirsch A, Glick JH, Gelber RD, Senn HJ. Meeting highlights: international consensus panel on the treatment of primary breast cancer. J Natl Cancer Instit 1998;90:1601-1608

2. Fisher B, Redmond C, Fisher ER, et al. Ten-year results of a randomized clinical trial comparing radical mastectomy and total mastectomy with or without radiation. $\mathrm{N}$ Eng J Med 1985;312:674-681

3. Orr RK. The impact of prophylactic axillary node dissection on breast cancer survival-a Bayesian meta-analysis. Ann Surg Oncol 1999;6:109-116

4. Cox CE, Bass SS, McCann CR, et al. Lymphatic mapping and sentinel lymph node biopsy in patients with breast cancer. Annu Rev Med 2000;51:525-542

5. Veronesi U, Paganelli G, Viale G, et al. Sentinel-lymph-node biopsy as a staging procedure in breast cancer: update of a randomised controlled study. Lancet Oncol 2006;7:983-990

6. Schijven MP, Vingerhoets AJ, Rutten $\mathrm{HJ}$, et al. Comparison of morbidity between axillary lymph node dissection and sentinel node biopsy. Eur J Surg Oncol 2003;29:341-350

7. Purushotham AD, Upponi $S$, Klevesath $M B$, et al. Morbidity after sentinel lymph node biopsy in primary breast cancer: results from a randomized controlled trial. J Clin Oncol 2005;23:43124321

8. Giuliano AE, Dale PS, Turner RR, et al. Improved axillary staging of breast cancer with sentinel lymphadenectomy. Ann Surg 1995;222:394-399

9. Tjan-Heijnen VCG, Bult $P$, de Wildt-Levert LM, et al. Micro-metastases in axillary lymph nodes: an increasing classification and treatment dilemma in breast cancer due to the introduction of the sentinel lymph node procedure. Breast Cancer Res and Treat 2001;70:81-88

10. Tan LK, Giri D, Hummer AJ, et al. Occult axillary node metastases in breast cancer are prognostically significant: Results in 368 node-negative patients with 20-year follow-up. J Clin Oncol 2008;26:1803-1809

11. Van der Heiden-van der Loo M, Bezemer PD, Hennipman A, et al. Introduction of sentinel node biopsy and stage migration of breast cancer. EJSO 2006;32:710-714

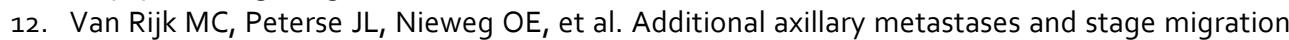
in breast cancer patients with micrometastases or submicrometastases in sentinel lymph nodes. Cancer 2006;107:467-71

13. Maaskant AJG, van de Poll-Franse LV, Voogd AC, et al. Stage Migration due to introduction of the sentinel node procedure: a population-based study. Breast Cancer Res Treat 2009;113:173179

14. Chen $\mathrm{SL}$, Hoehne FM, Guiliano AE. The prognostic significance of micrometastases in breast cancer: A SEER population-based analysis. Ann Surg Oncol 2007;14:3378-3384

15. de Boer M, van Deurzen CHM, van Dijck JAAM, et al. Micrometastases or isolated tumor cells and the outcome of breast cancer. N Eng J Med 2009;361:653-663

16. Gobardhan PD, Elias SG, Madsen EVE, et al. Prognostic value of micrometastases in sentinel lymph nodes of patients with breast carcinoma: a cohort study. Ann Oncol 2009;20:41-48

17. Hansen NM, Grube B, Ye X, et al. Impact of micrometastases in the sentinel node of patients with invasive breast cancer. J Clin Oncol 2009;27:4679-4684

18. Maaskant-Braat AJ, van de Poll-Franse LV, Voogd AC, et al. Sentinel node micrometastases in breast cancer do not affect prognosis: A population-based study. Breast Cancer Res. Treat. 2011;127:195-203

19. Nationaal Borstkanker Overleg Nederland (NABON). Richtlijn behandeling van het mammacarcinoom. Available from: www.oncoline.nl, 2005 
20. Viale G, Maiorano E, Pruneri G, et al. Predicting the risk for additional axillary metastases in patients with breast carcinoma and positive sentinel lymph node biopsy. Ann Surg 2005;241:319-325

21. Cserni G, Gregori D, Merletti F, et al. Meta-analysis of non-sentinel node metastases associated with micrometastatic sentinel nodes in breast cancer. Br J Surg 2004;91:1245-1252

22. Hermanek P, Sobin LH, editors. UICC TNM classification of malignant tumors. Berlin: SpringerVerlag 1987;94-99

23. Fan $Y, T a n Y, W u C$, et al. The effect of sentinel node tumor burden on non-sentinel node status and recurrence rates in breast cancer. Ann Surg Oncol 2005;12:705-711

24. Bilimoria KY, Bentrem DJ, Hansen NM, et al. Comparison of sentinel lymph node biopsy alone and completion axillary lymph node dissection for node-positive breast cancer. J Clin Onc 2009;27:2946-2953

25. Giuliano $A E$, Hunt $K K$, Ballman $K V$, et al. Axillary dissection vs no axillary dissection in women with invasive breast cancer and sentinel node metastasis: a randomized clinical trial. JAMA 2011;305:569-575

26. Clarke M, Collins R, Darby $S$, et al. Effects of radiotherapy and of differences in the extent of surgery for early breast cancer on local recurrence and 15-year survival: an overview of the randomized trials. Lancet 2005;366:2087-2106

27. Early Breast Cancer Trialists' Collaborative Group (EBCTCG). Effects of chemotherapy and hormonal therapy for early breast cancer on recurrence and 15-year survival: an overview of the randomized trials. Lancet 2005;365:1687-1717

28. Van Zee KJ, Manasseh DM, Bevilacqua JL, et al. A nomogram for predicting the likelihood of additional nodal metastases in breast cancer patients with a positive sentinel node biopsy. Ann Surg Oncol 2003;10:1140-1151

29. van den Hoven I, Kuijt GP, Voogd AC, et al. Value of Memorial Sloan-Kettering Cancer Center nomogram in clinical decision making for sentinel lymph node-positive breast cancer. Br J Surg 2010;97:1653-1658

30. Fougo JL, Senra FS, Araújo C, et al. Validating the MSKCC nomogram and a clinical decision rule in the prediction of non-sentinel node metastases in a Portuguese population of breast cancer patients. Breast 2011;20:134-140 
Chapter 3 


\section{Chapter 4}

\section{Sentinel node micrometastases in breast cancer do not affect prognosis: A population-based study}

A.J.G. Maaskant-Braat

L.V. van de Poll-Franse

A.C. Voogd

J.W.W. Coebergh

R.M.H. Roumen

M.C.B.J.E. Tutein Nolthenius-Puylaert G.A.P. Nieuwenhuijzen

Breast Cancer Res Treat 2011;127: 195-203 


\begin{abstract}
Background Sentinel node biopsy (SNB) for axillary staging in breast cancer allows the application of more extensive pathologic examination techniques. Micrometastases are being detected more often however coinciding with stage migration. Besides assessing the prognostic relevance of micrometastases and the need for administering adjuvant systemic and regional therapies, there still seems to be room for improvement.
\end{abstract}

Methods In a population based analysis we compared survival of patients with sentinel node micrometastases with those with node-negative and node-positive disease in the era after introduction of SNB. Data from the population based Eindhoven Cancer Registry were used on all $(n=6803)$ women who underwent SNB for invasive breast cancer in the Southeast Netherlands in the period 1996-2006.

Results In 451 patients (6.6\%) a sentinel node micrometastasis ( $\mathrm{pN} 1 \mathrm{mi}$ ) was detected and in 126 patients (1.9\%) isolated tumour cells ( $\mathrm{pNo}(\mathrm{i}+))$. Micrometastases or isolated tumour cells in the SNB did not convey any significant survival difference compared with nodenegative disease. After adjustment for age, $\mathrm{pT}$ and grade, still no survival difference emerged ( $\mathrm{pN}$ 1mi: HR 0.9 ( $95 \% \mathrm{Cl}, 0.6-1.3)$ and $\mathrm{pNo}(\mathrm{i}+)$ : ( $\mathrm{HR} 0.4(95 \% \mathrm{Cl}, 0.14-1.3)$ ) and neither was the case after additional adjustment for adjuvant systemic therapy.

Conclusion Our practice based study showed that the presence of sentinel node micrometastases in breast cancer patients has hardly any impact on breast cancer overall survival during the first years after diagnosis. 


\section{Introduction}

During the last decades an increase in breast cancer incidence has occurred ${ }^{1}$. Combined with improving survival rates this implies that the number of prevalent breast cancer cases will continue to rise as well as the health care burden of breast cancer. Sentinel node biopsy (SNB) as an axillary staging procedure in primary breast cancer was introduced about ten years ago to avoid axillary lymph node dissection (ALND) in patients with tumour negative lymph nodes. The main advantage of performing SNB is a markedly lower morbidity ${ }^{2,3}$ whereas axillary staging capacities are similar to $A_{L N D}^{4,5}$. A randomized trial showed the 8-year survival of patients with primary breast cancer to be equal in the SNB-group and the ALND-group ${ }^{6}$. Furthermore, in observational research with cancer registry data, survival of patients with negative SNB without completion ALND has been shown to be at least equivalent to the survival of node-negative patients with extensive ALND ${ }^{7}$. These findings support the validity and safety of SNB as a staging procedure and thus the removal of clinically negative axillary lymph nodes by ALND seems no longer justifiable.

Since only a few nodes are being removed, the introduction of the SNB led to application of more extensive time-consuming and costly pathologic examination techniques like serial sectioning and immunohistochemistry. Occult metastases or micrometastases were detected in $9-23 \%$ of originally Hematoxylin \& Eosin node-negative cases ${ }^{8}$. Recent studies showed a $4 \cdot 3-10 \%$ increase among patients diagnosed with micrometastatic disease in the sentinel node as well ${ }^{9,10}$. This increase led to stage migration after adjustment for the simultaneous, favourable trend in tumour size ${ }^{9}$. A discussion followed on prognostic significance and possible need for additional systemic and regional treatment. Some studies on the prognostic significance of micrometastases in ALND before introduction of the sentinel node biopsy showed that patients with axillary micrometastases had higher recurrence rates and lower overall survival ${ }^{11-14}$, others however demonstrated no such difference ${ }^{15,16}$. Although most studies with larger sample sizes and longer follow-up tend to show a negative effect of micrometastatic disease on overall and disease free survival ${ }^{17,18}$, comparison between these retrospective studies and extrapolation to patients with SNB is hampered by different inclusion criteria and large technical variances in the assessment of micrometastases.

The purpose of our study was to perform a population based analysis to determine survival of patients with sentinel node micrometastases as compared to patients with sentinel node-negative and sentinel node-positive disease and thus comment on the prognostic value of these micrometastases in the era after introduction of SNB. 


\section{Patients and methods}

Methodology, results and discussion of this study were reported according to the REMARK criteria on reporting of tumour marker studies ${ }^{19}$. Patient data were retrieved from the population based Eindhoven Cancer Registry, which records data on all patients newly diagnosed with cancer in the Southeast region of The Netherlands, an area with approximately 2.4 million inhabitants. Collected data were derived from 10 hospitals, consisting of large non-university teaching hospitals and community hospitals, and two radiotherapy departments. Data on patient- and tumour characteristics and local and systemic treatment were collected by the Cancer Registry based on the pathology reports and medical records. The patients were staged according to the Tumour-NodeMetastasis (TNM) system of the International Union Against Cancer (UICC) ${ }^{20}$.

Sentinel node biopsy followed by axillary lymph node dissection was introduced in the Southeast Netherlands in 1995. In 1997, surgeons gradually started to perform SNB procedures as a routine staging procedure and since 2000 indications for SNB were described in national guidelines ${ }^{21}$. We included all women who underwent SNB for primary invasive breast cancer in the Southeast Netherlands in the period 1996-2006 and we used characteristics and data of the entire group in the analyses.

In The Netherlands the pathology protocol advocated by the EORTC Breast Cancer Group has been adopted by the pathologists since 2000 and included in the Dutch evidencebased guideline for the treatment of breast cancer. According to this guideline, sentinel nodes should be investigated at three levels at $0.25 \mathrm{~mm}$ intervals and from each section at least two slides should be made: one for H\&E Hematoxylin \& Eosin staining and one for IHC [21]. For this study, data were categorized according to axillary lymph node status. Node-negative patients were categorized as pNo. Patients with metastases smaller than $0.2 \mathrm{~mm}$ were categorized as $\mathrm{pNo}(\mathrm{i}+$ ) (isolated tumour cells) and as $\mathrm{pN} 1 \mathrm{mi}$ (micrometastases) in case of metastases between $0.2 \mathrm{~mm}$ and 2.0. Node-positive patients were categorized as $\mathrm{pN} 1 \mathrm{a}$ if 1 to 3 axillary lymph nodes were positive and $>\mathrm{pN} 1 \mathrm{a}$ if more than 3 axillary lymph nodes were positive or if metastases were present in supraclavicular or internal mammary lymph nodes. The discrimination between micrometastases and isolated tumour cells in the Cancer Registration data has only been made since 2003, after introduction of the revised TNM system in 2002.

Follow-up was completed until January 2008 and endpoint of the study was question whether or not the patient was still alive. This information was obtained from the municipal registries in the area of the Eindhoven Cancer Registry and the Central Bureau for Genealogy. The latter institution collects data on all deceased Dutch citizens via the municipal registries. In this way, information on patients who moved outside the registry area was also obtained. The few patients $(<0.3 \%)$ who died outside The Netherlands might be wrongly considered as "being alive". 
Statistical analyses were carried out using SAS (version 9.1 for Windows, SAS institute Inc., Cary, NC). Survival analyses were carried out using the Kaplan-Meier life-table analysis. Survival time was defined as the period between the diagnosis of breast cancer and death or date of last available follow-up. Patients were stratified according to sentinel lymph node status and survival comparison between these groups was performed by means of the log-rank test. We censored the data if the effective sample size was smaller than 10 in the overall survival analyses. Multivariate analyses were carried out using Cox proportional hazards analyses. Variables that showed a significant influence on survival in univariate analyses were entered in the multivariate model. We adjusted for the possible confounding influences of age at diagnosis, tumour size (defined as T-stage) and grade. We additionally adjusted for the effects of administrating adjuvant systemic therapy. P-values $<0.05$ were considered statistically significant.

\section{Results}

Between 1996 and 2006 a total of 6803 patients underwent SNB for primary invasive breast cancer in the Southeast region of The Netherlands. Their characteristics stratified according to lymph node status are demonstrated in Table 1.

Micrometastatic lymph node involvement was observed in $6.6 \%$ of the patients. Age at diagnosis, PT-stage, grade and histology all differed significantly according to nodal status $(P<0.0001)$. Patients without metastases or with micrometastatic disease underwent breast-conserving surgery significantly more frequent than those with macrometastases $(\mathrm{P}<0.0001)$. Administration of adjuvant systemic therapy significantly increased with lymph node involvement. $28 \%$ of the patients with a negative sentinel node received adjuvant systemic therapy (chemo- and/or hormonal therapy) versus $74 \%$ in the $\mathrm{pN} 1 \mathrm{mi}$-group and $93 \%$ in the $\mathrm{pN} 1 \mathrm{a}$-group.

Median follow-up was 50 months for patients with pNo- and pN1mi-disease, 53 months for patients with $\mathrm{pN}$ 1a-disease, 47 months for patients with $>\mathrm{pN} 1 \mathrm{a}$-disease and 36 months for patients with pNo(i+)-disease. Overall (unadjusted) survival was significantly worse for patients with $\mathrm{pN} 1 \mathrm{a}$ - and $>\mathrm{pN}$ 1a-disease compared to $\mathrm{pNo}$-disease $(\mathrm{P}<0.0001)$. Survival of patients with $\mathrm{pNo}(\mathrm{i}+)$ and $\mathrm{pN} 1 \mathrm{mi}$ did not differ significantly from pNo-disease $(P=0.19$ and $P=0.52)$ (Figure 1 ). 
Table 1 Patient characteristics by lymph node status of 6803 patients who underwent SNB for primary invasive breast cancer in the Southeast Netherlands, 1996-2006.

\begin{tabular}{|c|c|c|c|c|c|c|}
\hline $\begin{array}{l}\text { Lymph node status } \\
\text { Number of patients (\%) }\end{array}$ & $\begin{array}{r}\text { pNo } \\
4562(67.1) \\
\end{array}$ & $\begin{array}{r}\mathrm{pNo}(\mathrm{i}+) \\
126(1.9) \\
\end{array}$ & $\begin{array}{r}\text { pN1mi } \\
451(6.6) \\
\end{array}$ & $\begin{array}{r}\text { pN1a } \\
1347(19.8) \\
\end{array}$ & $\begin{array}{r}>\text { pN1a } \\
317(4.7)\end{array}$ & P-value \\
\hline $\begin{array}{l}\text { Accrued months of } \\
\text { follow-up }\end{array}$ & 228100 & 4536 & 22550 & 71391 & 14899 & \\
\hline $\begin{array}{l}\text { Age at diagnosis } \\
\begin{array}{l}\leq 35 \\
36-49 \\
50-69 \\
\geq 70\end{array}\end{array}$ & $\begin{array}{r}107(2.4) \\
993(21.8) \\
2483(54.4) \\
979(21.5) \\
\end{array}$ & $\begin{array}{r}2(1.6) \\
29(23.0) \\
67(53.2) \\
28(22.2) \\
\end{array}$ & $\begin{array}{r}14(3.1) \\
119(26.4) \\
238(52.8) \\
80(17.7) \\
\end{array}$ & $\begin{array}{r}47(3.5) \\
409(30.4) \\
682(50.6) \\
209(15.5) \\
\end{array}$ & $\begin{array}{r}17(5.4) \\
98(10.9) \\
155(48.9) \\
47(14.8) \\
\end{array}$ & $<0.0001$ \\
\hline $\begin{array}{l}\text { pT-stage } \\
1 \\
2 \\
3 \\
4 \\
\text { Unknown } \\
\end{array}$ & $\begin{array}{r}3408(74.7) \\
1037(22.7) \\
17(0.4) \\
25(0.6) \\
75(1.6) \\
\end{array}$ & $\begin{array}{r}84(66.7) \\
39(31.0) \\
0(0.0) \\
2(1.6) \\
1(0.8) \\
\end{array}$ & $\begin{array}{r}294(65.2) \\
141(31.3) \\
8(1.8) \\
3(0.7) \\
5(1.1) \\
\end{array}$ & $\begin{array}{r}710(52.7) \\
564(41.9) \\
17(1.3) \\
28(2.1) \\
28(2.1) \\
\end{array}$ & $\begin{array}{r}114(36.0) \\
168(53.0) \\
15(4.7) \\
9(2.8) \\
11(3.8) \\
\end{array}$ & $<0.0001$ \\
\hline $\begin{array}{l}\text { Grade } \\
\text { I } \\
\text { II } \\
\text { III } \\
\text { Unknown }\end{array}$ & $\begin{array}{r}1077(23.6) \\
1590(43.9) \\
940(20.6) \\
955(20.9) \\
\end{array}$ & $\begin{array}{l}29(23.0) \\
49(38.9) \\
30(23.8) \\
18(14.3)\end{array}$ & $\begin{array}{r}91(20.2) \\
174(38.6) \\
97(21.5) \\
89(19.7) \\
\end{array}$ & $\begin{array}{l}236(17.5) \\
488(36.2) \\
335(24.9) \\
288(21.4)\end{array}$ & $\begin{array}{r}40(12.6) \\
118(37.2) \\
91(28.7) \\
68(21.5) \\
\end{array}$ & $<0.0001$ \\
\hline $\begin{array}{l}\text { Histology } \\
\text { Ductal } \\
\text { Lobular/mixed } \\
\text { Mucinous/tubular/ } \\
\text { medullary } \\
\text { Other } \\
\end{array}$ & $\begin{array}{r}3618(79.3) \\
635(13.9) \\
236(5.2) \\
73(1.6) \\
\end{array}$ & $\begin{array}{r}101(80.2) \\
18(14.3) \\
3(2.4) \\
4(3.2) \\
\end{array}$ & $\begin{array}{r}361(80.0) \\
75(16.6) \\
8(1.8) \\
7(1.6) \\
\end{array}$ & $\begin{array}{r}1100(81.7) \\
216(16.0) \\
24(1.8) \\
7(0.5) \\
\end{array}$ & $\begin{array}{r}241(76.0) \\
68(21.5) \\
5(1.6) \\
3(1.0) \\
\end{array}$ & $<0.0001$ \\
\hline $\begin{array}{l}\text { Type of definitive surgery } \\
\text { Breast-conserving } \\
\text { surgery } \\
\text { Mastectomy } \\
\text { None/unknown }\end{array}$ & $\begin{array}{r}3520(77.2) \\
1029(22.6) \\
13(0.3)\end{array}$ & $\begin{array}{r}84(66.7) \\
42(33.3) \\
0(0.0)\end{array}$ & $\begin{array}{r}307(68.1) \\
144(31.9) \\
0(0.0)\end{array}$ & $\begin{array}{r}817(60.7) \\
528(39.2) \\
2(0.2)\end{array}$ & $\begin{array}{r}149(47.0) \\
167(52.7) \\
1(0.3)\end{array}$ & $<0.0001$ \\
\hline $\begin{array}{l}\text { Type of axillary surgery } \\
\text { SNB alone } \\
\text { SNB+ALND }\end{array}$ & $\begin{array}{r}4097(89.8) \\
465(10.2)\end{array}$ & $\begin{array}{l}49(38.9) \\
77(61.1) \\
\end{array}$ & $\begin{array}{l}126(27.9) \\
325(72.1) \\
\end{array}$ & $\begin{array}{r}133(9.9) \\
1214(90.1) \\
\end{array}$ & $\begin{array}{r}8(2.5) \\
309(97.5) \\
\end{array}$ & $<0.0001$ \\
\hline $\begin{array}{l}\text { Radiotherapy } \\
\text { Yes } \\
\text { No } \\
\end{array}$ & $\begin{array}{l}3460(75.8) \\
1102(24.2)\end{array}$ & $\begin{array}{l}81(64.3) \\
45(35.7)\end{array}$ & $\begin{array}{l}296(65.6) \\
155(34.4) \\
\end{array}$ & $\begin{array}{l}875(65.0) \\
472(35.0)\end{array}$ & $\begin{array}{r}259(81.7) \\
58(18.3) \\
\end{array}$ & $<0.0001$ \\
\hline $\begin{array}{l}\text { Adjuvant systemic } \\
\text { therapy } \\
\text { Chemotherapy } \\
\text { Hormonal therapy } \\
\text { Chemo- and hormonal } \\
\text { therapy } \\
\text { None }\end{array}$ & $\begin{array}{r}447(9.8) \\
526(11.5) \\
301(6.6) \\
3288(72.1)\end{array}$ & $\begin{array}{r}16(12.7) \\
35(27.8) \\
12(9.5) \\
63(50.0)\end{array}$ & $\begin{array}{r}71(15.7) \\
180(39.9) \\
81(18.0) \\
119(26.4)\end{array}$ & $\begin{array}{r}368(27.3) \\
539(40.0) \\
342(25.4) \\
98(7.3)\end{array}$ & $\begin{array}{r}109(34.4) \\
81(25.6) \\
98(30.9) \\
29(9.2)\end{array}$ & $<0.0001$ \\
\hline
\end{tabular}

SNB: Sentinel Node Biopsy; ALND: Axillary Lymph Node Dissection 
Figure 1 Kaplan-Meier life table analysis of overall survival by lymph node status of 6803 patients who underwent SNB for primary breast cancer in the Southeast Netherlands, 1996-2006.

Overall survival according to $\mathrm{pN}$-status

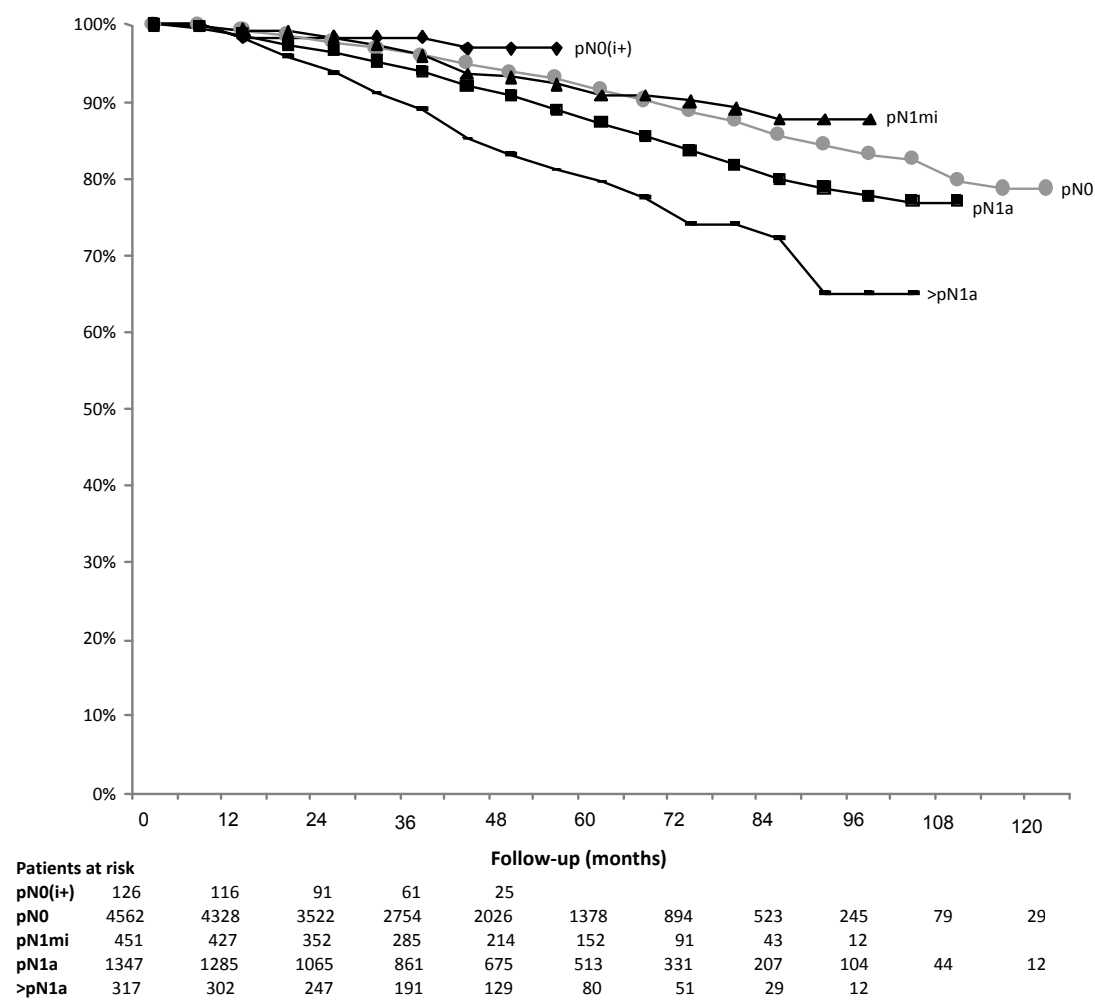

In multivariate analysis adjusted for age, pT and grade, no significant survival difference was shown between isolated tumour cells and node-negative disease ( $\mathrm{HR} 0.4(95 \% \mathrm{Cl}$, $0.14-1.3)$ ) or between micrometastatic disease and node-negative disease (HR 0.9 (95\% $\mathrm{Cl}$, 0.6-1.3)) (Table 2). Patients with pNia-disease had an increased risk of overall mortality with a hazard ratio of $1.4(95 \% \mathrm{Cl}, 1.2-1.7)$ compared to pNo. Patients with $>$ pNia-disease had a hazard ratio of 2.2 ( $95 \% \mathrm{Cl}, 1.7-3.0)$ compared to pNo.

After additional adjustment for adjuvant systemic therapy still no significant survival difference was observed for isolated tumour cells $(P=0.15)$ and micrometastatic disease $(p=0.97)$ compared to node-negative patients. Patients with $p N_{1} a-d i s e a s e$ and $>p N 1 a-$ disease still had an increased risk of overall mortality (Table 2). We performed additional analyses excluding grade as a covariate considering the relatively high percentage of missing values for this variable, but this did not change the result of our analyses in any 
way. Neither did the additional analyses we performed adjusting for the execution of completion ALND. Separate unadjusted analyses of prognosis by $\mathrm{N}$-stage according to whether patients received no adjuvant systemic therapy, adjuvant chemo- or hormonal therapy or both did also not change the result of our analyses (Figure 2, 3, 4 and 5).

Figure 2 Kaplan-Meier life table analysis of survival by lymph node status of patients who underwent SNB for primary breast cancer and received no systemic therapy, 1996-2006.

Survival according to $\mathrm{pN}$-status, no systemic therapy

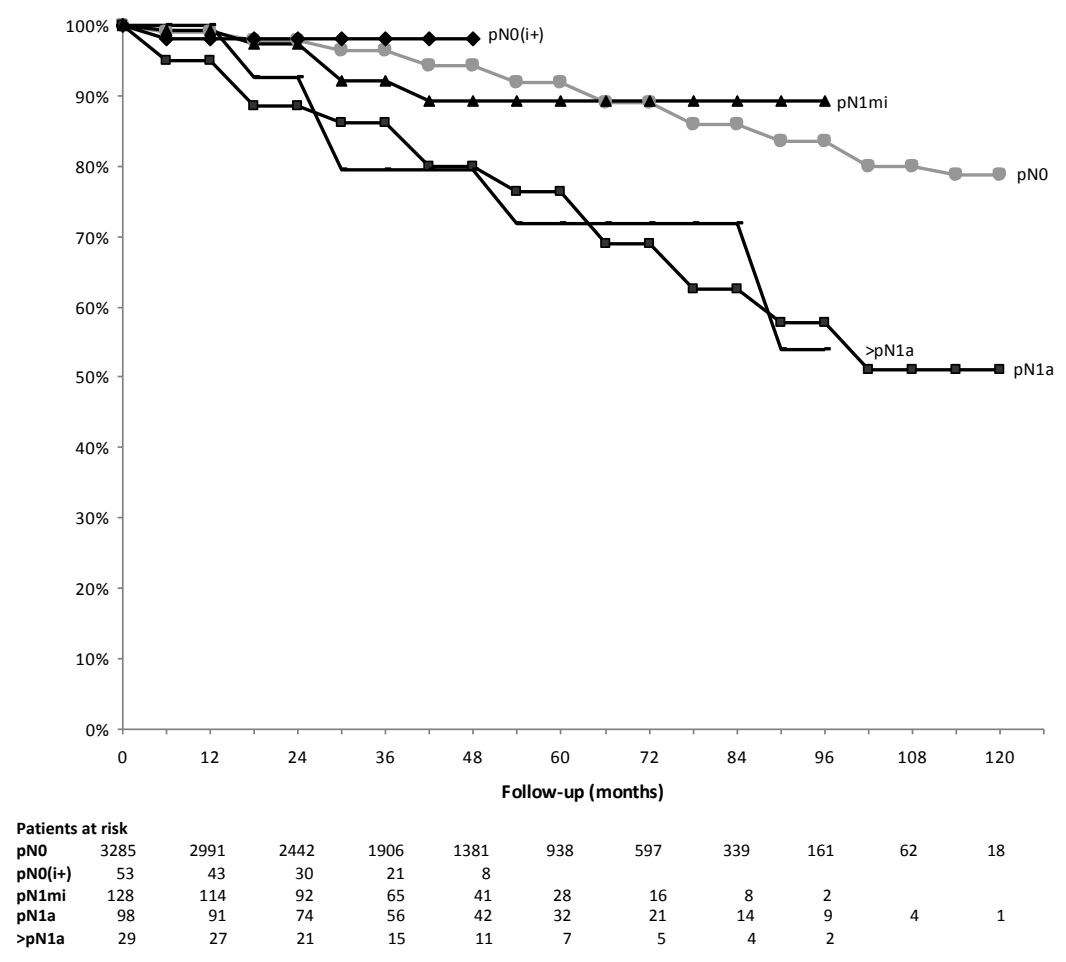




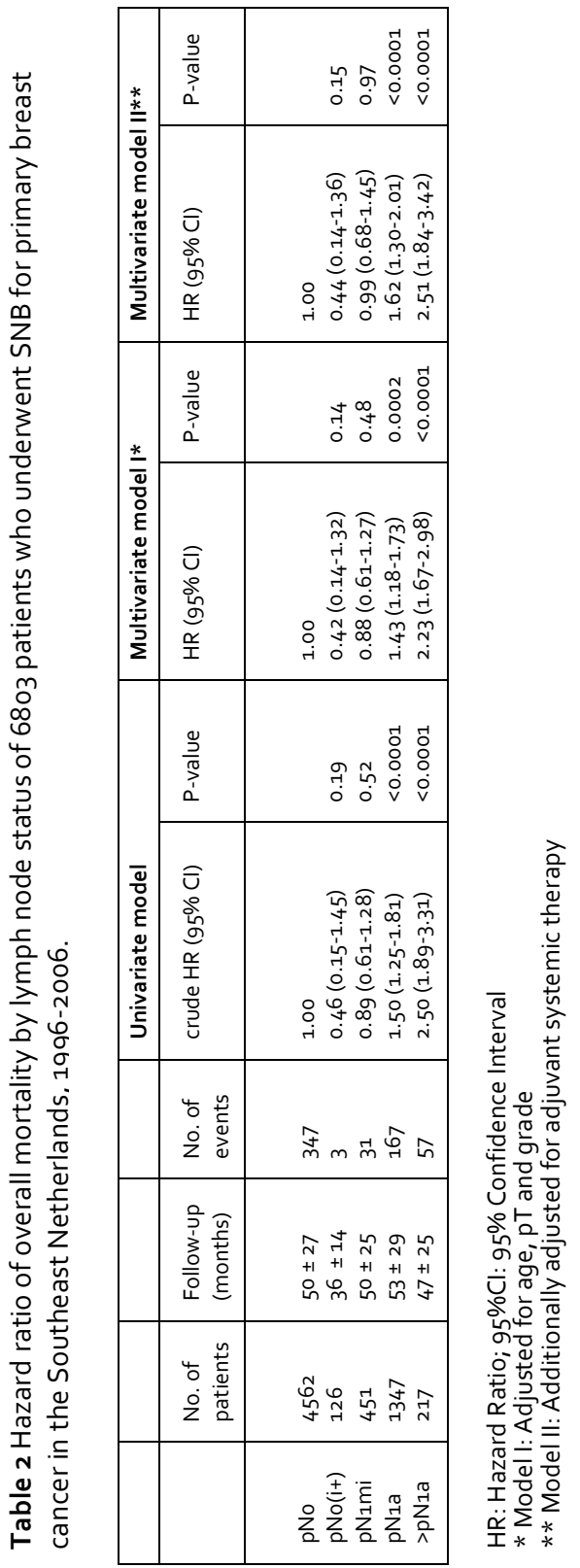


Figure 3 Kaplan-Meier life table analysis of survival by lymph node status of patients who underwent SNB for primary breast cancer and received both hormonal therapy and chemotherapy, 1996-2006.

Survival according to $\mathrm{pN}$-status, hormonal- and chemotherapy

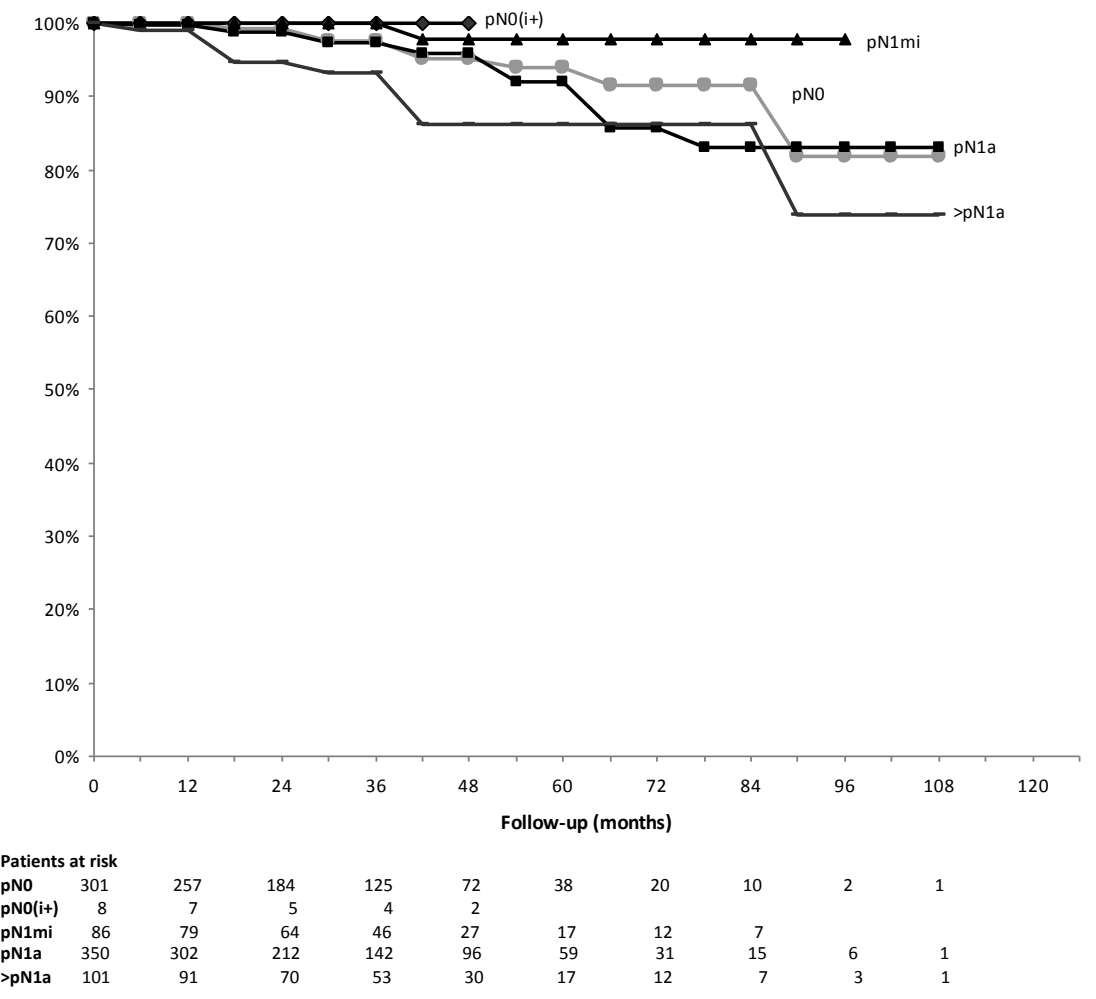


Figure 4 Kaplan-Meier life table analysis of survival by lymph node status of patients who underwent SNB for primary breast cancer and received hormonal therapy, 1996-2006.

Survival according to $\mathrm{pN}$-status, hormonal therapy

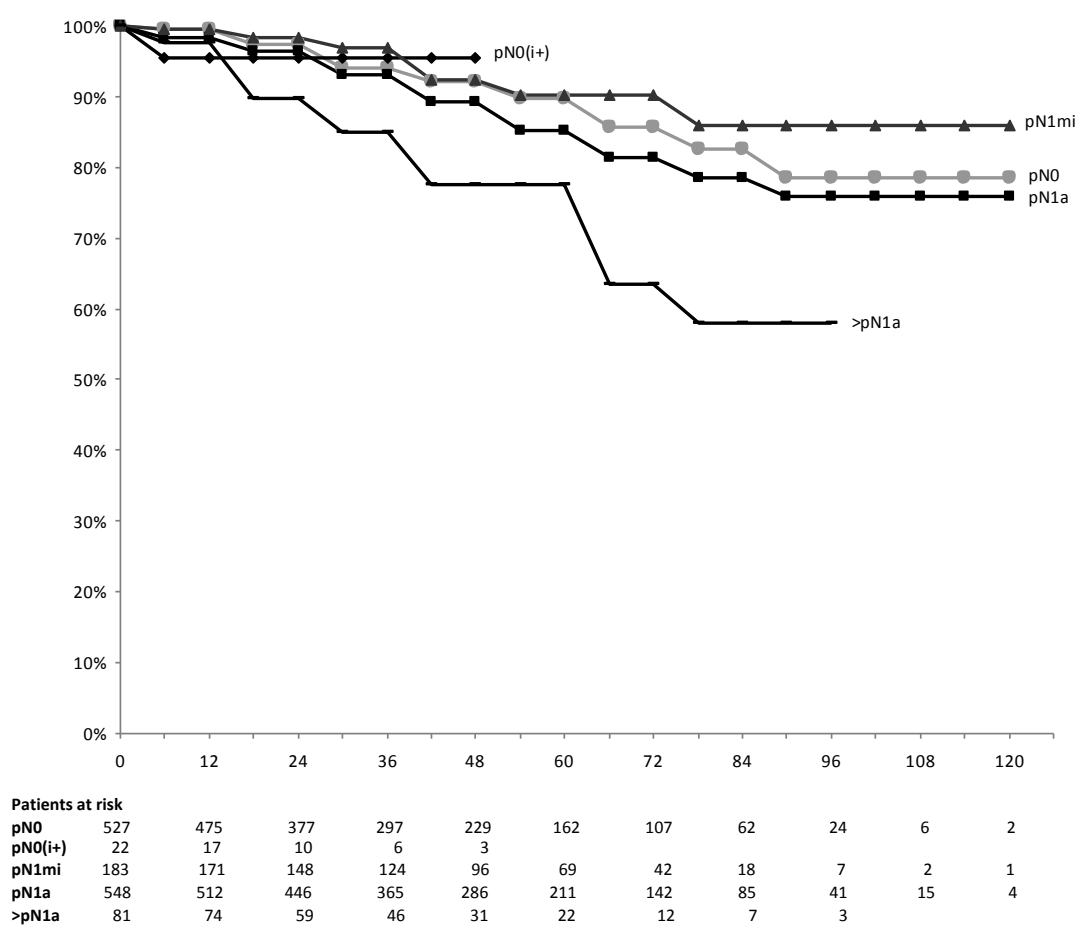


Figure 5 Kaplan-Meier life table analysis of survival by lymph node status of patients who underwent SNB for primary breast cancer and received chemotherapy, 1996-2006.

Survival according to $\mathrm{pN}$-status, chemotherapy

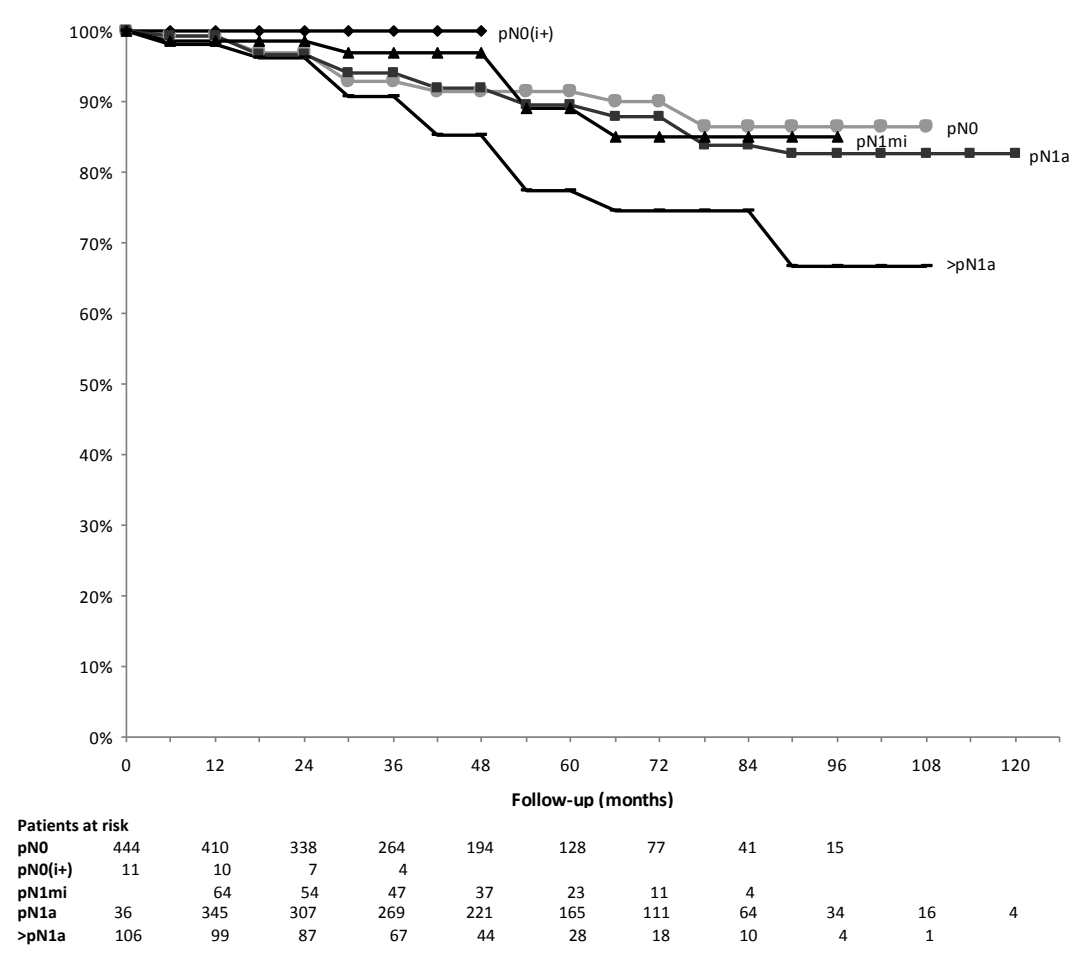

\section{Discussion}

Based on studies conducted before the introduction of the sentinel node procedure, administration of adjuvant systemic therapy to patients with micrometastatic disease in the sentinel node seems justifiable under the assumption that these micrometastases are prognostic indicators of worse survival and outcome. Our study however, which is based exclusively on patients who underwent SNB, showed no overall survival difference between patients with micrometastatic disease and those without axillary lymph node metastasis. Even after adjustment for age, pT, grade and administration of adjuvant systemic therapy no significant survival differences could be detected.

By using data of the Eindhoven Cancer Registry, we were able to present results based on a large, unselected population-based patient population. The patients were treated in 
both teaching and community hospitals and data are thought to reflect the usual care in The Netherlands. This report is one of the first on the prognosis of patients with micrometastases in the sentinel node. Despite a fairly short follow-up time and a small number of events, the $95 \%$ confidence intervals of the estimated Hazard Ratio's are small enough to rule out a large difference in survival between node-negative patients and patients with micrometastases.

Apparently, the biological behaviour of sentinel node micrometastases is of limited prognostic significance, at least during the first five years after diagnosis. In order for tumour cells to metastasize, a number of sequential processes have to take place, such as tumour cell invasion, adhesion and angiogenesis. This is a rather inefficient process and not all circulating tumour cells are viable and capable of forming regional and distant metastasis $^{22}$. Furthermore, expansion of metastasized tumour masses beyond 1-2 $\mathrm{mm}$ in diameter depends on the development of a new blood supply by angiogenesis, which again raises the question whether these very small metastases have biologic implications at all $^{23}$. The observation that occult axillary and distant involvement might never become clinically overt ${ }^{6,24}$ led to the emergence of the stem cell hypothesis, which postulates that a population of cancer cells consists of a limited number of cancer stem cells that cause cancer progression and a larger number of non-stem cancer cells being dormant ${ }^{25}$. Presence of cancer stem cells in a metastatic focus is hypothesized to be important or possibly crucial for development and growth of these foci. Without these stem cells the metastatic focus would be destined to disappear by apoptosis or have a very long dormancy.

As stated before, studies on the significance of micrometastases that used data from patients before the introduction of the sentinel node biopsy showed contradicting results. In one of the larger studies with long follow-up, which was also based on data from the Eindhoven Cancer Registry, 10111 patients were included, of whom 179 had micrometastases. They were diagnosed with invasive breast cancer between 1975 and 1997 and had complete follow-up until April 2002. Remarkably, the results of this study showed that patients with axillary nodal micrometastasis in ALND had a significantly worse survival rate than node-negative patients independent of age or tumour size ${ }^{14}$. Since these data were derived from the same database, covering the same hospitals and pathology laboratories, we must conclude that ALND nodal micrometastases do not have the same prognostic implication as sentinel node micrometastases. We might have studied two different breast cancer patient populations with different tumourcharacteristics and metastatic tumour burden. This seems quite unlikely however, since we adjusted for tumour stage and completion ALND and other studies showed no change in prognosis during this period. Treatment plans have altered and have included the use of systemic adjuvant therapy far more often, but we adjusted for the possible effect of adjuvant systemic therapy in our study. Detection of metastases might be directly 
dependent on the methods used to investigate them. By using serial sectioning and immunohistochemistry in routine daily practice, more and smaller metastases are being detected which may not be a harbinger of undetected macrometastases as may have been the case in older studies.

In an American publication the SEER database was used to determine prognostic significance of micrometastases in pre- as well as post-SN era ${ }^{26}$. This relatively large study demonstrated only a minimal detrimental impact in tumours less than $2.0 \mathrm{~cm}$ in diameter and a more significant detrimental impact in larger tumours ( 1 vs. 4-6\% decrease in 5-year survival). The authors, however, were not able to track the use of adjuvant therapies and therefore they could not adjust for the possible confounding effects of administration of adjuvant systemic therapy. Another Dutch publication based on a much smaller population sample showed that despite a higher risk of distant metastases in the micrometastatic group there was no significant difference in overall or disease-free survival between $\mathrm{pNo}$ - and $\mathrm{pN} 1 \mathrm{mi}$-disease ${ }^{27}$. In a recently published study by Hansen et $\mathrm{al}^{28}$ patients with isolated tumour cells or micrometastases did not have a worse disease-free and overall survival compared to $\mathrm{SN}$-negative patients. Also consistent with our results was their finding that patients with macrometastases have a worse prognosis than the $\mathrm{SN}$-negative patients and patients with isolated tumour cells or micrometastases.

The MIRROR study (Micrometastases and Isolated tumour cells: Relevant and Robust or Rubbish?) showed that patients with isolated tumour cells or micrometastases as final $\mathrm{N}$ stage after SNB had a significantly lower 5-year disease-free survival than patients without nodal involvement ${ }^{29}$. This study, which is also a retrospective cohort study, only included patients with favourable tumour characteristics for whom adjuvant systemic treatment was not indicated according to the Dutch treatment guidelines. In contrast, we also included patients who had been receiving systemic treatment according to those guidelines, as well as patients with macrometastases to see how their prognosis compares to the prognosis of patients with micrometastastic disease or isolated tumour cells. In the MIRROR study pathology of removed axillary lymph nodes was reviewed. Reviewing of the pathology seems to have led to a detection of more isolated tumour cells as compared to micrometastases and node-negative patients. We chose to base our analyses on the information that was retrieved from the pathology report and thus to present results based on usual care in The Netherlands. Finally, no data on overall survival were available in the MIRROR trial.

In conclusion, our population-based study showed that the presence of sentinel node micrometastases in breast cancer patients did not have significant impact on breast cancer overall survival during the first 5 years after diagnosis. We therefore postulate that micrometastatic disease itself should not be an indication for adjuvant systemic therapy. 


\section{References}

1. Louwman WJ, Voogd AC, Van Dijck JAAM, et al. On the rising trends of incidence and prognosis for breast cancer patients diagnosed 1975-2004: a long-term population-based study in southeastern Netherlands. Cancer Causes Control 2008;19:97-106

2. Schijven MP, Vingerhoets AJ, Rutten $\mathrm{HJ}$, et al. Comparison of morbidity between axillary lymph node dissection and sentinel node biopsy. Eur J Surg Oncol 2003;29:341-350

3. Ververs JM, Roumen RM, Vingerhoets AJ, et al. Risk, severity and predictors of physical and psychological morbidity after axillary lymph node dissection for breast cancer. Eur J Cancer 2001;37:991-999

4. Cox CE, Bass SS, McCann CR, et al. Lymphatic mapping and sentinel lymph node biopsy in patients with breast cancer. Ann Rev Med 2000;51:525-542

5. Veronesi U, Paganelli G, Galimberti V, et al. Sentinel-node biopsy to avoid axillary dissection in breast cancer with clinically negative lymphnodes. Lancet 1997;349:1864-1867

6. Veronesi $U$, Paganelli $G$, Viale $G$, et al. Sentinel-lymph-node biopsy as a staging procedure in breast cancer: update of a randomised controlled study. Lancet Oncol 2006;7:983-990

7. Kuijt GP, van de Poll-Franse LV, Voogd AC, et al. Survival after negative sentinel lymph node biopsy in breast cancer at least equivalent to after negative extensive axillary dissection. Eur J Surg Oncol 2007;33:832-837

8. Tjan-Heijnen VC, Bult $P$, de Widt-Levert LM, et al. Micro-metastases in axillary lymph nodes: an increasing classification and treatment dilemma in breast cancer due to the introduction of the sentinel lymph node procedure. Breast Cancer Res Treat 2001;70:81-88

9. Maaskant AJG, van de Poll-Franse LV, Voogd AC, et al. Stage migration due to introduction of the sentinel node procedure: a population-based study. Breast Cancer Res Treat 2009;113:173179

10. van der Heiden-van der Loo M, Bezemer PD, Hennipman A, et al. Introduction of sentinel node biopsy and stage migration of breast cancer. Eur J Surg Oncol 2006;32:710-714

11. de Mascarel I, Bonichon G, Coindre J, et al. Prognostic significance of breast cancer axillary lymph node metastases assessed by two special techniques: reevaluation with longer followup. Br J Cancer 1992;66:523-527

12. Hainsworth $\mathrm{P}$, Tjandra J, Stillwell $\mathrm{R}$, et al. Detection and significance of occult metastases in node-negative breast cancer. Br J Surg 1993;80:459-463

13. Ludwig Breast Cancer Study Group. Prognostic importance of occult axillary lymph node micrometastases from breast cancers. Lancet 1990;335:1565-1568

14. Kuijt GP, Voogd AC, van de Poll-Franse LV, et al. The prognostic significance of axillary lymphnode micrometastases in breast cancer patients. Eur J Surg Oncol 2005;31:500-505

15. Nasser I, Lee A, Bosari S, et al. Occult axillary lymph node metastases in node-negative breast carcinoma. Hum Pathol 1993;24:950-957

16. Fitzgibbons $P$, Page $D$, Weaver $D$, et al. Prognostic factors in breast cancer: College of American Pathologists Consensus statement 1999. Arch Pathol Lab Med 2000;124:966-978

17. Grabau D. Breast cancer patients with micrometastases only: Is a basis provided for tailored treatment? Surg Oncol 2008;17:211-217

18. Tan LK, Giri D, Hummer AJ, et al. Occult axillary node metastases in breast cancer are prognostically significant: Results in 368 node-negative patients with 20-year follow-up. J Clin Oncol 2008;26:1803-1809

19. Mc Shane LM, Altman DG, Sauerbrei W, et al. REporting recommendations for tumor MARKer prognostic studies (REMARK). Breast Cancer Res Treat 2006;100:229-235 
20. Hermanek P, Sobin LH, editors. UICC TNM classification of malignant tumors. Berlin: SpringerVerlag 1987;94-99

21. Roumen RMH, Pijpers HJ, Thunissen FBJM, et al. Samenvatting van de richtlijn "Schildwachtklierbiopsie bij mammacarcinoom". Ned Tijdschr Geneeskd 2000;144:1864-1867

22. Yeatman TJ, Nicolson GL. Molecular basis of tumor progression: Mechanisms of organ-specific tumor metastasis. Semin Surg Oncol 1993;9:256-263

23. Yeatman TJ, Cox CE. The significance of breast cancer lymph node micrometastases. Surg Onco Clin N Am 1999;3:481-496

24. Mansi JL, Gogas H, Bliss JM, et al. Outcome of primary-breast-cancer patients with micrometastases: a long-term follow-up study. Lancet 1999;354:197-202

25. Al-Hajj M, Wicha MS, Benito-Hernandez A, et al. Prospective identification of tumorigenic breast cancer cells. Proc Natl Acad Sci USA 2003;100:3983-3988

26. Chen SL, Hoehne FM, Guiliano AE. The prognostic significance of micrometastases in breast cancer: A SEER population-based analysis. Ann Surg Oncol 2007;14:3378-3384

27. Gobardhan PD, Elias SG, Madsen EVE, et al. Prognostic value of micrometastases in sentinel lymph nodes of patients with breast carcinoma: a cohort study. Ann Oncol 2009;20:41-48

28. Hansen NM, Grube B, Ye X, et al. Impact of micrometastases in the sentinel node of patients with invasive breast cancer. J Clin Oncol 2009;27:4679-4684

29. de Boer M, van Deurzen CHM, van Dijck JAAM, et al. Micrometastases or isolated tumor cells and the outcome of breast cancer. N Eng J Med 2009;361:653-663 


\section{Chapter 5}

\section{Axillary radiotherapy as a treatment modality for sentinel node-positive breast cancer patients}

A.J.G. Maaskant-Braat

M.E. Liebregts

M.J.C. van der Sangen

A.C. Voogd

H.J.T. Rutten

G.A.P. Nieuwenhuijzen

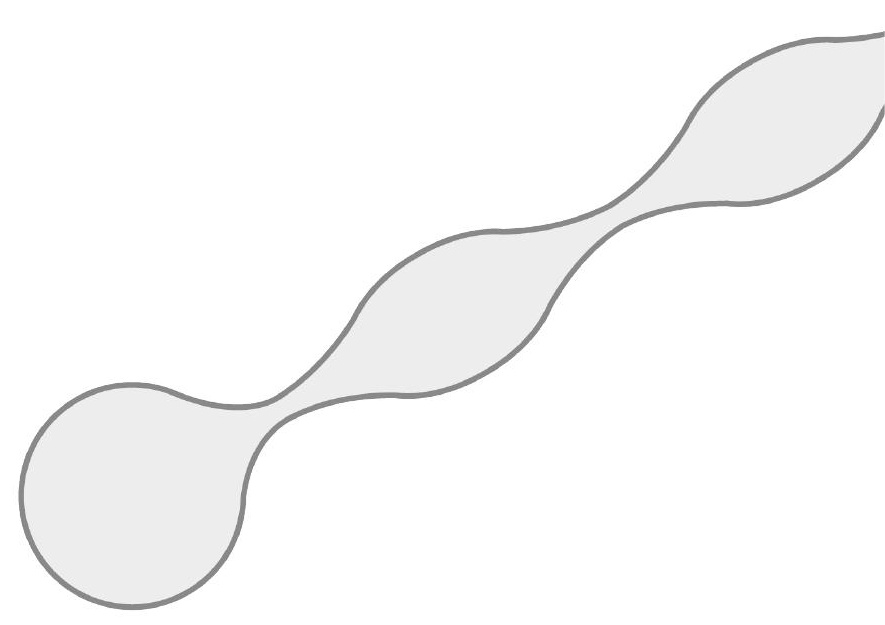




\begin{abstract}
Background Regional radiation therapy has been used for many years instead of or in addition to axillary lymph node dissection (ALND) in patients with breast cancer. Introduction of the sentinel node biopsy (SNB) has triggered the discussion on how to manage patients with a tumour-positive sentinel node. The current study investigated the long-term results of axillary radiotherapy (AxRT) with respect to recurrence rates and functional outcome.
\end{abstract}

Methods Between 1998-2001 35 patients with sentinel node-positive primary breast cancer underwent AxRT as an alternative to ALND. The median follow-up of patients still alive was 131 months (range 114-149). Twenty-one of the 24 patients still alive were available for analysis of late functional outcome.

Results The mean age of the patients was 53 years. No regional axillary recurrences were observed. Two patients (5.7\%) developed locally recurrent breast cancer and one patient developed a new contralateral breast cancer (2.9\%). Five patients developed distant metastases (14.3\%) and 3 died from these distant metastases during follow-up. On prospective analysis, in 6 patients $(28.6 \%)$ no functional limitations or complaints were observed. Arm edema was observed in 3 patients (14.3\%) and impaired shoulder function in 8 patients (38.1\%). Signs of brachial plexus neuropathy were seen in 8 patients $(38.1 \%)$ and 7 patients $(33.3 \%)$ reported pain in arm and/or shoulder.

Conclusion Despite the relative small amount of patients, our results suggest that AxRT might be an effective alternative to ALND in patients with sentinel node-positive breast cancer, with no axillary recurrences and a comparable morbidity to ALND. 


\section{Introduction}

Ever since the $18^{\text {th }}$ century when Henri Francois le Dran (1685-1773) recognized that axillary nodal involvement in a patient with breast cancer was indicative for a worse prognosis ${ }^{1}$, surgery of the axillary nodal basin has been a routine component of breast cancer treatment. Axillary nodal status is an important independent prognostic factor of disease behaviour and ultimate outcome and development of effective adjuvant systemic therapies has made recognition of axillary metastases critical for patient management ${ }^{2-4}$. Axillary lymph node dissection (ALND) has long been the standard of care for adequate axillary staging, but in the 1990's it was replaced by the less invasive technique of sentinel node biopsy $(\mathrm{SNB})^{5,6}$. SNB has been shown to accurately predict axillary nodal status ${ }^{7,8}$ with significantly lower morbidity than ALND ${ }^{9}$. Therefore, ALND has largely been displaced by SNB as a staging modality in breast cancer. As a treatment modality however, a level I and II ALND is still indicated in case of sentinel node-positivity according to national breast cancer treatment guidelines in The Netherlands ${ }^{10}$.

Regional radiation therapy has been used for many years instead of or in addition to axillary dissection. In patients with limited axillary nodal involvement regional adjuvant radiation therapy has been shown to increase local control and survival ${ }^{4}$. Furthermore, the success of axillary radiotherapy (AxRT) in controlling microscopic disease in lymph nodes has been described in patients with clinically negative axillary lymph nodes. Several trials have suggested that AxRT achieves the same regional control, disease-free and overall survival as ALND, but with a more favourable complication rate $\mathrm{e}^{11-13}$.

Unfortunately, prospective data are not yet available regarding the use of AxRT as a treatment modality for sentinel node-positive breast cancer patients. Inclusion of the EORTC 10981-22023 AMAROS trial (After Mapping of the Axilla: Radiotherapy or Surgery?), in which patients with a positive SNB are randomized between AxRT or an ALND, has been completed and the results of this trial are awaited soon. Pending these results we present our long-term results on axillary radiotherapy for sentinel-node positive breast cancer with respect to locoregional and distant recurrence and functional outcome.

\section{Patients and methods}

In the Catharina Hospital, Eindhoven, patients with clinically node-negative, sentinel node-positive primary breast cancer were offered AxRT as an alternative to ALND between 1998 and 2001. We retrospectively identified the patients that received AxRT and, after obtaining their written informed consent, included the data in our analyses. Patient data on initial therapy and pathology outcome as well as local and regional (lymph node) recurrences and distant metastasis were retrieved from the medical records 
and pathology reports. The patients were staged according to the Tumour-NodeMetastasis (TNM) system of the International Union Against Cancer (UICC) version $6^{14}$. All patients underwent breast-conserving therapy $(B C T)$ or mastectomy. Patients with $\mathrm{BCT}$ all received postoperative whole-breast radiation. After mastectomy, 4 patients received adjuvant radiotherapy on the chest wall. The periclavicular region was irradiated using one anterior-posterior field covering the supraclavicular region and the upper axilla with dose calculation at a point $3 \mathrm{~cm}$ beneath the skin surface. The breast and chest wall were radiated with tangential fields. All patients received a total dose of 46 Gray (Gy) in 20 fractions of $2.3 \mathrm{~Gy}$, four times a week. After BCT patients were given an additional boost dose of $13.8 \mathrm{~Gy}$ in 6 fractions of $2.3 \mathrm{~Gy}$, four times a week on the primary tumour bed. Adjuvant treatment was administered according to the Dutch national treatment guidelines for that period.

During follow-up all patients were invited to the outpatient clinic for an additional interview and clinical evaluation. Patients were asked to fill out a shoulder disability questionnaire $(S D Q)^{15}$, which subjectively grades pain and impaired range of motion of the shoulder by determining the impairment percentage as compared to no impairment at all (score 100\%). Also, patients were asked to describe pain in the breast or axilla on a visual analogue scale (VAS) from 1 to 10.

Objective signs of arm edema, impaired shoulder mobility and brachial plexus neuropathy were determined. All tests were also performed on and compared with the contralateral side. Edema of the arm was measured at two fixed levels of the upper- and forearm (15 $\mathrm{cm}$ cranial and $15 \mathrm{~cm}$ caudal from the medial epicondyle of the elbow) and compared with the contralateral side. It was scored as "none" (dominant arm: $<2 \mathrm{~cm}$ difference, nondominant arm: o cm difference), "mild" (dominant arm: $2-3 \mathrm{~cm}$ difference, non-dominant arm: 0-2 cm difference), "moderate" (dominant arm: $3-4 \mathrm{~cm}$ difference, non-dominant arm: $2-3 \mathrm{~cm}$ difference) or "severe" (dominant arm: $>4 \mathrm{~cm}$ difference, non-dominant arm: $>3 \mathrm{~cm}$ difference). Shoulder mobility was assessed in six directions (abduction, adduction, forward flexion, extension, internal rotation and external rotation). The worst impairment was documented and graded as "none" (< 20 degrees difference), "mild" (20-40 degrees difference), "moderate" (>40 degrees difference) or "severe" (rigidity). Muscle strength was graded on a scale of 1-5 in seven muscle groups of the shoulder, arm, wrist, and hand. Sensibility and tendon-muscle reflexes were tested. Follow-up was completed until September 2010. 


\section{Results}

\section{Patients}

Between 1998 and 2001, 35 patients received AxRT as regional treatment for sentinel node-positive breast cancer. Their characteristics are shown in Table 1 . The mean age of the patients was 53 years (range 33-82). Most of them had T1- and T2-tumors and underwent breast-conserving therapy. Six patients had micrometastatic disease in their sentinel lymph node. Adjuvant systemic therapy, being hormonal therapy, chemotherapy or both, was administered in 31 patients. Median follow-up of the 22 patients still alive was 131 months (range 114-149) versus 69 months (range 19-126) for the 11 patients who had died. Two patients were lost to follow-up.

\section{Disease recurrence and survival}

No regional axillary recurrences were observed. Two patients (5.7\%) developed locally recurrent breast cancer after $\mathrm{BCT}$, one 44 months after the initial treatment, the other after 58 months. Both patients were treated by a salvage mastectomy and in one of them a level I ALND was performed in which no axillary metastases were revealed. One patient developed a new contralateral breast cancer (2.9\%) for which she underwent a mastectomy with SNB and radiotherapy on chest wall and axilla. Five patients developed distant metastases (14.3\%) and 3 died from these distant metastases during follow-up. A total of 11 patients died during follow-up (31.4\%), 3 from breast cancer recurrence, 4 from cardiovascular disease and 4 from other causes.

\section{Functional analysis}

Since 11 patients died during follow-up, 2 patients were lost to follow-up and one patient underwent a subsequent mastectomy with level I ALND for locally recurrent breast cancer, 21 patients remained available for prospective functional analysis (Table 2). Median follow-up time to this functional analysis was more than 10 years ( 133 months), ranging from 114 to 149 months.

On prospective functional analysis 6 patients (28.6\%) reported no arm complaints. Arm edema was observed in 3 patients (14.3\%). In one patient this was graded as mild, in one as moderate and in one as severe. The patient with moderate arm edema had one sentinel node removed, the other ones 2 . In 8 patients (38.1\%) shoulder function was impaired as compared to the contralateral side. In 2 patients this impairment was graded as mild, in 5 as moderate and in 1 as severe. Muscle strength was abnormal in 1 patient $(4.8 \%)$, in 3 patients $(14.3 \%)$ sensory loss was documented and in 6 patients $(28.6 \%)$ tendon-muscle reflexes were diminished. Three patients $(14.3 \%)$ reported mild to moderate pain in arm and/or shoulder and 4 patients (19.1\%) reported severe pain. 
Table 1 Patient characteristics of 35 patients who underwent axillary radiotherapy for sentinel node-positive breast cancer, 1998-2001.

\begin{tabular}{|c|c|}
\hline & $\mathrm{N}(\%)$ \\
\hline \multicolumn{2}{|l|}{ Age at diagnosis } \\
\hline$\leq 35 \mathrm{yrs}$ & $\begin{array}{r}2(5.7) \\
10(28.6)\end{array}$ \\
\hline $\begin{array}{l}36-49 \text { yrs. } \\
50-69 \text { yrs. }\end{array}$ & $\begin{array}{l}10(28.6) \\
14(40.0)\end{array}$ \\
\hline$\geq 70$ yrs. & $9(25.7)$ \\
\hline Mean [range] & $53[33-82]$ \\
\hline \multicolumn{2}{|l|}{ pT-stage } \\
\hline 1 & $19(54.3)$ \\
\hline 2 & $13(37.1)$ \\
\hline 3 & $0(0.0)$ \\
\hline 4 & $3(8.6)$ \\
\hline \multicolumn{2}{|l|}{ Histology } \\
\hline Ductal & $27(77.1)$ \\
\hline Lobular & $3(8.6)$ \\
\hline Mixed & $5(14.3)$ \\
\hline \multicolumn{2}{|l|}{ Estrogen receptor } \\
\hline Positive & $8(22.9)$ \\
\hline Negative & $25(71.4)$ \\
\hline Unknown & $2(5.7)$ \\
\hline \multicolumn{2}{|l|}{ Progesterone receptor } \\
\hline Positive & $9(25.7)$ \\
\hline Negative & $23(65.7)$ \\
\hline Unknown & $3(8.6)$ \\
\hline \multicolumn{2}{|l|}{ Type of definitive surgery } \\
\hline Breast-conserving surgery & $31(88.6)$ \\
\hline Mastectomy & $3(8.6)$ \\
\hline Mastectomy after breast conserving surgery & $1(2.9)$ \\
\hline \multicolumn{2}{|l|}{ Number of sentinel nodes removed } \\
\hline 1 & $15(42.9)$ \\
\hline 2 & $12(34.3)$ \\
\hline$\geq 3$ & $8(22.9)$ \\
\hline \multicolumn{2}{|l|}{$\mathrm{pN}$-stage } \\
\hline $1 \mathrm{mi}$ & $6(17.1)$ \\
\hline $1 a$ & $28(80.0)$ \\
\hline$>1 a$ & $1(2.9)$ \\
\hline \multicolumn{2}{|l|}{ Stage } \\
\hline$\| \mathrm{A}$ & $20(57.1)$ \\
\hline II B & $12(34 \cdot 3)$ \\
\hline III B & $3(8.6)$ \\
\hline \multicolumn{2}{|l|}{ Radiotherapy } \\
\hline Breast or thoracic wall & $35(100.0)$ \\
\hline Periclavicular region & $35(100.0)$ \\
\hline \multicolumn{2}{|l|}{ Adjuvant systemic therapy } \\
\hline Chemotherapy alone & $6(17.1)$ \\
\hline Hormonal therapy alone & $17(48.6)$ \\
\hline Chemotherapy and hormonal therapy & $8(22.9)$ \\
\hline None & $4(11.4)$ \\
\hline
\end{tabular}


Table 2 Prospective functional analysis of 21 patients who underwent axillary radiotherapy for sentinel node-positive breast cancer, 1998-2001. Median follow-up: 133 months (range 114-149).

\begin{tabular}{|l|r|}
\hline Complaint/functional limitation & $\mathbf{N}(\%)$ \\
\hline Arm edema & $18(85.7)$ \\
None & $1(4.8)$ \\
Mild & $1(4.8)$ \\
Moderate & $1(4.8)$ \\
Severe & \\
\hline Impaired shoulder function & $13(61.9)$ \\
None & $2(9.5)$ \\
Mild & $5(23.8)$ \\
Moderate & $1(4.8)$ \\
\hline Severe & \\
\hline Muscle strength & $20(95.2)$ \\
Normal & $1(4.8)$ \\
Weakness (mild) & \\
\hline Sensory loss & $18(85.7)$ \\
Absent & $3(14.3)$ \\
\hline Present & $15(71.4)$ \\
\hline Abnormal reflexes & $6(28.6)$ \\
Absent & \\
Present & $14(66.7)$ \\
\hline Pain in arm/shoulder & $3(14.3)$ \\
Absent & $4(19.0)$ \\
\hline Mild/moderate (VAS 1-5) & $6(28.6)$ \\
Severe (VAS 6-10) & $5(23.8)$ \\
\hline Number of complaints/functional limitations* & \\
None & \\
One & \\
Two or more & \\
\hline
\end{tabular}

*Defined as the presence of any of the complaints or functional limitations reported in the table, irrespective of its severity

All 21 evaluable patients completed the Shoulder Disability Questionnaire (SDQ). Eleven patients $(52.4 \%)$ had a diminished score indicating impairment in shoulder function or pain at movement of the shoulder as compared to a score of $100 \%$, which indicates no functional impairment. The mean impairment percentage of daily functioning was $41 \%$ (range $6-100 \%)$. In 5 patients $(22.7 \%)$ the SDO indicated shoulder function impairment while objectively no impairment could be detected. On the other hand, in 2 patients (9.1\%) the SDO indicated no impairment while objectively an impaired range of motion could be measured. 


\section{Discussion}

This study shows the long-term results of the use of AxRT as a treatment modality for sentinel node-positive breast cancer. Despite the relative small number of patients, low overall recurrence rates and absence of regional lymph node recurrences suggest that AxRT might bean effective alternative to ALND. With respect to functional outcome, long-term complication rates seem to be equal to the functional results observed after an ALND.

Introduction of the SNB has resulted in substantial controversy about how to manage patients with positive sentinel nodes. Especially the increase in minimal nodal involvement due to more extensive pathologic examination techniques ${ }^{16}$ and the uncertainty regarding the prognostic impact of these micrometastases ${ }^{17-19}$ have triggered the discussion on the potential benefit of a completion ALND. Completion ALND in case of sentinel node-positivity is advised based on the observation in the literature that patients with metastases in their sentinel nodes have an approximately $20-50 \%$ chance of having additional non-sentinel node involvement, depending on the extent of sentinel node tumour involvement ${ }^{20,21}$. On the other hand, despite of the fact that the proportion of patients who underwent SNB alone for small volume sentinel node metastases increased from 24.7 to $45.3 \%$ in a population-based study, axillary recurrence and survival were not significantly different from patients that underwent completion $A L N D^{22}$. In order to predict which patients are at greater risk of having non-sentinel node metastases and might benefit from a completion ALND, a nomogram was developed based on which the risk of node-positivity in the completion ALND could be predicted ${ }^{23}$. Unfortunately, several validation studies showed that the performance of these nomograms was insufficient to make it a useful tool for individual decision-making in other than the original patient populations ${ }^{24,25}$.

Publication of the results of the ACOSOG Zooo11 trial, in which SNB positive patients were randomized between ALND and observation, further nurtured the discussion on management of SNB positive patients ${ }^{26,27}$. Despite of the fact that an estimated $27 \%$ of the patients had additional metastases in the non-sentinel axillary nodes, regional recurrence rates after a median follow-up of 6 years were less than $1 \%$ in the SNB alone group. Furthermore, in these cases with restricted tumour involvement of the sentinel node, ALND did not result in improved survival or a better local axillary control compared to SNB alone. Apparently, not all non-sentinel node metastases develop into clinically detectable disease. It is important to realize, however, that in the ACOSOG Zoo11 trial $97 \%$ of the patients received adjuvant systemic therapy and $89 \%$ of the patients received whole-breast irradiation with tangential fields to the axilla. Adjuvant systemic therapy is known for its potential to diminish locoregional recurrence in breast cancer patients ${ }^{28}$ and approximately $25 \%$ of patients with positive lymph nodes who are treated with neo- 
adjuvant chemotherapy have a complete eradication of nodal disease ${ }^{29}$. Whole-breast irradiation with tangential fields includes the majority of level I and II axillary lymph nodes. It is estimated that more than $50 \%$ of level I and $20-30 \%$ of level II nodes receive $95 \%$ of the prescribed radiation dose, depending on patient anatomy and the upper tangential field border ${ }^{30,31}$. It is obvious that the radiation treatment of the breast in the ACOSOG Zoo11 trial also delivered an adequate radiation dose to a large part of the axilla at risk and eradicated potentially present disease.

In the search for alternative methods for axillary treatment in clinically node-negative breast cancer patients the use of AxRT was investigated. Low axillary recurrence rates were consistently reported with no significant differences in survival ${ }^{32,33}$. Our low (axillary) recurrence rates are in line with those reported in literature ${ }^{34}$.

ALND has well-documented, considerable side effects, such as lymph edema, shoulder pain, paraesthesia and impaired range of motion of the shoulder, which have a negative impact on quality of life of women who underwent ALND for breast cancer ${ }^{35}$. A 5-30\% risk of arm edema was reported after axillary surgery, depending on the definition used and the extent of axillary surgery, and reported occurrence of impaired shoulder function and pain is approximately $20 \%{ }^{36,37}$. Reported side effects of AxRT include arm edema (2-9\%), impaired shoulder mobility (17\%), brachial plexus neuropathy (0-5\%) and radiation pneumonitis $(2-5 \%)^{11,34}$. Radiation-induced toxicity is thought to be the result of focal fibrosis, causing constriction of venous and lymphatic return, nerve entrapment and decreased shoulder function. The long-term complication rates in our study are somewhat higher than those reported in the literature. It is important to realize, however, that the onset of complaints due to radiation toxicity is highly variable and they usually appear after a latency period of 1.5 to 10 years ${ }^{38}$. Since we have reported a median followup of more than 10 years, a higher incidence of radiation-induced symptoms might be expected. Also, side effects of the SNB, such as pain (7.8\%), arm edema (1.1\%) and numbness $(3.9 \%)^{9}$, could contribute to the overall morbidity in these patients.

In conclusion, our long-term follow-up results suggest that AxRT might be an effective alternative to ALND in patients with SNB positive breast cancer. We have observed no axillary recurrences after AxRT and the morbidity of AxRT appears to be comparable to the morbidity observed after an ALND. Since we described a small number of patients, the results of the AMAROS trial have to be awaited in order to conclude that AxRT can definitively replace ALND as a treatment modality for SNB positive breast cancer patients. 


\section{References}

1. Le Dran HF. Memoires avec un précis de plusieurs observations sur le cancer. Memoires de I'Academie Royale de Chirurgie 1757;3:1-54

2. Glodhirsch A, Glick JH, Gelber RD, Senn HJ. Meeting highlights: international consensus panel on the treatment of primary breast cancer. J Natl Cancer Instit 1998;90:1601-1608

3. Orr RK. The impact of prophylactic axillary node dissection on breast cancer survival - a Bayesian meta-analysis. Ann SurgOncol 1999;6:109-116

4. Overgaard $M$, Jensen $M B$, Overgaard J, et al. Postoperative radiotherapy in high-risk postmenopausal breast-cancer patients given adjuvant tamoxifen: Danish Breast Cancer Cooperative Group DBCG 82c randomized trial. Lancet 1999; 353:1641-1648

5. Krag DN, Weaver DL, Alex JC, et al. Surgical resection and radiolocalization of the sentinel lymph node in breast cancer using a gamma probe. SurgOncol 1993;2:335-340

6. Giuliano $A E$, Kirgan $D M$, Guenther JM, Morton DL. Lymphatic mapping and sentinel lymphadenectomy for breast cancer. Ann Surg 1994;220:391-398

7. Krag $D$, Weaver $D$, Ashikaga $T$, et al. The sentinel node in breast cancer - a multicenter validation study. N Engl J Med 1998;339:941-946

8. Naik AM, Fey J, Gemignani $M$, et al. The risk of axillary relapse after sentinel lymph node biopsy for breast cancer is comparable with that of axillary lymph node dissection, a follow-up study of 4008 procedures. Ann Surg 2004;240:462-471

9. Schijven MP, Vingerhoets $\mathrm{AJ}$, Rutten $\mathrm{HJ}$, et al. Comparison of morbidity between axillary lymph node dissection and sentinel node biopsy. Eur J Surg Oncol 2003;29: 341-350

10. NationaalBorstkankerOverleg Nederland (NABON). Richtlijnbehandeling van het mammacarcinoom. 2012; Available: www.oncoline.nl.

11. Hoebers FJ, Borger JH, Hart AA, Peterse JL, Rutgers EJ, Lebesque JV. Primary axillary radiotherapy as axillary treatment in breast-conserving therapy for patients with breast carcinoma and clinically negative axillary lymph nodes. Cancer 2000;88: 1633-1642

12. Fisher $B$, Baver $M$, Margolese $R$, et al. Five-year results of a randomized clinical trial comparing total mastectomy and segmental mastectomy with of without radiation in the treatment of breast cancer. N Engl J Med 1985;312:665-673

13. Louis-Sylvestre $C$, Clough $K$, Asselain B, et al.Axillary treatment in conservative management of operable breast cancer: dissection or radiotherapy? Results of a randomized study with 15 years of follow-up. J Clin Oncol 2004;22:97-101

14. Hermanek P, Sobin LH, editors. UICC TNM classification of malignant tumors. Berlin: SpringerVerlag 1987;94-99

15. van der Windt DA, van der Heijden GJ, de Winter AF, Koes BW, Devillé W, Bouter LM. The responsiveness of the Shoulder Disability Questionnaire. Ann Rheum Dis 1998;57:82-87

16. Maaskant AJ, van de Poll-Franse LV, Voogd AC, Coebergh JW, Tutein Nolthenius-Puylaert MC, Nieuwenhuijzen GA. Stage migration due to introduction of the sentinel node procedure: a population-based study. Breast Cancer Res Treat 2009;113:173-179

17. de Boer M, van Deurzen CHM, van Dijck JAAM, et al. Micrometastases or isolated tumor cells and the outcome of breast cancer. NEJM 2009;361:653-663

18. Hansen NM, Grube B, Ye $X$, et al. Impact of micrometastases in the sentinel node of patients with invasive breast cancer. J Clin Oncol 2009; 27:4679-4684.

19. Maaskant-Braat AJ, van de Poll-Franse LV, Voogd AC, et al. Sentinel node micrometastases in breast cancer do not affect prognosis: A population-based study. Breast Cancer Res Treat 2011;127:195-203 
20. Van Rijk MC, Peterse JL, Nieweg OE, et al. Additional axillary metastases and stage migration in breast cancer patients with micrometastases or submicrometastases in sentinel lymph nodes. Cancer 2006;107:467-471

21. Cserni G, Gregori D, Merletti F, et al. Meta-analysis of non-sentinel node metastases associated with micrometastatic sentinel nodes in breast cancer. Br J Surg 2004;91: 1245-1252

22. Bilimoria KY, Bentrem DJ, Hansen NM, et al. Comparison of sentinel lymph node biopsy alone and completion axillary lymph node dissection for node-positive breast cancer. J Clin Oncol 2009;27:2946-2953

23. van Zee KJ, Manasseh DM, Bevilacqua JL, et al. A nomogram for predicting the likelihood of additional nodal metastases in breast cancer patients with a positive sentinel node biopsy. Ann Surg Oncol 2003;10:1140-1151

24. van den Hoven I, Kuijt GP, Voogd AC, et al. Value of Memorial Sloan-Kettering Cancer Center nomogram in clinical decision making for sentinel lymph node-positive breast cancer. Br J Surg 2010;97:1653-1658

25. Fougo JL, Senra FS, Araújo C, et al. Validating the MSKCC nomogram and a clinical decision rule in the prediction of non-sentinel node metastases in a Portuguese population of breast cancer patients. Breast 2011;20:134-140

26. Giuliano $A E, M c C a l l ~ L$, Beitsch $P$, et al. Locoregional recurrence after sentinel lymph node dissection with or without axillary dissection in patients with sentinel lymph node metastases. Ann Surg 2010;252:426-433

27. Giuliano $A E$, Hunt $K K$, Ballman $K V$, et al. Axillary dissection vs no axillary dissection in women with invasive breast cancer and sentinel node metastasis: a randomized clinical trial. JAMA 2011;305:569-575

28. Buchholz TA, Tucker SL, Erwin J, et al. Impact of systemic treatment on local control for patients with lymph node-negative breast cancer treated with breast-conservation therapy. J Clin Oncol 2001;19:2240-2246

29. Gralow JR, Burstein HJ, Wood W, et al. Preoperative therapy in invasive breast cancer: Pathologic assessment and systemic therapy issues in operable disease. J Clin Oncol 2008;26:814-819

30. Schlembach PJ, Buchholz TA, Ross MI, et al. Relationship of sentinel and axillary level I-II lymph nodes to tangential fields used in breast irradiation. Int J Radiat Oncol Biol Phys 2001;51:671678

31. Reznik J, Cicchetti MG, Degaspe B, et al. Analysis of axillary coverage during tangential radiation therapy to the breast. Int J Radiat Oncol Biol Phys 2005;61:163-168

32. Veronesi $U$, Orecchia R, Zurrida $S$, et al. Avoiding axillary dissection in breast cancer surgery: a randomized trial to assess the role of axillary radiotherapy. Ann Oncol 2005;16:383-388

33. Martelli $G$, Boracchi $P$, De Palo $M$, et al. A randomized trial comparing axillary dissection to no axillary dissection in older patients with $\mathrm{T}_{1}$ No breast cancer: results after 5 years of follow-up. Ann Surg 2005;242:1-9

34. Recht A. Can radiotherapy replace axillary dissection for patients with positive sentinel nodes? Breast Dis 2010;31:91-97

35. Voogd AC, Ververs JM, Vingerhoets AJ, Roumen RM, Coebergh JW, Crommelin MA. Lymphoedema and reduced shoulder function as indicators of quality of life after axillary lymph node dissection for invasive breast cancer. Br J Surg 2003;90:76-81

36. Pain SJ, Purushotham AD. Lymphoedema following surgery for breast cancer. Br J Surg 2000;87:1128-1141 
37. Ververs JM, Roumen RM, Vingerhoets AJ, et al. Risk, severity and predictors of physical and psychological morbidity after axillary lymph node dissection for breast cancer. Eur J Cancer 2001;37:991-999

38. Senkus-Konefka E, Jassem J. Complications of breast-cancer radiotherapy. Clin Oncol 2006;18:229-235 


\section{Chapter 6}

Staging and management of axillary

lymph nodes in patients with local

recurrence in the breast or chest wall after

a previous negative sentinel node procedure

F. Derkx

A.J.G. Maaskant-Braat

M.J.C. van der Sangen

G.A.P. Nieuwenhuijzen

L.V. van de Poll-Franse

R.M.H. Roumen

A.C. Voogd

Eur J Surg Oncol 2010;36:646-651

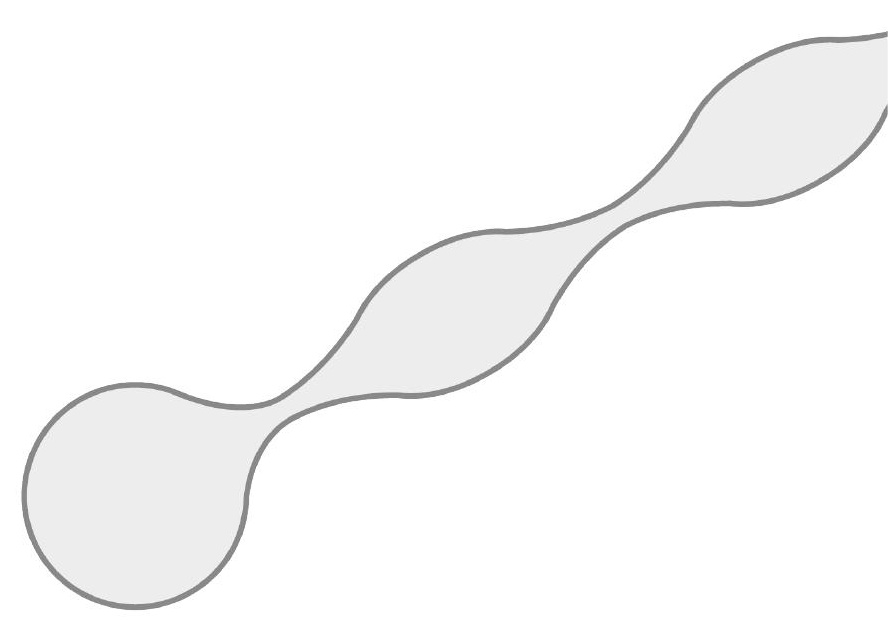




\begin{abstract}
Background The objective of this study was to evaluate axillary staging and management in patients with local recurrence (LR) after a previous negative sentinel lymph node biopsy (SNB).
\end{abstract}

Methods Between 1999 and 2008130 patients with previous negative SNB developed a LR of breast or chest wall. After examination of clinical records, 70 patients met the inclusion criteria and remained available for analysis.

Results Thirty-seven patients were treated with axillary lymph node dissection (ALND), followed by axillary radiotherapy in 9 cases. In 26 of these 37 patients no positive axillary lymph nodes were found. Nineteen patients received no treatment of the axilla at all. Of those, 9 were older than 70 years of age at diagnosis of LR. In 13 patients a second SNB was attempted, but was successful in only 5 cases. Eight patients underwent a complementary ALND. Overall, positive lymph nodes were detected in 13 of the 50 patients who underwent axillary staging, either by SNB or ALND. The median length of follow-up of the 70 patients following their diagnosis of LR was 24 months (range 2-81 months). During this follow-up period one patient developed an axillary recurrence. This was a patient who refused to undergo ALND but was given locoregional radiotherapy instead.

Conclusion In the absence of guidelines for staging and management of the axilla at time of LR of breast or chest wall, many different strategies are being used. Considering the high rate of positive axillary lymph nodes in these patients, repeat surgical staging is appropriate. 


\section{Introduction}

The axillary lymph node status is an important prognostic factor for disease recurrence and survival in patients with primary breast cancer. During the last decade sentinel lymph node biopsy (SNB) has become a routine procedure in the management of patients with early breast cancer. Numerous follow-up studies have shown that it is safe to omit axillary lymph node dissection (ALND) in patients with tumour-negative sentinel lymph nodes $(\mathrm{SLNs})^{1-3}$. However, during follow-up 5 to 15 percent of these patients will ultimately develop a local recurrence on the chest wall or in the breast after mastectomy or breastconserving therapy ${ }^{4,5}$. The number of patients with local recurrence (LR) appearing after a previous negative SNB is still small, but will increase with the expansion of the cohort of patients who undergo SNB. Currently, little is known about the best clinical approach of the axillary lymph nodes in these patients, especially when there is no clinical suspicion of tumour involvement of the axilla. We postulate that in the absence of evidence-based treatment guidelines, different strategies are in use. Although several studies have shown that a repeat SNB is technically feasible and can provide useful information ${ }^{6,7}$, it remains questionable whether it is a safe alternative to ALND.

The aim of this study was to evaluate axillary staging and management in patients who developed a local recurrence after a previous negative SNB, performed in 14 hospitals in the southern part of The Netherlands.

\section{Patients and methods}

Patients were identified by making use of the population based Eindhoven Cancer Registry, which records data on all patients newly diagnosed with cancer in the southern part of The Netherlands, an area with approximately 2.4 million inhabitants. Patient data were derived from 14 hospitals, consisting of large non-university teaching hospitals and community hospitals, two radiotherapy departments and 6 pathology laboratories.

SNB was introduced in the south of The Netherlands in 1995. In 1997, surgeons started performing SNB as a routine staging procedure and since the year 2000 indications for SNB have been described in national guidelines ${ }^{8}$. During the period of $1997-2006,6800$ patients with an invasive breast carcinoma underwent SNB in the South of the Netherlands. Of these, 4094 had negative SLNs and underwent no ALND.

In 1989 the Eindhoven Cancer Registry started collecting follow-up information on all patients with breast cancer diagnosed in the 7 hospitals in the eastern part of the region, including the data and site of local, regional and distant recurrence. The pathologists, radiotherapists and the majority of the surgeons provided the information. Since 2004 follow-up information has also been collected for patients diagnosed in the other 7 hospitals in the western part of the region covered by the Eindhoven Cancer Registry. 
Until September 2008, 130 women with a locoregional recurrence had been recorded by the cancer registry among the 4094 patients with a negative SNB. After examination of clinical records, 6o patients were excluded. Thirty-six patients had distant metastasis instead of or prior to LR, 15 patients had axillary metastasis only and medical records of 9 patients could not be retrieved. Eventually 70 patients with a LR remained available for analysis. The medical records were used to collect detailed information on the treatment of the primary tumour and the characteristics of the local recurrence, including the diagnostic procedures and different treatment strategies used for the axilla.

\section{Results}

\section{Patient characteristics}

Between 2000 and 2008 seventy patients were treated for an isolated local recurrence after negative SLB in the Southeast region of The Netherlands. Characteristics of these patients are presented in Table 1. Diagnosis of the primary tumour took place between 1999 and 2006. The median age at diagnosis of the primary tumour was 58 years (range 29-84 years). The median interval between diagnosis of the primary tumour and diagnosis of local recurrence was 40 months (range 7-99 months). Fifty-two patients underwent breast-conserving surgery at time of primary tumour and 49 of them received adjuvant radiotherapy of the breast. Chemotherapy and/or hormonal therapy were given to 22 patients.

\section{Management of the axilla}

The different staging and treatment strategies of the axilla are presented in Table 2. Thirty-seven patients underwent ALND, followed by axillary radiotherapy in 9 cases. In 26 of these 37 patients no positive axillary lymph nodes were found. Patients received axillary radiotherapy because of tumour involvement of the lymph node at the most cranial site of the axillary surgical specimen or because of an irradical resection, according to current guidelines. In one patient, the nodal status could not be given, because the axillary tissue had been completely invaded by tumour tissue and separate lymph nodes could not be identified.

In 13 patients a second SNB was attempted (Table 3). Twelve of the 13 patients had undergone breast-conserving therapy $(B C T)$ for their primary tumour. The SNB was successful in 5 patients and one of them was positive. Eight patients underwent a complementary ALND, including the patient with a positive SLN. Two of these patients turned out to have positive axillary lymph nodes. 
Table 1 Characteristics of 70 patients with local recurrence (LR) following a negative sentinel lymph node biopsy (SNB) at the time of diagnosis of the primary tumour.

\begin{tabular}{|c|c|}
\hline Characteristics & $\mathbf{N}$ \\
\hline \multicolumn{2}{|l|}{ Age at diagnosis primary tumour } \\
\hline$\leq 35$ yrs. & 4 \\
\hline $36-49$ yrs. & 19 \\
\hline $50-69$ yrs. & 34 \\
\hline$\geq 70$ yrs. & 13 \\
\hline Median [range] & $58[29-84]$ \\
\hline \multicolumn{2}{|l|}{ pT-Stage of primary tumour } \\
\hline 1 & 47 \\
\hline 2 & 22 \\
\hline Unknown & 1 \\
\hline \multicolumn{2}{|l|}{ Grade of primary tumour } \\
\hline I & 11 \\
\hline II & 26 \\
\hline III & 16 \\
\hline Unknown & 17 \\
\hline \multicolumn{2}{|l|}{ Histologic type of primary tumour } \\
\hline Ductal & 57 \\
\hline Lobular/mixed & 12 \\
\hline Mucinous/tubular/medullary & 1 \\
\hline \multicolumn{2}{|l|}{ Surgical treatment of primary tumour } \\
\hline Breast-conserving surgery & 52 \\
\hline Mastectomy & 18 \\
\hline \multicolumn{2}{|l|}{ Number of sentinel nodes removed at primary SNB } \\
\hline 1 & 29 \\
\hline 2 & 26 \\
\hline$\geq 3$ & 10 \\
\hline Unknown & 5 \\
\hline \multicolumn{2}{|l|}{ Radiotherapy } \\
\hline Breast & 49 \\
\hline Chest wall or axilla & o \\
\hline No & 21 \\
\hline \multicolumn{2}{|l|}{ Adjuvant therapy } \\
\hline Chemotherapy & 7 \\
\hline Hormonal therapy & 14 \\
\hline Chemotherapy and hormonal therapy & 1 \\
\hline No & 48 \\
\hline \multicolumn{2}{|l|}{ Interval between primary diagnosis of primary tumour and LR } \\
\hline$\leq 36$ months & 36 \\
\hline$\geq 36$ months & 34 \\
\hline Median [range] & 35 [7-99] \\
\hline \multicolumn{2}{|l|}{ Histology of LR } \\
\hline Ductal & 57 \\
\hline Lobular/mixed & 9 \\
\hline Mucinous/tubular/medullary & 1 \\
\hline DCIS & 3 \\
\hline \multicolumn{2}{|l|}{ Extension of LR } \\
\hline Single focus & 44 \\
\hline Multiple foci & 16 \\
\hline Diffuse & 8 \\
\hline Unknown & 2 \\
\hline \multicolumn{2}{|l|}{ Type of surgery for LR } \\
\hline Mastectomy & 45 \\
\hline Wide local excision & 15 \\
\hline Lumpectomy & 5 \\
\hline No & 5 \\
\hline
\end{tabular}


One patient, who presented without clinically suspicious findings in the axilla and refused to undergo surgery of the axilla, received locoregional radiotherapy without any surgical intervention. Nineteen patients received no treatment of the axilla. Of those, 9 were older than 70 years of age at diagnosis of LR. Distant metastases were detected simultaneously with local recurrence in three of them. In one, ALND was attempted, but was not successful because of fibrosis, probably originated at the time of the primary tumour.

Table 2 Overview of different treatment strategies of the axilla in 70 patients with local recurrence and a negative sentinel lymph node biopsy (SNB) at the time of diagnosis of the primary tumour.

\begin{tabular}{|c|c|c|c|c|c|}
\hline & ALND & $\begin{array}{l}\text { SNB } \\
\text { alone }\end{array}$ & $\begin{array}{l}\text { SNB + } \\
\text { ALND }\end{array}$ & $\begin{array}{l}\text { Axillary RT } \\
\text { alone }\end{array}$ & $\begin{array}{l}\text { No } \\
\text { treatment }\end{array}$ \\
\hline Total number & 37 & 5 & 8 & 1 & 19 \\
\hline \multicolumn{6}{|l|}{ Age at diagnosis of $L R, y r s$. } \\
\hline$<50 \mathrm{yrs}$ & 13 & 1 & 2 & 0 & 4 \\
\hline $50-69 \mathrm{yrs}$ & & 2 & 5 & 0 & 6 \\
\hline$\geq 70 \mathrm{yrs}$ & 7 & 2 & 1 & 1 & 9 \\
\hline \multicolumn{6}{|l|}{ Surgical treatment of primary tumour } \\
\hline BCT & 31 & 5 & 7 & 0 & 9 \\
\hline Mastectomy & 6 & 0 & 1 & 1 & 10 \\
\hline \multicolumn{6}{|l|}{ Interval between primary tumour and LR } \\
\hline$\leq 36$ months & 18 & 1 & 2 & 1 & 15 \\
\hline$>36$ months & 19 & 4 & 6 & 1 & 4 \\
\hline \multicolumn{6}{|l|}{$\begin{array}{l}\text { Clinically suspicious findings in axilla at } \\
\text { time of diagnosis } L R^{*}\end{array}$} \\
\hline Yes & 6 & 0 & 0 & 0 & 1 \\
\hline No & 31 & 5 & 8 & 1 & 18 \\
\hline \multicolumn{6}{|l|}{ Pathological nodal status at time of LR } \\
\hline No & 26 & 3 & 6 & & \\
\hline $\mathrm{N}_{1}$ & 5 & o & 1 & & \\
\hline$>\mathrm{N}_{1}$ & 5 & 0 & 1 & & \\
\hline Unknown & 1 & 2 & 0 & 1 & 19 \\
\hline \multicolumn{6}{|l|}{ Radiotherapy axilla at time of $L R$} \\
\hline Yes & 9 & 0 & 1 & 1 & 0 \\
\hline No & 28 & 5 & 7 & 0 & 19 \\
\hline \multicolumn{6}{|l|}{ Systemic treatment for LR } \\
\hline Chemotherapy & 9 & 0 & 1 & 0 & 2 \\
\hline Hormonal therapy & 17 & 2 & 2 & 0 & 10 \\
\hline Chemo- and hormonal therapy & 1 & 0 & 1 & 1 & 2 \\
\hline No & 10 & 3 & 3 & 0 & 5 \\
\hline \multicolumn{6}{|l|}{ Distant metastasis after LR } \\
\hline No & 29 & 4 & 8 & 0 & 14 \\
\hline$\leq 3$ months after LR & 1 & 1 & 0 & 0 & 3 \\
\hline 4 months -24 after LR & 6 & o & 0 & 1 & 1 \\
\hline$\geq 24$ months after $L R$ & 1 & 0 & 0 & 0 & 1 \\
\hline
\end{tabular}

RT: radiotherapy; LR: local recurrence

* Clinically suspicious findings after physical examination, ultrasound or aspiration cytology 


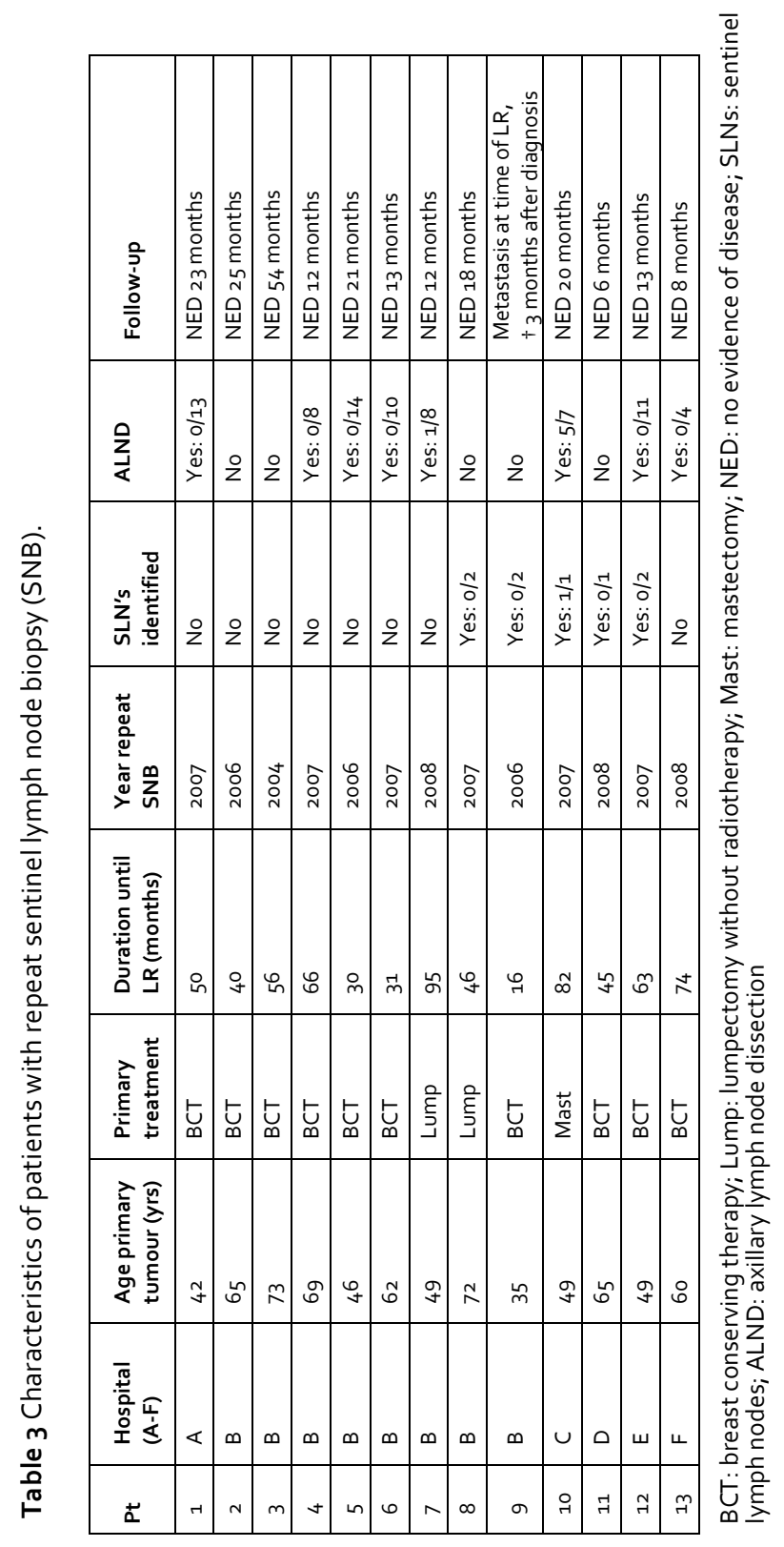




\section{Findings of axillary staging}

Pre-operative staging of the axilla by using ultrasound was performed in 14 patients and 5 of them had suspicious findings. Two other patients had suspicious findings in the axilla at clinical examination and one at both clinical examination and ultrasound. All 7 patients with suspicious findings underwent ALND, except for one patient, who already had distant metastasis at time of diagnosis of LR. Positive lymph nodes were found in 3 of the patients who underwent ALND. Overall, positive lymph nodes were detected in 13 of the 50 patients who underwent axillary lymph node staging, either by SNB or ALND.

\section{Follow-up}

The median length of follow-up of the 70 patients following their diagnosis of LR was 24 months (range 2-81 months). During this follow-up period one patient developed an axillary recurrence. This was the patient who refused to undergo ALND but was given locoregional radiotherapy instead. Distant metastases occurred in 15 patients. In 5 patients distant metastases were discovered at the time of local recurrence. Seven patients died from breast cancer, after a median follow-up time of 34 months (range 3-42 months) after diagnosis of LR.

\section{Discussion}

Our results show that, in the absence of guidelines, different treatment strategies are currently being used for patients with LR of the breast or chest wall after an initial negative SNB, ranging from second SNB and ALND with or without locoregional radiotherapy to no treatment at all. Despite the relatively short follow up, the size of our patient series is quite unique and clearly demonstrates the need for consensus in the management of the axilla at diagnosis of LR of the breast or chest wall.

\section{Reasons to stage the axilla}

In our study 13 of the 50 patients who underwent axillary staging appeared to have positive lymph nodes. This is only slightly lower than the percentage of patients showing positive axillary lymph nodes at the time of diagnosis of the primary tumour ${ }^{9,10}$, for whom there is no discussion about the value of axillary staging. To decide if axillary staging should also be a routine procedure in patients with local recurrence following previous negative SNB, we must first consider why staging is done.

Staging can provide useful prognostic information, which may help to decide about the need for systemic treatment. In case of a positive oestrogen and/or progesterone receptor status however, patients with local recurrence are candidates for hormonal treatment anyway, irrespective of their axillary nodal status. This decision is supported by 
results from a randomized controlled trial, which showed an increase of 5-year diseasefree survival for patients with local recurrence treated with tamoxifen compared to observation alone (Borner 1994) ${ }^{11}$. Until now, the effectiveness of chemotherapy in patients with local recurrence has remained unclear ${ }^{12,13}$, and a randomized study is ongoing to determine the value of chemotherapy in this setting ${ }^{14}$. So, at this moment, the possible need for adjuvant systemic treatment is not a convincing reason to re-stage the axilla in patients with local recurrence.

The second reason to treat the axilla is to improve locoregional disease control. Several trials studying the effects of additional locoregional therapy in patients with high-risk breast cancer have shown an improvement in survival, together with a decrease in the risk of locoregional recurrences ${ }^{15-18}$. So, the primary reason to re-stage the axilla in patients with local recurrence is to improve locoregional disease control, which in turn could contribute to the reduction of breast cancer mortality.

\section{Axillary staging in the elderly}

Almost half of the patients not receiving any axillary treatment at time of $L R$ were older than 70 years of age. Different opinions exist about the influence of age on the need to perform axillary surgery at time of breast cancer. Several randomized trials compared ALND with no ALND in elderly women with oestrogen-receptor-positive and clinically node-negative primary breast carcinoma. There were no differences in axillary recurrence rate, distant metastases or survival after 5 to 15 years of follow up ${ }^{19,20}$. Furthermore, ALND does not usually affect systemic treatment choice in the elderly ${ }^{21}$. This might implicate that it is appropriate to omit axillary staging in the majority of elderly patients, especially in those with a proven receptor-positive tumour.

\section{Axillary dissection versus sentinel node biopsy}

Once the decision to re-stage the axilla has been made, the next question is how this should be done. ALND is generally considered a safe procedure, but it is also associated with significant morbidity. Up to $50 \%$ of the patients undergoing ALND have been reported to suffer from complications, such as seroma formation, lymphedema and shoulder dysfunction with a subsequent negative impact on quality of life ${ }^{22}$. SNB is associated with a significant reduction in physical and psychological morbidity, as compared to $\mathrm{ALND}^{23}$. For patients with primary breast cancer and clinically negative lymph nodes SNB has been proven to be a safe and valid alternative to ALND. However, in patients with LR after negative SNB at time of primary tumour adequate lymph drainage might be obscured by previous surgery and radiotherapy, and for them the role of repeat SNB is not clear yet. In our study a SLN was identified in only 5 of 13 patients undergoing repeat SNB. Other studies have reported much higher identification rates, ranging from $65-97 \%^{24-26}$. This difference might be due to sampling error because of the 
small number of patients undergoing SNB in our study. It could also be related to the level of experience of the various surgeons from the different hospitals or to different techniques used for injection of radioactive material and blue dye $\mathrm{e}^{27}$.

\section{Pre-operative ultrasound of the axilla}

Only 7 of 70 patients had clinically suspicious findings in the axilla. A remarkable finding was that the large majority of the patients did not undergo standard axillary ultrasound investigation. In the absence of radiology reports we relied on information provided by surgeons and radiotherapists and therefore some underreporting may have resulted. In the latest version of the Dutch breast cancer guidelines, ultrasound of the axilla is recommended for all patients with pathologically confirmed breast carcinoma ${ }^{8}$. We cannot think of any good reason not to perform a routine ultrasound of the axilla as part of a re-staging procedure in patients with a LR.

\section{Conclusion}

The rate of positive axillary lymph nodes among patients with local recurrence after breast surgery and negative SNB is too high to be ignored. Therefore repeat surgical staging is appropriate in these patients. Whether SNB is accurate enough in these patients has to be evaluated in further, larger studies. 


\section{References}

1. Roumen RM, Kuijt GP, Liem IH, van Beek MW. Treatment of 100 patients with sentinel nodenegative breast cancer without further axillary dissection. Br J Surg 2001;88:1639-1643

2. Naik AM, Fey J, Gemignani M, et al. The risk of axillary relapse after sentinel node biopsy for breast cancer is comparable with that of axillary lymph node dissection: a follow-up study of 4008 procedures. Ann Surg 2004;240:462-468

3. Veronesi U, Paganelli G, Viale G, et al. Sentinel-lymph-node biopsy as a staging procedure in breast cancer: update of a randomised controlled study. Lancet Oncol 2006;7:983-990

4. Voogd AC, Nielsen $M$, Peterse $J L$, et al. Differences in risk factors for local and distant recurrence after breast-conserving therapy of mastectomy for stage I and II breast cancer: pooled results of two large European randomized trials. J Clin Oncol 2001;15:1688-1697

5. Jacobsen JA, Danforth DN, Cowan KH, et al. Ten-year results of a comparison of conservation with mastectomy in the treatment of stage I and II breast cancer. N Engl J Med 1995;332:907911

6. Roumen RMH, Kuijt GP, Liem IH. Lymphatic mapping and sentinel node harvesting in patients with recurrent breast cancer. Eur J Surg Oncol 2006;32:1076-1081

7. Port ER, Garcia-Etienne CA, Park J, Fey J, Borgen PI, Cody HS zrd. Reoperative sentinel lymph node biopsy: a new frontier in the management of ipsilateral breast tumor recurrence. Ann Surg Oncol 2007;14:2209-2214

8. Oncoline Oncological Guidelines (www.oncoline.nl). Accessed June 82009

9. Voogd $A C$, van Tienhoven $G$, Peterse $H L$, et al. Local recurrence after breast conservation therapy for early stage breast carcinoma: detection, treatment, and outcome in 266 patients. Dutch Study Group on Local Recurrence after Breast Conservation (BORST). Cancer 1999;85;437-446

10. Giuliano AE, Barth AM, Spivack B, Beitsch PD, Evans SW. Incidence and predictors of axillary metastasis in T1 carcinoma of the breast. J Am Coll Surg 1996;183:262-264

11. Borner $M$, Bacchi $M$, Goldhirsch $A$, et al. First isolated locoregional recurrence following mastectomy for breast cancer: results of a phase III multicenter study comparing systemic treatment with observation after excision and radiation. Swiss Group for Clinical Cancer Research. J Clin Oncol 1994;12:2071-2077

12. Haylock BJ, Coppin CM, Jackson J, Basco VE, Wilson KS. Locoregional first recurrence after mastectomy: prospective cohort studies with and without immediate chemotherapy. Int J Radiat Oncol Biol Phys 2000;46:355-362

13. Rauschecker $\mathrm{H}$, Clarke M, Gatzemeier, Recht A. Systemic therapy for treating locoregional recurrence in women with breast cancer. Cochrane Database Syst Rev 2001;4

14. Aebi S, Wapnir I. A randomized clinical trial of adjuvant chemotherapy for radically resected loco-regional relapse of breast cancer. IBCSG 27-02 / BIG 1-02 (BOOG 2003-02)

15. Overgaard $M$, Jensen $M B$, Overgaard J, et al. Postoperative radiotherapy in high-risk postmenopausal breast-cancer patients given adjuvant tamoxifen: Danish Breast Cancer Cooperative Group DBCG 82c randomised trial. Lancet 1999;353:1641-1648

16. Overgaard $M$, Hansen PS, Overgaard J, et al. Postoperative radiotherapy in high-risk premenopausal women with breast cancer who receive adjuvant chemotherapy. N Engl J Med 1997;337:949-955

17. Ragaz J, Olivotto IA, Spinelli JJ, et al. Locoregional radiation therapy in patients with high-risk breast cancer receiving adjuvant chemotherapy: 20-year result of the British Columbia randomized trial. J Natl Cancer Inst 2005;19:116-126 
18. Orr RK. The impact of prophylactic axillary node dissection on breast cancer survival - a Bayesian meta-analysis. Ann Surg Oncol 1999;6:109-116

19. Martelli G, Miceli R, Costa A, et al. Elderly breast cancer patients treated by conservative surgery alone plus adjuvant tamoxifen: fifteen-year results of a prospective study. Cancer 2008;112:481-488

20. Hughes KS, Schnaper LA, Berry $D$, et al. Lumpectomy plus tamoxifen with or without irradiation in women 70 years of age or older with early breast cancer. $N$ Engl J Med 2004;351:971-977

21. Wildiers $\mathrm{H}$, Kunkler I, Biganzolli $\mathrm{L}$, et al. Management of breast cancer in elderly individuals: recommendations of the International Society of Geriatric Oncology. Lancet Oncol 2007;8:1101-1115

22. Ververs $J M$, Roumen RM, Vingerhoets $A J$, et al. Risk, severity and predictors of physical and psychological morbidity after axillary lymph node dissection for breast cancer. Eur J Cancer 2001;37:991-999

23. Schijven MP, Vingerhoets AJ, Rutten $\mathrm{HJ}$, et al. Comparison of morbidity between axillary lymph node dissection and sentinel node biopsy. Eur J Surg Oncol 2003;29:341-350

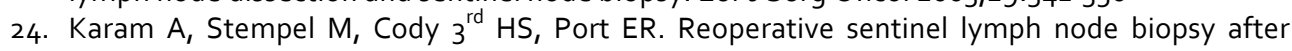
previous mastectomy. J Am Coll Surg 2008;207:543-548

25. Cox CE, Furman BT, Kiluk JV, et al. Use of reoperative sentinel lymph node biopsy in breast cancer patients. J Am Coll Surg 2008;207:57-61

26. Intra M, Trifirò G, Galimberti V, Gentilini O, Rotmensz N, Veronesi P. Second axillary sentinel node biopsy for ipsilateral breast tumour recurrence. Br J Surg 2007;94:1216-1219

27. Povoski SP, Olsen JO, Young DC, et al. Prospective randomized clinical trial comparing intradermal, intraparenchymal, and subareolar injection routes for sentinel node mapping and biopsy in breast cancer. Ann Surg Oncol 2006;13:1412-1421 


\section{Chapter 7}

\section{Repeat sentinel node biopsy in patients with locally recurrent breast cancer: A systematic review and meta-analysis of the literature}

A.J.G. Maaskant-Braat

A.C. Voogd

R.M.H. Roumen

G.A.P. Nieuwenhuijzen

Breast Cancer Res Treat 2013;138:13-20 


\begin{abstract}
Background Axillary staging in patients with locally recurrent breast cancer is important for obtaining locoregional control and predicting prognosis. The aim of the present study is to determine technical feasibility, validity, aberrant drainage patterns and clinical consequences of performing repeat sentinel node biopsy (SNB) in these patients.
\end{abstract}

Methods We performed a systematic review and meta-analysis of the literature and included all studies on repeat SNB in locally recurrent breast cancer.

Results A total of 692 patients were described, 301 after a previous SNB, 361 after a previous axillary lymph node dissection (ALND) and 30 with no previous axillary surgery. Sentinel node identification was successful in 452 of the 692 patients (65.3\%), which was significantly higher in patients who had undergone previous SNB compared to previous ALND (81.0 vs. 52.2\%) ( $P<0.0001)$. In 175 of 405 patients with successful lymphatic mapping aberrant drainage pathways were visualized (43.2\%), which were seen more frequently after previous ALND than after previous SNB (69.2\% vs. $17.4 \%)(P<0.0001)$. In $19.2 \%$ of the patients the sentinel node was tumour positive and $27.5 \%$ of these metastases were found in aberrant lymph drainage basins. Overall, 213 patients could be spared an ALND and in $17.9 \%$ of the patients the information derived from the repeat SNB led to a change in adjuvant radiotherapy or systemic treatment plans. The procedure had a false-negative rate of $0.2 \%$.

Conclusion Repeat SNB is technically feasible and accurate. Next to sparing patients an unnecessary ALND, the information can lead to a change in adjuvant treatment strategy. 


\section{Introduction}

The sentinel node biopsy (SNB) has become the standard of care for axillary staging in patients with clinically node-negative primary invasive breast cancer ${ }^{1}$. It has a high identification rate, an acceptable average false-negative rate of 7.3\% (range 0-29\%) and a very low axillary recurrence rate when the sentinel node contains no metastases ${ }^{2-5}$.

Unfortunately, approximately 5 to $10 \%$ of breast cancer patients develop a local recurrence in the breast or chest wall ${ }^{6,7}$. In accordance with primary breast cancer, axillary staging in case of locally recurrent breast cancer could be of benefit to improve locoregional control and may play a role in deciding whether or not adjuvant treatment could be of benefit ${ }^{8,9}$. For these reasons it seems sensible to perform axillary staging in case of locally recurrent breast cancer, despite the absence of guidelines on this topic. Until recently, this meant that patients with recurrent breast cancer and a previous negative sentinel node biopsy most probably would receive an axillary lymph node dissection (ALND) and that patients with a previous ALND would receive no additional axillary staging.

Over the past years the concept of the so-called "repeat sentinel node biopsy" has emerged. An increasing number of patients with locally recurrent breast cancer after previous axillary staging undergo repeat lymphatic mapping and, in case of visualized lymphatic drainage, a repeat SNB is performed. Patients who had a previous negative SNB could be spared an axillary lymph node dissection (ALND) and its associated morbidity assuming that performing the repeat SNB is both feasible and accurate ${ }^{10}$. Another issue to address is the possible alteration of lymphatic drainage pathways due to former surgery and/or radiotherapy. Both in the group of patients after a previous SNB and in the group who has previously been treated with ALND repeat SNB could reveal these aberrant drainage pathways and improve staging by identifying the new true sentinel node for this recurrent tumour.

In this systematic review and meta-analysis of the available literature we identify and describe all available knowledge on the concept of repeat sentinel node biopsy in patients with locally recurrent breast cancer with respect to identification rate, the accuracy of predicting sentinel node pathology, aberrant drainage patterns and the implications for adjuvant treatment.

\section{Methods}

We conducted a literature search in PubMed and included all original articles, case reports and abstracts of studies on patients with repeat SNB for locally recurrent breast cancer without clinical evidence of lymphatic metastases, irrespective of number of patients included and quality and completeness of reported data. We only included articles 
published in the English language. We used the following search terms: "recurrent breast cancer" AND "sentinel lymph node biopsy" and identified 55 articles of which 18 articles were regarded eligible after evaluating title and abstract. Also, a separate search using the following search terms was performed: ("sentinel lymph node biopsy" OR "lymphatic mapping") AND ("repeat" OR "re-operative") and 48 articles were found of which an additional 2 were included. Ultimately, this search strategy resulted in the identification of 20 eligible articles. Furthermore, we analysed "related citations" and reference lists and another 6 articles and one abstract on the subject were identified. The final search was performed on March $22^{\text {th }}, 2012$.

The following information was derived from the selected articles: 1) number of included patients with locally recurrent breast cancer, 2) previous axillary procedure, being either SNB, ALND or none, 3) previous breast treatment, being either lumpectomy/breast conserving treatment (BCT) or mastectomy, 4) lymphatic mapping technique, 5) lymphatic mapping and sentinel node biopsy success rate, 6) histopathology outcome, 7) aberrant lymph drainage pathways, being lymphoscintigraphic drainage patterns outside the ipsilateral axilla 8) validity of repeat sentinel node biopsy and axillary recurrence rates, 9) change of adjuvant treatment strategy.

The available data were pooled to calculate weighed estimates and corresponding 95\% confidence intervals $(\mathrm{Cl})$ of the success rates of lymphatic mapping and sentinel node biopsy and of the percentage of aberrant drainage patterns. The data were stratified according to previous axillary procedure (SNB, ALND or no axillary staging) and previous breast treatment (lumpectomy/BCT or mastectomy) and these patients were compared with respect to identification rate and aberrant drainage percentage by using the Chisquare test. $\mathrm{P}$-values $<0.05$ were considered statistically significant.

\section{Results}

A total of 26 articles and case reports and 1 published abstract on repeat SNB in case of locally recurrent breast cancer were identified and included in this systematic review of the literature, published from the year 2002 to 2011 . Two studies were updates of previously published studies, comprising the same study group. In these cases the earliest studies were excluded ${ }^{11,12}$. Ultimately 25 studies were included in this systematic review of the literature ${ }^{13-37}$.

A total of 692 patients with locally recurrent breast cancer were described, ranging from one to 117 patients per study. A previous SNB was performed in 301 patients, 361 patients had undergone a previous ALND and 30 patients had undergone no axillary treatment in the past. In 24 studies previous breast treatment was described (636 patients), being 
either lumpectomy alone or breast conserving treatment (BCT) including radiotherapy in 574 patients and mastectomy in 62 patients (Table 1 ).

Table 1 Number of patients with repeat sentinel node biopsy for locally recurrent breast cancer stratified according to previous axillary procedure and previous breast treatment.

\begin{tabular}{|c|c|c|c|c|c|c|c|}
\hline \multirow[t]{2}{*}{ Author } & \multirow[t]{2}{*}{ Year } & \multirow[t]{2}{*}{$\mathbf{N}$} & \multicolumn{3}{|c|}{ Axillary procedure } & \multicolumn{2}{|c|}{ Breast treatment } \\
\hline & & & SNB & ALND & None & BCT/Lump & Mast \\
\hline $\operatorname{Lim}^{13}$ & 2004 & 1 & o & 1 & 0 & o & 1 \\
\hline Sood $^{14}$ & 2004 & 3 & 0 & 3 & 0 & 3 & 0 \\
\hline Agarwal $^{15}$ & 2005 & 2 & 0 & 2 & 0 & 2 & o \\
\hline $\operatorname{Dinan}^{16}$ & 2005 & 16 & 2 & 14 & 0 & 16 & 0 \\
\hline Tada $^{17}$ & 2005 & 3 & 0 & 2 & 1 & 3 & o \\
\hline Boughey $^{18}$ & 2006 & 21 & 5 & 12 & 4 & 17 & 4 \\
\hline Jackson $^{19}$ & 2006 & 1 & 1 & 0 & 0 & 1 & 0 \\
\hline Newman $^{20}$ & 2006 & 10 & 1 & 7 & 2 & 10 & 0 \\
\hline Roumen $^{21}$ & 2006 & 12 & 2 & 10 & 0 & 10 & 2 \\
\hline Taback $^{22}$ & 2006 & 15 & 6 & 9 & 0 & 15 & 0 \\
\hline Barone $^{23}$ & 2007 & 19 & 7 & 12 & 0 & 19 & 0 \\
\hline Intra $^{24}$ & 2007 & 65 & 65 & 0 & 0 & 65 & 0 \\
\hline Port $^{25}$ & 2007 & 117 & 54 & 63 & 0 & 117 & 0 \\
\hline Axelsson $^{26}$ & 2008 & 47 & 1 & 43 & 3 & 33 & 14 \\
\hline $\operatorname{Cox}^{27}$ & 2008 & 56 & 56 & 0 & 0 & NR & NR \\
\hline Karam $^{28}$ & 2008 & 20 & 4 & 11 & 5 & o & 20 \\
\hline Koizumi $^{29}$ & 2008 & 31 & 3 & 16 & 12 & 31 & 0 \\
\hline Schrenk $^{30}$ & 2008 & 30 & 15 & 13 & 2 & 29 & 1 \\
\hline Tasevski $^{31}$ & 2009 & 18 & 3 & 15 & 0 & 16 & 2 \\
\hline Van der Ploeg ${ }^{32}$ & 2010 & 48 & 36 & 12 & 0 & 48 & 0 \\
\hline Vicente $^{33}$ & 2010 & 1 & 0 & 0 & 1 & 0 & 1 \\
\hline Yamashita $^{34}$ & 2011 & 1 & 0 & 1 & 0 & 1 & 0 \\
\hline Hattori $^{35}$ & 2011 & 1 & 0 & 1 & 0 & 1 & 0 \\
\hline $\mathrm{Kaur}^{36}$ & 2011 & 45 & 0 & 45 & 0 & 45 & o \\
\hline Maaskant-Braat $^{37}$ & 2011 & 109 & 40 & 69 & 0 & 92 & 17 \\
\hline $\begin{array}{l}\text { Total } \\
\text { Total-NR } \\
\text { Percentage (\%) }\end{array}$ & & 692 & $\begin{array}{l}301 \\
692 \\
43.5\end{array}$ & $\begin{array}{l}61 \\
692 \\
52.2\end{array}$ & $\begin{array}{c}30 \\
692 \\
4 \cdot 3\end{array}$ & $\begin{array}{l}574 \\
636 \\
90.3\end{array}$ & $\begin{array}{c}62 \\
636 \\
9.8\end{array}$ \\
\hline
\end{tabular}

N: Number; LM: Lymphatic mapping; SNB: Sentinel node biopsy; ALND: Axillary lymph node dissection; BCT: Breast-conserving therapy; Lump: Lumpectomy; Mast: mastectomy; NR: Not recorded

\section{Lymphatic mapping technique}

Lymphatic mapping was performed in 585 of 692 patients (84.5\%). Lymphatic mapping technique varied widely between the reported studies (Table 2). Injection of the radiotracer was located intra-/subdermally near the tumour in 6 studies, subareolar in 2 studies, deep in the parenchymal or scar tissue around the recurrent tumour in 7 studies and a combination of these superficial and deep injection techniques was used in 10 studies. The amount of radiotracer administered also varied between studies, from 3,7- 
$122 \mathrm{MBq}$ and $0.1-4.0 \mathrm{mCi}$ (partly dependent on a one or two-day lymphoscintigraphy protocol). In most studies a dual mapping method was used, so blue dye was injected preoperatively next to the already administered radiotracer. If reported, the time interval between injection of the radiotracer and obtaining the images varied between 1-240 minutes.

\section{Lymphatic mapping and sentinel node identification rate}

The success rates of identifying a sentinel node by repeat lymphatic mapping according to previous axillary procedure and previous breast treatment are shown in Tables 3 and 4 . Overall, lymphatic drainage was successful in 405 of 572 patients (70.8\%) (95\% Cl: 66.974.5). Lymphatic drainage was reported in 179 patients who had undergone SNB before and was visualized in 148 of them (82.7\%) (95\% Cl: 76.2-87.8). Among patients with previous ALND lymphatic drainage was reported in 197 and visualized in 139 of them (70.6\%) (95\% Cl: 63.6-76.7), which is significantly lower than after a previous SNB $(\mathrm{P}<0.01)$. Additionally, lymphatic drainage was reported in 22 patients after no previous axillary procedure and was observed in 21 of them (95.5\%) (95\% Cl: 75.1-99.8). Stratified according to previous breast treatment, lymphatic mapping was recorded in 425 patients after previous BCT or lumpectomy and was successful in 309 of them $(72.7 \%)(95 \% \mathrm{Cl}$ : 68.2-76.8). It was recorded in 41 patients after a previous mastectomy and successful in 31 of them (75.6\%) (95\% Cl: 59.4-87.1) ( $\mathrm{P}=\mathrm{NS})$.

A sentinel node was surgically retrieved in 243 of 300 described patients after a previous SNB procedure (81.0\%) (95\% Cl: 76.0-85.2) and in 166 of 318 described patients who had previously undergone an ALND (52.2\%) (95\% Cl: 46.6-57.8) ( $\mathrm{P}<0.0001)$ (Table 3). Additionally, a sentinel node was retrieved in 23 of the 27 described patients after no previous axillary procedure (85.2\%) (95\% Cl: 65.4-95.1). Stratified according to previous breast treatment, repeat SNB success rate was recorded in 496 patients after previous BCT or lumpectomy and successful in 325 of them $(65.5 \%)(95 \% \mathrm{Cl}: 61.1-69.7)$ and it was recorded in 45 patients after a previous mastectomy and successful in 31 of them (68.9\%) (95\% Cl: 53.2-81.4) (P=NS) (Table 4). 
Table $\mathbf{2}$ Lymphatic mapping technique of 25 studies on patients with repeat sentinel node biopsy for locally recurrent breast cancer.

\begin{tabular}{|c|c|c|c|c|c|c|}
\hline \multirow[t]{2}{*}{ Author } & \multirow[t]{2}{*}{ Year } & \multirow[t]{2}{*}{$\mathbf{N}$} & \multicolumn{4}{|c|}{ Lymphatic mapping number and technique } \\
\hline & & & $\mathbf{N}$ & Injection location & $\begin{array}{l}\text { Radiotracer } \\
(\mathrm{mCi} / \mathrm{MBq})\end{array}$ & $\begin{array}{c}\text { Time to } \\
\text { scan (min) }\end{array}$ \\
\hline $\operatorname{Lim}^{13}$ & 2004 & 1 & 1 & Peritumoral, intradermal & NR & NR \\
\hline Sood $^{14}$ & 2004 & 3 & 3 & Intradermal & $3,7-30 \mathrm{MBq}$ & NR \\
\hline Agarwal $^{15}$ & 2005 & 2 & 2 & Intraparenchymal, subareolar & $1.0 \mathrm{mCi}$ & 45 \\
\hline $\operatorname{Dinan}^{16}$ & 2005 & 16 & 16 & $\begin{array}{c}\text { Intraparenchymal, subdermal, } \\
\text { subareolar }\end{array}$ & $4-45 \mathrm{MBq}$ & NR \\
\hline $\operatorname{Tada}^{17}$ & 2005 & 3 & 3 & Subdermal & NR & 60 \\
\hline Boughey $^{18}$ & 2006 & 21 & 13 & $\begin{array}{l}\text { Intraparenchymal/ } \\
\text { peritumoral }\end{array}$ & $0.5-2.5 \mathrm{mCi}$ & NR \\
\hline Jackson $^{19}$ & 2006 & 1 & 1 & Subareolar & $1 \mathrm{mCi}$ & NR \\
\hline Newman $^{20}$ & 2006 & 10 & 9 & Subareolar & $4 \mathrm{mCi}$ & NR \\
\hline Roumen $^{21}$ & 2006 & 12 & 12 & $\begin{array}{l}\text { Intraparenchymal/ } \\
\text { peritumoral }\end{array}$ & $120 \mathrm{MBq}$ & NR \\
\hline Taback $^{22}$ & 2006 & 15 & 15 & Intraparenchymal & $0.5 \mathrm{mCi}$ & $13-240$ \\
\hline Barone $^{23}$ & 2007 & 19 & o & Intraparenchymal, subareolar & NR & NR \\
\hline $\operatorname{lntra}^{24}$ & 2007 & 65 & 65 & $\begin{array}{c}\text { Intraparenchymal, subdermal, } \\
\text { subareolar }\end{array}$ & NR & NR \\
\hline Port $^{25}$ & 2007 & 117 & 114 & Intradermal & $0.1-0.5 \mathrm{mCi}$ & $30-120$ \\
\hline Axelsson $^{26}$ & 2008 & 47 & 47 & Sub-, intradermal & $20-122 \mathrm{MBq}$ & $1+120-180$ \\
\hline $\operatorname{Cox}^{27}$ & 2008 & 56 & 13 & Intraparenchymal, subareolar & NR & NR \\
\hline Karam $^{28}$ & 2008 & 20 & 20 & Intradermal & $0.1-0.5 \mathrm{mCi}$ & NR \\
\hline Koizumi $^{29}$ & 2008 & 31 & 31 & Intraparenchymal, intradermal & $60 \mathrm{MBq}$ & $>60$ \\
\hline Schrenk $^{30}$ & 2008 & 30 & 30 & Intraparenchymal & $10-40 \mathrm{MBq}$ & NR \\
\hline Tasevski $^{31}$ & 2009 & 18 & 16 & $\begin{array}{c}\text { Intraparenchymal, subdermal, } \\
\text { subareolar }\end{array}$ & NR & $30-120$ \\
\hline Van der Ploeg ${ }^{32}$ & 2010 & 48 & 48 & Intraparenchymal & $120 \mathrm{MBq}$ & $\begin{array}{c}10+120+24 \\
0\end{array}$ \\
\hline Vicente $^{33}$ & 2010 & 1 & 1 & Peritumoral & $0.25 \mathrm{mCi}$ & $1+15$ \\
\hline Yamashita $^{34}$ & 2011 & 1 & 1 & Subdermal & $2 \mathrm{mCi}$ & 240 \\
\hline Hattori ${ }^{35}$ & 2011 & 1 & 1 & Intraparenchymal & $56 \mathrm{MBq}$ & 60 \\
\hline $\mathrm{Kaur}^{36}$ & 2011 & 45 & 14 & Intraparenchymal, subareolar & NR & NR \\
\hline Maaskant-Braat ${ }^{37}$ & 2011 & 109 & 109 & $\begin{array}{c}\text { Intraparenchymal/ } \\
\text { peritumoral, subareolar }\end{array}$ & NR & NR \\
\hline $\begin{array}{l}\text { Total } \\
\text { Percentage (\%) }\end{array}$ & & 692 & $\begin{array}{l}585 \\
84.5\end{array}$ & & & \\
\hline
\end{tabular}

N: Number; NR: Not recorded 
Table 3 Success rate of lymphatic mapping and sentinel node biopsy and risk of aberrant drainage in patients with locally recurrent breast cancer, stratified according to previous axillary procedure. Pooled data.

\begin{tabular}{|l|c|c|c|c|}
\hline \multirow{2}{*}{ Outcome } & \multicolumn{3}{|c|}{ Axillary procedure } & \\
\cline { 2 - 5 } & SNB & ALND & None & Overall \\
\hline Lymphatic mapping & & & & \\
Success rate, proportion & $148 / 179$ & $139 / 197$ & $21 / 22$ & $\mathbf{4 0 5 / 5 7 2}$ \\
Percentage (\%) & 82.7 & 70.6 & 95.5 & 70.8 \\
$95 \%$ Cl & $76.2-87.8$ & $63.6-76.7$ & $75.1-99.8$ & $\mathbf{6 6 . 9 - 7 4 . 5}$ \\
\hline Sentinel node biopsy & & & & \\
Success rate, proportion & $243 / 300$ & $166 / 318$ & $23 / 27$ & $\mathbf{4 5 2 / 6 9 2}$ \\
Percentage (\%) & 81.0 & 52.2 & 85.2 & $\mathbf{6 5 . 3}$ \\
$95 \%$ Cl & $76.0-85.2$ & $46.6-57.8$ & $65.4-95.1$ & $\mathbf{6 1 . 6 - 6 8 . 8}$ \\
\hline Aberrant drainage & & & & \\
Proportion & $37 / 144$ & $98 / 132$ & $5 / 17$ & $\mathbf{1 7 5 / 4 0 5}$ \\
Percentage (\%) & $\mathbf{2 5 . 7}$ & 74.2 & $\mathbf{2 9 . 4}$ & $\mathbf{4 3 . 2}$ \\
$95 \%$ Cl & $18.9-33.8$ & $65.8-81.3$ & $11.4-56.0$ & $\mathbf{3 8 . 4 - 4 8 . 2}$ \\
\hline
\end{tabular}

SNB: Sentinel node biopsy; ALND: Axillary lymph node dissection; Cl: Confidence interval

Table 4 Success rate of lymphatic mapping and sentinel node biopsy and risk of aberrant drainage in patients with locally recurrent breast cancer, stratified according to previous breast treatment. Pooled data.

\begin{tabular}{|l|c|c|c|}
\hline \multirow{2}{*}{ Outcome } & \multicolumn{2}{|c|}{ Breast treatment } & \\
\cline { 2 - 4 } & $\mathrm{BCT} /$ Lumpectomy & Mastectomy & Overall \\
\hline Lymphatic mapping & & & \\
Success rate, proportion & $309 / 425$ & $31 / 41$ & $\mathbf{4 0 5 / 5 7 2}$ \\
Percentage & 72.7 & 75.6 & $\mathbf{7 0 . 8}$ \\
$95 \% \mathrm{Cl}$ & $68.2-76.8$ & $59.4-87.1$ & $\mathbf{6 6 . 9}-\mathbf{7 4 . 5}$ \\
\hline Sentinel node biopsy & & & \\
Success rate, proportion & $325 / 496$ & $31 / 45$ & $\mathbf{4 5 2 / 6 9 2}$ \\
Percentage & $65 \cdot 5$ & 68.9 & $\mathbf{6 5 \cdot 3}$ \\
$95 \% \mathrm{Cl}$ & $61.1-69.7$ & $53.2-81.4$ & $\mathbf{6 1 . 6}-\mathbf{6 8 . 8}$ \\
\hline Aberrant drainage & & & $\mathbf{1 7 5 / 4 0 5}$ \\
Proportion & $124 / 309$ & $24 / 31$ & $\mathbf{4 3 . 2}$ \\
Percentage & 40.1 & 77.4 & $\mathbf{3 8 . 4 - 4 8 . 2}$ \\
$95 \% \mathrm{Cl}$ & $34.7-45.8$ & $58.5-89.7$ & \\
\hline
\end{tabular}

BCT: Breast-conserving therapy; $\mathrm{Cl}$ : Confidence interval 


\section{Histopathology outcome of repeat sentinel node biopsy}

In 87 of the 452 patients with a successful repeat SNB (micro)metastases were identified in the harvested sentinel node (19.2\%) (95\% Cl: 15.8-23.3); 15.2\% (95\% Cl: 11.1-20.5) after a previous SNB, $23.5 \%$ (95\% Cl: $17.4-30.8)$ after a previous ALND and 8.7\% (95\% Cl: 1.529.5) without a previous axillary procedure. The distinction between micro- and macrometastases was only made in 10 of the 21 studies in which metastases were found in the sentinel node(s). These 10 studies reported 36 nodal metastases, of which 12 micrometastases and 24 macrometastases.

Nineteen of the 69 metastases in which the location was described were found in aberrant lymph drainage basins (27.5\%) (95\% Cl: 17.8-39.8), being the contralateral axilla, internal mammary chain, periclavicular or interpectoral lymph node basins. Since exploration of extra-axillary lymph node basins was not always performed, this number could well be an underestimation of the actual situation.

\section{Aberrant lymph drainage pathways}

Detection of aberrant lymph drainage pathways outside of the ipsilateral axilla, stratified according to previous axillary procedure and previous breast treatment, is shown in Tables 3 and 4 . Aberrant lymph drainage pathways were reported in 24 of the 25 studies and were visualized in 175 of 405 patients with a successful lymphatic mapping (43.2\%) (95\% Cl: 38.4-48.2). In one patient the aberrant lymph drainage pattern was detected with use of the gamma-probe only, so without performing a preoperative lymphoscintigraphy.

Nineteen studies reported the success rate of lymphatic mapping and aberrant drainage percentage stratified according to previous axillary procedure and previous breast treatment. Aberrant drainage pathways were observed in $25.7 \%$ (95\% Cl: 18.9-33.8) of patients with a successful lymphatic mapping after a previous SNB and in $74.2 \%$ (95\% Cl: 65.8-81.3) of patients with a successful lymphatic mapping after a previous ALND, which was significantly more frequent $(\mathrm{P}<0.0001)$. Overall, aberrant drainage pathways were reported in $14.3 \%$ ( $95 \% \mathrm{Cl}: 10.6-18.9$ ) of patients after a previous SNB in total and in $32.7 \%$ (95\% Cl: $27.9-37.8)$ of patients after ALND in total $(\mathrm{P}<0.0001)$.

Stratified according to previous breast treatment, aberrant drainage pathways were observed in $40.1 \%$ (95\% Cl: $34.7-45.8)$ of patients with a successful lymphatic mapping procedure after a previous BCT or lumpectomy and in $77.4 \%$ (95\% Cl: $58.5-89.7)$ of patients with a successful lymphatic mapping procedure after a previous mastectomy $(\mathrm{P}<0.0001)$. Overall, aberrant drainage pathways were reported in $26.8 \%$ (95\% Cl: $23.0-$ 31.1) of patients after previous BCT or lumpectomy in total and in $57.8 \%$ ( $95 \% \mathrm{Cl}: 42.2$ 72.0) of patients after previous mastectomy in total $(P<0.0001)$.

The predominant aberrant drainage locations reported were the contralateral axilla $(34,3 \%)$ and the internal mammary chain (46.3\%). Additionally, drainage to supra- and 
infraclavicular sentinel nodes was reported (14.3\%) as well as to intramammary nodes (1.7\%), interpectoral nodes (2.3\%) and to supraclavicular and internal mammary nodes combined (1.1\%). Since it was not always standard to perform lymphoscintigraphy, the aberrant drainage percentage could in fact even be higher than already described. As reported earlier, 19 of the 69 metastases that were found on histopathology examination were located in these aberrant lymph drainage basins.

\section{Validity of repeat sentinel node biopsy}

A confirmation ipsilateral ALND was performed in 63 patients after a previous negative SNB and without metastases in the repeat sentinel node. Port et al. reported the identification of 2 additional non-sentinel node metastases. However, one of these metastases was identified on palpation and the other one was located in the internal mammary chain. Since palpation for enlarged and hardened axillary lymph nodes is an essential part of the sentinel node procedure and the other positive node was found outside of the ipsilateral axilla, these metastases may be considered as not being real false-negatives. Others reported finding no metastases on confirmation ipsilateral ALND. Axillary recurrence rates were reported in 13 of the 25 studies (a total of 422 patients) with a follow-up of 1-117 months. One axillary recurrence was reported after a negative repeat SNB (0.2\%) (95\% Cl: 0.0-1.5).

\section{Change of (adjuvant) treatment strategy}

In 310 patients with a relatively intact axillary lymph node basin (so after a previous SNB or no axillary surgery) SNB success and tumour positivity were reported and 213 of them had a successful repeat SNB that was tumour-negative $(68.7 \%)(95 \% \mathrm{Cl}: 63.2-73.8)$. These 213 patients could thus be spared the additional morbidity of an ALND. Since 63 of them had a confirmation ALND, 150 patients were actually spared an ipsilateral ALND. In addition, adjuvant treatment strategy could be altered as a result of information derived from the repeat SNB as well. Only 9 studies reported on the change of adjuvant treatment strategy. In 25 of these reported 239 patients (10.5\%) (95\% Cl: 7.0-15.2), or in 25 of the reported 140 patients with a successful repeat SNB (17.9\%) (95\% Cl: 12.1-25.4), adjuvant treatment plans were altered. In 14 patients the alteration was not further specified, in 6 patients a contralateral ALND was performed and in 7 patients adjuvant systemic therapy was administered because of a tumour-positive repeat sentinel node. Additionally, 2 patients also received adjuvant regional radiotherapy to the axillary region or internal mammary chain and supraclavicular region. 


\section{Discussion}

In this systematic review and meta-analysis of the literature we show that repeat SNB in patients with locally recurrent breast cancer has a high identification rate and an acceptable SNB success rate, especially after a previous negative SNB. It is very likely to find aberrant lymph drainage pathways, in particular after previous ALND, and in one out of 5 patients the sentinel node was tumour-positive. Nearly $70 \%$ of the patients could be spared additional morbidity in the form of an ALND and in one out of 5 patients adjuvant treatment plans were altered based on information derived from the SNB.

This systematic review of the literature consists of mostly small and retrospective studies in which quality of the reported data and lymphatic mapping technique varied widely. Nevertheless, the observed patterns are quite consistent and the total number of 692 described patients makes it reasonable to draw the above-mentioned conclusions.

Although the sentinel node identification rate of $65.3 \%$ is significantly lower than in SNB for primary breast cancer, it is still acceptable especially given its potential benefits, and supports at least an attempt to visualize a repeat sentinel node in patients with locally recurrent breast cancer. Identification rates could potentially improve as experience with lymphatic mapping in recurrent breast cancer increases. Also, time interval after the initial treatment could play a role in re-establishing lymphatic drainage and better patient selection could thus further increase this identification rate. Additionally, details of the lymphatic mapping technique, such as location of injection of the radiotracer, amount of radiotracer injected and time interval between injection and obtaining the lymphoscintigraphic images, could be tailored and improved potentially leading to a better repeat sentinel node identification rate. Little is known about the impact of lymphatic mapping technique on the performance of repeat SNB and, unfortunately, the studies mentioned in this review vary too much with respect to lymphatic mapping technique to draw any conclusions on this subject. A prospective randomized controlled trial comparing routes for lymphatic mapping after intradermal, intraparenchymal or subareolar injection in primary breast cancer showed significant differences in extraaxillary drainage between intraparenchymal and intradermal injection and between intraparenchymal and subareolar injection ${ }^{38}$. Unfortunately, due to diversity of used injection techniques (both superficial and deep techniques, in the area over or around the tumour and peri-areolarly) and use of different techniques within one described population in several articles, it was not possible to perform a reliable analysis on identification and aberrant drainage rate for the different breast injection techniques. In recurrent breast cancer we are especially interested in extra-axillary drainage and therefore, combined with the knowledge that the subareolar plexus might be damaged by surgery of radiotherapy, we postulate that the radiotracer should be injected deep in the parenchymal tissue around the recurrent tumour. 
A remarkable observation is the relatively high percentage of extra-axillary lymph drainage. According to Sappey's theory, lymphatic drainage of the breast occurs in a centripetal direction towards the subareolar plexus where pooling occurs before the lymph passes by specific channels to the axillary lymphatics 39,40 . Additionally, some lymph vessels pass over or through the breast parenchyma to the contralateral axilla or course beside the branches of the internal mammary vessels ${ }^{41}$. In recurrent breast cancer these lymphatic vessels may be disrupted and the anatomy of breast lymphatics may be changed due to surgery and/or radiotherapy resulting in aberrant lymph drainage patterns. These aberrant drainage pathways were indeed recorded in over one-third of the patients with a successful visualization of a repeat sentinel node and were seen significantly more frequent after a previous ALND than after a previous SNB. Remarkably, a quarter of the metastases that were found on histopathology examination were in fact located in these aberrant lymph drainage basins. This finding suggests that these extra-axillary drainage pathways do indeed represent clinically significant drainage. Additionally, the presence of these aberrant drainage pathways could shed new light on the phenomenon of contralateral axillary node metastasis after previous breast cancer treatment ${ }^{42}$. These contralateral metastases could well be a demonstration of regional lymph node metastasis through aberrant pathways instead of an occult contralateral breast cancer or even systemic disease.

An important issue to address is the clinical impact of the outcome of the repeat SNB. It may save the patient from unnecessary extended axillary surgery in case the sentinel node is tumour-negative and may play a role in locoregional disease control in case the sentinel node is tumour-positive. This is especially true when the tumour-positive sentinel node is found in an aberrant lymph drainage basin and would otherwise not be recognized. Staging could also be improved by identifying aberrant drainage pathways emerged due to prior surgery and/or radiotherapy leading to a possible alteration of adjuvant treatment strategies. Additional locoregional therapy in patients with high-risk breast cancer has proven to be effective in improving survival and decreasing the risk of local recurrences ${ }^{8,43}$. The question remains if implications for adjuvant systemic therapy are likely to be altered. Patients with breast cancer recurrence and a positive estrogen and/or progesterone receptor status are candidates for hormonal treatment irrespective of nodal status, since they show an increase of 5 -year disease free survival when treated with tamoxifen compared to observation alone ${ }^{44}$. With respect to chemotherapy, there is no consensus on the effectiveness in patients with locally recurrent breast cancer ${ }^{45,46}$. Nevertheless, the outcome of the repeat SNB may provide useful prognostic information and improve risk stratification and thus may play a role in making adjuvant systemic treatment decisions. Finally, residual disease in the ipsilateral axilla after a previous ALND could be detected with repeat SNB, possibly leading to better staging and locoregional control as well. Few studies in this review reported on the clinical implications of repeat 
SNB in patients with locally recurrent breast cancer, but still in one out of five patients adjuvant treatment plans were altered.

In conclusion, based on this systematic review of the literature in which 692 patients with locally recurrent breast cancer are described, repeat SNB is a technically feasible and safe procedure with a successful identification in two out of three patients, no additional metastases on confirmation ALND and a very low axillary recurrence rate. Aberrant drainage pathways were visualized in $43.2 \%$ of the patients. Next to unnecessary extensive axillary surgery that patients could be spared, the information derived from the repeat SNB led to a change in adjuvant treatment strategy in $17.9 \%$ of the patients. 


\section{References}

1. Nationaal Borstkanker Overleg Nederland (NABON) (2008). Richtlijn behandeling van het mammacarcinoom. Available: www.oncoline.nl [accessed 2 march 2012]

2. Kim T, Giuliano AE, Lyman GH. Lymphatic mapping and sentinel lymph node biopsy in earlystaged breast carcinoma, a metaanalysis. Cancer 2006;106:4-16

3. Naik AM, Fey J, Gemignani $M$, et al. The risk of axillary relapse after sentinel lymph node biopsy for breast cancer is comparable with that of axillary lymph node dissection, a follow-up study of 4008 procedures. Ann Surg 2004;240:462-471

4. Veronesi U, Paganelli G, Viale G et al. Sentinel-lymph-node biopsy as a staging procedure in breast cancer: update of a randomised controlled study. Lancet Oncol 2006;7:983-990

5. van der Ploeg IM, Nieweg OE, van Rijk MC, et al. Axillary recurrence after a tumour-negative sentinel node biopsy in breast cancer patients: A systematic review and meta-analysis of the literature. Eur J Surg Oncol 2008;34:1277-1284

6. Veronesi $U$, Cascinelli N, Mariani L, et al. Twenty-year follow-up of a randomized study comparing breast-conserving surgery with radical mastectomy for early breast cancer. $\mathrm{N}$ Engl J Med 2002;347:1227-1232

7. Voogd AC, Nielsen $M$, Peterse $J$, et al. Differences in risk factors for local and distant recurrence after breast-conserving therapy or mastectomy for stage I and II breast cancer: pooled results of two large European randomized trials. J Clin Oncol 2001;15:1688-1697

8. Overgaard M, Hansen PS, Overgaard J, et al. Postoperative radiotherapy in high-risk premenopausal women with breast cancer who receive adjuvant chemotherapy. $\mathrm{N}$ Engl J Med 1997;337:949-955

9. Orr RK. The impact of prophylactic axillary node dissection on breast cancer survival - a Bayesian meta-analysis. Ann Surg Oncol 1999;6:109-116

10. Schijven MP, Vingerhoets AJJM, Rutten HJT, Nieuwenhuijzen GAP, Roumen RMH, van Bussel $M E$, Voogd AC. Comparison of morbidity between axillary lymph node dissection and sentinel node biopsy. Eur J Surg Oncol 2003;29:341-350

11. Port ER, Fey J, Gemignani $M L$, et al. Reoperative sentinel lymph node biopsy: a new option for patients with primary or locally recurrent breast carcinoma. J Am Coll Surg 2002;195:167-172

12. Intra $M$, Trifirò $G$, Viale $G$, et al. Second biopsy of axillary sentinel lymph node for reappearing breast cancer after previous sentinel lymph node biopsy. Ann Surg Oncol 2005;12:895-899

13. Lim I, Shim J, Goyenechea M, Kim CK, Krynyckyi BR. Drainage across midline to sentinel nodes in the contralateral axilla in breast cancer. Clin Nucl Med 2004;29:346-347

14. Sood A, Youssef IM, Heiba SI, El-Zeftawy H, Axelrod D, Seigel B, Mills C, et al. Alternative lymphatic pathway after previous axillary node dissection in recurrent/primary breast cancer. Clin Nucl Med 2004;29:698-702

15. Agarwal A, Heron DE, Sumkin J, Falk J. Contralateral uptake and metastases in sentinel lymph node mapping for recurrent breast cancer. J Surg Oncol 2005;92:4-8

16. Dinan $D$, Nagle $C E$, Pettinga J. Lymphatic mapping and sentinel node biopsy in women with an ipsilateral second breast carcinoma and a history of breast and axillary surgery. Am J Surg 2005;190:614-617

17. Tada K, Nishimura S, Miyagi $Y$, et al. The effect of an old surgical scar on sentinel node mapping in patients with breast cancer: A report of five cases. Eur J Surg Oncol 2005;31:840844

18. Boughey JC, Ross MI, Babiera GV, et al. Sentinel lymph node surgery in locally recurrent breast cancer. Clin Breast Cancer 2006;7:248-253 
19. Jackson BM, Kim S, Davidson R, Schuchter L, Acs G, Czerniecki BJ. Repeat operative sentinel lymph node biopsy. Clin Breast Cancer 2006;6:530-532

20. Newman EA, Cimmino VM, Sabel MS, Diehl KM, Frey KA, Chang AE, Newman LA. Lymphatic mapping and sentinel lymph node biopsy for patients with local recurrence after breastconservation therapy. Ann Surg Oncol 2006;13:52-57

21. Roumen $\mathrm{RMH}$, Kuijt GP, Liem IH. Lymphatic mapping and sentinel node harvesting in patients with recurrent breast cancer. Eur J Surg Oncol 2006;32:1076-1081

22. Taback B, Nguyen P, Hansen N, Edwards GK, Conway K, Giuliano AE. Sentinel lymph node biopsy for local recurrence of breast cancer after breast-conserving therapy. Ann Surg Oncol 2006;13:1099-1104

23. Barone JL, Feldman SM, Estabrook A, Tartter PI, Rosenbaum Smith SM, Boolbol SK. Reoperative sentinel lymph node biopsy in patients with locally recurrent breast cancer. Am J Surg 2007;194:491-493

24. Intra M, Trifirò G, Galimberti V, Gentilini O, Rotmensz N, Veronesi P. Second axillary sentinel node biopsy for ipsilateral breast tumour recurrence. $\mathrm{Br} J$ Surg 2007;94:1216-1219

25. Port ER, Garcia-Etienne CA, Park J, Fey J, Borgen PI, Cody HS 3rd. Reoperative sentinel lymph node biopsy: a new frontier in the management of ipsilateral breast tumor recurrence. Ann Surg Oncol 2007;14:2209-2214

26. Axelsson CK, Jonsson PE. Sentinel lymph node biopsy in operations for recurrent breast cancer. Eur J Surg Oncol 2008;34:626-630

27. Cox CE, Furman BT, Kiluk JV, et al. Use of reoperative sentinel lymph node biopsy in breast cancer patients. J Am Coll Surg 2008;207:57-61

28. Karam A, Stempel M, Cody HS, Port ER. Reoperative sentinel lymph node biopsy after previous mastectomy. J Am Coll Surg 2008;207:543-548

29. Koizumi M, Koyama M, Tada K, et al. The feasibility of sentinel node biopsy in the previously treated breast. Eur J Surg Oncol 2008;34:365-368

30. Schrenk $P$, Tausch $C$, Wayand W. Lymphatic mapping in patients with primary or recurrent breast cancer following previous axillary surgery. Eur J Surg Oncol 2008;34:851-856

31. Tasevski R, Gogos AJ, Mann GB. Reoperative sentinel lymph node biopsy in ipsilateral breast cancer relapse. The Breast 2009;18:322-326

32. Van der Ploeg IMC, Oldenburg HSA, Rutgers EJT, et al. Lymphatic drainage patterns from the treated breast. Ann Surg Oncol 2010;17:1069-1075

33. Vicente DA, Henry LR, Hahm G, Soballe PW, Smart D. Axillary sentinel lymph node biopsy after mastectomy: a case report. World J Surg Oncol 2010;8:59

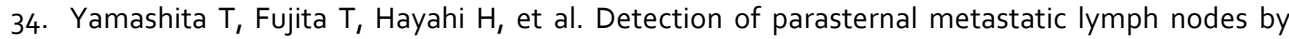
sentinel lymph node methods in a patient with recurrence in the conserved breast. Breast Cancer 2011; DOI 10.1007/s12282-010-0248-z

35. Hattori M, Nishimura S, Tada K, et al. Reoperative sentinel lymph node biopsy for ipsilateral breast tumor recurrence after previous axillary lymph node dissection: Report of a case. Surg Today 2011;41:247-250

36. Kaur P, Kiluk JV, Meade $T$, et al. Sentinel lymph node biopsy in patients with previous ipsilateral complete axillary lymph node dissection. Ann Surg Oncol 2011;18:727-732

37. Maaskant-Braat A, Roumen R, Pijpers $H$, Nieuwenhuijzen GAP. Sentinel Node And Recurrent Breast cancer (SNARB): Results of an interim-analysis. Ann Surg Oncol 2011;18:S1-S144. Abstract 37. DOI 10.1245/s10434-011-1552-3

38. Povoski SP, Olsen JO, Young DC, Clarke J, Burak WE, Walker MJ, Carson WE, et al. Prospective randomized clinical trial comparing intradermal, intraparenchymal, and subareolar injection 
routes for sentinel lymph node mapping and biopsy in breast cancer. Ann Surg Oncol 2006;13:1412-1421

39. Grant RN, Tabah EJ, Adair FE. The surgical significance of the subareolar lymph plexus in cancer of the breast. Surgery 1953;33:71-78

40. Suami H, Pan W, Taylor Gl. Historical review of breast lymphatic studies. Clinical Anatomy 2009;22:531-536

41. Suami H, Pan W, Mann GB, Taylor GI. The lymphatic anatomy of the breast and its implications for sentinel lymph node biopsy. Ann Surg Oncol 2007;15:863-871

42. Morcos B, Jaradat I, El-Ghanem M. Characteristics of and therapeutic options for contralateral axillary lymph node metastasis in breast cancer. Eur J Surg Oncol 2011;37:418-421

43. Overgaard $M$, Jensen $M B$, Overgaard $J$, et al. Postoperative radiotherapy in high-risk postmenopausal breast-cancer patients given adjuvant tamoxifen: Danish Breast Cancer Cooperative Group DBCG 82C randomised trial. Lancet 1999;353:1641-1648

44. Borner $M$, Bacchi $M$, Goldhirsch $A$, et al. First isolated locoregional recurrence following mastectomy for breast cancer: results of a phase III multicenter study comparing systemic treatment with observation after excision and radiation. Swiss Group for Clinical Cancer Research. J Clin Oncol 1994;12:2071-2077

45. Haylock BJ, Coppin CM, Jackson J, Basco VE, Wilson KS. Locoregional first recurrence after mastectomy: prospective cohort studies with and without immediate chemotherapy. Int J Radiat Oncol Biol Phys 2000;46:355-362

46. Rauschecker $\mathrm{H}$, Clarke M, Gatzemeier, Recht A. Systemic therapy for treating locoregional recurrence in women with breast cancer. Cochrane Database Syst Rev 2001;4:CDo02195 


\title{
Chapter 8
}

\section{Lymphatic mapping after previous breast surgery}

\author{
A.J.G. Maaskant-Braat \\ S.Z. de Bruijn \\ K. Woensdregt \\ R. Pijpers \\ A.C. Voogd \\ G.A.P. Nieuwenhuijzen
}

Breast 2012;21:444-448

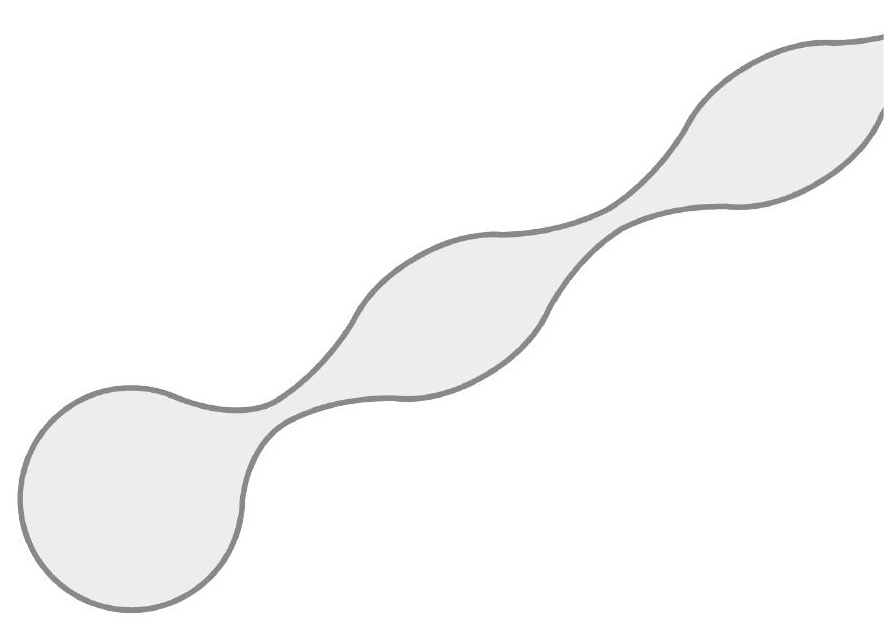




\begin{abstract}
Background To assess the feasibility of lymphatic mapping and determine the lymphatic drainage pathways in patients previously treated with breast conserving therapy (BCT).

Methods We included patients without current breast cancer that previously received BCT with sentinel node biopsy (SNB) and/or axillary lymph node dissection (ALND) for primary breast cancer. The study population consisted of 44 patients and was divided into two groups according to previous surgical treatment of the axilla: 22 patients after previous SNB and 22 patients after previous ALND. Standard lymphatic mapping was performed and the lymphatic drainage pattern was registered. Drainage located outside the ipsilateral axilla was recorded as aberrant.
\end{abstract}

Results Lymphoscintigraphy revealed a drainage pattern in 17 of 44 patients (39\%). The identification rate in the SNB-group was $41 \%$ and $36 \%$ in the ALND-group $(P=0.760) .8$ patients (18\%) showed aberrant drainage, which tended to be more frequent in the ALND-group than in the SNB-group (27\% versus 9\%, $\mathrm{P}=0.122$ ). Lymphatic drainage to the contralateral axilla was observed in 2 patients, both previously treated with ALND.

Conclusion Lymphatic mapping seems feasible after previous BCT with axillary treatment, in spite of a relatively low identification rate. Aberrant drainage tends to be more frequent after previous treatment with ALND. 


\section{Introduction}

The axillary lymph node status is of critical importance in the management of patients with breast cancer, both for its prognostic value and for its role in deciding whether or not to administer adjuvant therapy ${ }^{1}$. Sentinel lymph node biopsy (SNB) has been shown to be an accurate procedure for axillary staging in patients with primary breast cancer ${ }^{2}$. An increasing number of patients is diagnosed with early-stage breast cancer ${ }^{3}$. Most of them are treated with breast conserving therapy $(\mathrm{BCT})$ including $\mathrm{SNB}^{4}$. Unfortunately, approximately $10-15 \%$ of these patients will develop an ipsilateral breast tumour recurrence (IBTR) within 10 years after primary treatment ${ }^{5}$. Prognosis of recurrent breast cancer is, like in primary breast cancer, correlated with regional lymph node status ${ }^{6}$. Although axillary staging with SNB is generally implemented in the treatment of primary breast cancer, its role in management of recurrent breast cancer has yet to be elucidated. In patients with IBTR who underwent BCT with complete axillary lymph node dissection (ALND), salvage mastectomy without further lymph node dissection is considered to be standard of care ${ }^{7,8}$. When IBTR occurs in patients who had a previous negative SNB without a consecutive ALND, there is no consensus which axillary strategy should be followed. Currently however, for most clinicians an ALND will be the procedure of choice for staging and treatment of the axilla in these patients ${ }^{7}$. Unfortunately, long-term complications of ALND are common including lymphedema, seroma formation, shoulder dysfunction, pain and numbness[9]. SNB has been introduced as an alternative for ALND in primary breast cancer, since it has similar staging capacities but with markedly lower risk of morbidity ${ }^{1,9,10}$.

Because lymphatic pathways could have been altered due to prior surgery and/or radiotherapy, a previous procedure of the axilla either by SNB or ALND is considered to be a relative contraindication for performing a repeat SNB. Data available from experimental studies show that this disruption of lymphatic vessels may only be temporary and lymphatics are able to regenerate within a certain period from surgery ${ }^{11}$. Furthermore, when the original lymphatic vessels are interrupted due to surgery or radiotherapy, the lymphatic drainage may even follow collateral lymphatic channels to an alternative lymph node basin ${ }^{12,13}$. These drainage patterns could be different when compared to primary surgery and may thus result in unexpected aberrant lymphatic drainage $^{13-17}$. Several case reports and small heterogeneous series of patients suggest that it might be feasible to perform a repeat SNB in patients with IBTR after prior BCT

with axillary surgical staging and adjuvant radiotherapy ${ }^{18-25}$. The aim of this study was to assess the feasibility of lymphatic mapping and describe lymphatic drainage pathways in a more homogeneous population consisting exclusively of patients previously treated with breast conserving therapy with SNB and/or ALND. 


\section{Patients and Methods}

\section{Patients}

Patients who underwent BCT with SNB and/or ALND between January 2000 and December 2006 in the Catharina Hospital Eindhoven were evaluated. The medical records were used to collect detailed information on the treatment of the primary breast cancer. We included patients without current breast cancer who were treated with $\mathrm{BCT}$ with SNB and/or ALND for primary breast cancer located in the upper-outer quadrant of one breast at least 3 years before the analysis, with or without adjuvant chemo- or hormonal therapy. We chose to include only patients with breast cancer in the upperouter quadrant to create a homogeneous group of patients in which quadrant of the tumour would not be a possible interfering factor in the interpretation of the data. Furthermore, the time frame of 3 years was chosen arbitrarily in order for lymphatic drainage pathways to have sufficient time to regenerate. Patients were excluded if they had breast surgery for other reasons than breast cancer, if they had recurrent breast cancer or if they had a former allergic reaction to ${ }^{99 m}$ Tc-colloidal albumin. The study population based on these in- and exclusion criteria consisted of 44 patients. The patients were divided into two groups according to previous surgical treatment of the axilla: 22 patients after previous SNB and 22 patients after previous ALND. A formal study protocol consisting of the study objectives, study design, study population and study procedures was reviewed and approved by the ethical committee of the Catharina Hospital Eindhoven. Radiation exposure due to lymphatic mapping consists of a dose of o,46 mSV, which is well under the constraint of $5 \mathrm{mSV} / \mathrm{year}$ which is documented in the code of practice involving human research. The study was conducted according to the principles of the Declaration of Helsinki and in accordance with the Medical Research Involving Human Subjects Act (WMO). After informing the patients according to good clinical practice guidelines a written informed consent was obtained. The results were summarized and disclosed to the participating patients by means of a letter.

\section{Methods}

To assess the technical feasibility of lymphatic mapping and determine lymphatic drainage pathways, lymphatic mapping was performed. A dose of $60 \mathrm{MBq}{ }^{99 \mathrm{~m}} \mathrm{Tc}$-colloidal albumin (Nanocoll ${ }^{\circledR}$, GE-healthcare, Eindhoven, The Netherlands) in a volume of $1 \mathrm{ml}$ was injected deep in the breast parenchyma on both sides along the location of the previous lumpectomy. All injections were performed by the same physician. Images were obtained two hours after injection in 3 projections (anterior, anterior-oblique and lateral view) with the patient in supine position under a Siemens Ecam gamma camera. The imaging procedure is similar to the sentinel node procedure executed in our patients with primary breast cancer. Lymphatic drainage pathways and/or the location of the sentinel node(s) 
were registered. Lymphatic drainage outside the ipsilateral axilla was recorded as being aberrant. All lymphoscintigrafic studies were reviewed by the same nuclear medicine physician and researcher. Patients with previous SNB and ALND were compared with respect to identification rate and aberrant drainage pattern by using the Mann-Whitney $U$ test, with a statistically significant difference defined as a two-tailed $P$ value $<0.05$.

\section{Results}

The study population consisted of 44 patients. Patient and disease characteristics of 22 patients with BCT and SNB and 22 patients with BCT and ALND are presented and compared in Table 1. The mean age of participants in the SNB-group was 60.3 years (range 36-76) and 60.1 years (range 36-79) in the ALND-group. Treatment characteristics are outlined in Table 2. A mean number of 2 nodes was removed in primary surgery in the SNB-group and a mean number of 12 nodes was removed in the ALND-group ( $P=0.0001)$. The mean time interval between primary surgery and the current study was 64.8 months in the SNB-group and 75.1 months in the ALND-group $(P=0.167)$. All patients received irradiation of the breast after their primary surgery. The mean interval between administration of the radiotherapy and the current study was 63.4 months (range 37-93 months) in the SNB-group, and 71.6 months (range 33-113 months) in the ALND-group $(P=0.268)$. The average dose of radiotherapy was $59 \mathrm{~Gy}$. In 5 patients the axilla was included in the radiation field with an average dose of 34 Gy. 4 of these patients had a previous ALND, 1 patient underwent previous SNB. This patient received intra-operative axillary radiotherapy, because she had a palpable lesion in the axilla.

Lymphoscintigraphy revealed a drainage pattern in 17 of 44 patients (39\%). Identification rate in the SNB-group was $41 \%$ and in the ALND-group it was $36 \%(P=0.760)$. In eight of the 44 patients $(18 \%)$ an aberrant lymphatic drainage pathway was detected. Three patients showed drainage to the ipsilateral axilla and to parasternal lymph nodes. Furthermore, three patients showed lymphatic drainage to the parasternal lymph nodes without drainage to the ipsilateral axilla. Lymphatic drainage to the contralateral axilla was observed in 2 patients; both had an ALND as their primary axillary surgery. 
Table 1 Patient characteristics of patients receiving repeat lymphatic mapping.

\begin{tabular}{|c|c|c|c|}
\hline \multicolumn{4}{|l|}{ Patient characteristics } \\
\hline & BCT + SNB & $\mathrm{BCT}+\mathrm{ALND}$ & P-value \\
\hline Total N & 22 & 22 & \\
\hline Mean age, y (range) & $60,5(36-77)$ & $60,1(37-79)$ & 0.894 \\
\hline \multicolumn{4}{|l|}{ Tumour localisation $\mathrm{N},(\%)$} \\
\hline Left breast & 10 & 16 & \multirow[t]{2}{*}{0.069} \\
\hline Right breast & 12 & 6 & \\
\hline Original Tumour size, cm (range) & $1,3(0,2-2,5)$ & $1,9(0,6-3,6)$ & 0.005 \\
\hline \multicolumn{4}{|l|}{ Histology, N } \\
\hline Ductal carcinoma in situ & 0 & 1 & \multirow{3}{*}{0.712} \\
\hline Infiltrating ductal carcinoma & 18 & 16 & \\
\hline Infiltrating lobular carcinoma & 4 & 5 & \\
\hline Mean number of nodes removed in primary surgery & $1,7(1-6)$ & $11,7(4-20)$ & 0.0001 \\
\hline ER & 19 & 20 & 0.953 \\
\hline PR & 18 & 17 & 0.663 \\
\hline
\end{tabular}

BCT: Breast Conserving Therapy; SNB: Sentinel Node Biopsy; ALND: Axillary Lymph Node Dissection; ER: Estrogen Receptor positive; PR: Progesterone Receptor positive

Table $\mathbf{2}$ Treatment Characteristics of patients receiving repeat lymphatic mapping.

\begin{tabular}{|c|c|c|c|}
\hline \multicolumn{4}{|l|}{ Treatment } \\
\hline & $\mathrm{BCT}+\mathrm{SNB}$ & BCT + ALND & P-value \\
\hline $\begin{array}{l}\text { Total dose of radiotherapy in Gy, } \\
\text { mean (range) }\end{array}$ & $58(46-74)$ & $60(46-66)$ & 0.250 \\
\hline $\begin{array}{l}\text { Dose of radiotherapy on the axilla, } \\
N_{1} \text { (mean amount of } \mathrm{Gy} \text { ) }\end{array}$ & $1(9)$ & $4(37)$ & 0.077 \\
\hline Chemotherapy, N (\%) & $3(14)$ & $16(73)$ & 0.0001 \\
\hline Hormonal treatment, N (\%) & $4(18)$ & $18(82)$ & 0.0001 \\
\hline $\begin{array}{l}\text { Interval between surgery and lymphatic mapping } \\
\text { in months, mean (range) }\end{array}$ & $65(37-93)$ & $75(39-116)$ & 0.167 \\
\hline $\begin{array}{l}\text { Interval between radiotherapy and lymphatic } \\
\text { mapping in months, mean (range) }\end{array}$ & $63(37-92)$ & $72(33-113)$ & 0.268 \\
\hline
\end{tabular}

BCT: Breast Conserving Therapy; SNB: Sentinel Node Biopsy; ALND: Axillary Lymph Node Dissection 
Two of 5 patients that received irradiation of the axilla during primary treatment showed a drainage pattern on lymphoscintigraphy. One patient showed drainage to the ipsilateral axilla as well as to parasternal lymphnodes. This patient had an ALND as her primary treatment. The other patient was in the SNB group and showed drainage to the ipsilateral axilla after previous SNB. Results of the lymphoscintigraphic studies are summarized in Table 3. Drainage patterns outside the ipsilateral axilla tended to be found more often when patients were previously treated with ALND compared to patients previously treated with SNB ( $27 \%$ versus $9 \%, P=0.122)$. Examples of drainage patterns after lymphatic mapping are shown in Figure 1. No complications of the lymphoscintigraphies were reported. There was a significant difference in the administration of adjuvant chemotherapy between the two groups. In the SNB-group, three patients received adjuvant chemotherapy. Sixteen patients received adjuvant chemotherapy in the ALNDgroup $(P=0.0001)$. Furthermore, a significant difference was present between the two groups regarding the administration of adjuvant hormonal treatment. Four patients in the SNB-group versus 18 patients in the ALND-group received adjuvant hormonal treatment. $(P=0.0001)$.

Table 3 Drainage patterns of repeat lymphatic mapping.

\begin{tabular}{|c|c|c|c|c|}
\hline \multicolumn{5}{|l|}{ Results } \\
\hline & BCT + SNB & BCT + ALND & Total & P-value \\
\hline Drainage, N (\%) & $9(41)$ & $8(36)$ & $17(39)$ & 0.760 \\
\hline Ipsilateral axilla, N (\%) & $7(32)$ & $2(9)$ & $9(20)$ & 0.065 \\
\hline Aberrant drainage, $\mathrm{N}(\%)$ & $2(9)$ & $6(27)$ & $8(18)$ & 0.122 \\
\hline Ipsilateral axilla and parasternal, N (\%) & $1(5)$ & $2(9)$ & $3(7)$ & \\
\hline Parasternal, N (\%) & $1(5)$ & $2(9)$ & $3(7)$ & \\
\hline Parasternal and contralateral axilla, N (\%) & $\mathrm{o}(0)$ & $2(9)$ & $2(5)$ & \\
\hline
\end{tabular}

BCT: Breast Conserving Therapy; SNB: Sentinel Node Biopsy; ALND: Axillary Lymph Node Dissection 
Figure 1 Examples of drainage patterns after repeat lymphatic mapping in patients previously treated with surgery and irradiation as a part of breast conserving treatment.
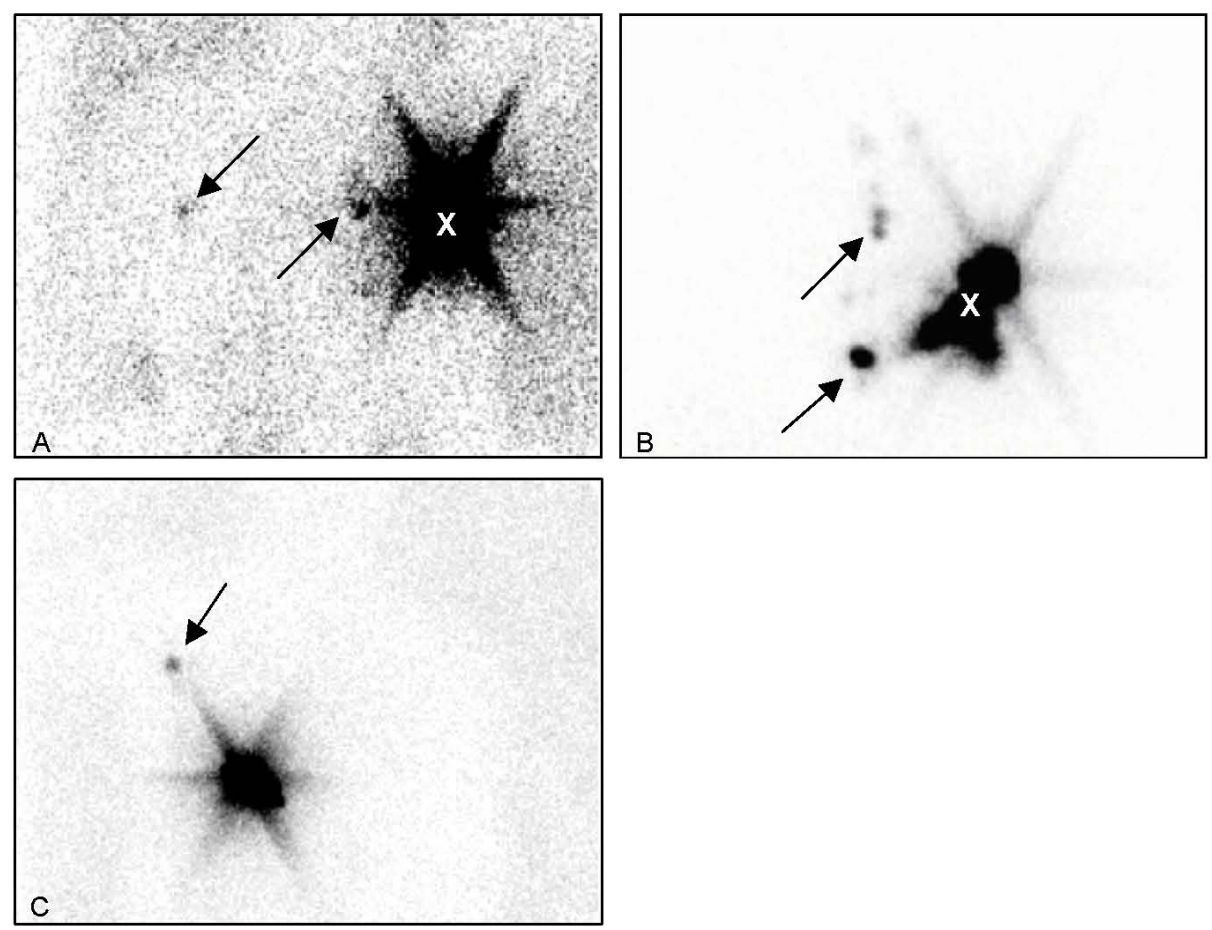

A: Patient with drainage to contralateral and parasternal lymphnode; B: Patient with drainage to

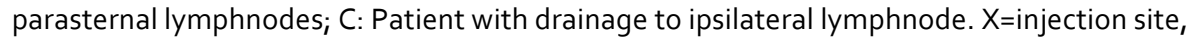
lymphnodes are marked by arrow. 


\section{Discussion}

This study describes the feasibility of lymphatic mapping after previous breast conserving therapy with axillary staging by SNB and/or ALND. The total identification rate of drainage to a lymph node basin in previously treated patients was $39 \%$. The identification rate after a previous SNB was $41 \%$ and after a previous $A L N D$ it was $36 \%(P=0.760)$. In $18 \%$ of all cases a drainage pathway was visualized outside the ipsilateral axilla. An aberrant drainage pattern tended to be more frequent after a previous ALND than after a previous SNB (27\% versus $9 \%, \mathrm{P}=0.122$ ).

Since the SNB has been used for more than 10 years as a standard axillary staging procedure in primary breast cancer, we frequently encounter patients with an IBTR after a previously performed SNB. Identifying and treating positive lymph nodes in case of IBTR could improve locoregional disease control as is the case in primary breast cancer ${ }^{26,27}$. Prognosis of patients with IBTR is dependent on disease free interval and dimensions and location of the recurrent tumour next to prognositcally bad characteristics of the primary tumour, such as nodal status and lymphovascular invasion ${ }^{28-30}$. There is no consensus whether administration of chemotherapy to patients with a local recurrent breast cancer could be effective or not ${ }^{31,32}$. Identification of positive lymphnodes in case of IBTR could improve risk stratification and play a role in making adjuvant systemic treatment recommendations.

The question rises whether or not it is possible to perform a repeat SNB in patients with IBTR. Since lymphatic mapping is an essential component of the sentinel node procedure, we tried to assess the feasibility of lymphatic mapping in patients with previous surgery and irradiation of the breast and axilla with this prospective single centre study. Until now, case reports and small series on lymphatic mapping after previous axillary surgery have been published. In these reports the overall success rate of lymphoscintigraphy for sentinel node identification in a previously treated breast ranged from 54 to 100 percent ${ }^{16,22,24}$. We recently published an article in which we retrospectively analysed axillary staging and management in patients with local recurrent breast cancer after previous negative SNB. In 13 of 70 patients a repeat SNB was attempted which was successful in 5 cases $(39 \%)^{33}$. Our sentinel node detection rate is comparable to the identification rate in this study, but lower than the identification rate in the other mentioned reports.

In 2002 Port et al. were one of the first to describe their experience with repeat SNB; they showed an identification rate of $54 \%$ (13 out of 24 cases) ${ }^{34}$. Another large series was reported by this study group in 2007, which showed that repeat SNB was successful in 64 of 117 cases $(55 \%)^{22}$. More recently, a Dutch study showed lymphatic mapping was successful in $84 \%$ of patients who had undergone previous surgery or biopsy of the same breast ${ }^{35}$. The success rate of lymphatic mapping was $72 \%$ in their SNB group and $50 \%$ in 
the group containing patients after ALND. An important difference between these reports and our study is the heterogeneity of the study populations. All mentioned reports describe different previous procedures, quadrant of surgery in the breast and timeframes after surgery or radiotherapy. Furthermore, in contrast to our patients, described patients in these studies have been diagnosed with recurrent breast cancer. Part of these patients probably had new primary tumours in the same breast instead of true recurrences near the initial scar. It is possible that lymphatic drainage percentages from these new primaries will be higher due to less interference of disruption of local lymphatic drainage pathways and radiotherapy boost.

Because previous studies investigated patients with recurrent breast cancer, a SNB was performed using lymphoscintigraphy and blue dye. Several studies have shown a higher identification rate in combined methods using injection of both blue dye and lymphoscintigraphy. One report showed a successful identification of sentinel nodes with preoperative lymphoscintigraphy in 29 of 48 patients $(60 \%)$, while $90 \%$ of sentinel node identification was successful with a dual mapping procedure ${ }^{36}$. The blue dye method provides visual aid to the surgeon that enhances the detection of a sentinel node. Since we studied patients without an IBTR who volunteered to undergo lymphoscintigraphy we did not want to expose them to the possible side effects of blue dye and it was not possible to perform a repeat sentinel node procedure. This could also explain the relatively low identification rate compared with other studies.

Another possible explanation for the differences in identification rates between our study and previous studies could be the time interval between injection of the radioactive tracer and lymphoscintigraphy. The interval used in previous reports ranged from 30 minutes to 48 hours. An interval of two hours was used in our study. Because of the prospective homogeneous nature of this study, patients in whom the sentinel node was not identified after 2 hours were not scanned again at a later time. It is not clear if a longer time interval would have been more beneficial for these patients. However, results of a study by Pijpers et al. showed no significant difference between lymphoscintigraphy taken 2 hours after injection, compared to scintigraphies taken 18 hours after injection ${ }^{37}$. If these results are also applicable to repeat sentinel node procedures needs to be elucidated.

As well as the time interval, the amount of radiotracer that needs to be injected is a subject of debate. Doses used in previous studies range from $10 \mathrm{MBq}$ to 122 $\mathrm{MBq}^{7,11,20,24,38,39}$. All these studies showed high identification rates. We chose an amount of $60 \mathrm{MBq}$ in order to decrease radiation dose administered to the patients. Since there was no need for a removal of the sentinel node in this study, radioactivity only had to last for a few hours. Therefore an amount of $60 \mathrm{MBq}$ seemed to be sufficient.

The site of radiopharmaceutical injection differs in previous studies, varying between subareolar, intraparenchymal and dermal injections. At present intraparenchymal injection is the most commonly used injection site for performing SNB in primary breast 
cancer ${ }^{40}$. Based on a review of the literature and their own assessments of two unrelated nuclear medicine departments' databases, Spillane et al. state that high-quality lymphatic mapping with peritumoral injections is the best known demonstrator of breast lymphatic anatomy ${ }^{41}$. A prospective randomised controlled trial comparing routes for lymphatic mapping in primary breast cancer after intradermal, intraparenchymal or subareolar injection showed significant differences in extra axillary drainage between intraparenchymal and intradermal injection and between intraparenchymal injection and subareolar injection ${ }^{40}$. Because original lymphatic vessels may be interrupted due to surgery and thus drainage from the subareolar plexus could have been altered, the incidence of extra-axillary drainage in patients after prior treatment of the breast could potentially be higher compared to patients without previous treatment. The incidence of extra-axillary drainage after prior treatment described in literature ranges from $29 \%$ to $67 \% \%^{7,21-23,25}$. We are interested in information on extra-axillary disease in repeat SNB because it may change radiation field planning and, in some instances, the use of adjuvant systemic therapy. Therefore, we chose to inject ${ }^{99 m}$ Tc-Nanocolloid deep in the breast parenchyma at the site of the skin scar.

In order to be able to draw valid conclusions on identification rate and aberrant drainage patterns we included a homogeneous group of patients. Because of these strict in- and exclusion criteria our group consisted of only 44 patients. Since this is a prospective single centre, single investigator trial we believe that valid conclusions can indeed be drawn from our results. Since our study did not provide data on the accuracy of the sentinel node procedure and no studies have performed a standard confirmation lymph node dissection of the whole lymphatic basin, we strongly believe it is too early to implement the repeat SNB as the only axillary staging procedure. Large, unselected and prospective studies are needed to decide if lymphatic mapping and subsequent SNB can be implemented in patients with IBTR. Currently, a Dutch multicentre trial 'Sentinel Node And Recurrent Breast cancer' (SNARB) is conducted to investigate the confirming lymphatic dissection after repeat SNB. Until the results from this and other studies become available, we believe that a standard ipsilateral confirmation lymphatic dissection is still mandatory as part of standard care. Whether or not a confirmation lymph node dissection of the aberrant drainage basin is needed is debatable, since exploration of these basins has never been standard of care.

In conclusion, lymphatic mapping seems feasible after previous BCT with axillary treatment, in spite of a relatively low identification rate. Aberrant drainage patterns tend to be visualized more frequent in the group of patients after previous ALND. 


\section{References}

1. Veronesi U, Paganelli G, Galimberti V, Viale G, Zurrida S, Bedoni M, Costa A, et al. Sentinelnode biopsy to avoid axillary dissection in breast cancer with clinically negative lymph-nodes. Lancet 1997;349:1864-1867

2. Veronesi U, Paganelli G, Viale G, Luini A, Zurrida S, Galimberti V, Intra M, et al. Sentinellymph-node biopsy as a staging procedure in breast cancer: update of a randomised controlled study. Lancet Oncol 2006;7:983-990

3. Louwman WJ, Voogd AC, van Dijck JA, Nieuwenhuijzen GA, Ribot J, Pruijt JF, Coebergh JW. On the rising trends of incidence and prognosis for breast cancer patients diagnosed 1975-2004: a long-term population-based study in southeastern Netherlands. Cancer Causes Control 2008;19:97-106

4. Maaskant AJ, van de Poll-Franse LV, Voogd AC, Coebergh JW, Tutein Nolthenius-Puylaert MC, Nieuwenhuijzen GA. Stage migration due to introduction of the sentinel node procedure: a population-based study. Breast Cancer Res Treat 2009;113:173-179

5. Fisher B, Bryant J, Dignam JJ, Wickerham DL, Mamounas EP, Fisher ER, Margolese RG, et al. Tamoxifen, radiation therapy, or both for prevention of ipsilateral breast tumor recurrence after lumpectomy in women with invasive breast cancers of one centimeter or less. J Clin Oncol 2002;20:4141-4149

6. Voogd AC, van TG, Peterse HL, Crommelin MA, Rutgers EJ, van d, V, van Geel BN, et al. Local recurrence after breast conservation therapy for early stage breast carcinoma: detection, treatment, and outcome in 266 patients. Dutch Study Group on Local Recurrence after Breast Conservation (BORST). Cancer 1999;85:437-446

7. Roumen RM, Kuijt GP, Liem IH. Lymphatic mapping and sentinel node harvesting in patients with recurrent breast cancer. Eur J Surg Oncol 2006;32:1076-1081

8. Vereniging van Integrale Kankercentra. Landelijke richtlijn mammacarcinoom. Available: http://www.oncoline.nl

9. Schijven MP, Vingerhoets AJ, Rutten HJ, Nieuwenhuijzen GA, Roumen RM, van Bussel ME, Voogd AC. Comparison of morbidity between axillary lymph node dissection and sentinel node biopsy. Eur J Surg Oncol 2003;29:341-350

10. Cox CE, Bass SS, McCann CR, Ku NN, Berman C, Durand K, Bolano M, et al. Lymphatic mapping and sentinel lymph node biopsy in patients with breast cancer. Annu Rev Med 2000;51:525-542

11. Schrenk $P$, Tausch $C$, Wayand W. Lymphatic mapping in patients with primary or recurrent breast cancer following previous axillary surgery. Eur J Surg Oncol 2008;34:851-856

12. Stelzner F, Friedrichs N, Buttner R, Wernert N, von MD, Ruhlmann J, Steinau HU. Lymph vascularity and lymph node metastases on PET and PET-CT: immunohistological and clinical observations. Chirurg 2005;76:493-500

13. Rees WV, Robinson DS, Holmes EC, Morton DL. Altered lymphatic drainage following lymphadenectomy. Cancer 1980;45:3045-3049

14. Dinan $D$, Nagle $C E$, Pettinga J. Lymphatic mapping and sentinel node biopsy in women with an ipsilateral second breast carcinoma and a history of breast and axillary surgery. Am J Surg 2005;190:614-617

15. Perre Cl, Hoefnagel CA, Kroon BB, Zoetmulder FA, Rutgers EJ. Altered lymphatic drainage after lymphadenectomy or radiotherapy of the axilla in patients with breast cancer. Br J Surg $1996 ; 83: 1258$ 
16. Sood A, Youssef IM, Heiba SI, El-Zeftawy H, Axelrod D, Seigel B, Mills C, et al. Alternative lymphatic pathway after previous axillary node dissection in recurrent/primary breast cancer. Clin Nucl Med 2004;29:698-702

17. Agarwal A, Heron DE, Sumkin J, Falk J. Contralateral uptake and metastases in sentinel lymph node mapping for recurrent breast cancer. J Surg Oncol 2005;92:4-8

18. Karam A, Stempel M, Cody HS, III, Port ER. Reoperative sentinel lymph node biopsy after previous mastectomy. J Am Coll Surg 2008;207:543-548

19. Barone JL, Feldman SM, Estabrook A, Tartter PI, Rosenbaum Smith SM, Boolbol SK. Reoperative sentinel lymph node biopsy in patients with locally recurrent breast cancer. Am J Surg 2007;194:491-493

20. Koizumi M, Koyama M, Tada K, Nishimura S, Miyagi Y, Makita M, Yoshimoto $M$, et al. The feasibility of sentinel node biopsy in the previously treated breast. Eur J Surg Oncol 2008;34:365-368

21. Boughey JC, Ross MI, Babiera GV, Bedrosian I, Feig BW, Hwang RF, Kuerer HM, et al. Sentinel lymph node surgery in locally recurrent breast cancer. Clin Breast Cancer 2006;7:248-253

22. Port ER, Garcia-Etienne CA, Park J, Fey J, Borgen PI, Cody HS, III. Reoperative sentinel lymph node biopsy: a new frontier in the management of ipsilateral breast tumor recurrence. Ann Surg Oncol 2007;14:2209-2214

23. Taback B, Nguyen P, Hansen N, Edwards GK, Conway K, Giuliano AE. Sentinel lymph node biopsy for local recurrence of breast cancer after breast-conserving therapy. Ann Surg Oncol 2006;13:1099-1104

24. Intra M, Trifiro G, Viale G, Rotmensz N, Gentilini OD, Soteldo J, Galimberti V, et al. Second biopsy of axillary sentinel lymph node for reappearing breast cancer after previous sentinel lymph node biopsy. Ann Surg Oncol 2005;12:895-899

25. Newman EA, Cimmino VM, Sabel MS, Diehl KM, Frey KA, Chang AE, Newman LA. Lymphatic mapping and sentinel lymph node biopsy for patients with local recurrence after breastconservation therapy. Ann Surg Oncol 2006;13:52-57

26. Overgaard M, Hansen PS, Overgaard J, et al. Postoperative radiotherapy in high-risk premenopausal women with breast cancer who receive adjuvant chemotherapy. N Engl J Med 1997;337:949-955

27. Orr RK. The impact of prophylactic axillary node dissection on breast cancer survival - a Bayesian meta-analysis. Ann Surg Oncol 1999;6:109-116

28. van Tienhoven $G$, Voogd AC, Peterse $J L$, et. al. on behalf of the EORTC Breast Cancer Cooperative Group and the Danish Breast Cancer Cooperative Group. Prognosis after treatment for loco-regional recurrence after mastectomy or breast conserving therapy in two randomized trials (EORTC 10801 and DBCG-82TM). Eur J Cancer 1999;35:32-38

29. Van der Sangen MJ, Coebergh JW, Roumen RM, Rutten HJ, Vreugdenhil G, Voogd AC. Detection, treatment, and outcome of isolated supraclavicular recurrence in 42 patients with invasive breast carcinoma. Cancer 2003;98:11-17

30. Voogd AC, van Oost FJ, Rutgers EJ, Elkhuizen PH, van Geel AN, Scheijmans LJ et. al. Long-term prognosis of patients with local recurrence after conservative surgery and radiotherapy for early breast cancer. Eur J Cancer 2005;41:2637-2644

31. Haylock BJ, Coppin CM, Jackson J, Basco VE, Wilson KS. Locoregional first recurrence after mastectomy: prospective cohort studies with and without immediate chemotherapy. Int J Radiat Oncol Biol Phys 2000;46:355-362

32. Rauschecker $\mathrm{H}$, Clarke $M$, Gatzemeier, Recht A. Systemic therapy for treating locoregional recurrence in women with breast cancer. Cochrane Database Syst Rev. 2001;(4):CDo02195 
33. Derkx F, Maaskant-Braat AJ, van der Sangen MJ, Nieuwenhuijzen GA, van de Poll-Franse LV, Roumen RM, Voogd AC. Staging and management of axillary lymph nodes in patients with local recurrence in the breast or chest wall after a previous negative sentinel node procedure. Eur J Surg Oncol 2010;36:646-651

34. Port ER, Fey J, Gemignani ML, Heerdt AS, Montgomery LL, Petrek JA, Sacchini V, et al. Reoperative sentinel lymph node biopsy: a new option for patients with primary or locally recurrent breast carcinoma. J Am Coll Surg 2002;195:167-172

35. van der Ploeg, I, Oldenburg HS, Rutgers EJ, Baas-Vrancken Peeters MJ, Kroon BB, Valdes Olmos RA, Nieweg OE. Lymphatic drainage patterns from the treated breast. Ann Surg Oncol 2010;17:1069-1075

36. Tsugawa K, Noguchi M, Miwa K, Bando E, Yokoyama K, Nakajima K, Michigishi T, et al. Dyeand gamma probe-guided sentinel lymph node biopsy in breast cancer patients: using patent blue dye and technetium-99m-labeled human serum albumin. Breast Cancer 2000;7:87-94

37. Pijpers R, Meijer S, Hoekstra OS, Collet GJ, Comans EF, Boom RP, van Diest PJ, et al. Impact of lymphoscintigraphy on sentinel node identification with technetium-99m-colloidal albumin in breast cancer. J Nucl Med 1997;38:366-368

38. Doting MH, Stiekema HM, de Vries J, Lemstra C, Hoekstra HJ, Vrieling M, Rietman L, et al. Immediate dynamic lymphoscintigraphy delivers no additional value to lymphoscintigraphy 3 hr after tracer injection in sentinel lymph node biopsy in breast cancer patients. J Surg Oncol 2007;95:469-475

39. Axelsson CK, Jonsson PE. Sentinel lymph node biopsy in operations for recurrent breast cancer. Eur J Surg Oncol 2008;34:626-630

40. Povoski SP, Olsen JO, Young DC, Clarke J, Burak WE, Walker MJ, Carson WE, et al. Prospective randomized clinical trial comparing intradermal, intraparenchymal, and subareolar injection routes for sentinel lymph node mapping and biopsy in breast cancer. Ann Surg Oncol 2006;13:1412-1421

41. Spillane AJ, Noushi F, Cooper RA, Gebski V, Uren RF. High-resolution lymphoscintigraphy is essential for recognition of the significance of internal mammary nodes in breast cancer. Ann Oncol 2009;20:977-984 


\section{Chapter 9}

\section{Sentinel Node And Recurrent Breast cancer (SNARB): Results of a nationwide registration study}

A.J.G. Maaskant-Braat

R.M.H. Roumen
A.C. Voogd
R. Pijpers
E.J.T. Luiten
E.J.T. Rutgers
G.A.P. Nieuwenhuijzen

on behalf of the Dutch Sentinel Node And Recurrent Breast cancer (SNARB) study group

Ann Surg Oncol 2013;20:620-626

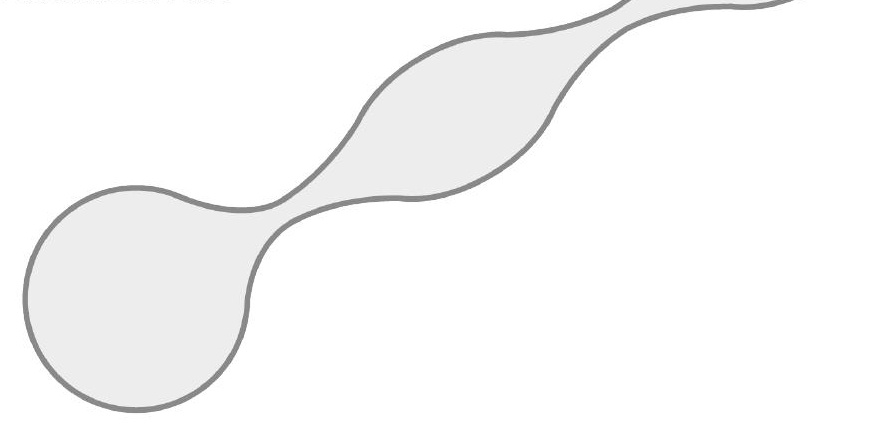




\begin{abstract}
Background Knowledge of regional lymph node involvement is important in patients with recurrent breast cancer for obtaining better locoregional control and predicting prognosis. To determine technical feasibility, validity, aberrant drainage rates and clinical consequences of performing repeat sentinel node biopsy (SNB) in patients with locally recurrent breast cancer we conducted the "Sentinel Node And Recurrent Breast cancer (SNARB)" study.
\end{abstract}

Methods One hundred and fifty patients with locally recurrent breast cancer underwent lymphatic mapping and SNB. In case of an intact axillary lymph node basin, ipsilateral axillary lymph node dissection (ALND) was performed subsequently.

Results Forty-one patients previously underwent breast conserving therapy (BCT) with SNB, 82 patients BCT with ALND and 21 patients a mastectomy, of which 9 with SNB and 12 with ALND. In 95 patients (63.3\%) a sentinel node was identified and in 78 patients $(52 \%)$ the sentinel node was successfully removed. In 18 patients (22.8\%) a (micro)metastasis was found on pathologic examination. Confirmation ALND in 18 patients showed no axillary lymph node metastases. Aberrant drainage pathways were visualized in $58.9 \%$ of the patients, significantly more frequent after a previous ALND $(79.3 \%)$ than after a previous SNB $(25.0 \%)(P<0.0001)$. Overall, the result of this repeat SNB led to a change in the adjuvant treatment plan in $16.5 \%$ of the patients with a successful repeat SNB.

Conclusion Repeat SNB is technically feasible and provides reliable results in patients with locally recurrent breast cancer, leading to change in management in one out of six patients. 


\section{Introduction}

Currently, the sentinel node biopsy (SNB) is the standard of care for regional lymph node staging in clinically node-negative breast cancer patients ${ }^{1}$. It has a high identification rate and an acceptable false-negative rate ${ }^{2}$. Furthermore, the risk of axillary recurrence after negative sentinel node biopsy (SNB) is very low and thus completion axillary lymph node dissection (ALND) can safely be omitted ${ }^{3 / 4}$. Nowadays, over $60 \%$ of patients with primary operable breast cancer are ultimately being staged with lymphatic mapping and $\mathrm{SNB}^{5,6}$.

Unfortunately, approximately 5 to $10 \%$ of breast cancer patients develop a local recurrence in the breast or chest wall, depending on treatment modality, being either breast conservation therapy or mastectomy ${ }^{7,8}$. Treatment of locally recurrent breast cancer without synchronous distant metastasis has a curative intent and usually consists of salvage mastectomy or surgical resection of the recurrent cancer with of without locoregional radiotherapy ${ }^{1,9}$. There are no specific guidelines available regarding staging and treatment of the regional lymph nodes. However, the reported risk of axillary lymph node metastasis among patients with local recurrence after breast surgery and a previous negative SNB of $26 \%$ is too high to be ignored ${ }^{10}$. Moreover, evaluation of the regional lymph node basins might be helpful to decide on the indication for adjuvant radiotherapy and systemic treatment. For these reasons it seems sensible to perform a regional lymph node staging procedure in patients with locally recurrent breast cancer. In general practice, this would mean that patients with recurrent breast cancer and a previous negative sentinel node biopsy would receive ALND and that patients with a previous ALND would receive no additional axillary staging. A recent study in 14 hospitals in the south of The Netherlands showed that many different strategies are being used ranging from no axillary staging at all to axillary radiotherapy, ALND and repeat SNB [9]. Remarkably, in only $20 \%$ of the patients in this study an ultrasound study of the axilla was performed as part of axillary staging.

On theoretical grounds it has been questioned if it is possible to perform SNB as an axillary staging procedure in locally recurrent breast cancer after previous axillary surgery similar to primary breast cancer. If it is possible and valid to perform lymphatic mapping and SNB in case of recurrence, additional morbidity resulting from ALND could be prevented $^{11}$. Furthermore, due to previous surgery and radiotherapy lymph drainage pathways might have been altered. These aberrant drainage pathways could be detected with lymphatic mapping leading to a more thorough staging of the disease. Although several small retrospective and heterogeneous studies have shown that a repeat SNB seems technically feasible and can provide useful information ${ }^{12-14}$, it remains questionable whether it is a safe alternative to ALND.

To determine technical feasibility, validity and clinical consequences of performing SNB in patients with locally recurrent breast cancer and the likelihood of finding aberrant 
drainage patterns, we conducted the Dutch "Sentinel Node And Recurrent Breast cancer (SNARB)" registration study.

\section{Patients and methods}

\section{Patients}

The SNARB-study is a multicentre, national registration study in which 35 Dutch hospitals participate (trial number: $\mathrm{TC}_{1450}$ ). After approval from the central medical ethical committee of the Catharina Hospital in Eindhoven, patients were prospectively entered in our database after having obtained an informed consent. Additionally, some patients were retrospectively entered in the database after initially being staged with repeat SNB outside of this study, but in accordance with the study protocol. The collected data presented in this manuscript were derived from 22 hospitals, consisting of university hospitals, large non-university teaching hospitals and community hospitals. The remaining 13 hospitals that participate were not able to include patients due to lack of exposure of patients with recurrent breast cancer. We included women above 18 years old with operable locally recurrent breast cancer confirmed by cytology and/or histology. Exclusion criteria were ipsi- or contralateral clinical regional lymph node metastases proven by ultrasound and fine needle aspiration and/or known allergy to " $199 \mathrm{~m} T \mathrm{~T}$-colloidal albumin" or blue dye injection fluids. Several patient groups can be distinguished: patients with local recurrence after BCT or MRM and negative SNB (thus a relatively intact axillary lymph node basin), patients with local recurrence after BCT or MRM and ALND and patients with ipsilateral breast cancer after previous DCIS treatment or reconstructive surgery. The patients were staged according to the Tumour-NodeMetastasis (TNM) system of the International Union Against Cancer (UICC) version $6^{15}$.

Between February 2008 and July 2011150 women with operable locally recurrent breast cancer were entered in the study. These patients were divided into five different groups: local recurrence following 1) BCT and SNB 2) mastectomy and SNB 3) BCT and ALND 4) mastectomy and ALND and 5) $\mathrm{BCT} /$ mastectomy or reconstructive surgery alone (without axillary staging or surgery).

\section{Technical procedure}

Lymphatic mapping was carried out according to local protocol, similar to lymphatic mapping in primary breast cancer. ${ }^{99 \mathrm{~m}} \mathrm{Tc}$-colloidal albumin was injected deep in the parenchymal or scar tissue around the recurrent tumour the day before or on the day of surgery. On the day of surgery a lymphoscintigraphy was performed and the detected sentinel nodes were marked on the skin. In case of no visualization it was allowed to inject a $2^{\text {nd }}$ dose of colloidal albumin or act according to local protocol. After induction of 
anaesthesia, blue dye was injected) to help localize the sentinel lymph node(s). During surgery the sentinel node(s) was (were) being identified using the gamma probe and surgery was guided by blue coloured lymph drainage pathways. An attempt was made to excise all sentinel nodes in any lymph node basin that was identified by lymphoscintigraphy and the sentinel nodes were sent to the pathology department for examination according to national guidelines ( $H \& E$ and immunohistochemistry) ${ }^{1}$. For validation, the surgeons were advised, but not obliged, to perform an ipsilateral axillary lymph node dissection in case of a relatively intact axillary lymph node basin.

\section{Data registration and statistics}

Patient data were captured on standardized registration forms. Lymphoscintigraphic drainage patterns outside the ipsilateral axilla were recorded as aberrant. Since this is a registration study mainly descriptive statistics were used. Patients with previous SNB and ALND were compared with respect to identification rate and aberrant drainage pattern by using the Chi-square test. $\mathrm{P}$-values $<0.05$ were considered statistically significant.

\section{Results}

\section{Patients}

The mean age of all 150 patients with locally recurrent breast cancer included in the study was 64 years (range: 28-81) with a mean disease free interval of 135 months (range: 6355). The characteristics of the patient population are shown in Table 1. Forty-one patients with a local recurrence had previously undergone BCT with SNB (27.3\%), 9 patients a mastectomy with SNB (6.0\%), 82 patients BCT with ALND (54.7\%), 12 a mastectomy with ALND (8.0\%) and 6 a lumpectomy for DCIS or plastic surgery without any axillary staging (4.0\%). Overall, 50 of the 150 patients with locally recurrent breast cancer (33.3\%) had a previous SNB, 94 patients (62.7\%) a previous ALND and 6 patients (4.0\%) had no previous axillary staging (Table 2 ).

Table 1 Lymphatic mapping and sentinel node biopsy success rate of 150 patients with locally recurrent breast cancer according to primary treatment of breast and axilla.

\begin{tabular}{|l|c|c|c|c|c|r|}
\hline Primary treatment & $\begin{array}{c}\text { BCT+ } \\
\text { SNB } \\
\text { Number of patients (\%) }\end{array}$ & $\begin{array}{c}\text { Mast+ } \\
\text { SNB }\end{array}$ & $\begin{array}{c}\text { BCT+ } \\
\text { ALND } \\
\mathbf{8 2}\end{array}$ & $\begin{array}{c}\text { Mast+ } \\
\text { ALND } \\
\mathbf{1 2}\end{array}$ & $\begin{array}{c}\text { BCT/plastic } \\
\text { surgery } \\
\mathbf{6}\end{array}$ & Total \\
\hline $\begin{array}{l}\text { Lymphatic mapping } \\
\text { successful }\end{array}$ & $\mathbf{2 5 ( 6 1 . 0 )}$ & $7(77.8)$ & $49(59.8)$ & $9(75)$ & $5(83.3)$ & $95(63.3)$ \\
\hline SNB successful & $\mathbf{2 2 ( 5 3 . 7 )}$ & $7(77.8)$ & $37(45.1)$ & $8(66.7)$ & $5(83.3)$ & $79(52.7)$ \\
\hline
\end{tabular}

BCT: Breast Conserving Therapy; SNB: Sentinel Node Biopsy; Mast: Mastectomy; ALND: Axillary Lymph Node Dissection 
Table 2 Sentinel node pathology of 79 patients with locally recurrent breast cancer and successful repeat Sentinel Node Biopsy according to primary treatment of breast and axilla.

\begin{tabular}{|l|c|c|c|c|c|r|}
\hline Primary treatment & BCT+ & Mast+ & BCT+ & Mast+ & BCT/plastic & Total \\
SNB successful (\%) & SNB & SNB & ALND & ALND & surgery & \\
& $\mathbf{2 2}$ & $\mathbf{7}$ & $\mathbf{3 7}$ & $\mathbf{8}$ & $\mathbf{5}$ & $\mathbf{7 9}$ \\
\hline $\mathrm{pNo}$ & $19(86.4)$ & $7(100.0)$ & $27(73.0)$ & $5(62.5)$ & $3(60.0)$ & $61(77.2)$ \\
\hline $\mathrm{pN} 1 \mathrm{mi}$ & $\mathbf{1}(4.5)$ & $0(0.0)$ & $6(16.2)$ & $2(25.0)$ & $0(0.0)$ & $9(11.4)$ \\
\hline $\mathrm{pN} 1 \mathrm{a}$ & $\mathbf{2 ( 9 . 1 )}$ & $0(0.0)$ & $4(10.8)$ & $\mathbf{1}(12.5)$ & $2(40.0)$ & $9(11.4)$ \\
\hline
\end{tabular}

BCT: Breast Conserving Therapy; SNB: Sentinel Node Biopsy; Mast: Mastectomy; ALND: Axillary Lymph Node Dissection

\section{Success rate and outcome of repeat sentinel node biopsy}

The success rates of identifying a sentinel node using repeat SNB according to patient group are shown in Table 1 . We observed lymphatic drainage in 32 of the 50 patients who had undergone SNB before (64\%) and in 58 of the 94 patients who had been treated with ALND before (61.7\%) ( $P=N S)$. Overall, lymphatic mapping was successful in 95 of the 150 patients (63.3\%). An actual sentinel node was retrieved in 29 of the 50 patients with a previous SNB (58.0\%) and in 45 of the 94 patients who previously had ALND (47.9\%) $(P=N S)$. Overall, repeat SNB was successful in 79 of the 150 patients in total $(52.7 \%)$ or in 79 of the 95 patients with a successful lymphatic mapping procedure (83.2\%).

Sixty-one of the $79(77.2 \%)$ retrieved sentinel nodes were node-negative $(\mathrm{pNo})$, in 9 sentinel nodes $(11.4 \%)$ a micrometastasis was found $(\mathrm{pN} 1 \mathrm{mi})$ and in 9 sentinel nodes (11.4\%) a macrometastasis ( $\mathrm{pN1a}$ ). Distribution of these metastases over the patient groups is shown in Table 2. Three of the 9 macrometastases were found in the contralateral axilla and 2 in the internal mammary chain. In case of detection of micrometastases 2 out of 9 were found in the contralateral axilla and 6 in the internal mammary chain (Table 3). A confirmation ipsilateral ALND was performed in 18 patients after previous negative SNB and without metastases in their repeat sentinel node. No metastases were found. 
Table 3 Frequency and location of lymph node metastasis in 79 patients with locally recurrent breast cancer and successful repeat sentinel node biopsy according to primary treatment of breast and axilla.

\begin{tabular}{|l|c|c|c|c|r|r|}
\hline \multirow{2}{*}{ Location of metastases } & \multicolumn{7}{|c|}{ Primary treatment } & \multirow{2}{*}{ Total } \\
\cline { 2 - 6 } & $\begin{array}{c}\text { BCT+ } \\
\text { SNB }\end{array}$ & $\begin{array}{c}\text { Mast+ } \\
\text { SNB }\end{array}$ & $\begin{array}{c}\text { BCT+ } \\
\text { ALND }\end{array}$ & $\begin{array}{c}\text { Mast+ } \\
\text { ALND }\end{array}$ & $\begin{array}{c}\text { BCT/plastic } \\
\text { surgery }\end{array}$ \\
\hline Ipsilateral axilla & $\mathbf{1}$ & 0 & $\mathbf{2}$ & 0 & $\mathbf{2}$ & $\mathbf{5 ( 2 7 . 8 )}$ \\
pN1mi & 0 & 0 & 1 & 0 & 0 & 1 \\
pN1a & 1 & 0 & 1 & 0 & 2 & 0 \\
\hline Contralateral axilla & 1 & 0 & 4 & 0 & 0 & $5(27.8)$ \\
pN1mi & 0 & 0 & 2 & 0 & 0 & 2 \\
pN1a & 1 & 0 & 2 & 0 & 0 & 3 \\
\hline Internal mammary chain & $\mathbf{1}$ & 0 & $\mathbf{4}$ & $\mathbf{3}$ & 0 & $\mathbf{8 ( 4 4 . 4 )}$ \\
pN1mi & 1 & 0 & 3 & 2 & 0 & 6 \\
pN1a & 0 & 0 & 1 & 1 & 0 & 2 \\
\hline Total (\%) & $\mathbf{3 ( 1 3 . 6 )}$ & $\mathbf{0 ( 0 . 0 )}$ & $\mathbf{1 0 ( 2 7 . 0 )}$ & $\mathbf{3 ( 3 7 . 5 )}$ & $\mathbf{2 ( 4 0 . 0 )}$ & $\mathbf{1 8 ( 2 2 . 8 )}$ \\
\hline
\end{tabular}

BCT: Breast Conserving Therapy; SNB: Sentinel Node Biopsy; Mast: Mastectomy; ALND: Axillary Lymph Node Dissection

\section{Aberrant drainage pathways}

Aberrant drainage pathways were visualized in 56 of the 95 patients with successful lymphatic mapping (58.9\%). These drainage pathways outside of the ipsilateral axilla were visualized significantly more frequent after a previous ALND than after a previous SNB $(79.3 \%$ vs. $25.0 \%$ after previous SNB) $(\mathrm{P}<0.0001)$. The predominant aberrant drainage locations were the contralateral axilla and internal mammary chain (Table 4 ).

\section{Change of treatment plan}

Overall, in 13 of the 150 patients in total (9.0\%) or 13 of the 79 patients with a successful repeat SNB (16.5\%) adjuvant treatment plans were altered based on information derived from the repeat SNB. These alterations ranged from the administration of adjuvant systemic therapy $(n=6)$ to radiotherapy on the internal mammary chain, ipsilateral or contralateral axilla or periclavicular regions $(n=6)$ and performing a contralateral ALND because of the finding of metastases in contralateral sentinel nodes $(n=4)$. Additionally, 29 of the 56 patients with a previous negative SNB (51.8\%) had a successful repeat SNB, which showed node-negative disease. These 29 patients could thus have been spared an ipsilateral ALND if the accuracy of repeat SNB is considered to be sufficient. 


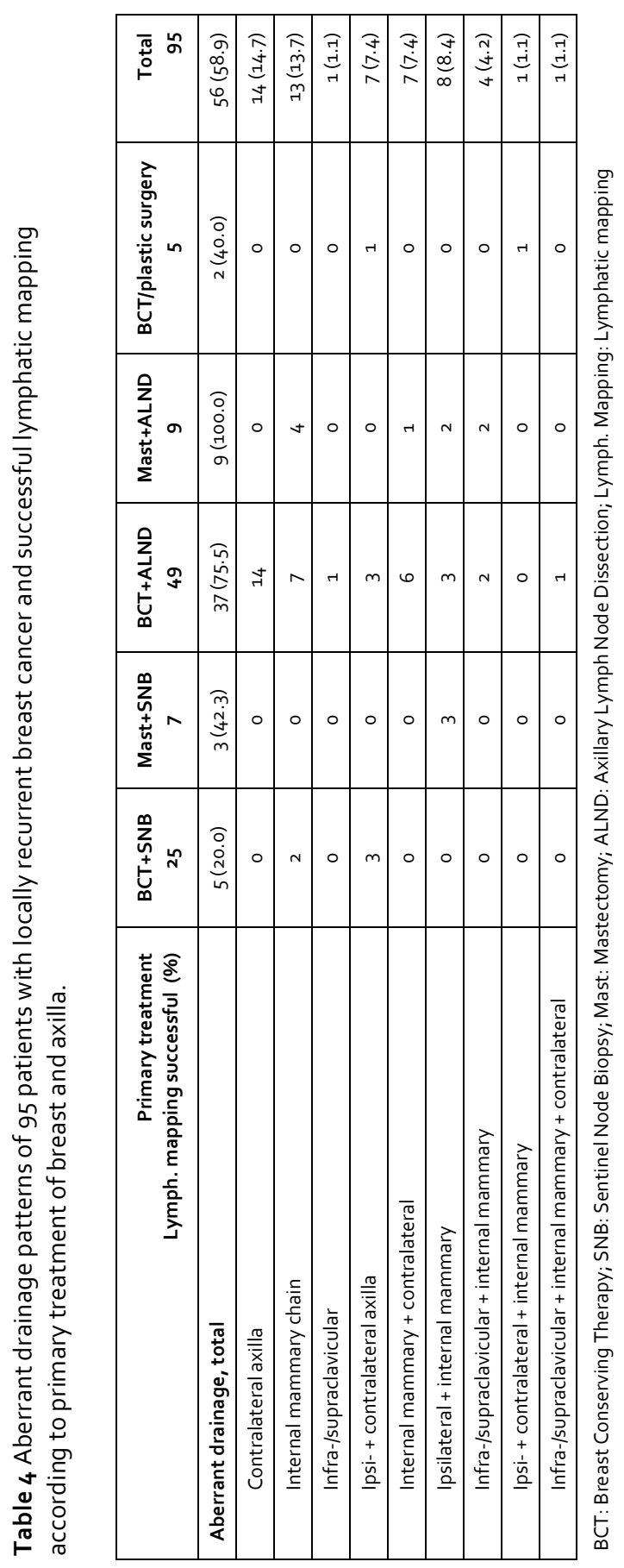




\section{Discussion}

Lymphatic mapping and SNB in patients with locally recurrent breast cancer appear to be technically feasible with an identification rate of $63.3 \%$ and a SNB success rate of $52.7 \%$. In $83.2 \%$ of the patients with a successful lymphatic mapping procedure a sentinel node could surgically be harvested. In $58.9 \%$ of the patients aberrant drainage pathways were visualized, which were seen significantly more frequent after previous ALND. In $22.8 \%$ of the patients undergoing repeat SNB one or more sentinel nodes were tumour positive and in 13 patients the information derived from the repeat SNB led to a change in treatment plans. More importantly, ALND could possibly be omitted in more than $50 \%$ of the patients with local recurrence and a previous negative SNB. Although a completion ALND was only performed in a small subset of patients, the false negative rate of $0 \%$ in this group is encouraging and suggests a very low probability of non-sentinel node involvement.

As stated before, repeat lymphoscintigraphy and axillary staging of patients with recurrent breast cancer seems appropriate considering the high rate of positive axillary lymph nodes in these patients ${ }^{9}$, which is confirmed by the $22.8 \%$ positivity rate in this study, and the above mentioned significant aberrant drainage rates. Identifying and treating these positive lymph nodes could improve locoregional disease control, as is the case in primary breast cancer ${ }^{16,17}$. Whether completion ALND would indeed be beneficial in case of identification of axillary lymph node metastases is debatable. Results of the ACOSOG Zooo11 trial, in which SNB positive patients were randomized between ALND and observation, nurtured the discussion on management of SNB positive patients ${ }^{18,19}$. Regional recurrence rates were $<1 \%$ in the SNB alone group despite of the fact that an estimated $27 \%$ of them had additional metastases in the undissected axillary nodes. It is important to realize, however, that in the ACOSOG Zoo11 trial 97\% of the patients received adjuvant systemic therapy and $89 \%$ of the patients received whole-breast irradiation with the use of tangential fields. This combined multidisciplinary treatment could have been sufficient in reducing the risk of locoregional breast cancer recurrences and caution is warranted in extrapolating these results to patients with locally recurrent breast cancer. Since contralateral axillary metastasis in case of locally recurrent breast cancer is probably a demonstration of regional lymph node dissemination through aberrant pathways, it is very well possible that the discussion on the benefit of a completion ALND in case of ipsilateral axillary node-positivity also applies to these contralateral metastases. In this study, 3 patients with ipsilateral axillary metastases after a previous SNB or no axillary staging all underwent completion ALND. Five patients had contralateral axillary metastases on repeat SNB. In 3 cases a contralateral ALND was performed, one combined with contralateral axillary radiotherapy, and in 2 cases no 
additional ALND was proposed. These two patients both had micrometastastic disease in their contralateral axillary lymph node.

Prognosis of patients with locally recurrent breast cancer depends on disease free interval, the extent and location of the recurrent tumour and prognostic characteristics of the primary tumour, such as nodal status and lymphovascular invasion ${ }^{20-22}$. Patients with a local recurrence have an increased risk of developing distant disease compared to those who remain disease-free ${ }^{23}$, but still 5-year survival rates of $40-65 \%$ can be reached ${ }^{20,22,24}$. A randomized controlled trial showed an increase of 5 -year disease free survival for patients with breast cancer recurrence treated with tamoxifen compared to observation alone $^{25}$. Based on these data, patients with a positive estrogen and/or progesterone receptor status are candidates for hormonal treatment irrespective of nodal status. With respect to chemotherapy, there is no consensus on the effectiveness in patients with locally recurrent breast cancer ${ }^{26,27}$. Identification of positive lymph nodes in patients with a local recurrence could improve risk stratification and might play a role in making adjuvant systemic treatment decisions.

Up to now, only retrospective series on repeat SNB have been published and, except for the series of 117 patients described by Port et al., they all involve small numbers of patients. Thanks to the participation of 35 hospitals in The Netherlands we were able to create the largest series of patients with locally recurrent breast cancer staged by repeat SNB. In this series a repeat SNB was technically feasible in $52.7 \%$ of patients, $58.0 \%$ after a previous SNB and $47.9 \%$ after a previous ALND. These numbers are a bit lower than those described in the literature. Also, in the present series there is no significant difference in the identification rate after a previous SNB or ALND, which is not in line with previous literature that suggested that feasibility might be less after $\operatorname{ALND}^{13,28,29}$. Selection and publication bias in the existing literature could have played a role in this as well as experience and lymphatic mapping technique. Despite existing doubts on the possibility of performing repeat SNB after a previous mastectomy, the procedure was successful in $71 \%$ of the patients. This result is consistent with the SNB success rate of $65 \%$ after a previous mastectomy found in the literature ${ }^{28}$. The patients in our study were included in university hospitals, large non-university teaching hospitals and community hospitals, and as a result of this our findings are most likely a reflection of current practice in patients with local recurrence and the feasibility of repeat SNB throughout The Netherlands.

A remarkable observation is the high percentage of aberrant drainage pathways, especially after previous ALND. The French anatomist Sappey in his book "Anatomie, Physiology, Pathologie des vaisseaux lymphatiques", first described lymphatic drainage from the breast in 1874 . He described a centripetal direction of the drainage pathways towards the areola where pooling occurs before the lymph passes by specific channels to the axillary lymphatics. Although there is still some controversy on the role of the 
subareolar plexus, it is generally believed to be a critical region in which the parenchymal lymph, the cutaneous lymphatics and the fascial plexus communicate with each other ${ }^{30,31}$. However, some lymph vessels don't follow this pattern and pass over or through the breast parenchyma to the contralateral axilla or course beside the branches of the internal mammary vessels ${ }^{32}$. Presence of these lymph vessels could explain the observation of atypical axillary metastases, originating from ipsilateral occult or contralateral breast cancer ${ }^{33}$. Lymphatic vessels may be disrupted and the anatomy of breast lymphatics may be changed due to surgery and/or radiotherapy ${ }^{34}$. For example, a change of the drainage pattern could be demonstrated with lymphoscintigraphy in 11 of 25 patients following excision biopsy of the breast ${ }^{35}$. It appears that drainage can be reestablished by local reconnection, connection to dermal or deep lymphatics or lymphovenous communication to superficial veins. As a result of this, aberrant drainage pathways to contralateral, internal mammary chain, supraclavicular and infraclavicular lymph node basins can be visualized in patients with locally recurrent breast cancer. Under the assumption that the subareolar plexus might be damaged after previous treatment, we asked the participating nuclear physician to inject the radioactive tracer in the deep parenchymal tissue around the recurrent tumour after BCT, to be able to detect these aberrant drainage patterns. In the literature, these aberrant drainage patterns are shown in approximately $60 \%$ of patients after previous ALND and in $10 \%$ of patients after previous $\mathrm{SNB}^{13,14,36-4^{0}}$. These numbers are lower than our aberrant drainage rates of $79.3 \%$ after a previous ALND and $25.0 \%$ after a previous SNB. Our finding that $66.7 \%$ of the metastases were found in these aberrant lymph node basins suggests that these drainage pathways do indeed represent relevant and significant drainage to a true sentinel node.

Although our series is the largest described in the literature so far, the number of patients is still relatively small which makes it difficult to draw conclusions on the technical feasibility and validity of repeat SNB for different patient groups. However, the patterns are quite consistent with other studies described in the literature. Preferably, we would have conducted a randomized controlled trial, comparing ipsilateral ALND or no axillary staging after a previous ALND with repeat SNB. However, due to the low absolute risk of breast cancer recurrence and the anticipated small effect on survival, such a trial was considered not to be feasible.

In conclusion, it seems technically feasible and valid to perform SNB in patients with locally recurrent breast cancer. In almost $10 \%$ of the patients adjuvant treatment plans were altered based on information derived from the repeat SNB and more than $50 \%$ of the patients with a previous negative SNB could be spared an ipsilateral ALND as a result of a successful repeat SNB, with a negligible false-negative rate. 


\section{References}

1. Nationaal Borstkanker Overleg Nederland (NABON) (2008). Richtlijn behandeling van het mammacarcinoom. Available: www.oncoline.nl

2. Kim T, Giuliano AE, Lyman GH. Lymphatic mapping and sentinel lymph node biopsy in earlystaged breast carcinoma, a meta-analysis. Cancer 2006;106:4-16

3. Naik AM, Fey J, Gemignani $M$, et al. The risk of axillary relapse after sentinel lymph node biopsy for breast cancer is comparable with that of axillary lymph node dissection, a follow-up study of 4008 procedures. Ann Surg 2004;240:462-471

4. Veronesi U, Paganelli $G$, Viale $G$, et al. Sentinel-lymph-node biopsy as a staging procedure in breast cancer: update of a randomised controlled study. Lancet Oncol 2006;7:983-990

5. Maaskant AJG, van de Poll-Franse LV, Voogd AC, Coebergh JWW, Tutein Nolthenius-Puylaert MCBJE, Nieuwenhuijzen GAP. Stage Migration due to introduction of the sentinel node procedure: a population-based study. Breast Cancer Res Treat 2009;113:173-179

6. Edge SB, Niland JC, Bookman MA, et al. Emergence of sentinel node biopsy in breast cancer as standard-of-care in academic comprehensive cancer centers. J Natl Cancer Inst 2003;95:15141521

7. Veronesi $U$, Cascinelli $N$, Mariani $L$, et al. Twenty-year follow-up of a randomized study comparing breast-conserving surgery with radical mastectomy for early breast cancer. $\mathrm{N}$ Engl J Med 2002;347:1227-1232

8. Voogd $A C$, Nielsen $M$, Peterse $J L$, et al. Differences in risk factors for local and distant recurrence after breast-conserving therapy or mastectomy for stage I and II breast cancer: pooled results of two large European randomized trials. J Clin Oncol 2001;15:1688-1697

9. Recht A, Come SE, Troyan SL, Sadowski NL. Management of recurrent breast cancer. In: Harris J, Lippman M, Morrow M, Osborne CK, editors. Diseases of the breast. Philadelphia: Lippincott Williams \& Wilkins; 2000. p. 731-748

10. Derkx F, Maaskant-Braat AJG, van der Sangen MJC, Nieuwenhuijzen GAP, van de Poll-Franse LV, Roumen RMH, Voogd AC. Staging and management of axillary lymph nodes in patients with local recurrence in the breast or chest wall after a previous negative sentinel node procedure. Eur J Surg Oncol 2010;36:646-651

11. Schijven MP, Vingerhoets AJJM, Rutten HJT, Nieuwenhuijzen GAP, Roumen RMH, van Bussel $M E$, Voogd AC. Comparison of morbidity between axillary lymph node dissection and sentinel node biopsy. Eur J Surg Oncol 2003;29:341-350

12. Roumen $\mathrm{RMH}$, Kuijt GP, Liem IH. Lymphatic mapping and sentinel node harvesting in patients with recurrent breast cancer. Eur J Surg Oncol 2006;32:1076-1081

13. Port ER, Garcia-Etienne CA, Park J, Fey J, Borgen PI, Cody HS zrd. Reoperative sentinel lymph node biopsy: a new frontier in the management of ipsilateral breast tumor recurrence. Ann Surg Oncol 2007;14:2209-2214

14. Intra M, Trifirò G, Galimberti V, Gentilini O, Rotmensz N, Veronesi P. Second axillary sentinel node biopsy for ipsilateral breast tumour recurrence. Br J Surg 2007;94:1216-1219

15. Hermanek P, Sobin LH, editors (1987) UICC TNM classification of malignant tumors. Berlin: Springer-Verlag 94-99

16. Overgaard M, Hansen PS, Overgaard J, et al. Postoperative radiotherapy in high-risk premenopausal women with breast cancer who receive adjuvant chemotherapy. N Engl J Med 1997;337:949-955

17. Orr RK. The impact of prophylactic axillary node dissection on breast cancer survival - a Bayesian meta-analysis. Ann Surg Oncol 1999;6:109-116 
18. Giuliano AE, McCall L, Beitsch P, Whitworth PW, Blumencranz P, Leitch AM, et al. Locoregional recurrence after sentinel lymph node dissection with or without axillary dissection in patients with sentinel lymph node metastases. Ann Surg 2010;252: 426-433

19. Giuliano AE, Hunt KK, Ballman KV, et al. Axillary dissection vs no axillary dissection in women with invasive breast cancer and sentinel node metastasis: a randomized clinical trial. JAMA 2011;305:569-575

20. van Tienhoven $G$, Voogd AC, Peterse JL, et al. on behalf of the EORTC Breast Cancer Cooperative Group and the Danish Breast Cancer Cooperative Group. Prognosis after treatment for loco-regional recurrence after mastectomy or breast conserving therapy in two randomized trials (EORTC 10801 and DBCG-82TM). Eur J Cancer 1999;35:32-38

21. Van der Sangen MJ, Coebergh JW, Roumen RM, Rutten HJ, Vreugdenhil G, Voogd AC. Detection, treatment, and outcome of isolated supraclavicular recurrence in 42 patients with invasive breast carcinoma. Cancer 2003;98:11-17

22. Voogd AC, van Oost FJ, Rutgers EJ, Elkhuizen PH, van Geel AN, Scheijmans LJ et al. Long-term prognosis of patients with local recurrence after conservative surgery and radiotherapy for early breast cancer. Eur J Cancer 2005;41:2637-2644

23. Fisher B, Anderson $S$, Fisher ER, et al. Significance of ipsilateral breast tumour recurrence after lumpectomy. Lancet. 1991;338:327-331

24. Clemons M, Danson S, Hamilton T, Goss P. Locoregionally recurrent breast cancer: incidence, risk factors and survival. Cancer Treat Rev. 2001;27:67-82

25. Borner $M$, Bacchi $M$, Goldhirsch $A$, et al. First isolated locoregional recurrence following mastectomy for breast cancer: results of a phase III multicenter study comparing systemic treatment with observation after excision and radiation. Swiss Group for Clinical Cancer Research. J Clin Oncol 1994;12:2071-2077

26. Haylock BJ, Coppin CM, Jackson J, Basco VE, Wilson KS. Locoregional first recurrence after mastectomy: prospective cohort studies with and without immediate chemotherapy. Int J Radiat Oncol Biol Phys 2000;46:355-362

27. Rauschecker $\mathrm{H}, \mathrm{Clarke} M$, Gatzemeier, Recht A. Systemic therapy for treating locoregional recurrence in women with breast cancer. Cochrane Database Syst Rev. 2001;(4):CDoo2195

28. Karam A, Stempel M, Cody HS, Port ER. Reoperative sentinel lymph node biopsy after previous mastectomy. J Am Coll Surg 2008;207:543-548

29. Schrenk P, Tausch $C$, Wayand W. Lymphatic mapping in patients with primary or recurrent breast cancer following previous axillary surgery. Eur J Surg Oncol 2008;34:851-856

30. Grant RN, Tabah EJ, Adair FE. The surgical significance of the subareolar lymph plexus in cancer of the breast. Surgery 1953;33:71-78

31. Suami H, Pan W, Taylor GI. Historical review of breast lymphatic studies. Clinical Anatomy 2009;22:531-536

32. Suami H, Pan W, Mann GB, Taylor GI. The lymphatic anatomy of the breast and its implications for sentinel lymph node biopsy. Ann Surg Oncol 2007;15:863-871

33. Lanitis S, Behranwala KA, Al-Mufti R, Hadjiminas D. Axillary metastatic disease as presentation of occult or contralateral breast cancer. The Breast 2009;18:225-227

34. Perre $\mathrm{Cl}$, Hoefnagel CA, Kroon BB, Zoetmulder FA, Rutgers EJ. Altered lymphatic drainage after lymphadenectomy of radiotherapy of the axilla in patients with breast cancer. $\mathrm{Br} J$ Surg 1996;83:1258

35. Estourgie SH, Valdes Olmos RA, Nieweg OE, Hoefnagel CA, Rutgers EJT, Kroon BBR. Excision biopsy of breast lesions changes the pattern of lymphatic drainage. $\mathrm{Br} J$ Surg 2007;94:10881091 
36. Boughey JC, Ross MI, Babiera GV, et al. Sentinel lymph node surgery in locally recurrent breast cancer. Clin Breast Cancer 2006;7:248-253

37. Dinan $D$, Nagle $C E$, Pettinga J. Lymphatic mapping and sentinel node biopsy in women with an ipsilateral second breast carcinoma and a history of breast and axillary surgery. Am J Surg 2005;190:614-617

38. Koizumi M, Koyama M, Tada K, et al. The feasibility of sentinel node biopsy in the previously treated breast. Eur J Surg Oncol 2008;34:365-368

39. Taback B, Nguyen P, Hansen N, Edwards GK, Conway K, Giuliano AE. Sentinel lymph node biopsy for local recurrence of breast cancer after breast-conserving therapy. Ann Surg Oncol 2006;13:1099-1104

40. Tasevski R, Gogos AJ, Mann GB. Reoperative sentinel lymph node biopsy in ipsilateral breast cancer relapse. The Breast 2009;18:322-326 
Chapter 10

\section{Summary, discussion and recommendations}


Chapter 10 


\section{Summary, discussion and recommendations}

Over 13000 women are diagnosed with invasive breast cancer each year in The Netherlands and the lifetime risk of being diagnosed with breast cancer is $12-13 \%{ }^{1}$. The combination of an increased breast cancer incidence ${ }^{2}$ and improved survival rates $s^{3,4}$ implies that the number of prevalent breast cancer cases will continue to rise along with a subsequent burden on health care. Over time, the surgical treatment of breast cancer has evolved from radical mastectomy and super-radical mastectomy to eventually less radical operations such as the modified radical mastectomy, quadrantectomy and lumpectomy. Ever since the 18th century axillary nodal involvement in breast cancer has been recognized as indicative for a worse prognosis and from that moment on surgery of the axillary nodal basin has been a routine component of breast cancer surgery. In analogy with the trend to use a more conservative approach with regard to surgery of the breast, the search for a less invasive alternative to axillary lymph node dissection (ALND) as regional staging method led to the introduction of the sentinel node procedure in the early 1990's. According to the sentinel node hypothesis the sentinel node is the first (axillary) lymph node draining the tumour and it is thus most likely to contain regional breast cancer metastases.

Prognostic impact of minimal nodal disease and the role of axillary lymph node dissection after introduction of the sentinel node procedure

The first study (chapter 2) confirmed the assumption that the introduction of the sentinel node biopsy (SNB) led to an increase in the proportion of patients with positive axillary lymph nodes due to easier identification of malignant cells, resulting in stage migration. Data were analysed on 17100 women diagnosed with invasive breast cancer in the Southeast Netherlands in the period 1994-2005. The percentage of patients with micrometastases increased from $1.0 \%$ in 1994 to $4.3 \%$ in 2005 ( $P<0.0001)$, whereas no significant increase was observed of the proportion of patients with positive axillary lymph nodes. After adjustment for tumour size, age at diagnosis and histology however, the probability of having a positive axillary lymph node status was $10 \%$ higher in period 2003-2005, as compared to period 1994-1996. Tvedskov et al. recently reported an increase in the proportion of patients with positive lymph nodes after the introduction of SNB in Denmark of $3.9 \%$ due to the increased detection of micrometastases ${ }^{5}$. In that study, the proportion of patients that were offered adjuvant systemic treatment because of a positive nodal status however only increased from $7.8 \%$ to $8.8 \%$, indicating that nodal status nowadays is less important in risk-allocation. Nevertheless, the debate on the prognostic impact of these micrometastases and isolated tumour cells (ITC's) is reflected by the large variation between hospitals in the South of The Netherlands in the use of completion ALND and administration of systemic therapy in these patients, as 
described in chapter 3 . In a population-based study of 9038 women who underwent SNB for invasive breast cancer from $1996-2008,45 \%$ of 172 patients with ITC's and $76 \%$ of 605 patients with micrometastases received adjuvant systemic treatment. Administration of adjuvant systemic therapy was probably based solely on the presence of minimal nodal involvement in $21 \%$ of patients with ITC's and $40 \%$ of patients with micrometastases. Multivariate analyses showed a significantly higher chance of receiving systemic treatment when ITC's (OR $1.5(95 \% \mathrm{Cl}, 1.05-2.15)$ ) or micrometastases (OR $10.7(95 \% \mathrm{Cl}$, 8.56-13.27)) were present, compared to a negative lymph node status. A completion ALND was performed in $37 \%$ of the patients with ITC's compared to $75 \%$ of the patients when micrometastases were present.

If adjuvant systemic therapy should be advised based solely on the presence of sentinel node ITC's and micrometastases is dependent on their impact on survival. From the study described in chapter 4 we learned that detection of ITC's and micrometastases in women who underwent SNB for invasive breast cancer $(n=6803)$ did not confer any significant survival difference compared with node-negative disease. In this cohort of women treated in the Southeast region of The Netherlands from 1996-2006, 451 patients (6.6\%) had sentinel node micrometastases and in 126 patients (1.9\%) ITC's were detected. Even after adjustment for a potentially confounding effect of patient- and tumour characteristics and administration of adjuvant systemic therapy, we found no impact of minimal sentinel nodal involvement on breast cancer overall survival during the first years after diagnosis. This lack of prognostic impact of micrometastases was confirmed by several retrospective studies that showed no impact of micrometastases on disease-free or overall survival ${ }^{6-8}$ as well as by the results of the prospective ACOSOG Zoo1o trial in which immunohistochemical detection of sentinel node metastases was not associated with a worse overall survival ${ }^{9}$. On the other hand, several other studies suggest a small but significant impact of sentinel node micrometastases on disease-free and overall survival ${ }^{10,11}$. Remarkably, in the MIRROR study (Micrometastases and Isolated tumour cells: Relevant and Robust or Rubbish?), a worse 5-year disease-free survival was observed for patients with ITC's and micrometastases ${ }^{12}$. This study contained data from patients that were also included in our study on prognostic significance of micrometastases as well as in the studies conducted by Gobardhan ${ }^{6,7}$, all of which showed no significant impact of micrometastatic sentinel lymph node involvement on breast cancer overall survival. In the MIRROR study, three breast cancer pathologists reviewed pathology of removed axillary lymph nodes, which seems to have led to the identification of more patients with ITC's (30.3\%) and micrometastases $(38.1 \%)$. We chose not to perform central pathology review and to base our analyses on the information that was retrieved from the pathology reports and thus to present results based on usual care in The Netherlands. Furthermore, the MIRROR study only reports on disease-free survival, a composite endpoint of distant metastasis, local recurrence, contralateral breast cancer 
and death from other causes. Given the large contribution of local recurrence and contralateral breast cancer to disease-free survival in breast cancer, this decrease in disease-free survival might not translate into a significant difference in the overall survival rate.

In several reviews attempts have been made to formulate definitive conclusions regarding the prognostic impact of minimal sentinel nodal disease ${ }^{13-15}$, but small groups and short follow-up in the SNB-groups limit the results of these contradicting reviews. It is conceivable however, that micrometastases may be a heterogeneous entity and that biologic behaviour of the tumour is a more powerful predictor of development of distant metastasis. If this is the case, the use of gene-expression profiling (e.g. microarray) might, after further validation, become a useful means in guiding adjuvant therapy in lymph node positive breast cancer patients ${ }^{16,17}$.

The use of completion ALND as a treatment modality for patients with sentinel node (micro)metastases has been a subject of debate as well. In spite of an estimated $20-50 \%$ risk of finding additional metastases in the ALND specimen ${ }^{18-20}$, only a small percentage of these metastases become clinically overt ${ }^{21,22}$. Omission of ALND in these patients did not result in worse survival or local axillary control ${ }^{21,22}$. Especially in women with small and low to intermediate grade tumours ALND for minimal sentinel nodal involvement can safely be avoided ${ }^{23}$. The International Breast Cancer Study Group (IBCSG) 23.01 trial in which patients with sentinel node micrometastases were randomized between completion ALND and no further treatment indeed shows that ALND could be avoided in patients with early breast cancer and sentinel node micrometastases with no adverse effect on survival ${ }^{24}$. It is important to realize, however, that administration of adjuvant systemic therapy is known for its potential to diminish locoregional recurrence in breast cancer patients ${ }^{25}$ and approximately $25 \%$ of patients with positive lymph nodes who are treated with neo-adjuvant chemotherapy have a complete eradication of nodal disease ${ }^{26}$. Also, whole-breast irradiation with tangential fields includes the majority of level I and II axillary lymph nodes. It is estimated that more than $50 \%$ of level I and $20-30 \%$ of level II nodes receive $95 \%$ of the prescribed radiation dose, depending on patient anatomy and the upper tangential field border ${ }^{27,28}$. As mentioned earlier, knowledge of tumour biology might assist clinicians in identifying those node-positive patients who could be spared chemotherapy in the future without compromising long-term outcomes. This must be considered when deciding whether to carry out an ALND in the management of these patients $^{29}$.

An alternative to ALND for sentinel node-positive breast cancer is axillary radiotherapy (AxRT). Our study (chapter 5) provided data suggesting that AxRT is an effective and safe alternative to ALND for sentinel node-positive breast cancer. Between 1998 and 2001, 35 patients with sentinel node-positive primary breast cancer underwent AxRT as an alternative to ALND. After a median follow-up of 131 months (range 114-149) no regional 
axillary recurrences were observed and on prospective analysis morbidity was comparable to ALND. A point of discussion regarding this treatment strategy is the lack of knowledge of extent of nodal involvement. In the AMAROS trial, in which patients with sentinel node-positive breast cancer were randomized between ALND and AxRT, the influence of ALND on the administration of adjuvant treatment was assessed in the first 566 patients. The authors concluded that the lack of knowledge of extent of nodal involvement in the AxRT arm had no impact on the administration of adjuvant systemic treatment ${ }^{30}$.

In conclusion, the impact of micrometastases on prognosis and regional tumour control seems to be overestimated and the most recent studies increasingly support the thesis that remaining axillary metastases neither increase the axillary recurrence rate nor decrease overall survival. Based on these studies, presence of micrometastases in itself should probably not be an indication for administration of adjuvant systemic therapy. Also, axillary metastases are sensitive to systemic treatment and are targeted by postoperative tangential breast irradiation, so patients with (micro)metastases who receive these treatment modalities should not necessarily be subjected to the extra morbidity of an ALND. In patients who do not receive adjuvant systemic therapy or tangential breast irradiation, AxRT could be a less invasive alternative to ALND.

\section{Repeat sentinel node biopsy for locally recurrent breast cancer}

Approximately 5 to $10 \%$ of breast cancer patients develop a local recurrence in the breast or chest wall ${ }^{31,32}$. In accordance with primary breast cancer, axillary staging in case of locally recurrent breast cancer could be of benefit to improve locoregional control and may play a role in making recommendations for adjuvant systemic treatment administration ${ }^{33,34}$. For these reasons it seems sensible to perform axillary staging in case of locally recurrent breast cancer, despite the absence of guidelines on this topic. So far, in patients with locally recurrent breast cancer and a previous negative SNB an ALND would be suggested and in patients with a previous ALND no additional axillary staging would be proposed. In both cases a repeat SNB could be considered for regional staging and identification of aberrant lymph drainage pathways as well.

The absence of guidelines on axillary staging in patients with locally recurrent breast cancer is reflected by the diverse treatment strategies of the axilla observed in the Southeast Netherlands as described in chapter 6. We analysed axillary staging and management in 70 patients with locally recurrent breast cancer after a previous negative SNB from 1996-2006. Staging strategies of the axilla were diverse and included ALND (52.9\%), SNB alone (7.1\%), SNB and ALND (11.4\%), axillary radiotherapy (1.4\%) and no treatment at all (27.1\%). Remarkably, positive axillary lymph nodes were detected in 13 of 
the 50 patients who underwent axillary staging (26.0\%), warranting repeat surgical staging in these patients.

First, a systematic review was conducted to identify all available knowledge on repeat SNB for locally recurrent breast cancer (chapter 7). Weighed analyses of the pooled data of 692 patients showed repeat SNB to be both technically feasible and safe, with a successful identification in two out of three patients, no additional metastases on confirmation ALND and a very low axillary recurrence rate. Aberrant drainage pathways were visualized in $43.2 \%$ of the patients and in one out of five patients the sentinel node was tumour-positive. Additional morbidity could be prevented in nearly $70 \%$ of the patients by leaving out an ALND and in $17.9 \%$ of the patients the information derived from the repeat SNB led to a change in the decisions for adjuvant treatment.

In the prospective single centre trial described in chapter 8 the concept of repeat SNB was researched as a "proof of principle" in patients after previous breast-conserving therapy (BCT) with SNB and/or ALND. We included 44 patients, 22 after a previous SNB and 22 after a previous ALND, and we recorded both identification rate and aberrant drainage patterns. The lymphoscintigraphy success rate was $39 \%$ and in $18 \%$ of all cases a drainage pathway was visualized outside the ipsilateral axilla. An aberrant drainage pattern tended to be more frequent after a previous ALND than after a previous SNB ( $27 \%$ versus $9 \%, \mathrm{P}=0.122$ ).

The feasibility and safety of the repeat SNB were confirmed in the Dutch nationwide "Sentinel Node And Recurrent Breast cancer (SNARB)" registration study (chapter 9), the largest study published on the subject so far. Hundred and fifty patients treated in 22 hospitals were included after previous BCT or mastectomy with SNB or ALND. Sentinel node identification rate was $63.3 \%$ and in $52.7 \%$ of the patients the sentinel node was successfully surgically removed. Aberrant drainage pathways were visualized in $58.9 \%$ of the patients, significantly more frequent after a previous ALND (79.3\%) than after a previous SNB (25.0\%) ( $P<0.0001)$. In one out of five patients undergoing repeat SNB one or more sentinel nodes were tumour positive and in $16.5 \%$ of the patients the information derived from the repeat SNB led to a change in treatment plans. More importantly, ALND could possibly be omitted in more than $50 \%$ of the patients as a result of a successful repeat SNB, with a negligible false-negative rate. The cohort is currently being expanded and we hope to report on the results of 300 included patients, including first follow-up results, in the near future. Also, we will analyse possible factors that could be of influence on the repeat sentinel node identification rate, such as location of injection of the radioactive tracer and time between injection and lymphoscintigrapy.

In conclusion, after conducting a systematic review of the literature and a proof of principle-study on repeat SNB after previous breast- and axillary treatment, the nationwide Sentinel Node And Recurrent Breast cancer (SNARB) study confirmed the 
feasibility and validity of the concept of repeat SNB in case of locally recurrent breast cancer. Also, by identifying aberrant drainage pathways, additional information was acquired based on which treatment plans were altered. These results were largely consistent with the results of the review and, in our opinion, warrant a change in national guideline recommendations to include repeat SNB as an axillary staging procedure in locally recurrent breast cancer. 


\section{References}

1. Dutch Cancer Registry, Comprehensive Cancer Centre the Netherlands (CCCNL). Available from URL: http://cijfersoverkanker.nl [accessed 2 march, 2012]

2. Louwman WJ, Voogd AC, Van Dijck JAAM et. al. On the rising trends of incidence and prognosis for breast cancer patients diagnosed 1975-2004: a long-term population-based study in southeastern Netherlands. Cancer Causes Control 2008;19:97-106

3. Vervoort MM, Draisma G, Fracheboud J, van de Poll-Franse LV, de Koning HJ. Trends in the usage of adjuvant systemic therapy for breast cancer in the Netherlands and its effect on mortality. Br J Cancer 2004;91:242-247

4. Otto SJ, Fracheboud J, Looman CW, Broeders MJ, Boer R, Hendriks JH, Verbeek AL, de Koning HJ. Initiation of population-based mammography screening in Dutch municipalities and effect on breast-cancer mortality: a systematic review. Lancet 2003;361:1411-1417

5. Tsvedskov $T F$, Jensen $M$, Balslev $E$, et al. Stage migration after introduction of sentinel lymph node dissection in breast cancer treatment in Denmark: A nationwide study. Eur J Cancer 2011;47:872-878

6. Gobardhan PD, Elias SG, Madsen EV, et al. Prognostic value of micrometastases in sentinel lymph nodes of patients with breast carcinoma: a multicenter cohort study. Ann Surg Oncol 2011;18:1657-1664

7. Gobardhan PD, Elias SG, Madsen EVE et al. Prognostic value of micrometastases in sentinel lymph nodes of patients with breast carcinoma: a cohort study. Ann Oncol 2009;20:41-48

8. Hansen NM, Grube B, Ye X et al. Impact of micrometastases in the sentinel node of patients with invasive breast cancer. J Clin Oncol 2009;27:4679-4684

9. Giuliano $A E$, Hawes $D$, Ballman KV, et al. Association of occult metastases in sentinel lymph nodes and bone marrow with survival among women with early-stage invasive breast cancer. JAMA 2011;306:385-393

10. Colleoni M, Rotmensz N, Peruzzotti $G$, et al. Size of breast cancer metastases in axillary lymph nodes: Clinical relevance of minimal lymph node involvement. J Clin Oncol 2005;23:1379-1389

11. Weaver DL, Ashikaga T, Krag DN, et al. Effect of occult metastases on survival in nodenegative breast cancer. N Engl J Med 2011;364:412-421

12. de Boer M, van Deurzen CHM, van Dijck JAAM et al. Micrometastases or isolated tumor cells and the outcome of breast cancer. N Engl J Med 2009;361:653-663

13. Gerber B, Heintze $K$, Stubert J, et al. Axillary lymph node dissection in early-stage invasive breast cancer: is it still standard today? Breast Cancer Res Treat 2011;128:613-624

14. Salhab M, Patani N, Mokbel K. Sentinel lymph node micrometastasis in human breast cancer: An update. Surg Oncol 2011;doi:10.1016/j.suronc.2011.06.0 06

15. de Boer M, van Dijck JA, Bult P, Borm GF, Tjan-Heijnen VC. Breast cancer prognosis and occult lymph node metastases, isolated tumor cells, and micrometastases. J Natl Cancer Inst 2010;102:410-425

16. Rutgers E, Piccart-Gebhart MJ, Bogaerts J, et al. The EORTC 10041/BIG 03-04 MINDACT trial is feasible: results of the pilot phase. Eur J Cancer 2011;47:2742-2749

17. Van de Vijver MJ, He YD, van 't Veer LJ, et al. A gene-expression signature as a predictor of survival in breast cancer. N Engl J Med 2002;347:1999-2009

18. Van Rijk MC, Peterse JL, Nieweg $\mathrm{OE}$, et al. Additional axillary metastases and stage migration in breast cancer patients with micrometastases or submicrometastases in sentinel lymph nodes. Cancer 2006;107:467-471

19. Cserni G, Gregori D, Merletti F, et al. Meta-analysis of non-sentinel node metastases associated with micrometastatic sentinel nodes in breast cancer. Br J Surg 2004;91:1245-1252 
20. Fan $Y, T a n Y, W u C$, et al. The effect of sentinel node tumor burden on non-sentinel node status and recurrence rates in breast cancer. Ann Surg Oncol 2005;12:705-711

21. Giuliano $A E$, McCall $L$, Beitsch $P$, Whitworth PW, Blumencranz $P$, Leitch $A M$, et al. Locoregional recurrence after sentinel lymph node dissection with or without axillary dissection in patients with sentinel lymph node metastases. Ann Surg 2010;252:426-433

22. Giuliano $A E$, Hunt $K K$, Ballman $K V$, et al. Axillary dissection vs no axillary dissection in women with invasive breast cancer and sentinel node metastasis: a randomized clinical trial. JAMA 2011;305:569-575

23. Galimberti V, Botteri E, Chifu C, et al. Can we avoid axillary dissection in the micrometastastic sentinel node in breast cancer? Breast Cancer Res Treat 2012;131:819-825

24. Galimberti V, Cole BF, Zurrida S, et al. Axillary dissection versus no axillary dissection in matients with sentinel-node micrometastases (IBCSG 23-01): a phase 3 randomised controlled trial. Lancet Oncol 2013;14:297-305

25. Buchholz TA, Tucker SL, Erwin J, et al. Impact of systemic treatment on local control for patients with lymph node-negative breast cancer treated with breast-conservation therapy. J ClinOncol 2001;19:2240-2246

26. Gralow JR, Burstein HJ, Wood W, et al. Preoperative therapy in invasive breast cancer: Pathologic assessment and systemic therapy issues in operable disease. J ClinOncol 2008;26:814-819

27. Schlembach PJ, Buchholz TA, Ross MI, et al. Relationship of sentinel and axillary level I-II lymph nodes to tangential fields used in breast irradiation. Int J Radiat Oncol Biol Phys 2001;51:671678

28. Reznik J, Cicchetti MG, Degaspe $B$, et al. Analysis of axillary coverage during tangential radiation therapy to the breast. Int J Radiat Oncol Biol Phys 2005;61:163-168

29. Oliveira $M$, Cortes J, Bellet $M$, et al. Management of the axilla in early breast cancer patients in the genomic era. Ann Oncol 2013;24:1163-1170

30. Straver ME, Meijnen $P$, van Tienhoven $G$, et al. Role of axillary clearance after a tumor-positive sentinel node in the administration of adjuvant therapy in early breast cancer. J Clin Oncol 2010; doi:10.1200/JCO.2008.21.7554

31. Veronesi U, Cascinelli N, Mariani L, et al. Twenty-year follow-up of a randomized study comparing breast-conserving surgery with radical mastectomy for early breast cancer. $\mathrm{N}$ Engl J Med 2002;347:1227-1232

32. Voogd AC, Nielsen $M$, Peterse $J L$, et al. Differences in risk factors for local and distant recurrence after breast-conserving therapy or mastectomy for stage I and II breast cancer: pooled results of two large European randomized trials. J Clin Oncol 2001;15:1688-1697

33. Overgaard M, Hansen PS, Overgaard J, et al. Postoperative radiotherapy in high-risk premenopausal women with breast cancer who receive adjuvant chemotherapy. $\mathrm{N}$ Engl J Med 1997;337:949-955

34. Orr RK. The impact of prophylactic axillary node dissection on breast cancer survival - a Bayesian meta-analysis. Ann Surg Oncol 1999;6:109-116 


\section{Samenvatting, discussie en aanbevelingen}




\section{Samenvatting, discussie en aanbevelingen}

In Nederland worden ieder jaar meer dan 13000 vrouwen gediagnosticeerd met borstkanker en het risico om tijdens het leven de diagnose borstkanker te krijgen is 12$13 \%{ }^{1}$. De combinatie van een verhoogde borstkanker incidentie ${ }^{2}$ en een verbeterde overlevingskans ${ }^{3 / 4}$ betekent dat het aantal patiënten met borstkanker de komende jaren verder zal stijgen samen met een dientengevolge druk op het zorgstelsel. De chirurgische behandeling van borstkanker heeft zich door de jaren heen ontwikkeld van radicale en super-radicale mastectomie tot uiteindelijk minder radicale operaties zoals de gemodificeerde radicale mastectomie, quadrantectomie en lumpectomie.

Reeds sinds het moment dat in de $18^{\mathrm{e}}$ eeuw betrokkenheid van de axillaire lymfeklieren werd erkend als indicatief voor een slechtere prognose, is chirurgie van de axillaire lymfeklieren een standaard onderdeel van de behandeling van borstkanker geworden. In navolging van de trend om chirurgie van de borst conservatiever te benaderen, heeft de zoektocht naar een minder invasief alternatief voor de okselklierdissectie (OKD) als een regionale stageringsmethode geleid tot de introductie van de schildwachtklier (SWK) procedure in de vroege jaren 1990. Volgens de schildwachtklier hypothese is de schildwachtklier de eerste (axillaire) lymfeklier waarop de tumor draineert en deze klier heeft dus de grootste kans om regionale borstkanker metastasen te bevatten.

\section{Prognostische betekenis van geïsoleerde tumorcellen en micrometastasen en de rol van de okselklierdissectie na introductie van de schildwachtklierprocedure}

In het eerste onderzoek (hoofdstuk 2) wordt de aanname bevestigd dat de introductie van de SWK procedure heeft geleid tot een toename in het aantal patiënten met positieve okselklieren door een gemakkelijker identificatie van maligne cellen. Hierdoor is stadiummigratie ontstaan. We analyseerden data van 17100 vrouwen die van 1994-2005 met borstkanker gediagnosticeerd werden in het Zuidoosten van Nederland. Het percentage patiënten met micrometastasen steeg van $1.0 \%$ in 1994 tot $4.3 \%$ in 2005 $(\mathrm{P}<0.0001)$, terwijl geen significante stijging werd gezien in het deel van de patiënten dat positieve axillaire lymfeklieren had. Na correctie voor tumor grootte, leeftijd ten tijde van de diagnose en histologie werd echter wel een 10\% hogere kans gezien op positieve axillaire lymfeklieren in de periode 2003-2005 ten opzichte van 1994-1996. Tvedskov et al. rapporteerden recent een toename van 3.9\% van het aantal patiënten met positieve okselklieren na introductie van de SWK biopsie in Denemarken ${ }^{5}$. In dat onderzoek nam het deel van de patiënten dat adjuvante systemische behandeling kreeg aangeboden vanwege een positieve okselklierstatus echter slechts toe van $7.8 \%$ naar $8.8 \%$. Hieruit kan worden afgeleid dat de lymfeklierstatus tegenwoordig minder belangrijk is geworden in de risico inschatting. Desalniettemin wordt het debat over de prognostische betekenis van deze micrometastasen en geïsoleerde tumorcellen weergegeven door de grote 
variatie in het uitvoeren van een completerende okselklierdissectie of toedienen van adjuvante systemische therapie bij deze patiënten in het Zuiden van Nederland, zoals beschreven in hoofdstuk 3. In dit population-based onderzoek van 9038 vrouwen die de SWK biopsie ondergingen voor borstkanker van 1996-2008, ontvingen 45\% van 172 patiënten met geïsoleerde tumorcellen en $76 \%$ van 605 patiënten met micrometastasen adjuvante systemische behandeling. Toediening van deze systemische behandeling was waarschijnlijk alleen gebaseerd op de aanwezigheid van deze minimale betrokkenheid van de lymfeklieren in $21 \%$ van de patiënten met geïsoleerde tumorcellen en $40 \%$ van de patiënten met micrometastasen. Multivariate analyses tonen een significant hogere kans op het ontvangen van systemische behandeling in de aanwezigheid van geïsoleerde tumorcellen (OR 1.5 (95\% BI, 1.05-2.15)) of micrometastasen (OR 10.7 (95\% Cl, 8.5613.27), vergeleken met een negatieve lymfeklierstatus. Een completerende OKD werd uitgevoerd in $37 \%$ van de patiënten met geïsoleerde tumorcellen en in $75 \%$ van de patiënten met micrometastasen.

De vraag of adjuvante systemische therapie geadviseerd dient te worden gebaseerd op slechts de aanwezigheid van minimale betrokkenheid van de lymfeklieren hangt af van de invloed van deze geïsoleerde tumorcellen en micrometastasen op de overleving. Het onderzoek dat in hoofdstuk $\mathbf{4}$ beschreven wordt toont aan dat detectie van geïsoleerde tumorcellen en micrometastasen in vrouwen die een SWK biopsie voor borstkanker hebben ondergaan $(n=6803$ ) geen significant overlevingsverschil oplevert ten opzichte van vrouwen met een negatieve lymfeklierstatus. In dit cohort van vrouwen dat behandeld werd in Zuidoost Nederland van 1996-2006, hadden 451 patiënten (6.6\%) SWK-micrometastasen en bij 126 patiënten (1.9\%) werden geïsoleerde tumorcellen gedetecteerd. Zelfs na correctie voor de potentieel storende effecten van zowel patiënten tumorkarakteristieken als toediening van adjuvante systemische therapie werd geen invloed gevonden van de aanwezigheid van deze SWK-micrometastasen op borstkanker overleving gedurende de eerste jaren na de diagnose. Dit gebrek aan prognostische invloed van micrometastasen werd bevestigd door verschillende retrospectieve studies die geen invloed op de ziektevrije of algehele overleving konden aantonen ${ }^{6-8}$, net als de resultaten van de prospectieve ACOSOG Zoo10 studie waarin immunohistochemische detectie van SWK-metastasen niet geassocieerd werd met een slechtere overleving ${ }^{9}$. Aan de andere kant suggereren enkele andere studies de aanwezigheid van een kleine maar significante invloed van micrometastasen op ziektevrije en algehele overleving ${ }^{10-11}$. Opvallend is dat in de MIRROR studie (Micrometastases and Isolated tumor cells: Relevant and Robust or Rubbish?) wel een slechtere 5-jaars ziektevrije overleving wordt aangetoond voor patiënten met geïsoleerde tumorcellen en micrometastasen ${ }^{12}$. Deze studie bevat data van patiënten die ook geïncludeerd werden in onze studie en in de studies van Gobardhan ${ }^{6,7}$, die allen geen significante invloed van minimale betrokkenheid van de SWK op de algehele borstkanker overleving konden aantonen. In de MIRROR 
studie werden de pathologie uitslagen gereviseerd door drie borstkanker pathologen, waardoor naar het schijnt een hoger percentage patiënten met geïsoleerde tumorcellen (30.3\%) en micrometastasen (38.1\%) geïdentificeerd werd. In onze studie is ervoor gekozen om geen centrale pathologie revisie uit te voeren, maar de analyses te baseren op de reeds aanwezige pathologie uitslagen zodat de resultaten dus gebaseerd zijn op de standaardbehandeling van borstkanker in Nederland. Verder rapporteert de MIRROR studie slechts over ziektevrije overleving, een samengesteld eindpunt bestaande vit metastasen op afstand, lokaal recidief, contralaterale borstkanker en overlijden door andere redenen. Door de grote bijdrage van het lokaal recidief en contralaterale borstkanker aan het eindpunt ziektevrije overleving, is het geenszins zeker dat een verschil in ziektevrije overleving zich ook zal uiten in een uiteindelijk significant verschil in algehele overleving.

In meerdere overzichtsartikelen wordt een poging gedaan om definitieve conclusies te formuleren ten aanzien van de prognostische invloed van beperkte betrokkenheid van de $\mathrm{SWK}^{13-15}$, maar deze elkaar tegensprekende resultaten worden beïnvloed door kleine groepen en korte follow-up van de SWK-patiënten. Het is echter aannemelijk dat de micrometastasen een heterogene entiteit zijn en dat het biologisch gedrag van de tumor een sterkere voorspeller is van de ontwikkeling van metastasen op afstand. Als dat daadwerkelijk het geval is kan de rol van het in kaart brengen van genexpressie, na verdere validatie, een nuttige rol spelen in het adviseren van toedienen van adjuvante systemische therapie bij lymfeklier-positieve borstkankerpatienten ${ }^{16,17}$.

Het toepassen van een completerende OKD als behandeling bij patiënten met SWK(micro)metastasen is tevens onderwerp van debat. Ondanks een geschat risico van 20$50 \%$ dat additionele metastasen in het OKD preparaat gevonden zullen worden ${ }^{18-20}$, komt slechts een klein deel van deze metastasen klinisch aan het licht ${ }^{21,22}$. Het nalaten van een OKD bij deze patiënten resulteerde niet in een slechtere overleving of lokale axillaire controle $^{21,22}$. Bij vrouwen met kleine en laaggradige tumoren in het bijzonder, kan een OKD voor beperkte SWK betrokkenheid veilig achterwege gelaten worden ${ }^{23}$. De International Breast Cancer Study Group (IBCSG) 23.01 studie, waarin patiënten met SWK-micrometastasen gerandomiseerd werden tussen wel of geen completerende OKD, toont inderdaad dat een OKD vermeden kan worden in patiënten met vroeg stadium borstkanker en SWK-micrometastasen, zonder een negatief effect op overleving ${ }^{24}$. Het is echter belangrijk om te realiseren dat de toediening van adjuvante systemische therapie het risico op het ontstaan van een locoregionaal recidief mammacarcinoom doet afnemen $^{25}$ en dat ongeveer $25 \%$ van de patiënten met positieve axillaire klieren die behandeld worden met neo-adjuvante chemotherapie een complete respons in de klieren hebben $^{26}$. Ook ligt bij de bestraling van de gehele borst met gebruik van schampvelden de meerderheid van de level I en II okselklieren in het bestralingsgebied. Er wordt geschat dat meer dan 50\% van de level I okselklieren en $20-30 \%$ van de level II okselklieren 95\% 
van de voorgeschreven stralingsdosis ontvangen, afhankelijk van de anatomie van de patiënt en de bovengrens van het bestralingsveld ${ }^{27,28}$. Zoals reeds eerder aangegeven zou kennis van de tumorbiologie de behandelaar in de toekomst kunnen helpen bij het identificeren van die lymfeklierpositieve patiënten die chemotherapie bespaard kan blijven, zonder concessies te doen aan de lange termijn vitkomst. Met het al dan niet toedienen van chemotherapie moet rekening gehouden worden bij het besluiten om wel of niet een OKD vit te voeren bij deze patienten ${ }^{29}$.

Een alternatief voor de OKD bij SWK-positieve borstkankerpatiënten is axillaire radiotherapie (AxRT). Onze studie (hoofdstuk 5) laat data zien die suggereren dat AxRT een veilig en effectief alternatief is voor de OKD in SWK-positieve borstkanker patiënten. Tussen 1998 en 2001 ondergingen 35 patiënten met SWK-positieve borstkanker AxRT als alternatief voor een OKD. Na een mediane follow-up van 131 maanden (range 114-149) werden geen regionale axillaire recidieven geobserveerd en bij prospectieve analyse was de morbiditeit vergelijkbaar met die van de OKD. Een discussiepunt bij deze behandelingsstrategie is het gebrek aan kennis van het aantal positieve axillaire lymfeklieren. In de AMAROS studie, waarin patiënten met SWK-positieve borstkanker werden gerandomiseerd tussen OKD en AxRT, werd de invloed van de OKD op de toediening van adjuvante behandeling beoordeeld in de eerste 566 patiënten. De auteurs concludeerden dat het gebrek aan kennis over de uitgebreidheid van de axillaire lymfekliermetastasering in de AxRT arm geen invloed had op het al dan niet toedienen van adjuvante systemische therapie ${ }^{30}$.

Concluderend lijkt de invloed van micrometastasen op de prognose en regionale tumorcontrole overschat te worden en de meest recente studies onderschrijven in toenemende mate de veronderstelling dat achterblijvende axillaire metastasen zowel de axillaire recidiefkans als de algehele overleving niet beïnvloeden. Gebaseerd op deze studies zou de aanwezigheid van micrometastasen op zichzelf geen indicatie moeten zijn voor het toedienen van adjuvante systemische therapie. Axillaire metastasen zijn gevoelig voor adjuvante systemische therapie en worden bereikt door postoperatieve bestraling van de borst, waardoor patiënten met (micro)metastasen die deze behandelingsmodaliteiten ondergaan niet per se hoeven worden blootgesteld aan de extra morbiditeit van een OKD. Bij patiënten die geen adjuvante systeemtherapie of bestraling van de borst ondergaan zou AxRT een minder invasief alternatief voor een OKD kunnen zijn. 


\section{Herhaalde SWK procedure voor het lokaal recidief mammacarcinoom}

Ongeveer 5 tot $10 \%$ van de borstkanker patiënten ontwikkelt een lokaal recidief in de borst of thoraxwand ${ }^{31,32}$. Analoog aan het primaire mammacarcinoom kan axillaire stagering in geval van een recidief meerwaarde hebben voor de locoregionale controle en het kan een rol spelen in het geven van adviezen aangaande adjuvante systemische behandeling ${ }^{33,34}$. Om deze redenen lijkt het logisch om axillaire stagering uit te voeren in geval van een lokaal recidief mammacarcinoom, ondanks het feit dat er geen richtlijn bestaat over dit onderwerp. Tot voor kort zou bij patiënten met een lokaal recidief mammacarcinoom en een eerdere negatieve SWK procedure een OKD uitgevoerd worden en bij patiënten na een eerdere OKD zou geen additionele axillaire stagering uitgevoerd worden. In beide gevallen kan overwogen worden om een herhaalde SWK procedure uit te voeren voor regionale stagering en voor identificatie van aberrante lymfedrainage wegen.

De afwezigheid van richtlijnen met betrekking tot axillaire stagering bij het lokaal recidief mammacarcinoom is terug te zien in de diverse behandelingsstrategieën van de axilla in het Zuidoosten van Nederland, zoals beschreven in hoofdstuk 6. De axillaire stagering en behandeling werden geanalyseerd bij 70 patiënten die van 1996-2006 gediagnosticeerd werden met een lokaal recidief mammacarcinoom na een eerdere negatieve SWK procedure. Stagerings-strategieën van de axilla waren uiteenlopend en omvatten de OKD (52.9\%), de SWK procedure alleen (7.1\%), de SWK procedure en OKD (11.4\%), axillaire radiotherapie (1.4\%) en geen enkele stagering of behandeling (27.1\%). Opvallend was dat bij 13 van de 50 patiënten die axillaire stagering ondergingen (26\%) axillaire lymfekliermetastasen aangetroffen werden, waarbij het nut van axillaire stagering bij deze patiënten benadrukt wordt.

Allereerst is een systematische review van de literatuur uitgevoerd om de reeds aanwezige kennis over de herhaalde SWK procedure voor het lokaal recidief mammacarcinoom te analyseren (hoofdstuk 7). We voerden een gewogen analyse uit van de gepoolde gegevens van 692 patiënten waarbij we tot de conclusie kwamen dat de herhaalde SWK procedure zowel technisch mogelijk als valide is, met een succesvolle identificatie in $2 / 3$ van de patiënten, geen additionele metastasen bij completerende OKD en een zeer lage axillaire recidiefkans. Aberrante lymfedrainagewegen werden gezien bij $43.2 \%$ van de patiënten en bij 1 op de 5 patiënten was de SWK tumor-positief. Additionele morbiditeit kon voorkomen worden bij bijna 70\% van de patiënten door het achterwege laten van een OKD en in $\mathbf{1 7 . 9 \%}$ van de patiënten leidde de informatie van de herhaalde SWK procedure tot een verandering in het adjuvante behandelplan.

In de prospectieve studie die in hoofdstuk $\mathbf{8}$ beschreven wordt, werd het concept van de herhaalde SWK procedure onderzocht bij patiënten na eerdere borstsparende behandeling met SWK procedure en/of OKD. In het onderzoek werden 44 patiënten geïncludeerd, 22 na een eerdere SWK procedure en 22 na een eerdere OKD en zijn 
identificatie percentage en aberrante drainagepatronen geobserveerd. Het lymfoscintigrafie succespercentage was $39 \%$ en in $18 \%$ van alle gevallen werd een drainagepatroon gevisualiseerd buiten de ipsilaterale axilla. Een aberrant drainagepatroon leek vaker voor te komen na een eerdere OKD dan na een eerdere SWK procedure (27\% versus $9 \%, \mathrm{P}=0.122)$.

De toepasbaarheid en veiligheid van de herhaalde SWK procedure werden bevestigd in de Nederlandse nationale "Sentinel Node And Recurrent Breast cancer (SNARB)" registratie studie (hoofdstuk 9), de grootste studie die tot dusver over dit onderwerp gepubliceerd is. Er werden 150 patiënten uit 22 ziekenhuizen geïncludeerd met een lokaal recidief mammacarcinoom na eerdere borstsparende chirurgie of ablatio mammae met SWK procedure of OKD. Het SWK identificatie percentage was $63.3 \%$ en in $52.7 \%$ van de patiënten werd de SWK succesvol operatief verwijderd. Aberrante drainagepatronen werden gezien in $58.9 \%$ van de patiënten en kwamen significant vaker voor na een eerdere OKD (79.3\%) dan na een eerdere SWK procedure $(25 \%)(\mathrm{P}<0.0001)$. In 1 op de 5 patiënten die een herhaalde SWK procedure ondergingen waren 1 of meer klieren tumorpositief en in $16.5 \%$ van de patiënten leidde de informatie verkregen van de SWK procedure tot een verandering van de behandelstrategie. Nog belangrijker is het gegeven dat meer dan 50\% van de patiënten een OKD bespaard kan blijven ten gevolge van een succesvolle en negatieve herhaalde SWK procedure en dit alles met een verwaarloosbaar vals-negatief risico. Dit cohort wordt momenteel verder uitgebreid en de resultaten van 300 patiënten evenals de eerste follow-up resultaten worden op korte termijn verwacht. Daarnaast zullen de factoren die mogelijk van invloed zijn op het identificatie percentage van de herhaalde SWK procedure geanalyseerd worden, zoals de locatie van de injectie van de radioactieve tracer en de tijd tussen injectie en het vervaardigen van het lymfoscintigram.

Na het uitvoeren van een systematische review van de bestaande literatuur en een "proof of principle" studie over de herhaalde SWK procedure na eerdere borst- en okselbehandeling, bevestigt de Sentinel Node And Recurrent Breast cancer (SNARB) studie de toepasbaarheid en validiteit van het concept van de herhaalde SWK procedure bij het lokaal recidief mammacarcinoom. Door het identificeren van aberrante drainagepatronen wordt additionele informatie verkregen op basis waarvan behandelplannen worden aangepast. Deze resultaten zijn grotendeels in overeenstemming met de resultaten van het overzichtsartikel en rechtvaardigen een aanpassing van de huidige richtlijn waarbij de herhaalde SWK procedure toegevoegd wordt als axillaire stageringsmethode bij het lokaal recidief mammacarcinoom. 


\section{Referenties}

1. Dutch Cancer Registry, Comprehensive Cancer Centre the Netherlands (CCCNL). Available from URL: http://cijfersoverkanker.nl [accessed 2 march, 2012]

2. Louwman WJ, Voogd AC, Van Dijck JAAM et. al. On the rising trends of incidence and prognosis for breast cancer patients diagnosed 1975-2004: a long-term population-based study in southeastern Netherlands. Cancer Causes Control 2008;19:97-106

3. Vervoort MM, Draisma G, Fracheboud J, van de Poll-Franse LV, de Koning HJ. Trends in the usage of adjuvant systemic therapy for breast cancer in the Netherlands and its effect on mortality. Br J Cancer 2004;91:242-247

4. Otto SJ, Fracheboud J, Looman CW, Broeders MJ, Boer R, Hendriks JH, Verbeek AL, de Koning HJ. Initiation of population-based mammography screening in Dutch municipalities and effect on breast-cancer mortality: a systematic review. Lancet 2003;361:1411-1417

5. Tsvedskov $T F$, Jensen $M$, Balslev $E$, et al. Stage migration after introduction of sentinel lymph node dissection in breast cancer treatment in Denmark: A nationwide study. Eur J Cancer 2011;47:872-878

6. Gobardhan PD, Elias SG, Madsen EV, et al. Prognostic value of micrometastases in sentinel lymph nodes of patients with breast carcinoma: a multicenter cohort study. Ann Surg Oncol 2011;18:1657-1664

7. Gobardhan PD, Elias SG, Madsen EVE et al. Prognostic value of micrometastases in sentinel lymph nodes of patients with breast carcinoma: a cohort study. Ann Oncol 2009;20:41-48

8. Hansen NM, Grube B, Ye X et al. Impact of micrometastases in the sentinel node of patients with invasive breast cancer. J Clin Oncol 2009;27:4679-4684

9. Giuliano $A E$, Hawes $D$, Ballman KV, et al. Association of occult metastases in sentinel lymph nodes and bone marrow with survival among women with early-stage invasive breast cancer. JAMA 2011;306:385-393

10. Colleoni M, Rotmensz N, Peruzzotti $G$, et al. Size of breast cancer metastases in axillary lymph nodes: Clinical relevance of minimal lymph node involvement. J Clin Oncol 2005;23:1379-1389

11. Weaver DL, Ashikaga T, Krag DN, et al. Effect of occult metastases on survival in nodenegative breast cancer. N Engl J Med 2011;364:412-421

12. de Boer M, van Deurzen CHM, van Dijck JAAM et al. Micrometastases or isolated tumor cells and the outcome of breast cancer. N Engl J Med 2009;361:653-663

13. Gerber B, Heintze $K$, Stubert J, et al. Axillary lymph node dissection in early-stage invasive breast cancer: is it still standard today? Breast Cancer Res Treat 2011;128:613-624

14. Salhab M, Patani N, Mokbel K. Sentinel lymph node micrometastasis in human breast cancer: An update. Surg Oncol 2011;doi:10.1016/j.suronc.2011.06.0 06

15. de Boer M, van Dijck JA, Bult P, Borm GF, Tjan-Heijnen VC. Breast cancer prognosis and occult lymph node metastases, isolated tumor cells, and micrometastases. J Natl Cancer Inst 2010;102:410-425

16. Rutgers E, Piccart-Gebhart MJ, Bogaerts J, et al. The EORTC 10041/BIG 03-04 MINDACT trial is feasible: results of the pilot phase. Eur J Cancer 2011;47:2742-2749

17. Van de Vijver MJ, He YD, van 't Veer LJ, et al. A gene-expression signature as a predictor of survival in breast cancer. N Engl J Med 2002;347:1999-2009

18. Van Rijk MC, Peterse JL, Nieweg $\mathrm{OE}$, et al. Additional axillary metastases and stage migration in breast cancer patients with micrometastases or submicrometastases in sentinel lymph nodes. Cancer 2006;107:467-471

19. Cserni G, Gregori D, Merletti F, et al. Meta-analysis of non-sentinel node metastases associated with micrometastatic sentinel nodes in breast cancer. Br J Surg 2004;91:1245-1252 
20. Fan $Y, T a n Y, W u C$, et al. The effect of sentinel node tumor burden on non-sentinel node status and recurrence rates in breast cancer. Ann Surg Oncol 2005;12:705-711

21. Giuliano AE, McCall L, Beitsch P, Whitworth PW, Blumencranz $P$, Leitch $A M$, et al. Locoregional recurrence after sentinel lymph node dissection with or without axillary dissection in patients with sentinel lymph node metastases. Ann Surg 2010;252:426-433

22. Giuliano $A E$, Hunt $K K$, Ballman $K V$, et al. Axillary dissection vs no axillary dissection in women with invasive breast cancer and sentinel node metastasis: a randomized clinical trial. JAMA 2011;305:569-575

23. Galimberti V, Botteri E, Chifu C, et al. Can we avoid axillary dissection in the micrometastastic sentinel node in breast cancer? Breast Cancer Res Treat 2012;131:819-825

24. Galimberti V, Cole BF, Zurrida S, et al. Axillary dissection versus no axillary dissection in matients with sentinel-node micrometastases (IBCSG 23-01): a phase 3 randomised controlled trial. Lancet Oncol 2013;14:297-305

25. Buchholz TA, Tucker SL, Erwin J, et al. Impact of systemic treatment on local control for patients with lymph node-negative breast cancer treated with breast-conservation therapy. J ClinOncol 2001;19:2240-2246

26. Gralow JR, Burstein HJ, Wood W, et al. Preoperative therapy in invasive breast cancer: Pathologic assessment and systemic therapy issues in operable disease. J ClinOncol 2008;26:814-819

27. Schlembach PJ, Buchholz TA, Ross MI, et al. Relationship of sentinel and axillary level I-II lymph nodes to tangential fields used in breast irradiation. Int J Radiat Oncol Biol Phys 2001;51:671678

28. Reznik J, Cicchetti MG, Degaspe $B$, et al. Analysis of axillary coverage during tangential radiation therapy to the breast. Int J Radiat Oncol Biol Phys 2005;61:163-168

29. Oliveira $\mathrm{M}$, Cortes J, Bellet $\mathrm{M}$, et al. Management of the axilla in early breast cancer patients in the genomic era. Ann Oncol 2013;24:1163-1170

30. Straver ME, Meijnen $P$, van Tienhoven $G$, et al. Role of axillary clearance after a tumor-positive sentinel node in the administration of adjuvant therapy in early breast cancer. J Clin Oncol 2010; doi:10.1200/JCO.2008.21.7554

31. Veronesi U, Cascinelli N, Mariani L, et al. Twenty-year follow-up of a randomized study comparing breast-conserving surgery with radical mastectomy for early breast cancer. $\mathrm{N}$ Engl J Med 2002;347:1227-1232

32. Voogd AC, Nielsen $M$, Peterse $J L$, et al. Differences in risk factors for local and distant recurrence after breast-conserving therapy or mastectomy for stage I and II breast cancer: pooled results of two large European randomized trials. J Clin Oncol 2001;15:1688-1697

33. Overgaard M, Hansen PS, Overgaard J, et al. Postoperative radiotherapy in high-risk premenopausal women with breast cancer who receive adjuvant chemotherapy. N Engl J Med 1997;337:949-955

34. Orr RK. The impact of prophylactic axillary node dissection on breast cancer survival - a Bayesian meta-analysis. Ann Surg Oncol 1999;6:109-116 
Dankwoord

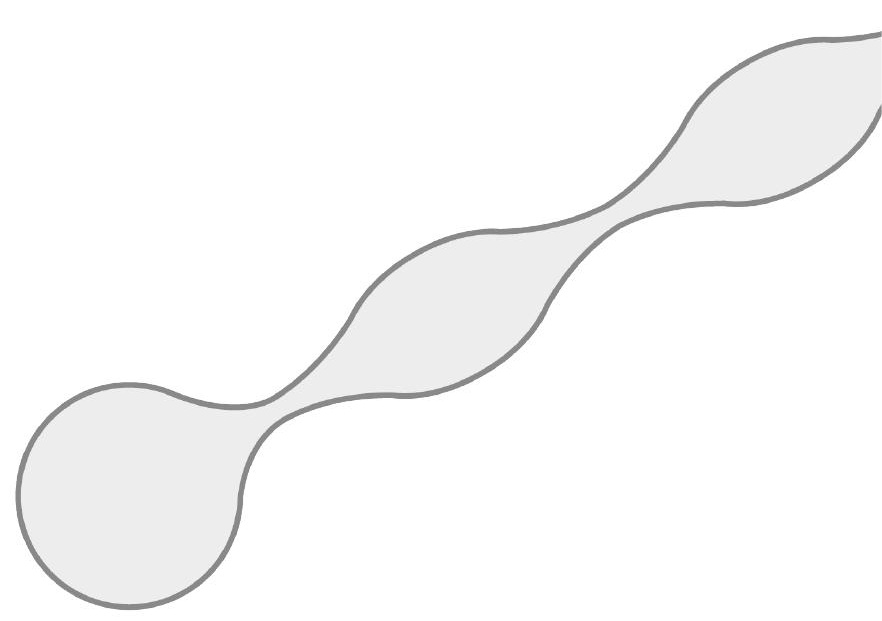




\section{Dankwoord}

De afronding van dit proefschrift valt samen met de afronding van mijn opleiding tot chirurg en markeert daarmee voor mij het einde van een intense periode. In de afgelopen 7 jaar heb ik veel geleerd over het vak en over mijzelf. Ik heb hoogtepunten meegemaakt en helaas ook, op persoonlijk vlak, een aantal dieptepunten. De niet aflatende hulp en steun van velen hebben mij in staat gesteld om het voorliggende onderzoek te vervolmaken en dit proefschrift te voltooien. Enkelen van hen wil ik op deze plaats in het bijzonder bedanken.

Allereerst mijn promotor, Harm Rutten. Ik zette mijn eerste stappen binnen de chirurgie reeds onder jouw supervisie en ik voel me enorm bevoorrecht dat ik mij nu onder jouw hoede als "Catharina CHIVO-opleider" verder kan ontwikkelen binnen de chirurgische oncologie. Ik hoop dat ik zowel op wetenschappelijk als op chirurgisch technisch gebied nog veel van je mag leren en ik vind het een enorme eer dat ik je eerste promovenda zal zijn.

Vervolgens mijn copromotores, Grard Nieuwenhuijzen, Adri Voogd en Rudi Roumen. Grard, vanaf dag 1 was jij mijn onderzoeksbegeleider en mentor. Later werd je ook nog mijn opleider. Je was de drijvende kracht achter de onderzoeken en je hebt me al die jaren van advies voorzien, zowel op wetenschappelijk en chirurgisch gebied als op persoonlijk gebied. Wat ik ontzettend waardeer is dat je me ook altijd de mogelijkheid en ruimte hebt geboden om mijn eigen weg te kiezen. Je nooit aflatende enthousiasme en energie zijn een enorme inspiratie geweest. Het palet aan chirurgisch oncologische ingrepen dat jij beheerst is onnavolgbaar en ik hoop daar de komende jaren nog heel veel kennis en kunde van mee te pikken.

Adri, al snel na de start van dit onderzoek heb jij ons team versterkt. Door je grote wetenschappelijke kennis van het mammacarcinoom en goede beheersing van de Engelse wetenschappelijke taal en stijl wist je ieder artikel na revisie weer naar een hoger niveau te tillen. Jij bracht de rust die nodig was om de zaken weer overzichtelijk te maken wanneer ik door de bomen het bos niet meer zag. Daarnaast wil ik je bedanken voor je oprechte interesse in mijn persoonlijke leven op momenten dat niet alles van een leien dakje ging.

Rudi, ik herinner me nog goed dat we om de tafel zaten om jouw idee over een nationale registratiestudie met als onderwerp de hernieuwde schildwachtklierprocedure bij het recidief mammacarcinoom te bespreken. We zaten al snel op één lijn en toen we een acroniem nodig hadden stelde jij SNARB, Sentinel Node And Recurrent Breast cancer, voor. De SNARB studie was geboren. Bedankt voor het vertrouwen dat je in me stelde om 
dit enorme project op te pakken. Het heeft veel, met name administratieve, moeite gekost, maar ik denk dat we trots kunnen zijn op het resultaat.

Prof. dr. V.C.G. Tjan-Heijnen, prof. dr. R. van Hillegersberg en dr. M.L. Smidt, hartelijk dank voor het aanvaarden van uw positie in de beoordelingscommissie en voor het investeren van de tijd en moeite om dit proefschrift door te nemen en te beoordelen. Marjolein, na onze prettige samenwerking in Maastricht vind ik het extra bijzonder dat jij zitting hebt willen nemen in de beoordelingscommissie. Ik hoop dat we onze wetenschappelijke discussies in de toekomst nog regelmatig voort zullen zetten.

Aan de totstandkoming van de artikelen in dit proefschrift hebben vele auteurs meegewerkt die ik op deze plaats tevens wil bedanken.

Lonneke van de Poll, inmiddels prof. dr. L.V. van de Poll-Franse, jij was degene binnen het IKZ die me als beginnend onderzoeker onder je hoede nam. Je hebt een dappere poging gedaan om mijn statistische kennis te verbeteren en dankzij jouw inspanningen hebben we een aantal prachtige vraagstukken kunnen beantwoorden met gebruik van de IKZ database. Bedankt voor je tijd, moeite, gezellige gesprekken en waardevol advies op wetenschappelijk en persoonlijk gebied.

Rik Pijpers, jouw kennis op het gebied van de sentinel node procedure heeft ervoor gezorgd dat we een mooi protocol hebben kunnen schrijven voor zowel de LABS (Lymphatic mapping After previous Breast Surgery) als de SNARB studie. We hebben uitgebreid gediscussieerd over inspuitplaatsen, hoeveelheid radioactieve tracer en het tijdstip van de lymfeklierscan. Bedankt voor je input en het delen van je wetenschappelijke inzichten.

Floor Derkx, Marjolein Leclercq-Liebregts en Suze de Bruijn. Het was een genot en bovendien zeer leerzaam om jullie tijdens het wetenschappelijke deel van jullie semi-arts stage mede te begeleiden. Bedankt voor jullie inzet bij het verzamelen en analyseren van de data en het schrijven van jullie artikelen. Heel veel succes en plezier in jullie eigen carrière.

Jan-Willem Coebergh, Cathelijne Tutein Nolthenius-Puylaert, Maurice van der Sangen, Karlijn Woensdregt, Ernest Luiten en Emiel Rutgers, hartelijk dank voor jullie waardevolle aanvullingen en commentaar op de stukken in dit proefschrift.

Deelnemers aan de SNARB studie, zonder jullie geloof in de herhaalde schildwachtklierprocedure en jullie inspanningen om de patiënten te includeren en behandelen hadden we nooit een dergelijk fraai en nationaal resultaat kunnen neerzetten.

Collega's in het Catharina Ziekenhuis en MUMC+, bedankt voor de prettige samenwerking. Van 2005 tot 2011 heb ik in het "Cathrien" mogen werken. Ik zette hier 
mijn eerste stappen op medisch, wetenschappelijk en chirurgisch gebied en vond het erg jammer om na zoveel jaren weg te gaan uit het ziekenhuis dat ik van binnen en buiten kende. Na 3 mooie jaren in Maastricht ben ik dan ook erg blij om weer terug in jullie gelederen te zijn. Bedankt voor een prachtige tijd waarin ik heel erg veel heb geleerd, maar waarin ook veel ruimte was voor gezelligheid. In Maastricht werd ik met open armen ontvangen door een bijzonder warme groep van assistenten en chirurgen. Ik heb genoten van mijn tijd in de academie. Het was leerzaam om vraagstukken bij tijd en wijle op een andere manier te benaderen, maar ook om de gang van zaken in een ander ziekenhuis mee te maken. Daarnaast wil ik jullie als groep, en in het bijzonder Laurents Stassen en Kees Dejong, bedanken voor jullie flexibiliteit en steun in voor mij moeilijke tijden.

Yvonne van Riet, je zei laatst dat je je nog goed kunt herinneren hoe ik je aansprak als coassistent tijdens een nachtelijke ingreep omdat ik graag mijn keuze coschap bij de chirurgie wilde doen ("het meisje met de Prada bril"). Je ontving me met open armen en bood me de mogelijkheid om naast mijn keuze coschap ook een artikel met je te schrijven. Eigenlijk was dat het begin van mijn carrière binnen het onderzoek en de chirurgie. We hebben ontzettend leuke tijden gehad op de verschillende congressen. Naar jouw voorbeeld zal ik, wanneer ik zelf "baas" ben, tijdens congressen in het buitenland de assistenten zeker mee uit eten nemen in de meest fantastische restaurants. Ik hoop de komende jaren nog heel veel van je te leren tijdens onze gezamenlijke operaties, met name op oncoplastisch gebied.

Petra Boelens, jij hebt me van het begin af aan onder je hoede genomen en hebt me wegwijs gemaakt in de chirurgische wereld. Ik heb me pas later gerealiseerd hoe waardevol jouw steun in de eerste jaren is geweest en daar ben ik je erg dankbaar voor. Ik heb genoten van onze uitgebreide lunches en wandelingen in de stad (je moet toch iets tijdens je zwangerschapsverlof).

Sietske van de Sande-Folkersma, Ingrid Martijnse en Janneke Berlage, bedankt voor jullie vriendschap en gezelligheid. Bedankt voor de heerlijke dagjes sauna, voor de stapavonden tijdens congressen, cursussen en de winterbijscholing. Bedankt voor jullie goede raad en luisterend oor.

Guusje Vugts, we werken pas kort samen en toch kan ik je nu al niet meer missen. Je hebt je in heel korte tijd het SNARB onderzoek eigen gemaakt en bent inmiddels bezig met het uitbreiden van de database en het opzetten van SNARB-II. Ik heb er het volste vertrouwen in dat dit onderzoek en alles wat daarmee te maken heeft bij jou in goede handen is en ik heb er veel plezier in om je hierin te begeleiden.

Lieve Gitta, Esther, Laura en Maaike, mijn vriendinnen voor het leven. We zijn samen opgegroeid en hebben al ontelbare dingen meegemaakt, leuk en minder leuk, mooi en moeilijk. We kennen elkaar door en door en hebben aan een half woord genoeg om te 
begrijpen wat er speelt. In onze vriendschap is afstand geen issue en de basis is zo goed dat het niet uitmaakt als we elkaar door drukte even wat minder kunnen zien. We hebben heerlijke tijden beleefd op de hockey, in de Jan Steen, de Poort van Kleef, de Heksenketel, in Zeeland, Praag, Berlijn, Rome en Dublin. Menig studentenstad hebben we samen onveilig gemaakt. Jullie waren er voor me toen ik trouwde en de kinderen kreeg, maar jullie waren er ook bij het overlijden van opa en oma en toen mijn zusje ziek werd. Jullie aanwezigheid is een basis waarop ik bouw en vertrouw.

Mijn schoonouders, Ad en Lia. Ik was pas 16 jaar toen ik voor het eerst bij jullie thuis kwam en jullie me liefdevol in de familie opnamen. Ik wil jullie bedanken voor jullie betrokkenheid bij en interesse in mijn leven, van het behalen van mijn diploma, het doorlopen van mijn studie en mijn coschappen tot aan mijn carrière keuze. Jullie stonden altijd paraat om advies te geven of boeken voor me te regelen. Ad, het was fijn om de mening van iemand te horen die de medische wereld kent. Bedankt ook voor de mooie en gezellige tijden op vakantie, van Amerika tot aan China en Tibet en, niet te vergeten, onze jaarlijkse wintersport in Grindelwald. Uiteraard ook bedankt voor het oppassen op onze jongens, jullie zijn geweldige grootouders en Lucas en Simon vinden het altijd één groot feest als opa en oma weer komen.

David en Karin, bedankt voor jullie betrokkenheid, gezelligheid en warmte. Ik heb nu al weer zin in die heerlijke wintersportweek samen.

Lieve Marissa en Iris, mijn zusjes. De laatste jaren hebben we moeilijke tijden meegemaakt, maar we zijn er ook een stuk hechter door geworden.

Maris, toen jij ziek werd stond de wereld even stil en het bericht dat ik je niet kon helpen met een beenmergtransplantatie is me heel erg zwaar gevallen. Je bent door diepe dalen gegaan om uiteindelijk weer normaal te kunnen functioneren en de bijwerkingen van de medicijnen neem je voor lief. De manier waarop jij je hier doorheen geslagen hebt is voor mij een voorbeeld van wat doorzettingsvermogen nu echt is. Ik heb enorm veel respect voor de manier waarop jij en Robert alles weer opgepakt hebben en voor de manier waarop jullie ervoor gezorgd hebben dat Aidan van dit alles zo weinig mogelijk heeft meegemaakt. Jullie bruiloft was een prachtig begin van een nieuwe toekomst. Ik geniet nog elke keer van onze oeverloze telefoongesprekken en het is heerlijk om te zien hoe fijn onze jongens samen kunnen spelen. Rob, bedankt voor alles wat je voor ons gedaan hebt de afgelopen jaren.

lertje, inmiddels een kop groter dan ik. Ik weet nog goed hoe je als meisje van 6 met me meeging naar de universiteit en vol bewondering naar die grote glazen bibliotheek stond te kijken. Jarenlang heb je het daarover gehad en nu studeer je zelf inmiddels in Amsterdam. Ook voor jou zijn de afgelopen jaren moeilijk geweest, vooral de onzekerheid over een mogelijke genetische factor heeft je lang bezig gehouden. Weet 
dat je altijd bij me aan kan kloppen. Ik ben niet alleen je oudere zus, ik begrijp ook hoe je in elkaar zit en hoe moeilijk het soms is om over bepaalde gevoelens te praten. Ik ben super trots op de mooie en zelfstandige vrouw die je bent geworden.

Lieve papa en mama, jullie hebben me altijd geleerd op mezelf te vertrouwen en in mezelf te geloven. Jullie hebben me opgevoed met de boodschap dat niets onmogelijk is als je maar bereid bent om er hard voor te werken. Wat ik me ook in mijn hoofd haalde, naar het Conservatorium in Den Haag op mijn elfde of op kamers in Maastricht toen ik 17 was, jullie stonden achter me. Dankzij jullie manier van opvoeden en de vrijheid die jullie me lieten ben ik een zelfstandige vrouw geworden die voor zichzelf op kan komen en voor zichzelf kan zorgen. Maar in tijden van onzekerheid en van angst weet ik dat ik altijd op jullie kan vertrouwen en op jullie kan terugvallen. Ik wil jullie bedanken voor de solide thuisbasis, het goede voorbeeld, de enorme gezelligheid en voor het feit dat jullie zulke super grootouders zijn. Ik geniet enorm van de vreugde op jullie gezicht als jullie met de jongens aan het spelen zijn.

Lieve Lucas en Simon, mijn jongens, jullie aanwezigheid maakt van elke dag een feest en maakt elk moment onbetaalbaar. Jullie onbevangenheid en oprechtheid is adembenemend. Ik hou van jullie met alles wat ik in mij heb. Jullie hebben de balans teruggebracht in mijn leven. Dikke kus en knuffel van mama!

Lieve Ruben, mijn man, mijn liefste, mijn steun en toeverlaat. We zijn al 15 jaar samen en wat hebben we veel meegemaakt. Zonder jou was ik nooit gekomen waar ik vandaag ben. Je hebt me al die jaren aangespoord om mijn dromen na te jagen en mijn ambities waar te maken. Boven alles heb jij mij de kracht gegeven om door te gaan in tijden dat ik niet meer dacht te door te kunnen gaan en heb je me werk uit handen genomen wanneer het mij te veel werd. Ik zou niet weten wat ik zou moeten doen zonder de zekerheid dat jij er bent om mee te lachen, om mee te huilen, om mee te genieten en om me bij te staan in moeilijke tijden. Mijn liefde voor jou is allesomvattend. 
Curriculum vitae

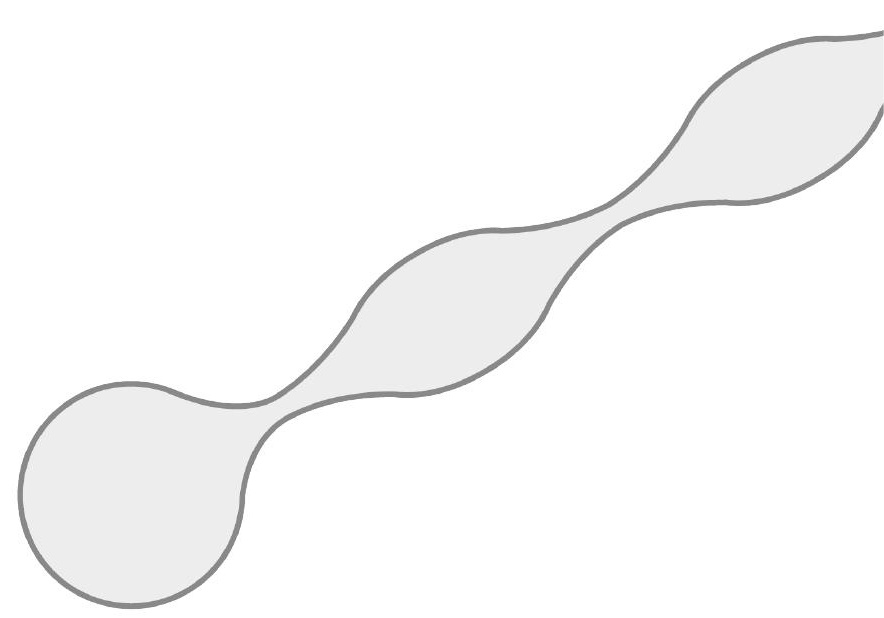




\section{Curriculum vitae}

Adriana Jacoba Gerdina (Sabrina) Maaskant was born on 19 September 1981 in Breda, The Netherlands, and raised in the nearby city of Zevenbergen. After attending The Royal Conservatory in The Hague where she studied the alto saxophone (1993-1995), she continued her secondary school at the Norbertus College in Roosendaal (gymnasium) (1995-1999). After her graduation, Sabrina started medical school at the University of Maastricht (1999-2005). She had her first research experiences at the IVF-laboratory of the Maastricht University Medical Centre, studying apoptosis in pre-implantation embryos. She was also involved in the organisation of an extracurricular term on Tropical Medicine and she was president of de "International Federation of Medical Students' Associations", IFMSA-Maastricht. In 2003 Sabrina obtained her doctorate cum laude. During her internships she spent a trimester in the Academic Hospital of Paramaribo, Surinam, to study Tropical diseases and she followed her surgical internship at the Pretoria Academic Hospital, South Africa. Sabrina completed medical school with an elective in General Surgery at the Catharina Hospital Eindhoven, where she continued working after obtaining her medical degree (2005). She started as a resident in the ICU department en soon thereafter switched to the Surgery department, where she started the research that is presented in this thesis. In January 2007 Sabrina started her surgical training program at the Catharina Hospital Eindhoven under supervision of dr. G.A.P. Nieuwenhuijzen. During the last two years of her surgical training she differentiated in oncological and gastro-intestinal surgery at the Maastricht University Medical Centre under supervision of prof. dr. L.P.S. Stassen. Currently, Sabrina is undertaking a fellowship in oncological and gastro-intestinal surgery at the Catharina Hospital Eindhoven under supervision of prof. dr. H.J.T. Rutten. Sabrina is married to Ruben Braat and together they have two sons, Lucas (2010) and Simon (2012). 